\title{
Multispecies probiotics and antibiotic-associated side effects : pathophysiological and clinical evidence
}

Citation for published version (APA):

Koning, C. J. A. (2010). Multispecies probiotics and antibiotic-associated side effects : pathophysiological and clinical evidence. [Doctoral Thesis, Maastricht University]. Maastricht University. https://doi.org/10.26481/dis.20100604ck

Document status and date:

Published: 01/01/2010

DOI:

10.26481/dis.20100604ck

Document Version:

Publisher's PDF, also known as Version of record

\section{Please check the document version of this publication:}

- A submitted manuscript is the version of the article upon submission and before peer-review. There can be important differences between the submitted version and the official published version of record.

People interested in the research are advised to contact the author for the final version of the publication, or visit the DOI to the publisher's website.

- The final author version and the galley proof are versions of the publication after peer review.

- The final published version features the final layout of the paper including the volume, issue and page numbers.

Link to publication

\footnotetext{
General rights rights.

- You may freely distribute the URL identifying the publication in the public portal. please follow below link for the End User Agreement:

www.umlib.nl/taverne-license

Take down policy

If you believe that this document breaches copyright please contact us at:

repository@maastrichtuniversity.nl

providing details and we will investigate your claim.
}

Copyright and moral rights for the publications made accessible in the public portal are retained by the authors and/or other copyright owners and it is a condition of accessing publications that users recognise and abide by the legal requirements associated with these

- Users may download and print one copy of any publication from the public portal for the purpose of private study or research.

- You may not further distribute the material or use it for any profit-making activity or commercial gain

If the publication is distributed under the terms of Article $25 \mathrm{fa}$ of the Dutch Copyright Act, indicated by the "Taverne" license above, 


\section{Multispecies probiotics and}

\section{antibiotic-associated side effects}

- pathophysiological and clinical evidence - 
(C) Catherina Johanna Maria Koning, Maastricht 2010

Cover: Rogier Trompert Medical Art

Layout: Tiny Wouters

Production: Datawyse | Universitaire Pers Maastricht

ISBN: 978-90-5278-937-8

The research in this thesis was financially supported by SenterNovem, an agency of the Dutch Ministry of Economic Affairs (grant number TSGE 1041)

The printing of this thesis was financially supported by Winclove Bio Industries BV. 


\title{
Multispecies probiotics and
}

\section{antibiotic-associated side effects}

- pathophysiological and clinical evidence -

\author{
PROEFSCHRIFT \\ ter verkrijging van de graad van doctor \\ aan de Universiteit Maastricht, \\ op gezag van de Rector Magnificus, \\ Prof. mr. G.P.M.F. Mols \\ volgens het besluit van het College van Decanen, \\ in het openbaar te verdedigen op \\ vrijdag 4 juni 2010 om 12.00 uur
}

door

Catherina Johanna Maria Koning

Geboren op 4 mei 1977 te Bunschoten

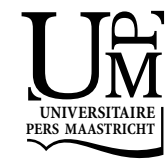


Promotor:

Prof. dr. R.W. Stockbrügger

\section{Copromotores:}

Dr. E.E. Stobberingh

Dr. D.M.A.E. Jonkers

\section{Beoordelingscommissie:}

Prof. dr. C.H.C. Dejong (Voorzitter)

Prof. dr. A. Bast

Dr. M.A. Benninga (Academic Medical Centre, the Netherlands)

Prof. dr. J.W. Cohen Tervaert

Dr. ir. G.T. Rijkers (UMC Utrecht and St. Antonius Ziekenhuis, the Netherlands) 



\section{Contents}

Chapter $1 \quad$ General introduction

Chapter 2 Monostrain, multistrain and multispecies probiotics.

A comparison of functionality and efficacy

Chapter 3 The effect of a multispecies probiotic on the intestinal microbiota and bowel movements in healthy volunteers taking the antibiotic amoxycillin

Chapter $4 \quad$ Monitoring the effect of a multispecies probiotic and short-term amoxycillin intake on the fecal microbiota in healthy volunteers

Chapter 5 The effect of a multispecies probiotic on biomarkers of the mucosal and systemic immune system in healthy volunteers treated with amoxycillin

Chapter 6 The effect of a multispecies probiotic on the composition of the faecal microbiota and bowel habits in COPD patients treated with antibiotics

Chapter $7 \quad$ Immunomodulatory effect of a multispecies probiotic during and after antibiotic therapy in COPD patients

Chapter $8 \quad$ General discussion

Summary

Samenvatting

Dankwoord

List of publications

Curriculum Vitae

List of abbreviations 

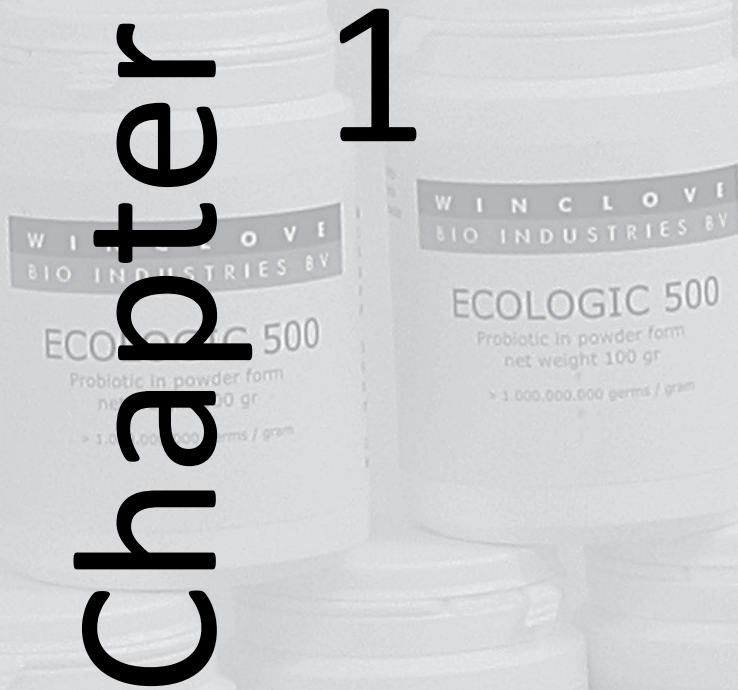

ECOLOGIC 500

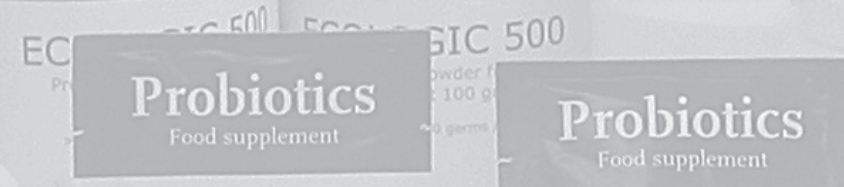

Ecologic

$$
500
$$

Ecologic

500 


\section{General introduction}





\section{Intestinal microbiota}

The gastrointestinal tract (GI-tract) comprises a complex bacterial ecosystem (i.e. the intestinal microbiota) colonizing the entire length of the gut and containing approximately hundred times as many genes as the human genome ${ }^{1}$. The intestinal microbiota contains approximately $10^{14}$ bacteria, is composed of more than 1000 different species ${ }^{2}$, of which anaerobes are a hundred times more abundant, and is dominated (60-90\%) by two phyla: the Bacteroidetes and the Firmicutes ${ }^{3}$. On genus level, Bacteroides spp., Lactobacillus spp., Bifidobacterium spp., Escherichia coli and Clostridium spp., are the most prevalent spp. ${ }^{4}$. Only a minority of the species present in the intestinal microbiota can be cultured. The application of culture-independent approaches, based on 16S rRNA and the corresponding gene, has provided a better and more comprehensive insight into the diversity and dynamics of the intestinal microbiota and the association with various diseases. The majority of the intestinal microbiota, has been able to entrench itself in a niche and is considered indigenous and stable ("autochthonous" bacteria), though transient members of the microbiota are also found ("allochthonous" bacteria) . $^{5}$ Moreover, the composition differs both along the Gl-tract and from lumen to mucosa ${ }^{6}$.

In utero the foetal Gl-tract is sterile, but microbes start to colonize the Gl-tract immediately at birth. This colonization is highly determined by interindividual variation and is further influenced by numerous factors including gestational age, mode of delivery, nutrition, hospitalisation and antibiotic use ${ }^{7}$, gradually developing into a stable microbial community through childhood ${ }^{8}$.

Adaptive co-evolution has led to a symbiotic interrelationship between the microbiota and the mammalian host. The microbiota plays an important role in human physiology exerting their effect on three levels (Figure 1.1);

Level 1 ; microbe - microbe interactions

Level 2; microbe - intestinal epithelium interactions

Level 3; microbe - immune system interactions

The intestinal microbiota aids for example in the break-down of non-digested and indigestible polysaccharides, and supplies essential substrates like vitamins and shortchain fatty acids. It also provides colonization resistance by competing for substrates and adhesion sites and by producing antibacterial substances, thereby preventing the overgrowth of potential pathogens (level 1). The intestinal microbiota affects mucosal barrier function by influencing the metabolism, proliferation and survival of the intestinal epithelial cells, the production and composition of mucus and by the strengthening of tight junctions (level 2$)^{3}$. Moreover there is an active cross-talk between the intestinal microbiota and the immune system via three pathways (level 3). Firstly, bacteria can adhere to epithelial cells (via Toll-Like Receptors (TLRs)) and modulate signalling pathways and thereby cytokine production, which in turn modulates the immune function of dendritic cells (DCs), T cells and B cells. Secondly, they can be internalized by $M$ cells that cover Peyer's patches where they interact 
with Peyer's patch macrophages and DCs or thirdly are directly sampled by lamina propria DCs. Subsequently, they are presented to organized lymphoid tissue (Peyer's patches (PPs)) or mesenteric lymph nodes (MLNs)), where they initiate reactions mediated by $T$ and B lymphocytes ${ }^{9,10}$.

Though marked variations are present between individuals, within adults the intestinal microbiota is found to be relatively stable over time ${ }^{11,12}$. However, several factors like physiological and emotional stress, aging, antibiotic intake, gastric acid inhibitors, nutrition and endurance sport can disturb this microbiota. Nowadays accumulating evidence indicates that a disturbance of the intestinal microbiota plays an important role in many disorders ranging from allergies to diarrhoea, irritable bowel syndrome (IBS), inflammatory bowel disease (IBD) and colorectal cancer, ${ }^{3,13-15}$. Whether the disturbed microbiota is the consequence and/or the cause of the diseases remains to be clarified.

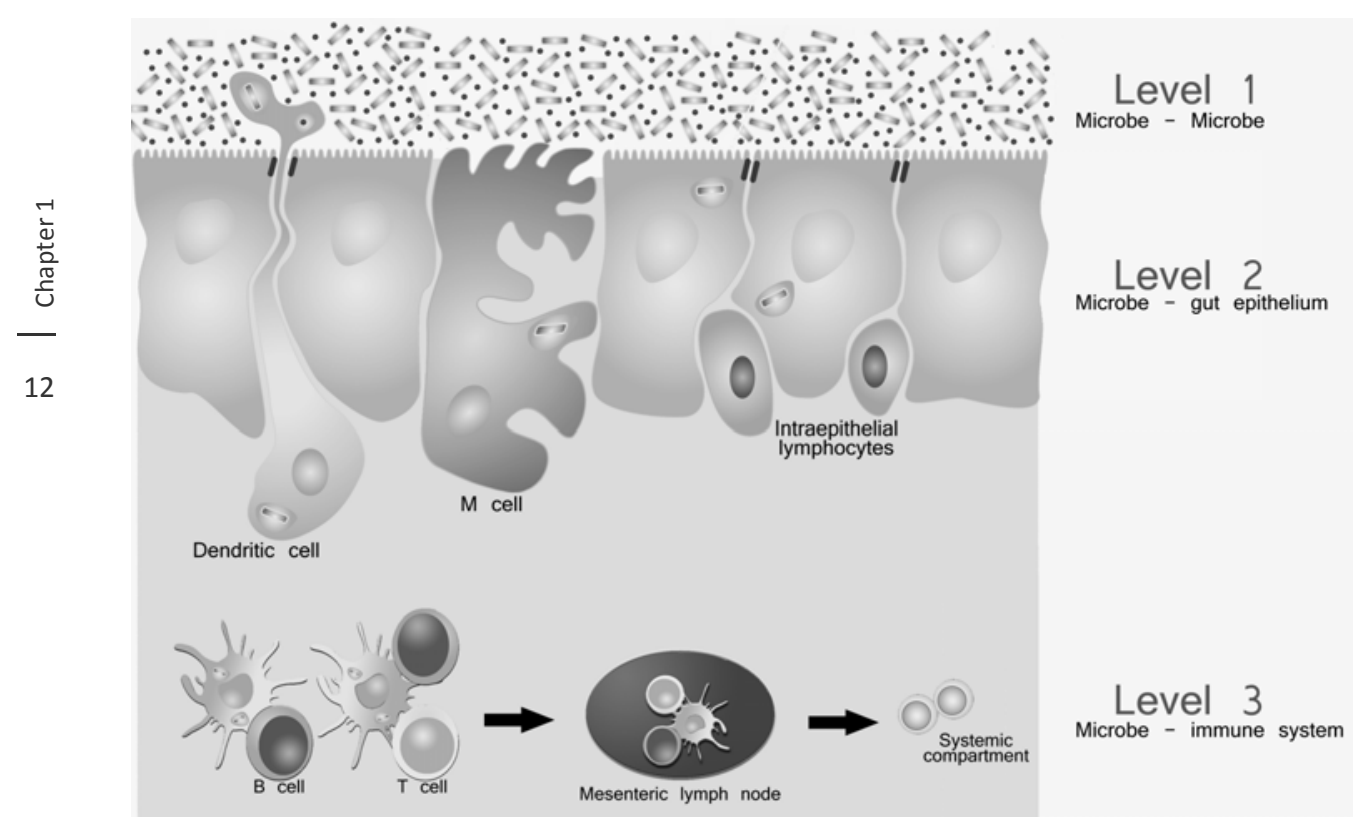

Figure 1.1

A multilevel overview of bacterial interaction with the host ${ }^{135}$.

\section{Antibiotics}

Antibiotic is derived from the ancient Greek words ávti - anti, "against", and ßíos bios, "life". According to the Food and Agricultural Organization of the United Nations (FAO) an antibiotic is defined as a compound of natural or synthetic origin that has the capacity to kill (bactericidal) or to inhibit the growth (bacteriostatic) of bacteria. Ever 
since the discovery of the first antibiotic, penicillin, by Alexander Fleming in 1928, many types of antibiotics and antibiotic groups have been developed and they are categorized based on their target specificity and mode of action. The antibiotics prescribed $^{16,17}$ and the frequency and amount of antibiotic use varies markedly among European countries ${ }^{17,18}$. Antibiotic use is highest in southern European countries like Greece and France and lowest in Scandinavian countries and the Netherlands ${ }^{19}$.

\section{Antibiotic associated side effects}

Antibiotics have become one of the cornerstones in the prevention and treatment of infectious diseases, but their use is not without side effects including: 1) the development of antibiotic resistance, 2) direct effects on the intestine, 3) a disturbance of the intestinal microbiota and 4) effects on the immune system.

\section{Antibiotic resistance}

Antibiotic resistance is present if a bacterium is not susceptible to a clinically relevant concentration of an antibiotic. There are two types of resistance, i.e. intrinsic and acquired resistance. Intrinsic or natural resistance is present in all strains of a given species or genus. Acquired resistance is resistance of bacteria due to the acquisition of exogenous genes ${ }^{20}$. Intrinsic resistance has a low risk of horizontal transfer. However, acquired resistance poses a high risk of transferring resistance genes, not only to the commensal bacterial population but also to potential pathogenic and opportunistic bacteria $^{20}$. Antibiotic use exerts a strong selective pressure on the appearance of resistant strains and there is a clear correlation between the amount of antibiotic use and the occurrence of resistance ${ }^{21}$. Antibiotic resistance can not only lead to treatment failure of infectious diseases but is also associated with an increase in morbidity and mortality ${ }^{22}$.

\section{Direct effects on the intestine}

Direct effects on the intestine have been described for antibiotics and include allergic and toxic effects on epithelial cells and pharmacological effects on intestinal motility. However, only limited in vivo data are reported. It has been shown for example that neomycin affects the intraluminal phase of fat digestion and causes histological changes in the small-bowel mucosa, such as shortening of the villi ${ }^{23}$. Moreover, prolonged treatment with clofazimine may cause enteropathy ${ }^{24}$, and both antibiotics can cause epithelial inflammation and dysfunction ${ }^{23,24}$. Erythromycin induces antral contractions, accelerates gastric emptying and has a prokinetic action on the gut, mediated at least in part, by its motilin receptor stimulating activity ${ }^{25,26}$. In addition, in an Ussing chamber model clindamycin, erythromycin, gentamicin and lincomycin each 
reduced the response of rabbit distal colonic epithelium to electrical field stimulation $^{27}$.

\section{Disturbance of the intestinal microbiota}

Antibiotics not only affect the pathogens to which they are directed, but also have a profound impact on the intestinal microbiota ${ }^{28-31}$. It has since long been accepted that antibiotic treatment can cause ecological disturbances of the intestinal microbiota, the extent of which depends on the spectrum of the antimicrobial agent, the dose, the route of administration as well as pharmacokinetic and pharmacodynamic properties. Also in vivo inactivation of the agent, potential enzymatic degradation and/or binding to faecal material and host factors are important ${ }^{32-34}$. Overviews of the ecological disturbances due to different types of antibiotics have recently been published by Edlund et al. and Sullivan et al. ${ }^{29,34}$. In these reviews it was generally found that the microbiota was only temporarily disturbed, returning to its original composition 1-2 months after cessation. However, mainly cultivation-based techniques were used, while it is estimated that less than $25 \%$ of the intestinal bacterial populations can be cultured $^{2,35,36}$. The application of culture-independent methods based on 16S rRNA provides a better and more comprehensive insight into the diversity of the intestinal microbiota and the ecological disturbances due to antibiotic treatment ${ }^{30,37-40}$. Nowadays, literature data suggests that short-term use of antibiotics can also have long-term consequences on the intestinal ecology. Using terminal restriction fragment length polymorphism (T-RFLP), Jernberg et al. showed that a 7-day clindamycin intake caused short-term disturbances in the total bacterial profiles. In addition, large and persistent changes were found in the Bacteroides community, which did not return to its original status within two years post-treatment ${ }^{30}$. A similar finding was reported by Dethlefsen et al. using pyrosequencing. They found that 5 days of ciprofloxacin reduced the diversity and stability of one third of the bacterial taxa in the gut. Although the majority of the microbial communities returned to pre-treatment values after four weeks, several taxa failed to recover within six months ${ }^{39}$. Recently, Lindgren et al. showed that clindamycin treatment had a prolonged impact on Enterococus spp. variation $^{31}$. Moreover, a study in mice using qPCR showed that total bacterial numbers returned to normal within 1 week after cessation of antibiotic intake, but alterations in Bacteroides and segmented filamentous bacteria persisted more than 3 weeks ${ }^{28}$.

Antibiotic-induced disturbances of the intestinal microbiota can result in important functional differences in the microbial metabolome, as evidenced by changes in carbohydrate digestion, production of short-chain fatty acids, bile acid metabolism and xenobiotic degradation ${ }^{41}$. Two recent studies in mice found that antibiotic induced alterations of the microbiota profoundly enhanced susceptibility to enteric Salmonella infection ${ }^{28,42}$. Moreover, antibiotic-induced perturbations of the intestinal microbiota can disturb colonization resistance and have been associated with overgrowth of Candida, E.coli, Staphylococcus aureus, Clostridium perfringens and 
Klebsiella oxytoca ${ }^{41}$. In addition, it is well known that approximately $20 \%$ of AAD cases can be attributed to overgrowth of $C$. difficile ${ }^{43}$. Using profiling of bacterial $16 \mathrm{~S}$ rDNA coupled with partial least square regression analysis, it was shown that specific microbial patterns of the resident microbiota can predict $C$. difficile-associated diarrhoea $(C D A D)^{37}$. Finally, perturbations of the intestinal microbiota can influence immune responses of the host, which will be discussed in the next paragraph.

\section{Effects on the immune system}

The effects of antibiotics on the immune system are heterogeneous and may be indirect and related to alterations of the intestinal microbiota, or direct due to effects of antibiotics on the function of components of the immune system. It is well recognised that there is an active "cross-talk" between the intestinal microbiota and the immune system ${ }^{44}$. From studies in germ-free and conventional animals it was established that the intestinal microbiota is essential for the development and functioning of the immune system. Moreover the immune system is able to discriminate between commensals and pathogens. Since the intestinal microbiota influences the maturation and functioning of the immune system, perturbations of the microbiota due to antibiotics might contribute to individual variations in immunological behaviour. Studies in mice have linked the microbiota with specific patterns of immune behaviour. Although several gaps in our knowledge on the mechanisms linking the intestinal microbiota with immunological behaviour exist, the intestinal microbiota seems to play a pivotal role in numerous immune related conditions. A disturbance of this intestinal microbiota due to antibiotics has thus been associated with local inflammation and a disturbed immunological functioning of the host $^{13,45,46}$. A number of epidemiological studies have demonstrated an association between the use of antibiotics during early childhood and an increased risk for acquiring allergy or asthma ${ }^{47-50}$. Also, alteration of the intestinal microbiota due to antibiotic treatment was found to induce or exacerbate $\mathrm{IBS}^{51}$.

Several antibiotics can also directly affect immune function. These effects may be inhibitory or stimulatory very much depending on the type of antibiotic used and the immune function studied. Immune functions studied both in vitro and in vivo include phagocytosis, chemotaxis, endotoxin release, cytokine and antibody production and delayed type hypersensitivity reaction, which was reviewed in detail by Van Vlem et $a^{52}{ }^{52}$. In addition, several more recent studies have shown interesting effects ${ }^{53-55}$. When interpreting these findings it should be taken into account that inflammation induced by an infection may influence the interaction of an antibiotic with the immune system. Furthermore, it remains to be established whether in vivo effects are related to antibacterial effects or to direct effects on immune competent cells. 


\section{Antibiotic-associated diarrhoea (AAD)}

A common and clinically manifest side effect of antibiotic use is antibiotic-associated diarrhoea (AAD), which can occur shortly after antibiotic intake and up to 8 weeks after cessation ${ }^{32,56}$. The incidence of $A A D$ ranges from $5-39 \%$, depending on the definition of diarrhoea, the route of administration, the type of antibiotic used and host factors $^{32}$. In general, broad-spectrum antibiotics, amoxycillin, amoxycillin/ clavulanic acid, clindamycin and cephalosporines are associated with a high risk of $A A D^{57}$. AAD can be divided into two types: non-specific $A A D$, which is usually mild and CDAD, which can lead to severe pseudomembranous colitis ${ }^{58}$. C. difficile is thought to be the causative agent in up to $20 \%$ of $A A D^{43}$ but the pathogenesis of the majority of cases of AAD is not clear. The proposed mechanisms include direct and indirect effects: direct effects of the antibiotic on the intestine include allergic and toxic effects on the mucosa and on intestinal motility. Indirect effects focus on the disturbance of the intestinal microbiota leading to functional differences in the metabolome (i.e. the collective biochemical output of the microbiota) and loss of colonisation resistance (Figure 1.2), as described above.

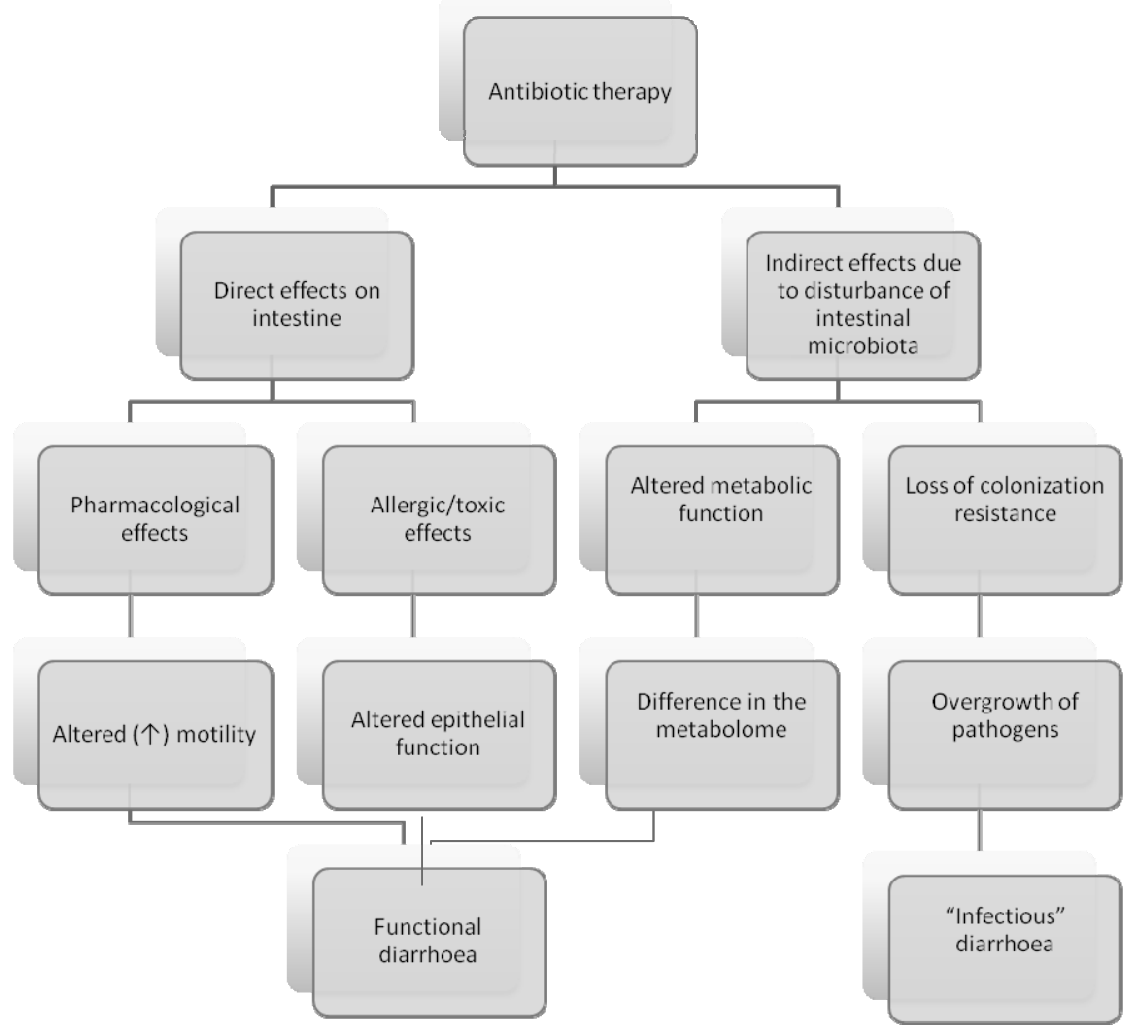

Figure 1.2 Putative mechanisms of AAD. 


\section{Clostridium difficile-associated diarrhoea (CDAD)}

C. difficile is a Gram-positive, spore-forming bacillus that was first linked to GI disease in $1978^{59}$ and is at present one of the most important causes of nosocomial gastrointestinal infections ${ }^{60}$. The prevalence of $C$. difficile colonization varies between different populations roughly ranging from $3 \%$ in healthy adults to $15-35 \%$ in hospitalised patients ${ }^{61,62}$. Elderly people with prolonged stays in a health-care setting are the main group at risk for CDAD. However, evidence suggests that there is an increasing incidence of CDAD in community-associated populations (i.e. healthy persons living in the community and peripartum women) previously thought to be at low risk ${ }^{63}$. Overall, $C$. difficile infections, in particular (CDAD), have been increasing in incidence, severity, and morbidity, which is particularly associated with the emergence of a new hyper virulent strain classified as either restriction-endonuclease analysis $\mathrm{BI}$, North American pulse-field type 1 (BI/NAP1) or PCR ribotype $027^{64,65}$. Initially outbreaks were reported in hospitals in Canada ${ }^{65}$ and the USA ${ }^{64}$, but did subsequently appear in a number of European countries including the Netherlands ${ }^{66}$.

C. difficile produces two toxins, enterotoxin $A$ and cytotoxin $B$, which are responsible for the symptoms ${ }^{67}$. Metronidazole and vancomycin are the standard treatment options, but these result in high relapse rates $(10-40 \%)^{62,68,69}$.

\section{Probiotics}

The term 'probiotics' is derived from the Greek words $\pi \rho 0$ and ßiotos, meaning "for life". The first documented observation that certain bacteria can play a positive role was in 1905 by Elie Metchnikoff, a later Nobel prize winner. He suggested that Bulgarians owed their longevity to the consumption of large quantities of yoghurt containing Lactobacillus bulgaricus ${ }^{70}$. Kollath was the first to introduce the term 'probiotic' in $1953^{71}$. Contrasting antibiotics, probiotics were initially defined as microbially derived factors that stimulate the growth of other micro-organisms. In 1974 , Parker ${ }^{72}$ was the first to use the word probiotic in relation to the interaction of micro-organisms with the animal or human host. In 1989, Fuller suggested a definition that has ever since been widely used: "A live microbial feed supplement, which beneficially affects the host animal by improving its intestinal microbial balance ${ }^{173}$. At present probiotics are defined by the FAO and the WHO as "live micro-organisms, which, when administered in adequate amounts, confer a health benefit on the host". Lactobacilli and bifidobacteria are the most commonly used probiotics, mostly given as fermented milk products or in a freeze-dried form. However, E.coli, Saccharomyces boulardii and species from the genera Enterococcus, Streptococcus and Lactococcus are also frequently applied.

Although many products are termed 'probiotics' micro-organisms must fulfil a number of criteria to be rendered a probiotic. They have to survive passage through the 
Gl-tract (e.g. low gastric pH, bile and digestive enzymes), be metabolically active, preferably be able to adhere to the intestinal mucosa and produce antimicrobial substances, and they should show functional efficacy ${ }^{74}$.

So far proper dose-response studies have hardly been performed to determine the 'minimal effective dose' of a probiotic. Although the minimal daily dose reported in the literature varies, probiotic-induced changes are rarely reported at daily dosages of less than $10^{6}$ to $10^{8}$ colony forming units (cfu). Therefore, a daily intake of minimum $10^{9}$ to $10^{10} \mathrm{cfu} /$ day seems to be required to show an effect ${ }^{75}$.

\section{Mechanisms of action}

Given the complexity of the intestinal microbiota and the interaction with the host the mechanisms of probiotic action remain to be further elucidated. However, numerous data from in vitro, ex vivo, in vivo and animal studies have indicated several mechanisms for the (potential) functional efficacy of probiotics. In line with the indigenous microbiota, probiotics may also exert beneficial effects on three levels, which partly overlap. Probiotics can influence the microbial environment (level 1), the intestinal barrier function (level 2) and the immune system (level 3) all working in concert to maintain homeostasis.

Firstly, probiotics can influence the microbial environment by i) affecting metabolic activity (like the inhibition of procarcinogenic enzymatic activity and the production of certain short-chain fatty acids (SCFAs), ii) preventing the overgrowth of potential pathogens by competing for substrates and adhesion sites, iii) decreasing luminal $\mathrm{pH}$, and iv) producing bacteriocins. For example, Sherman et al. showed that $L$. acidophilus and $L$. rhamnosus were found to adhere to a T84 epithelial cell monolayer and inhibited the adhesion of enterotoxic E.coli ${ }^{76}$. In mice infected with Shiga toxinproducing E. coli $0157: \mathrm{H7}$, B. breve lowered luminal $\mathrm{pH}$ by producing acetic acid. The $\mathrm{pH}$ reduction was associated with increased mice survival ${ }^{77}$. Moreover, in a study by Collado et al., several human bifidobacteria strains produced bacteriocin-like compounds that inhibited the growth of both Gram-positive and Gram-negative bacteria $^{78}$.

Secondly, probiotics can also influence intestinal barrier function by i) increasing mucus production, ii) enhancing intestinal barrier integrity, iii) inducing the production of cytoprotective substances, iv) modulating epithelial cell survival. Cabalero-Franco et al. found a pronounced increase $(60 \%)$ in luminal mucin secretion in rats following treatment with the multispecies probiotic VSL\#3 ${ }^{79}$. Probiotics can affect intestinal barrier integrity by preserving tight junction (TJ) structure and function. Parasol et al. showed that $L$. casei prevents the redistribution of TJ protein zonula occludens (ZO)-1, caused by infection with enteropathogenic E.coli. Zyrek et al. showed that the probiotic E.coli Nissle prevented the disruptive effects of (enteropathogenic E. coli) EPEC on T84 epithelial monolayers by altering protein kinase $C$ signalling and causing the redistribution and increased expression of ZO- $2^{80}$. Furthermore, L. rhamnosus GG 
(LGG) induced specific heat shock proteins, important for maintaining cytoskeletal integrity, by activation of mitogen-activated protein kinases in mice colonic epithelial cells $^{81}$. There is also evidence that probiotics can increase the production of the antimicrobial peptides defensins, thereby enhancing the intestinal barrier. VSL\#3 interferes with the production of defensins in the intestinal crypts ${ }^{82}$ and E.coli Nissle can induce the expression of human beta-defensins- 2 in Caco-2 intestinal epithelial cells $^{82}$. In addition, LGG-derived soluble factors can activate the Akt/protein kinase B pathway, inhibit cytokine mediated apoptosis and promote cell growth in human and mouse colon epithelial cells ${ }^{83}$.

Thirdly, probiotics can modulate the immune system. Activation of innate immunity depends on recognition of microbe-associated molecular patterns (MAMPs) through pattern recognition receptors (PRRs), in particular Toll-like receptors (TLRs). TLRs are expressed on both epithelial cells and immune cells and at least 10 TLRs are currently known. Specific MAMPs have been identified for many TLRs and include LPS, flagellin, single-stranded RNA and unmethylated CpG motifs ${ }^{84}$. Grabig et al. showed that human $T$ cells cultured with the probiotic E. coli Nissle expressed increased levels of TLR2 and TLR4 ${ }^{85}$. E. coli Nissle also reduced dextran sodium sulphate (DSS) induced colitis and modulated cytokine production in wildtype but not in TLR2 and TLR4 knockout mice ${ }^{85}$. Interestingly, VSL\#3 reduced the severity of DSS-induced colitis in both wildtype and TLR2 and TLR4 knockout mice but not in a TLR9 knockout mouse model $^{86}$. These results showed that specific probiotic bacteria stimulate distinct TLRs. Stimulation of TLRs can lead to activation of nuclear factor-kappaB (NF-kB), mitogenactivated protein kinase (MAPK) and the type I interferon pathway. Importantly, these receptors can be down-regulated or inhibited depending on whether activation occurs through commensal or potential pathogenic micro-organisms ${ }^{87}$. Probiotics can inhibit NF-kB-induced cytokine and chemokine production. For example, L. casei downregulated invasive $S$. flexneri-induced transcription cytokines and chemokines and adherence molecules in epithelial cells through modulation of the ubiquitin/proteasome pathway involved in the induction of NF-KB-mediated proinflammatory signalling ${ }^{88}$. VSL\#3 produced soluble factors that inhibit the chymotrypsin-like activity of the proteasome in gut epithelial cells resulting in inhibition of NF-KB and increased expression of heat shock proteins ${ }^{89}$. Furthermore, E. faecalis regulated the phosphorylation, expression and transcription of peroxisome proliferator-activated receptor (PPAR) $-\nu$ and increased expression of IL-10 by colonic epithelial cells ${ }^{90}$.

In addition, numerous studies have shown that probiotics can increase antiinflammatory or suppress pro-inflammatory cytokine production, affect regulatory T cells and their associated cytokines ${ }^{10,91,92}$ and generate IgA producing B cells. The stimulation of $T$ cells by allogeneic antigen presenting cells in the presence of L. paracasei led to decreased T cell proliferation and the production of IL-10 and TGF- $\beta^{93}$. Moreover, LGG administration in children ${ }^{94}$ and peroral administration of 
B. bifidum in mice ${ }^{95}$ induced $\lg$, IgA and $\lg M$ secretion from circulating lymphocytes and MLN and spleen cells, respectively.

Probiotics have been applied in the prevention and/or treatment of several disorders including, IBD, pouchitis, IBS, necrotising colitis, Helicobacter pylori eradication therapy, $A A D$, infectious and traveller's diarrhoea and lactose intolerance ${ }^{46,96,97}$. Although in vivo data are increasing, many mechanistic findings are based on in vitro, ex vivo or animal studies which do not necessarily correlate with clinical efficacy in humans. It should be noted that each probiotic strain has its specific properties. Properties that apply to one probiotic strain do not necessarily apply to another probiotic strain. Even closely related bacterial strains of the same species may have different physiological effects. It can be hypothesised that by combining strains with specific properties (e.g. a multispecies probiotic) they may complement each others' effect through synergism and/or symbiosis resulting in an enhanced efficacy. Indeed, in cultured peripheral blood mononuclear cells (PBMCs) a combination of probiotic strains resulted in higher IL-10 levels compared to the individual strains separately ${ }^{98}$. Furthermore, the pathophysiology of every specific disease differs, and many diseases have a multifactorial aetiology. This underlines the need for "custom-made" probiotics, consisting of strains with properties that are effective for a particular application. In this context it should also be taken into account that the response to probiotics also depends on the composition of the endogenous microbiota and genetic differences between individuals.

\section{The effect of probiotics on AAD}

The treatment and/or prevention of AAD by probiotics have been subject of many trials and are reviewed in several meta-analyses and some systematic reviews (Table 1.1). The meta-analyses by Cremonini, D'Souza, Szajewska (2005 and 2006) and Johnston found combined relative risks of $0.37-0.44$ in favour of probiotic over placebo treatment in the prevention of $A A D^{99-103}$. In these 5 meta-analyses including two with only paediatric trials and one with only $S$. boulardii trials, no subgroup analyses were performed due to the limited number of studies included ${ }^{99-103}$. McFarland ${ }^{104}$ and Sazawal ${ }^{105}$ both conducted large meta-analyses (25 and 19 studies, respectively) including many different strains and types of probiotics. Both metaanalyses also showed that probiotics were efficacious in preventing AAD with a RR of 0.43 and 0.48 , respectively. Moreover, McFarland stratified by probiotic type and showed that only $S$. boulardii, LGG and probiotic mixtures showed significant efficacy ${ }^{104}$. Sazawal analysed the use of probiotics in the prevention of acute diarrhoea $(n=34)$. Subgroup analyses were performed on type of diarrhoea (AAD:19 studies), age groups, products and quality of trial and showed that only type of diarrhoea and product influenced the effect ${ }^{105}$. 


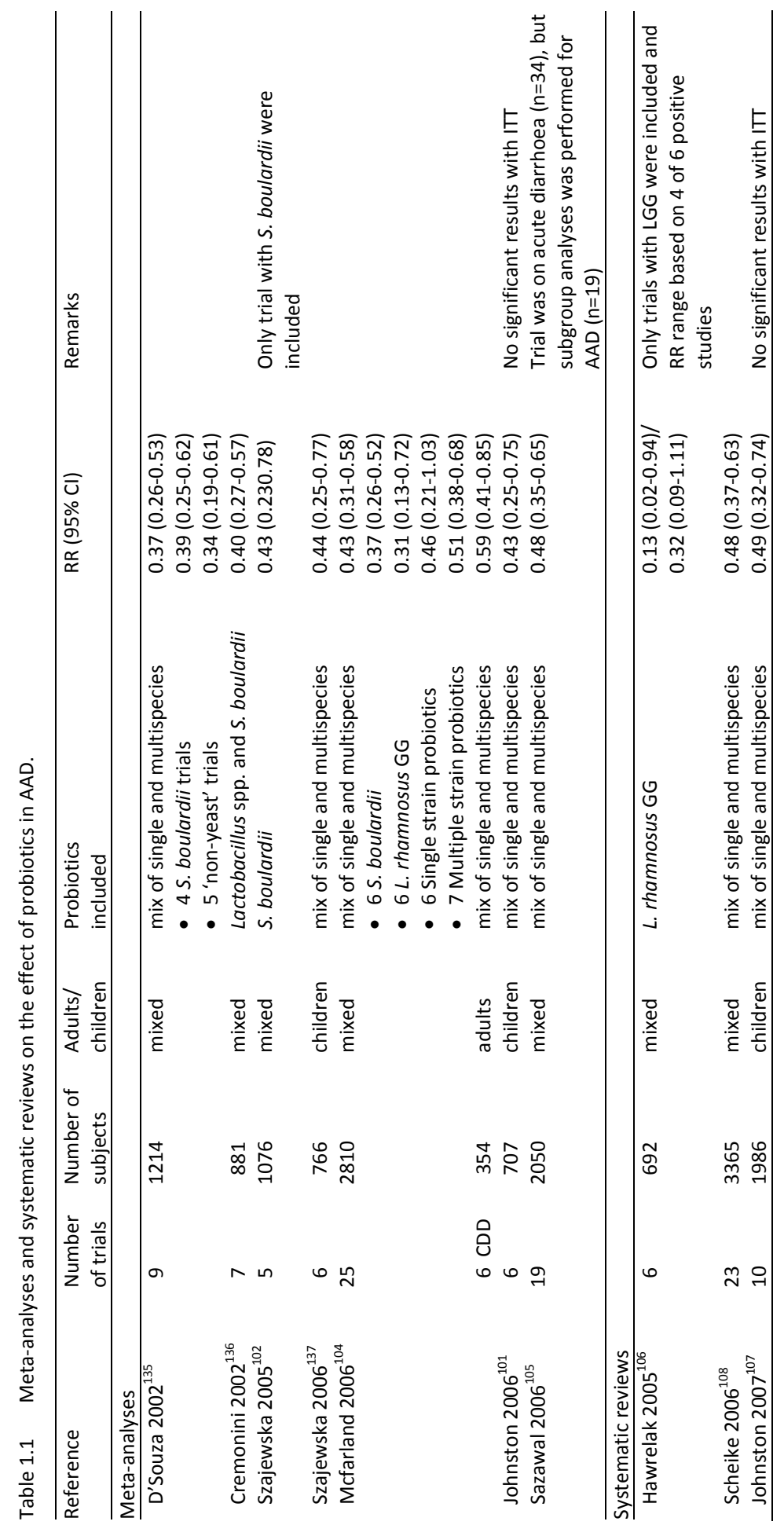


Next to several meta-analyses also three systematic reviews were published ${ }^{106-108}$. In the systematic review by Hawrelak, evaluating only papers on LGG, 4 of 6 studies found a significant reduction of $A A D$, one study found a significant decrease in the number of days with diarrhoea and one study was negative ${ }^{106}$. Scheike ${ }^{108}$ reviewed 23 trials and found that probiotics were associated with a relative reduction of AAD of $52 \%$ compared to placebo with a number to treat (NTT) of 8 . Despite statistical heterogeneity between studies, detailed analysis revealed that the effects of probiotics were consistent. Moreover, a stratified analysis revealed that $S$. boulardii, LGG and multispecies products were more effective than monospecies products. Furthermore, no relation between trial quality and magnitude of effect on probiotic treatment was found and no adverse events were reported ${ }^{108}$. The Cochrane database of systematic reviews published a review on probiotics for the prevention of paediatric AAD. The per protocol analysis showed a pooled relative risk of 0.49 in favour of probiotic use. However, the intention to treat analysis showed nonsignificant results. Moreover, higher trial quality showed more efficacy than lower trial quality ${ }^{107}$.

Only a limited number of studies investigated the effect of probiotic in the prevention of CDAD. As approximately $20 \%$ of $A A D$ is $C D A D^{43}$, this is probably due to the large sample size required to detect a significant difference. In the meta-analysis by McFarland a separate analysis of Clostridium difficile associated diarrhoea was performed, resulting in a pooled relative risk of 0.59 in favour of probiotic use ${ }^{104}$. Analyzing recurrences of CDAD, significant results were found for $S$. boulardii but not for LGG or L. plantarum 299V. In a recent trial testing a probiotic mix for the prevention of $A A D$, prevention of $C D A D$ was a secondary outcome. A significant reduction in the occurrence of CDAD with a NTT of 6 was found ${ }^{109}$.

In conclusion, there is compelling evidence that at least some probiotics can be efficacious in the treatment and prevention of AAD but it remains difficult to extrapolate these results to make general recommendations. This is due to the statistical heterogeneity between the studies, the difference in methodological quality, and the lack of standardization in terms of study population, dose and duration of both probiotic and antibiotic treatment and definition of diarrhoea.

\section{The effects of probiotics on antibiotic-associated side effects}

Recognition of the beneficial effect of probiotics has increased the interest in probiotic in preventing antibiotic-associated side effects.

The use of probiotics to decrease the emergence of bacterial resistance and the transfer of resistance genes has been briefly investigated. Maisonneuve et al. found that probiotic yogurt intake inhibited horizontal antibiotic resistance gene transfer in mice ${ }^{110,111}$. Intake of bifidobacteria also significantly decreased transfer of $\beta$-lactam resistance among enterobacteria in gnotobiotic mice ${ }^{112}$. Moreover, intake of Lactobacillus F19 was found to have a limited effect on the emergence of resistant 
isolates during treatment with penicillin and quinolones ${ }^{113}$. Furthermore, Plummer et al. found that the number of patients harbouring antibiotic-resistant enterococci after antibiotic therapy was significantly lower in the group taking a probiotic mixture compared to placebo ${ }^{33}$.

The effect of probiotic intake on the composition of intestinal microbiota during and after antibiotic intake has recently been investigated. However, most studies focus on survival of ingested probiotic strains, emergence of antibiotic resistance or prevention of disturbances in specific bacterial groups ${ }^{33,113-116}$. Mainly culture-dependent approaches were used and the effect on the total microbiota was rarely investigated. Recently, the effect of a probiotic mixture during amoxicillin/clavulanic acid intake was studied in healthy volunteers using a combination of culture and terminal restriction fragment length polymorphism. This study indicated that probiotic intake promotes a more rapid return of the faecal microbiota to the pre-antibiotic state ${ }^{117}$. Many studies have investigated the effect of either antibiotics or probiotics on the immune system. However, to the best of our knowledge, no studies have assessed the effect of probiotic intake on the immune system during and after antibiotic treatment.

Few in vivo studies have investigated the mechanism of action on the (potential) efficacy of probiotics in preventing antibiotic-associated side effects. In vitro and animal data have (indirectly) provided basic mechanisms of action, though mostly related to AAD/CDAD. For example, S. boulardii up-regulated total and specific antitoxin A secretory IgA expression in animal models ${ }^{118,119}$. Some probiotics have the ability to directly destroy or inhibit the binding of pathogenic toxins ${ }^{118,120,121}$. For example $S$. boulardii has also shown to inhibit $C$. difficile toxin $A$ binding and enterotoxicity in rat ileum ${ }^{122}$. This effect is probably mediated through the secretion of protease that can hydrolyse the toxin ${ }^{123}$. VSL\#3 restored chloride channel activity in damaged rat epithelium, which has a vital role in water absorption and thus diarrhoea $^{124}$. Moreover, probiotics provide colonisation resistance against $C$. difficile and putative aetiologies for AAD (i.e. enterotoxic E.coli) ${ }^{125}$. Probiotics may also affect metabolic activity (i.e. bile acids and SCFAs), enhance intestinal barrier integrity ${ }^{125}$ and affect regulation of the enteric nervous system ${ }^{126}$.

However, in order to investigate the relationship between probiotics, antibiotics, the intestinal microbiota and the immune system, clinical trials are needed.

\section{Safety}

Probiotics have been widely used in food processing for many years, and overall have an excellent safety record ${ }^{127,128}$. In Finland, where LGG has been widely used as a probiotic since 1990, no significant increase in reported adverse reactions or bacteraemia attributable to the probiotic strain has been observed ${ }^{129}$. Many clinical studies also support the safety of specific probiotic strains in high-risk populations. For example, different Lactobacillus strains have been given to patients infected with HIV, 
to infants, and to neonates with necrotizing enterocolitis without significant adverse effects $^{130,131}$.

Despite their long history of safe use probiotics may still induce detrimental effects. Cases of bacteraemia and fungaemia, mainly in children, elderly and immunocompromised patients, have been reported ${ }^{68,132}$, although it was not always clear whether this involved intestinal translocation or contamination of a venous catheter. Several probiotics have been studied in animal models of translocation and only show translocation if the animals were compromised by antibiotic pressure or were immuno-compromised ${ }^{133}$. Moreover, in many cases translocation was facilitated by underlying disorders of the oral cavity or Gl-tract. Therefore, it is not recommended to give probiotics to those patients who are at increased risk of translocation-related problems (e.g. central venous catheters, artificial heart valves, after dental surgery) and those at high risk of developing bloodstream infections (e.g. low white blood cell count).

Unexpectedly, a recent randomised controlled trial of a multispecies probiotic in patients with acute pancreatitis found an increased risk of mortality (RR $2.5395 \% \mathrm{Cl}$ $1.22-5.25)^{134}$. Ever since, probiotics can no longer be considered as harmless adjuvant to enteral nutrition, especially in critically ill patients.

Finally, as antibiotic resistance is becoming an increasing problem, an important safety consideration is that probiotic strains should not have the ability to transfer antibiotic resistance genes. In addition, the safety of genetically modified probiotics should be considered. 


\section{Aims and outline of the thesis}

One of the side effects of antibiotic intake is a marked disturbance of the intestinal microbiota, which can result in antibiotic-associated diarrhoea. Probiotics can affect the composition of the intestinal microbiota, and beneficial effects have been observed in the prevention of $A A D$, though focusing mainly on clinical outcome. The potential mechanisms of action underlying these effects have largely remained unexplored. The main aim of the present project was to investigate the effect of a multispecies probiotic on bacteriological, immunological and clinical parameters during as well as after antibiotic treatment in healthy volunteers and chronic obstructive pulmonary disease (COPD) patients. Although short-term antibiotic use can cause long-term disturbances of the intestinal microbiota, the effect of frequent antibiotic use is not known. COPD patients often suffer from acute exacerbations for which antibiotic therapy is frequently prescribed. Therefore, COPD patients are used as a model for patients with frequent antibiotic use not prescribed for infections of the Gl-tract.

Properties that apply to one probiotic strain do not necessarily apply to another and large variation in the efficacy of the different strains and combination of strains used is reported. By combining strains with specific properties they may complement each others' effect through synergism and/or symbiosis, thereby enhancing efficacy. In Chapter 2, the literature was reviewed to make a comparison of functionality and efficacy between monostrain, multistrain and multispecies probiotics. Chapter $\mathbf{3}$ describes the effect of a multispecies probiotic on the composition of the intestinal microbiota, using microbiological culture, in healthy volunteers during and after amoxycillin intake. In addition, the effect on the metabolic activity of the intestinal microbiota and on bowel habits was investigated.

Culture-dependent approaches provide only very limited information on the temporal and treatment-related dynamics of the intestinal microbiota. Therefore, the effect of amoxycillin on the diversity and temporal stability of the faecal microbiota and a potential restoration by a multispecies probiotic using denaturing gradient gel electrophoresis (DGGE) is described in Chapter 4.

As both probiotics and antibiotics can affect the immune system directly or indirectly, via modulation of the intestinal microbiota, the influence of amoxycillin and the multispecies probiotic on components of both the systemic and mucosal immune system is assessed in Chapter $\mathbf{5}$.

Next, the intervention with a multispecies probiotic during and after antibiotic intake was repeated in patients with a history of frequent antibiotic use. The disturbance of the dominant faecal microbiota and the possible restoration by a multispecies probiotic in COPD patients treated with antibiotics for an acute exacerbation is described in Chapter 6. Again, the effect on specific bacterial subgroups, using both culture-dependent and molecular-based techniques, bowel habits, the incidence of 
antibiotic resistance, endotoxins and $\mathrm{pH}$ was studied (Chapter 6). Whether probiotic intake was able to influence immune biomarkers in these patients is described in Chapter 7. A general discussion is presented in Chapter $\mathbf{8}$, summarising the major findings of all studies and discussing remaining questions and implications for future research. 


\section{References}

1. Gill SR, Pop M, Deboy RT, Eckburg PB, Turnbaugh PJ, Samuel BS, Gordon JI, Relman DA, Fraser-Liggett CM, Nelson KE. Metagenomic analysis of the human distal gut microbiome. Science. 2006;312:1355-9.

2. Rajilic-Stojanovic M, Smidt $\mathrm{H}$, de Vos WM. Diversity of the human gastrointestinal tract microbiota revisited. Environ Microbiol. 2007;9:2125-36.

3. Dethlefsen L, Eckburg PB, Bik EM, Relman DA. Assembly of the human intestinal microbiota. Trends Ecol Evol. 2006;21:517-23.

4. Servin AL. Antagonistic activities of lactobacilli and bifidobacteria against microbial pathogens. FEMS Microbiol Rev. 2004;28:405-40.

5. Savage DC. Microbial ecology of the gastrointestinal tract. Annu Rev Microbiol. 1977;31: 107-33.

6. Isolauri E, Salminen S, Ouwehand AC. Microbial-gut interactions in health and disease. Probiotics. Best Pract Res Clin Gastroenterol. 2004;18:299-313.

7. Penders J, Thijs C, Vink C, Stelma FF, Snijders B, Kummeling I, van den Brandt PA, Stobberingh EE. Factors influencing the composition of the intestinal microbiota in early infancy. Pediatrics. 2006;118:511-21.

8. Hopkins MJ, Sharp R, Macfarlane GT. Age and disease related changes in intestinal bacterial populations assessed by cell culture, 16S rRNA abundance, and community cellular fatty acid profiles. Gut. 2001;48:198-205.

9. Galdeano CM, de Moreno de LeBlanc A, Vinderola G, Bonet ME, Perdigon G. Proposed model: mechanisms of immunomodulation induced by probiotic bacteria. Clin Vaccine Immunol. 2007;14:485-92.

10. Shida K, Nanno M. Probiotics and immunology: separating the wheat from the chaff. Trends Immunol. 2008;29:565-73.

11. Eckburg PB, Bik EM, Bernstein CN, Purdom E, Dethlefsen L, Sargent M, Gill SR, Nelson KE, Relman DA. Diversity of the human intestinal microbial flora. Science. 2005;308:1635-8.

12. Zoetendal EG, Rajilic-Stojanovic M, de Vos WM. High-throughput diversity and functionality analysis of the gastrointestinal tract microbiota. Gut. 2008;57:1605-15.

13. Othman M, Aguero R, Lin HC. Alterations in intestinal microbial flora and human disease. Curr Opin Gastroenterol. 2008;24:11-6.

14. Penders J, Stobberingh EE, van den Brandt PA, Thijs C. The role of the intestinal microbiota in the development of atopic disorders. Allergy. 2007;62:1223-36.

15. Shreiner A, Huffnagle GB, Noverr MC. The "Microflora Hypothesis" of allergic disease. Adv Exp Med Biol. 2008;635:113-34.

16. Coenen S, Muller A, Adriaenssens N, Vankerckhoven V, Hendrickx E, Goossens H. European Surveillance of Antimicrobial Consumption (ESAC): outpatient parenteral antibiotic treatment in Europe. J Antimicrob Chemother. 2009;64:200-5.

17. Molstad S, Lundborg CS, Karlsson AK, Cars O. Antibiotic prescription rates vary markedly between 13 European countries. Scand J Infect Dis. 2002;34:366-71.

18. Goossens H, Ferech M, Vander Stichele R, Elseviers M. Outpatient antibiotic use in Europe and association with resistance: a cross-national database study. Lancet. 2005;365:579-87.

19. Muller A, Coenen S, Monnet DL, Goossens H. European Surveillance of Antimicrobial Consumption (ESAC): outpatient antibiotic use in Europe, 1998-2005. Euro Surveill. 2007;12:E071011 1.

20. Levy SB, Marshall B. Antibacterial resistance worldwide: causes, challenges and responses. Nat Med. 2004;10:S122-9.

21. Bronzwaer SL, Cars O, Buchholz U, Molstad S, Goettsch W, Veldhuijzen IK, Kool JL, Sprenger MJ, Degener JE. A European study on the relationship between antimicrobial use and antimicrobial resistance. Emerg Infect Dis. 2002;8:278-82.

22. Murray BE. New aspects of antimicrobial resistance and the resulting therapeutic dilemmas. J Infect Dis. 1991;163:1184-94.

23. Dobbins WO, 3rd, Herrero BA, Mansbach CM. Morphologic alterations associated with neomycin induced malabsorption. Am J Med Sci. 1968;255:63-77.

24. Parizhskaya M, Youssef NN, Di Lorenzo C, Goyal RK. Clofazimine enteropathy in a pediatric bone marrow transplant recipient. J Pediatr. 2001;138:574-6. 
25. Annese V, Janssens J, Vantrappen G, Tack J, Peeters TL, Willemse P, Van Cutsem E. Erythromycin accelerates gastric emptying by inducing antral contractions and improved gastroduodenal coordination. Gastroenterol. 1992;102:823-8.

26. Catnach SM, Fairclough PD. Erythromycin and the gut. Gut. 1992;33:397-401.

27. Goldhill JM, Rose K, Percy WH. Effects of antibiotics on epithelial ion transport in the rabbit distal colon in-vitro. J Pharm Pharmacol. 1996;48:651-6.

28. Croswell A, Amir E, Teggatz P, Barman M, Salzman NH. Prolonged impact of antibiotics on intestinal microbial ecology and susceptibility to enteric Salmonella infection. Infect Immun. 2009;77:2741-53.

29. Edlund C, Nord CE. Effect on the human normal microflora of oral antibiotics for treatment of urinary tract infections. J Antimicrob Chemother. 2000;46:41-8;63-5.

30. Jernberg C, Lofmark S, Edlund C, Jansson JK. Long-term ecological impacts of antibiotic administration on the human intestinal microbiota. Isme J. 2007;1:56-66.

31. Lindgren M, Lofmark S, Edlund C, Huovinen P, Jalava J. Prolonged impact of a one-week course of clindamycin on Enterococcus spp. in human normal microbiota. Scand J Infect Dis. 2009;41:215-9.

32. McFarland LV. Epidemiology, risk factors and treatments for antibiotic-associated diarrhea. Dig Dis. 1998;16:292-307.

33. Plummer SF, Garaiova I, Sarvotham T, Cottrell SL, Le Scouiller S, Weaver MA, Tang J, Dee P, Hunter J. Effects of probiotics on the composition of the intestinal microbiota following antibiotic therapy. Int J Antimicrob Agents. 2005;26:69-74.

34. Sullivan A, Edlund C, Nord CE. Effect of antimicrobial agents on the ecological balance of human microflora. Lancet Infect Dis. 2001;1:101-14.

35. Tannock GW. Analysis of the intestinal microflora using molecular methods. Eur J Clin Nutr. 2002;56:S44-9.

36. Zoetendal EG, Vaughan EE, de Vos WM. A microbial world within us. Mol Microbiol. 2006;59:1639-50.

37. De La Cochetiere MF, Durand T, Lalande V, Petit JC, Potel G, Beaugerie L. Effect of antibiotic therapy on human fecal microbiota and the relation to the development of Clostridium difficile. Microb Ecol. 2008;56:395-402.

38. De La Cochetiere MF, Durand T, Lepage P, Bourreille A, Galmiche JP, Dore J. Resilience of the dominant human fecal microbiota upon short-course antibiotic challenge. J Clin Microbiol. 2005;43:5588-92.

39. Dethlefsen L, Huse S, Sogin ML, Relman DA. The Pervasive Effects of an Antibiotic on the Human Gut Microbiota, as Revealed by Deep 16S rRNA Sequencing. PLoS Biol. 2008;6:e280.

40. Young VB, Schmidt TM. Antibiotic-associated diarrhea accompanied by large-scale alterations in the composition of the fecal microbiota. J Clin Microbiol. 2004;42:1203-6.

41. Beaugerie L, Petit JC. Microbial-gut interactions in health and disease. Antibiotic-associated diarrhoea. Best Pract Res Clin Gastroenterol. 2004;18:337-52.

42. Sekirov I, Tam NM, Jogova M, Robertson ML, Li Y, Lupp C, Finlay BB. Antibiotic-induced perturbations of the intestinal microbiota alter host susceptibility to enteric infection. Infect Immun. 2008;76:472636.

43. Pillai A, Nelson R. Probiotics for treatment of Clostridium difficile-associated colitis in adults. Cochrane Database Syst Rev. 2008:CD004611.

44. Macpherson AJ, Uhr T. Induction of protective IgA by intestinal dendritic cells carrying commensal bacteria. Science. 2004;303:1662-5.

45. Rautava S, Isolauri E. The development of gut immune responses and gut microbiota: effects of probiotics in prevention and treatment of allergic disease. Curr Issues Intest Microbiol. 2002;3:15-22.

46. Preidis GA, Versalovic J. Targeting the human microbiome with antibiotics, probiotics, and prebiotics: gastroenterology enters the metagenomics era. Gastroenterol. 2009;136:2015-31.

47. Droste JH, Wieringa MH, Weyler JJ, Nelen VJ, Vermeire PA, Van Bever HP. Does the use of antibiotics in early childhood increase the risk of asthma and allergic disease? Clin Exp Allergy. 2000;30:1547-53.

48. Farooqi IS, Hopkin JM. Early childhood infection and atopic disorder. Thorax. 1998;53: 927-32.

49. Johnson CC, Ownby DR, Alford SH, Havstad SL, Williams LK, Zoratti EM, Peterson EL, Joseph CL. Antibiotic exposure in early infancy and risk for childhood atopy. J Allergy Clin Immunol. 2005;115:1218-24.

50. Wickens K, Pearce N, Crane J, Beasley R. Antibiotic use in early childhood and the development of asthma. Clin Exp Allergy. 1999;29:766-71. 
51. Spiller R, Campbell E. Post-infectious irritable bowel syndrome. Curr Opin Gastroenterol. 2006;22: 13-7.

52. Van Vlem B, Vanholder R, De Paepe P, Vogelaers D, Ringoir S. Immunomodulating effects of antibiotics: literature review. Infection. 1996;24:275-91.

53. Hamilton-Miller JM. Immunopharmacology of antibiotics: direct and indirect immunomodulation of defence mechanisms. J Chemother. 2001;13:107-11.

54. Mangano K, Quattrocchi C, Aiello C, Scalia G, Speciale A, Nicoletti G, Di Marco R. Immunomodulatory properties of cefaclor: in vivo effect on cytokine release and lymphoproliferative response in rats. J Chemother. 2006;18:641-7.

55. Morikawa K, Zhang J, Nonaka M, Morikawa S. Modulatory effect of macrolide antibiotics on the Th1and Th2-type cytokine production. Int J Antimicrob Agents. 2002;19:53-9.

56. Bartlett JG. Antibiotic-associated diarrhea. Clin Infect Dis. 1992;15:573-81.

57. McFarland LV. Epidemiology of infectious and iatrogenic nosocomial diarrhea in a cohort of general medicine patients. Am J Infect Control. 1995;23:295-305.

58. Wilkins TD, Lyerly DM. Clostridium difficile testing: after 20 years, still challenging. J Clin Microbiol. 2003;41:531-4.

59. Bartlett JG, Chang TW, Gurwith M, Gorbach SL, Onderdonk AB. Antibiotic-associated pseudomembranous colitis due to toxin-producing clostridia. N Engl J Med. 1978;298:531-4.

60. Song X, Bartlett JG, Speck K, Naegeli A, Carroll K, Perl TM. Rising economic impact of clostridium difficile-associated disease in adult hospitalized patient population. Infect Control Hosp Epidemiol. 2008;29:823-8.

61. Aslam S, Hamill RJ, Musher DM. Treatment of Clostridium difficile-associated disease: old therapies and new strategies. Lancet Infect Dis. 2005;5:549-57.

62. Bartlett JG. Clinical practice. Antibiotic-associated diarrhea. N Engl J Med. 2002;346:334-9.

63. Chernak E. Severe Clostridium difficile-associated disease in populations previously at low risk-four states. MMWR Morb Mortal Wkly. 2005;Rep 54:1201-5.

64. McDonald LC, Killgore GE, Thompson A, Owens RC, Jr., Kazakova SV, Sambol SP, Johnson S, Gerding DN. An epidemic, toxin gene-variant strain of Clostridium difficile. N Engl J Med. 2005;353:2433-41.

65. Pepin J, Valiquette L, Cossette B. Mortality attributable to nosocomial Clostridium difficile-associated disease during an epidemic caused by a hypervirulent strain in Quebec. CMAJ. 2005;173:1037-42.

66. Kuijper EJ, Coignard B, Brazier JS, Suetens C, Drudy D, Wiuff C, Pituch H, Reichert P, Schneider F, Widmer AF, Olsen KE, Allerberger F, Notermans DW, Barbut F, Delmee M, Wilcox M, Pearson A, Patel BC, Brown DJ, Frei R, Akerlund T, Poxton IR, Tull P. Update of Clostridium difficile-associated disease due to PCR ribotype 027 in Europe. Euro Surveill. 2007;12:E1-2.

67. Borriello SP. Pathogenesis of Clostridium difficile infection. J Antimicrob Chemother. 1998;41:13-9.

68. McFarland LV. Evidence-based review of probiotics for antibiotic-associated diarrhea and Clostridium difficile infections. Anaerobe. 2009;15:274-80.

69. Parkes GC, Sanderson JD, Whelan K. The mechanisms and efficacy of probiotics in the prevention of Clostridium difficile-associated diarrhoea. Lancet Infect Dis. 2009;9:237-44.

70. Metchnikoff E. The prolongation of life. Optimistic studies. London, United Kingdom: William Heinemann; 1907.

71. Hamilton-Miller JM, Gibson GR, Bruck W. Some insights into the derivation and early uses of the word 'probiotic'. Br J Nutr. 2003;90:845.

72. Parker RB. Probiotics. The other half of the antibiotics story. Anim Nutr Health. 1974;29:4-8.

73. Fuller R. Probiotics in man and animals. J Appl Bacteriol. 1989;66:365-78.

74. Borchers AT, Selmi C, Meyers FJ, Keen CL, Gershwin ME. Probiotics and immunity. J Gastroenterol. 2009;44:26-46.

75. Sanders ME, Huis in't Veld J. Bringing a probiotic-containing functional food to the market: microbiological, product, regulatory and labeling issues. Antonie Van Leeuwenhoek. 1999;76:293-315.

76. Sherman PM, Johnson-Henry KC, Yeung HP, Ngo PS, Goulet J, Tompkins TA. Probiotics reduce enterohemorrhagic Escherichia coli 0157:H7- and enteropathogenic E. coli 0127:H6-induced changes in polarized T84 epithelial cell monolayers by reducing bacterial adhesion and cytoskeletal rearrangements. Infect Immun. 2005;73:5183-8. 
77. Asahara T, Shimizu K, Nomoto K, Hamabata T, Ozawa A, Takeda Y. Probiotic bifidobacteria protect mice from lethal infection with Shiga toxin-producing Escherichia coli 0157:H7. Infect Immun. 2004;72:2240-7.

78. Collado MC, Gueimonde M, Hernandez M, Sanz Y, Salminen S. Adhesion of selected Bifidobacterium strains to human intestinal mucus and the role of adhesion in enteropathogen exclusion. J Food Prot. 2005;68:2672-8.

79. Caballero-Franco C, Keller K, De Simone C, Chadee K. The VSL\#3 probiotic formula induces mucin gene expression and secretion in colonic epithelial cells. Am J Physiol Gastrointest Liver Physiol. 2007;292:G315-22.

80. Zyrek AA, Cichon C, Helms S, Enders C, Sonnenborn U, Schmidt MA. Molecular mechanisms underlying the probiotic effects of Escherichia coli Nissle 1917 involve ZO-2 and PKCzeta redistribution resulting in tight junction and epithelial barrier repair. Cell Microbiol. 2007;9:804-16.

81. Tao Y, Drabik KA, Waypa TS, Musch MW, Alverdy JC, Schneewind O, Chang EB, Petrof EO. Soluble factors from Lactobacillus GG activate MAPKs and induce cytoprotective heat shock proteins in intestinal epithelial cells. Am J Physiol Cell Physiol. 2006;290:C1018-30.

82. Schlee M, Harder J, Koten B, Stange EF, Wehkamp J, Fellermann K. Probiotic lactobacilli and VSL\#3 induce enterocyte beta-defensin 2. Clin Exp Immunol. 2008;151:528-35.

83. Yan F, Cao H, Cover TL, Whitehead R, Washington MK, Polk DB. Soluble proteins produced by probiotic bacteria regulate intestinal epithelial cell survival and growth. Gastroenterol. 2007;132: 562-75.

84. Cario E, Podolsky DK. Toll-like receptor signaling and its relevance to intestinal inflammation. Ann N Y Acad Sci. 2006;1072:332-8.

85. Grabig A, Paclik D, Guzy C, Dankof A, Baumgart DC, Erckenbrecht J, Raupach B, Sonnenborn U, Eckert J, Schumann RR, Wiedenmann B, Dignass AU, Sturm A. Escherichia coli strain Nissle 1917 ameliorates experimental colitis via toll-like receptor 2- and toll-like receptor 4-dependent pathways. Infect Immun. 2006;74:4075-82.

86. Rachmilewitz D, Katakura K, Karmeli F, Hayashi T, Reinus C, Rudensky B, Akira S, Takeda K, Lee J, Takabayashi K, Raz E. Toll-like receptor 9 signaling mediates the anti-inflammatory effects of probiotics in murine experimental colitis. Gastroenterol. 2004;126:520-8.

87. Abreu MT, Fukata M, Arditi M. TLR signaling in the gut in health and disease. J Immunol. 2005;174:4453-60.

88. Tien MT, Girardin SE, Regnault B, Le Bourhis L, Dillies MA, Coppee JY, Bourdet-Sicard R, Sansonetti PJ, Pedron T. Anti-inflammatory effect of Lactobacillus casei on Shigella-infected human intestinal epithelial cells. J Immunol. 2006;176:1228-37.

89. Petrof EO, Kojima K, Ropeleski MJ, Musch MW, Tao Y, De Simone C, Chang EB. Probiotics inhibit nuclear factor-kappaB and induce heat shock proteins in colonic epithelial cells through proteasome inhibition. Gastroenterol 2004;127:1474-87.

90. Are A, Aronsson L, Wang S, Greicius G, Lee YK, Gustafsson JA, Pettersson S, Arulampalam V. Enterococcus faecalis from newborn babies regulate endogenous PPARgamma activity and IL-10 levels in colonic epithelial cells. Proc Natl Acad Sci U S A. 2008;105:1943-8.

91. Boirivant $M$, Strober W. The mechanism of action of probiotics. Curr Opin Gastroenterol. 2007;23:679-92.

92. Vanderpool C, Yan F, Polk DB. Mechanisms of probiotic action: Implications for therapeutic applications in inflammatory bowel diseases. Inflamm Bowel Dis. 2008;14:1585-96.

93. von der Weid T, Bulliard C, Schiffrin EJ. Induction by a lactic acid bacterium of a population of CD4(+) T cells with low proliferative capacity that produce transforming growth factor beta and interleukin-10. Clin Diagn Lab Immunol. 2001;8:695-701.

94. Kaila M, Isolauri E, Soppi E, Virtanen E, Laine S, Arvilommi H. Enhancement of the circulating antibody secreting cell response in human diarrhea by a human Lactobacillus strain. Pediatr Res. 1992;32: 141-4.

95. Park JH, Um JI, Lee BJ, Goh JS, Park SY, Kim WS, Kim PH. Encapsulated Bifidobacterium bifidum potentiates intestinal IgA production. Cell Immunol. 2002;219:22-7.

96. de Vrese M, Schrezenmeir J. Probiotics, prebiotics, and synbiotics. Adv Biochem Eng Biotechnol. 2008;111:1-66. 
97. Jonkers D, Stockbrugger R. Review article: Probiotics in gastrointestinal and liver diseases. Aliment Pharmacol Ther. 2007;26:133-48.

98. Timmerman HM, Niers LE, Ridwan BU, Koning CJ, Mulder L, Akkermans LM, Rombouts FM, Rijkers GT. Design of a multispecies probiotic mixture to prevent infectious complications in critically ill patients. Clin Nutr. 2007;26:450-9.

99. Cremonini F, Di Caro S, Covino M, Armuzzi A, Gabrielli M, Santarelli L, Nista EC, Cammarota G, Gasbarrini G, Gasbarrini A. Effect of different probiotic preparations on Anti-Helicobacter pylori therapy-related side effects: A parallel group, triple blind, placebo-controlled study. Am J Gastroenterol. 2002;97:2744-9.

100. D'Souza AL, Rajkumar C, Cooke J, Bulpitt CJ. Probiotics in prevention of antibiotic associated diarrhoea: meta- analysis. BMJ. 2002;324:1361.

101. Johnston BC, Supina AL, Vohra S. Probiotics for pediatric antibiotic-associated diarrhea: a metaanalysis of randomized placebo-controlled trials. CMAJ. 2006;175:377-83.

102. Szajewska H, Mrukowicz J. Meta-analysis: non-pathogenic yeast Saccharomyces boulardii in the prevention of antibiotic-associated diarrhoea. Aliment Pharmacol Ther. 2005;22:365-72.

103. Szajewska H, Ruszczynski M, Radzikowski A. Probiotics in the prevention of antibiotic-associated diarrhea in children: A meta-analysis of randomized controlled trials. J Pediatr. 2006;149:367-72 e1.

104. McFarland LV. Meta-analysis of probiotics for the prevention of antibiotic associated diarrhea and the treatment of Clostridium difficile disease. Am J Gastroenterol. 2006;101:812-22.

105. Sazawal S, Hiremath G, Dhingra U, Malik P, Deb S, Black RE. Efficacy of probiotics in prevention of acute diarrhoea: a meta-analysis of masked, randomised, placebo-controlled trials. Lancet Infect Dis. 2006;6:374-82.

106. Hawrelak JA, Whitten DL, Myers SP. Is Lactobacillus rhamnosus GG effective in preventing the onset of antibiotic-associated diarrhoea: a systematic review. Digestion. 2005;72:51-6.

107. Johnston BC, Supina AL, Ospina M, Vohra S. Probiotics for the prevention of pediatric antibioticassociated diarrhea. Cochrane Database Syst Rev. 2007:CD004827.

108. Scheike I, Connock M, Taylor R, Fry-Smith A, Ward D. Probiotics for the prevention of antibiotic associated diarrhea: a systematic review. Department of Public Health and Epidemiology. 2006.

109. Hickson M, D'Souza AL, Muthu N, Rogers TR, Want S, Rajkumar C, Bulpitt CJ. Use of probiotic Lactobacillus preparation to prevent diarrhoea associated with antibiotics: randomised double blind placebo controlled trial. BMJ. 2007;335:80.

110. Maisonneuve S, Ouriet M, Duval-Iflah Y. Effects of yoghurt intake on plasmid transfer and colonisation with transconjugants in the digestive tract of mice associated with human faecal flora. FEMS Microbiol Ecol. 2000;31:241-8.

111. Maisonneuve S, Ouriet MF, Duval-Iflah Y. Comparison of yoghurt, heat treated yoghurt, milk and lactose effects on plasmid dissemination in gnotobiotic mice. Antonie Van Leeuwenhoek. 2001;79:199-207.

112. Moubareck C, Lecso M, Pinloche E, Butel MJ, Doucet-Populaire F. Inhibitory impact of bifidobacteria on the transfer of beta-lactam resistance among Enterobacteriaceae in the gnotobiotic mouse digestive tract. Appl Environ Microbiol. 2007;73:855-60.

113. Sullivan A, Johansson A, Svenungsson B, Nord CE. Effect of Lactobacillus F19 on the emergence of antibiotic-resistant microorganisms in the intestinal microflora. J Antimicrob Chemother. 2004;54:791-7.

114. Jernberg C, Sullivan A, Edlund C, Jansson JK. Monitoring of antibiotic-induced alterations in the human intestinal microflora and detection of probiotic strains by use of terminal restriction fragment length polymorphism. Appl Environ Microbiol. 2005;71:501-6.

115. Madden JA, Plummer SF, Tang J, Garaiova I, Plummer NT, Herbison M, Hunter JO, Shimada T, Cheng L, Shirakawa T. Effect of probiotics on preventing disruption of the intestinal microflora following antibiotic therapy: a double-blind, placebo-controlled pilot study. Int Immunopharmacol. 2005;5:1091-7.

116. Sullivan A, Barkholt L, Nord CE. Lactobacillus acidophilus, Bifidobacterium lactis and Lactobacillus F19 prevent antibiotic-associated ecological disturbances of Bacteroides fragilis in the intestine. J Antimicrob Chemother. 2003;52:308-11. 
117. Engelbrektson A, Korzenik JR, Pittler A, Sanders ME, Klaenhammer TR, Leyer G, Kitts CL. Probiotics to minimize the disruption of faecal microbiota in healthy subjects undergoing antibiotic therapy. J Med Microbiol. 2009;58:663-70.

118. Buts JP. Twenty-five years of research on Saccharomyces boulardii trophic effects: updates and perspectives. Dig Dis Sci. 2009;54:15-8.

119. Qamar A, Aboudola S, Warny M, Michetti P, Pothoulakis C, LaMont JT, Kelly CP. Saccharomyces boulardii stimulates intestinal immunoglobulin $A$ immune response to Clostridium difficile toxin $A$ in mice. Infect Immun. 2001;69:2762-5.

120. Castagliuolo I, LaMont JT, Nikulasson ST, Pothoulakis C. Saccharomyces boulardii protease inhibits Clostridium difficile toxin A effects in the rat ileum. Infect Immun. 1996;64:5225-32.

121. Kyne L, Warny M, Qamar A, Kelly CP. Association between antibody response to toxin A and protection against recurrent Clostridium difficile diarrhoea. Lancet. 2001;357:189-93.

122. Pothoulakis C, Kelly CP, Joshi MA, Gao N, O'Keane CJ, Castagliuolo I, Lamont JT. Saccharomyces boulardii inhibits Clostridium difficile toxin A binding and enterotoxicity in rat ileum. Gastroenterol. 1993;104:1108-15.

123. Castagliuolo I, Riegler MF, Valenick L, LaMont JT, Pothoulakis C. Saccharomyces boulardii protease inhibits the effects of Clostridium difficile toxins $A$ and $B$ in human colonic mucosa. Infect Immun. 1999;67:302-7.

124. Madsen K, Cornish A, Soper P, McKaigney C, Jijon H, Yachimec C, Doyle J, Jewell L, De Simone C. Probiotic bacteria enhance murine and human intestinal epithelial barrier function. Gastroenterol. 2001;121:580-91.

125. Ng SC, Hart AL, Kamm MA, Stagg AJ, Knight SC. Mechanisms of action of probiotics: recent advances. Inflamm Bowel Dis. 2009;15:300-10.

126. Verdu EF, Bercik P, Verma-Gandhu M, Huang XX, Blennerhassett P, Jackson W, Mao Y, Wang L, Rochat $\mathrm{F}$, Collins SM. Specific probiotic therapy attenuates antibiotic induced visceral hypersensitivity in mice. Gut. 2006;55:182-90.

127. Borriello SP, Hammes WP, Holzapfel W, Marteau P, Schrezenmeir J, Vaara M, Valtonen V. Safety of probiotics that contain lactobacilli or bifidobacteria. Clin Infect Dis. 2003;36:775-80.

128. Ishibashi N, Yamazaki S. Probiotics and safety. Am J Clin Nutr. 2001;73:465S-70S.

129. Salminen MK, Tynkkynen S, Rautelin H, Saxelin M, Vaara M, Ruutu P, Sarna S, Valtonen V, Jarvinen A. Lactobacillus bacteremia during a rapid increase in probiotic use of Lactobacillus rhamnosus $\mathrm{GG}$ in Finland. Clin Infect Dis. 2002;35:1155-60.

130. Deshpande G, Rao S, Patole S. Probiotics for prevention of necrotising enterocolitis in preterm neonates with very low birthweight: a systematic review of randomised controlled trials. Lancet. 2007;369:1614-20.

131. Salminen MK, Tynkkynen S, Rautelin H, Poussa T, Saxelin M, Ristola M, Valtonen V, Jarvinen A. The efficacy and safety of probiotic Lactobacillus rhamnosus GG on prolonged, noninfectious diarrhea in HIV Patients on antiretroviral therapy: a randomized, placebo-controlled, crossover study. HIV Clin Trials. 2004;5:183-91.

132. Boyle RJ, Robins-Browne RM, Tang ML. Probiotic use in clinical practice: what are the risks? Am J Clin Nutr. 2006;83:1256-64;446-7.

133. McCullough MJ, Clemons KV, McCusker JH, Stevens DA. Species identification and virulence attributes of Saccharomyces boulardii (nom. inval.). J Clin Microbiol. 1998;36:2613-7.

134. Besselink MG, van Santvoort HC, Buskens $E$, Boermeester MA, van Goor $H$, Timmerman $H M$, Nieuwenhuijs VB, Bollen TL, van Ramshorst B, Witteman BJ, Rosman C, Ploeg RJ, Brink MA, Schaapherder AF, Dejong $\mathrm{CH}$, Wahab PJ, van Laarhoven $\mathrm{CJ}$, van der Harst E, van Eijck $\mathrm{CH}$, Cuesta MA, Akkermans LM, Gooszen HG. Probiotic prophylaxis in predicted severe acute pancreatitis: a randomised, double-blind, placebo-controlled trial. Lancet. 2008;371:651-9.

135. D'Souza AL, Rajkumar C, Cooke J, Bulpitt CJ. Probiotics in prevention of antibiotic associated diarrhoea: meta-analysis. BMJ. 2002;324:1361.

136. Cremonini F, Di Caro S, Nista EC, Bartolozzi F, Capelli G, Gasbarrini G, Gasbarrini A. Meta-analysis: the effect of probiotic administration on antibiotic-associated diarrhoea. Aliment Pharmacol Ther. 2002;16:1461-7.

137. Szajewska H, Ruszczynski M, Radzikowski A. Probiotics in the prevention of antibiotic-associated diarrhea in children: a meta-analysis of randomized controlled trials. J Pediatr. 2006;149:367-72. 



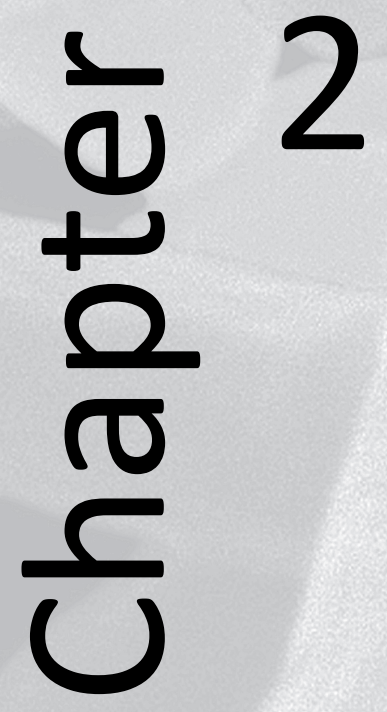




\section{Monostrain, multistrain and multispecies probiotics}

A comparison of functionality and efficacy

Harro M. Timmerman, Catherina J.M. Koning, Linda Mulder,

Frans M. Rombouts, Anton C. Beynen

Int J Food Microbiol. 2004;96:219-33 


\section{Abstract}

This literature review was carried out to make a comparison of functionality and efficacy between monostrain, multistrain and multispecies probiotics. A monostrain probiotic is defined as containing one strain of a certain species and consequently multistrain probiotics contain more than one strain of the same species or, at least of the same genus. Arbitrarily, the term multispecies probiotics is used for preparations containing strains that belong to one or preferentially more genera.

Multispecies probiotics were superior in treating antibiotic-associated diarrhoea in children. Growth performance and particularly mortality in broilers could be improved with multistrain probiotics. Mice were better protected against $S$. typhimurium infection with a multistrain probiotic. A multispecies probiotic provided the best clearance of E. coli 0157:H7 from lambs. Rats challenged with S. enteritidis showed best post-challenge weight gains when treated with a multispecies probiotic.

Possible mechanisms underlying the enhanced effects of probiotic mixtures are discussed. It is also emphasized that strains used in multistrain and multispecies probiotics should be compatible or, preferably, synergistic. The design and use of multistrain and multispecies probiotics should be encouraged. 


\section{Introduction}

There is ample evidence from laboratory experiments that ingestion of probiotic microbes, especially lactic acid bacteria and bifidobacteria, alleviates or prevents various disorders, such as lactose intolerance, rotavirus diarrhoea and atopy ${ }^{1}$. Despite this evidence, functionality of the probiotics in practice remains questionable. The main reason may be that commercial probiotic products often do not meet a quality standard in that composition and viability are variable ${ }^{2-6}$. A second major issue in relation to the application of probiotics is the poor evidence for efficacy as based on clinical trials ${ }^{7}$.

There are at least three issues that interfere with the identification of specific health effects of probiotics ${ }^{7}$. First, the complexity and variability of the gastrointestinal environment in relation to gastrointestinal diseases complicate the description of clear effects of probiotics on health and disease. Secondly, the confusion as to identity, viability and activity of probiotic strains contributes to the misidentification of cultures used in clinical investigations. Thirdly, single probiotic strains (monostrain probiotics) are assumed to induce a multitude of effects among different individuals in a test population.

Functionality of a multistrain probiotic could be more effective and more consistent than that of a monostrain probiotic. Colonization of an ecosystem providing a niche for more than 400 species in combination with individually determined host-factors is anticipated to be more successful with multistrain (multispecies) probiotics than with monostrain preparations. Indeed, Famularo et al. ${ }^{8}$ have envisaged that probiotic preparations containing bacteria of only one strain have little chances of successfully colonizing the GI-tract. Furthermore, probiotics are expected to control multi-factorial diseases demanding a variety of probiotic properties, whereas such properties are strain-specific ${ }^{9}$. Therefore Dunne et $a .^{10}$ and Rolfe ${ }^{11}$ have suggested that probiotics should consist of a combination of strains. In 1992 a group of probiotic experts concluded that the optimal prophylactic culture is a mixed one: 'Different strains can be targeted toward different ailments and can be blended into one preparation'12. Mixed cultures may contain bacteria that complement each other's health effect and thus have synergistic probiotic properties.

Furthermore, research with probiotic strains aims at unraveling mechanisms of action which can be claimed for one specific strain. The elucidation of underlying mechanisms for multistrain probiotics requires sophisticated study designs that are expensive ${ }^{7}$. A further drawback is that most clinical studies are funded by companies with interest in one specific strain only ${ }^{9}$. Finding a single strain with unique properties can lead to patents whereas the clinical effectiveness of multistrain probiotics is not easily patentable.

The aim of this review is to compare the efficacy of multistrain and multispecies probiotics with that of monostrain probiotics. We have been able to identify only a limited number of publications explicitly dealing with this topic, but much more 
valuable information could be obtained from other publications. In these studies animals or humans with a normal gastrointestinal flora were administered different types of probiotics of the lactic acid bacteria genera. It is important to stress that most studies were not designed to compare the efficacy of multi- versus monostrain probiotics. For the purpose of this review we have created a new set of probiotic definitions regarding their strain composition. Monostrain probiotics are defined as probiotics containing one strain of a certain species, and consequently multistrain probiotics contain more than one strain of the same species or closely related species, for instance Lactobacillus acidophilus and Lactobacillus casei. Multispecies probiotics are defined as containing strains of different probiotic species that belong to one or preferentially more genera, e.g. Lactobacillus acidophilus, Bifidobacterium longum, Enterococcus faecium and Lactococcus lactis.

\section{Effect of different Lactobacillus preparations on growth performance of chickens}

Jin et al. ${ }^{13}$ have isolated a total of 42 Lactobacillus strains from tissue fragments excised out of the jejunum, ileum and caecum of chickens. The strains were tested in vitro for their ability to adhere to chicken ileal epithelial cells. Twelve strains of the species Lactobacillus acidophilus, Lactobacillus brevis, Lactobacillus fermentum and Lactobacillus crispatus showed moderate to good ability to adhere. A single strain of L. acidophilus ( 26 ), which was the most adherent of the 12 strains, and a mixture of the twelve strains were tested in two different experiments. Both probiotic preparations were processed into freeze-dried cultures and subsequently mixed into the diet.

In the first study Jin et al. ${ }^{14}$ investigated the effects of the two probiotic preparations on growth, organ weight, intestinal microflora and intestinal volatile fatty acids (VFA) in broilers. It was hypothesized that the animal-specific Lactobacillus strains, by excluding pathogenic bacteria, would enhance chicken performance. The populations of intestinal lactobacilli and coliforms were assessed together with the concentrations of VFA in the ileum and caecum. It was believed that the probiotics would raise VFA levels, thereby decreasing the intestinal $\mathrm{pH}$ and creating an unfavourable environment for opportunistic pathogens. In the second study, Jin et al. ${ }^{15}$ looked at the impact of the two probiotic treatments on growth characteristics and the levels of digestive and bacterial enzyme activities in broilers. It was postulated that the ingested probiotics would deliver fermentative enzymes to the gastrointestinal tract and would inhibit growth of putrefactive bacteria. Putrefactive bacteria produce a wide variety of enzymes, such as $\beta$-glucuronidase and $\beta$-glucosidase. Reduction of these noxious bacterial enzymes and an increment of digestive enzyme activity could enhance growth performance and lower mortality of broiler chickens. 
The probiotic treatments in both studies significantly increased body weights and decreased feed-to-gain ratios (Table 2.1). The multistrain preparation, but not the monostrain probiotic, tended to reduce mortality. The first study showed that probiotic treatment induced a significantly lower $\mathrm{pH}$ in the caecum associated with an increased concentration of total VFA in ileal and caecal contents. The observed decrease in coliforms in the caecum after 10 and 20 days could be a consequence of the higher VFA level. No effects of probiotics on the relative weights of liver, spleen, bursa, gizzard, duodenum, jeju-ileum and total small intestine were found. In the second study it was found that supplementation with the probiotics significantly increased amylolytic activity in the small intestine. Furthermore, a significant reduction in intestinal $\beta$-glucuronidase was seen for both treatments but only the monostrain probiotic significantly reduced the faecal $\beta$-glucuronidase activity. The activity of $\beta$-glucosidase in the intestine was unaffected, but the activity of this enzyme in faeces was significantly reduced by both treatments.

The results of the two experiments indicate that growth performance of the chickens was improved by both the multi- and monostrain probiotic while the magnitude of the effect was similar. With regard to lowering mortality the multistrain probiotic tended to be more effective than the monostrain probiotic. However, functionality of the multistrain probiotic might be underestimated. During propagation, the 12 Lactobacillus strains were incubated together rather than as separate strains. It is likely that some strains were inhibited throughout the fermentation, resulting in an end-product with an unequal distribution of the individual strains. Separate fermentation of the strains followed by mixing of the cultures might enhance the functionality of this kind of multistrain probiotics.

\section{Effect of probiotics on faecal bacteria in children treated with the antibiotic ceftriaxone}

Zoppi et al. ${ }^{16}$ evaluated the clinical effectiveness of 6 different commercially available probiotics in preventing or correcting imbalance in the intestinal ecosystem caused by the antibiotic ceftriaxone which was parenterally administered to children to treat upper respiratory tract infections. Use of this antibiotic is known to induce a certain dysbiosis which is characterized by a shift in microbiological numbers representative for the flora of healthy persons ${ }^{17}$. This shift has a negative impact on colonisation resistance which can result in overgrowth of antibiotic resistant microbes or opportunistic pathogens. Eventually, this may induce clinical symptoms, most commonly (antibiotic associated) diarrhoea ${ }^{18}$. As a consequence, the dysbiosis is associated with deviating patterns of fermentative enzyme activities. The products of carbohydrate fermentation (saccharolytic activity) are thought to be beneficial to the host whereas the products of protein fermentation (proteolytic activity) may be potentially toxic. Lactobacilli and bifidobacteria are mainly saccharolytic, resulting in 
production of short chain fatty acids (SCFAs) which induce a lowering of the intestinal $\mathrm{pH}$ and subsequently leads to inhibition of typical proteolytic bacteria ${ }^{19}$. The probiotic bacteria generally have low activities of xenobiotic metabolizing enzymes like $\beta$-glucuronidase when compared with Bacteroides and Enterobacteriaceae ${ }^{20}$.

This study shows that ceftriaxone induces a decrease in Escherichia coli and Lactobacillus counts and an increase in cocci and Clostridium counts. Furthermore, these microbial shifts were associated with a reduction in the activities of fermentative enzymes such as $\beta$-galactosidase and $\beta$-glucosidase and an increase in the activity of $\beta$-glucuronidase, an enzyme involved in the formation of toxic and carcinogenic compounds. From this it was concluded that the parenterally administered ceftriaxone caused a significant dysbiosis.

Six commercial preparations were tested for their ability to reverse the adverse effects caused by the ceftriaxone therapy. Probiotic treatments were administered as freeze-dried preparations in sachets or capsules. Three monostrain probiotics were used: Saccharomyces boulardii, Enterococcus faecium SF68 and Lactobacillus rhamnosus GG. The following three multistrain/multispecies probiotics were used: a multistrain preparation containing three different Lactobacillus strains namely Lactobacillus rhamnosus, Lactobacillus acidophilus and Lactobacillus bifidus (current taxonomy could not be retrieved), a multispecies preparation containing two different species of lactic acid bacteria (Bifidobacterium bifidum and Lactobacillus acidophilus) and a multispecies preparation, named VSL\#3, containing high numbers (as compared to the others) of nine different strains (Streptococcus thermophilus, E. faecium, Bifidobacterium breve, Bifidobacterium infantis, Bifidobacterium longum, Lactobacillus acidophilus, Lactobacillus plantarum, Lactobacillus casei and Lactobacillus delbrueckii subspecies bulgaricus). A total of 51 children were included in the study, who received either ceftriaxone therapy alone (control) or in combination with one of the probiotics mentioned above. Recorded variables before and after treatment were stool frequency and consistency and the intestinal microflora composition of faecal samples. The faecal samples were also used to measure microbial enzyme activities. Faecal antibiotic resistance was measured to establish whether probiotics affect bacterial resistance as induced by the antibiotic treatment. Bacterial resistance was measured as the occurrence of $\beta$-lactamase in the faeces, an enzyme produced by resistant bacteria that inactivate $\beta$-lactam antibiotics such as ceftriaxone. 


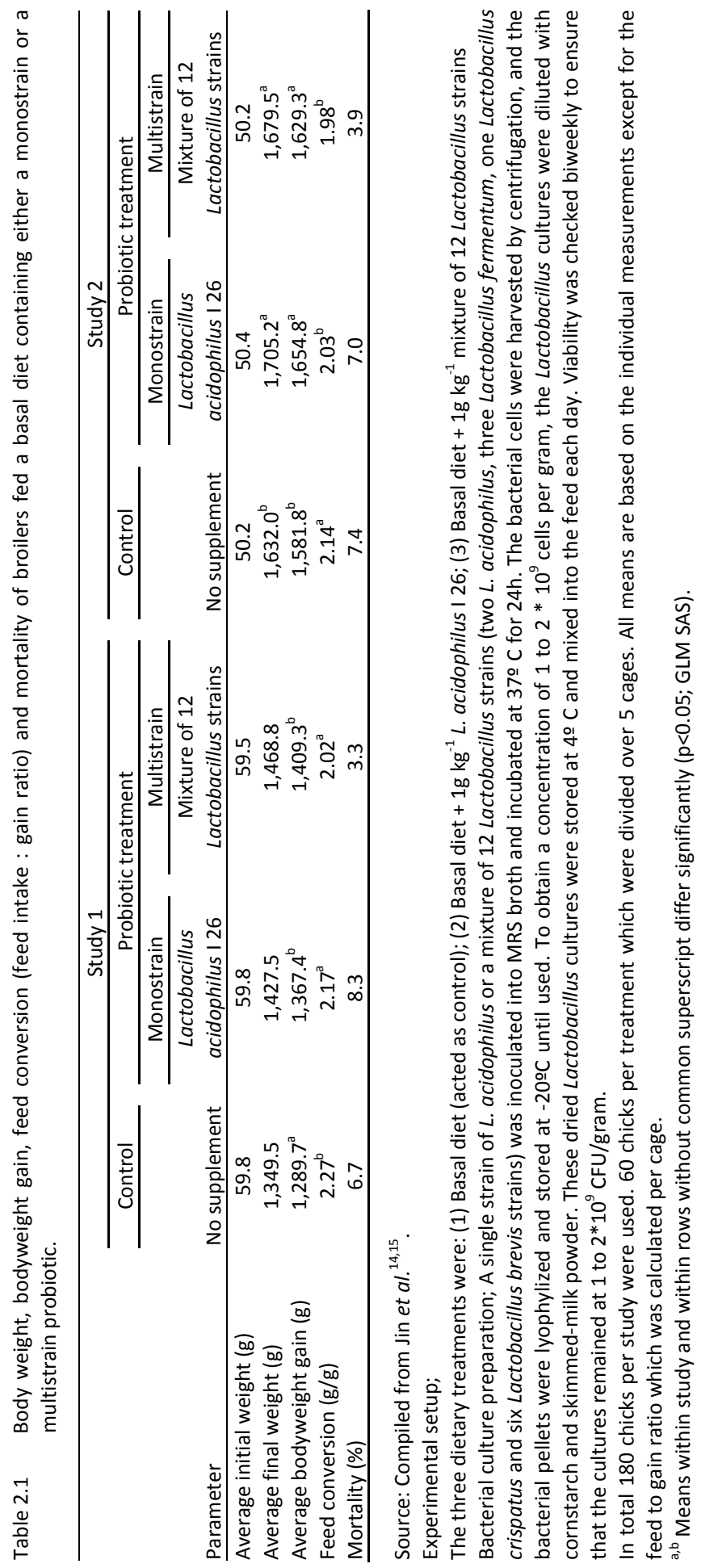


The following observations were made for the monostrain probiotics. Sacch. boulardii treatment left the microflora essentially unchanged, except for an increase in fungi (Sacch. boulardii is a yeast). The activity of $\beta$-glucuronidase was increased by Sacch. boulardii treatment, which can be regarded as a potential hazard. Treatment with $E$. faecium SF68 did not correct dysbiosis even though it successfully colonized the gastrointestinal tract by replacing the endogenous E. faecium population. However, the mean anaerobic cocci count was significantly increased and in this respect the dysbiosis caused by ceftriaxone therapy can be considered to be enhanced due to E. faecium SF68 supplementation. The administration of L. rhamnosus GG induced favourable alterations in the microflora, but these were less marked than those induced by the multistrain treatments. Both the Sacch. boulardii and the L. rhamnosus GG treatment groups reached the highest percentage of $\beta$-lactamase positive samples after treatment, namely $83 \%$. This presence of $\beta$-lactamase indicates that there was bacterial resistance towards ceftriaxone and possibly to other $\beta$-lactam drugs.

Table 2.2 gives an overview of the changes induced by the different probiotic treatments as compared to the values before therapy. Only the two multispecies probiotics containing the mixture of lactobacilli and bifidobacteria significantly counteracted the increase in number of stools per day caused by ceftriaxone therapy (data not shown). The mixture of nine different strains (VSL\#3) had the greatest impact on the change in microflora composition as caused by ceftriaxone. No effects of probiotic treatments were found for bacterial enzyme activities. All probiotics studied induced a decrease in stool $\mathrm{pH}$. This decrease can be interpreted as a positive effect because an acidic environment inhibits the growth of pathogenic bacteria and reduces bacterial putrefactive activity. Only two probiotics, both multispecies preparations, were able to induce a statistically significant $\mathrm{pH}$ reduction. From this study it can be concluded that probiotics containing multiple species of lactobacilli and bifidobacteria may be more effective in preventing dysbiosis induced by ceftriaxone treatment than other probiotic preparations. 


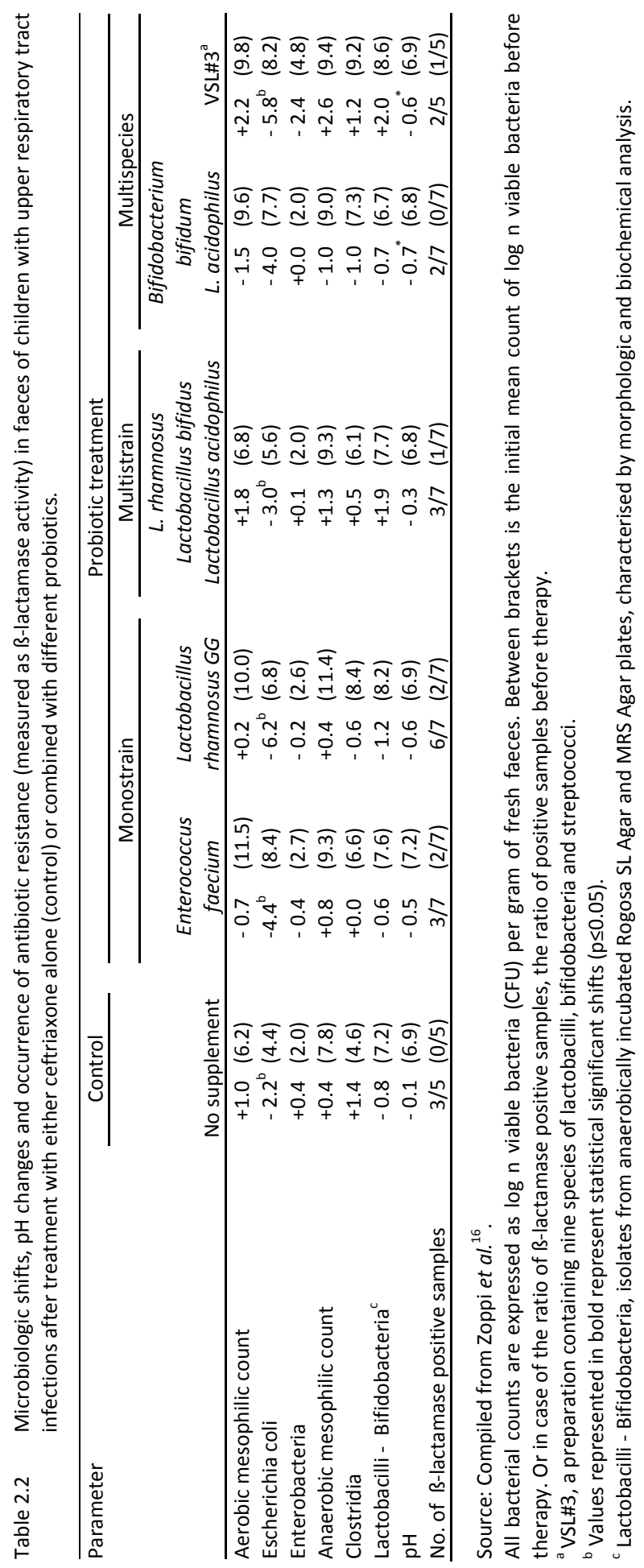




\section{Effect of various Lactobacillus fermented milks on the severity of a Salmonella typhimurium infection in mice}

In the 1980s Perdigon and her colleagues have published numerous studies on the effect of Lactobacillus fermented milk on the immune system in mice. In one study Perdigon et al. ${ }^{21}$ tested the protective effect of milk fermented with either Lactobacillus acidophilus, Lactobacillus casei or a combination of both strains in mice challenged with Salmonella typhimurium. Mice were fed for 8 days one of the fermented products followed by an oral challenge with S. typhimurium. The fermented milks were administered as a $20 \%$ suspension in the drinking water, resulting in a total of $2.4 \times 10^{9}$ viable organisms administered per day. The control group received a $10 \%$ solution of skim milk powder mixed with the drinking water in a 1:4 ratio. Survival of the mice was followed for 21 days. The number of viable salmonellae in liver and spleen was determined at different time intervals and so were serum and intestinal fluid antibodies concentrations against $S$. typhimurium.

The results are given in Table 2.3. The monostrain fermented milks failed to enhance resistance towards $S$. typhimurium, although the initial survival rates were higher than those of the controls. The monostrain preparations with $L$. casei induced a significant reduction in salmonellae counts in liver and spleen on day 10 after challenge and produced an almost two-fold higher serum antibody titre than seen in the controls. L. acidophilus treated mice showed the lowest antibody titres in both serum and intestinal fluid.

It is clear that only pre-treatment with multistrain fermented milk was effective in preventing colonization of $S$. typhimurium in liver and spleen. On day 7 after challenge viable salmonellae had disappeared from the liver and spleen. This was associated with a $100 \%$ survival of the mice in the $L$. casei $+L$. acidophilus group. Serum antibodies against $S$. typhimurium in mice fed multistrain fermented milk were higher than in the other groups. The successful multistrain treatment may be the result of an optimal combination of strain-specific properties such as activation of the specific immune response by $L$. casei (Table 2.3 ) and the induction of non-specific immune responses by $L$. acidophilus shown in another study published by the same group ${ }^{22}$. In any event, the data in Table 2.3 show convincingly that the combination of $L$. casei and $L$. acidophilus provided protection against $S$. typhimurium whereas the bacterium strains alone did not. 
Table 2.3 Survival, number of viable salmonellae in liver and spleen and the levels of specific antibodies in serum and intestinal fluid of mice challenged with Salmonella typhimurium and fed either skim milk powder or milk fermented with either Lactobacillus casei, Lactobacillus acidophilus or a combination of both strains.

\begin{tabular}{|c|c|c|c|c|}
\hline \multirow{3}{*}{$\begin{array}{l}\text { Day after } \\
\text { challenge }\end{array}$} & \multirow{3}{*}{$\begin{array}{c}\text { Control } \\
\text { Skim milk } \\
\text { powder }\end{array}$} & \multicolumn{3}{|c|}{ Probiotic treatment } \\
\hline & & \multicolumn{2}{|c|}{ Monostrain } & \multirow{2}{*}{$\begin{array}{c}\text { Multistrain } \\
\text { L. casei + } \\
\text { L. acidophilus }\end{array}$} \\
\hline & & $\begin{array}{c}\text { Lactobacillus } \\
\text { casei }\end{array}$ & $\begin{array}{c}\text { Lactobacillus } \\
\text { acidophilus }\end{array}$ & \\
\hline \multicolumn{5}{|c|}{ Survival rates of mice fed different fermented milks ${ }^{a}$} \\
\hline 0 & $100 \%$ & $100 \%$ & $100 \%$ & $100 \%$ \\
\hline 7 & $20 \%$ & $97 \%$ & $80 \%$ & $100 \%$ \\
\hline 15 & $20 \%$ & $77 \%$ & $30 \%$ & $100 \%$ \\
\hline 21 & $20 \%$ & $20 \%$ & $20 \%$ & $100 \%$ \\
\hline \multicolumn{5}{|c|}{ Number of viable salmonellae in livers / spleens ${ }^{b}$} \\
\hline 1 & $0.0 / 0.0$ & $0.0 / 0.0$ & $0.0 / 0.0$ & $0.0 / 0.0$ \\
\hline 2 & $0.0 / 0.0$ & $3.9 / 4.1$ & $4.7 / 4.2$ & $0.0 / 0.0$ \\
\hline 3 & $0.0 / 0.0$ & $4.4 / 4.1$ & $0.0 / 0.0$ & $3.3 / 3.3$ \\
\hline 4 & $3.0 / 2.3$ & $4.1 / 3.9$ & $0.0 / 0.0$ & $3.7 / 2.4$ \\
\hline 7 & $5.2 / 4.6$ & $2.4 / 2.1$ & $3.2 / 2.7$ & $0.0 / 0.0$ \\
\hline 10 & $3.3 / 3.9$ & $1.5 / 1.2$ & $2.9 / 2.4$ & $0.0 / 0.0$ \\
\hline \multicolumn{5}{|c|}{ Levels of anti-Salmonella typhimurium antibodies in serum / intestinal fluid ${ }^{c}$} \\
\hline 4 & $278 / 226$ & $370 / 545$ & 139 / 82 & $833 / 464$ \\
\hline 7 & $617 / 150$ & 1049 / 1064 & $324 / 55$ & $1991 / 545$ \\
\hline 10 & $355 / 55$ & 741 / 286 & $253 / 82$ & 2531 / 232 \\
\hline 15 & 139 / 55 & 309 / 218 & 93 / 82 & 627 / 164 \\
\hline
\end{tabular}

Source: Compiled from Perdigon et al. ${ }^{21}$.

Significance and the number of animals per group or measurement were not exclusively mentioned in the reviewed article, these are therefore not included in this table.

a This group received a more lethal dose of $40_{\mathrm{LD} 50} \mathrm{~S}$. typhimurium.

b This group received a dose of $20_{\text {LD50 }}$ S. typhimurium, number of salmonellae in liver or spleens is expressed as log viable bacteria per organ.

c This group received a dose of $20_{\text {LD50 }} \mathrm{S}$. typhimurium, levels of antibodies against salmonellae are expressed as the highest serum or intestinal fluid dilution giving a positive agglutination reaction.

\section{Effect of Lactobacillus casei strains alone or in combination on survival in mice challenged with Salmonella typhimurium}

Paubert-Braquet et $a .^{23}$ used mice orally infected with Salmonella typhimurium to test the protective effect of milks fermented with different strains of the Lactobacillus casei species, yogurt ferments or a combination of both kinds of ferments. The bacterial contents of the test preparations are presented in Table 2.4 (see footnote). Mice were supplemented for a 7-day period with one of the fermented milks, standard milk or received no supplement. Then the mice were orally infected with 
S. typhimurium and the survival was monitored daily for 14 days. The phagocytosis index was determined by injecting colloidal carbon into the tail vein and measuring its clearance from the blood. Furthermore, serum IgA levels and ß-glucuronidase (in this regard a bactericidal enzyme produced by macrophages) activity in the supernatant of peritoneal macrophages were measured.

Table 2.4 shows that milks fermented with different species of the Lactobacillus genus induced different protection levels against $S$. typhimurium. Irrespective of the type of fermented milk administered, survival in all treatment groups was significantly higher than in the control group supplemented with standard milk.

Table 2.4 The effect of five different fermented milks versus either no supplement or non-fermented milk on survival of mice infected with Salmonella typhimurium.

\begin{tabular}{|c|c|c|c|c|c|c|c|}
\hline \multirow{3}{*}{$\begin{array}{l}\text { Day after } \\
\text { challenge }\end{array}$} & \multicolumn{2}{|c|}{ Control } & \multicolumn{5}{|c|}{ Probiotic treatment } \\
\hline & \multirow[b]{2}{*}{$\begin{array}{c}\text { No } \\
\text { supplement }\end{array}$} & \multirow[b]{2}{*}{$\begin{array}{l}\text { Non- } \\
\text { fermented } \\
\text { milk }\end{array}$} & \multicolumn{3}{|c|}{ Monostrain } & \multicolumn{2}{|c|}{ Multispecies } \\
\hline & & & $\begin{array}{l}\text { Lactobacillus } \\
\text { casei (LAB-1) }\end{array}$ & $\begin{array}{l}\text { L. casei } \\
(\text { LAB-2) }\end{array}$ & $\begin{array}{l}\text { L. casei } \\
\text { strain } \\
\text { Shirota }\end{array}$ & $\begin{array}{c}\text { Yogurt } \\
\text { ferment }\end{array}$ & $\begin{array}{c}\text { L. casei } \\
(\text { LAB-1) }+ \\
\text { Yogurt ferment }\end{array}$ \\
\hline 2 & $100 \%$ & $100 \%$ & $100 \%$ & $100 \%$ & $100 \%$ & $100 \%$ & $100 \%$ \\
\hline 6 & $62.5 \%$ & $62.5 \%$ & $87.5 \%$ & $62.5 \%$ & $62.5 \%$ & $75 \%$ & $87.5 \%$ \\
\hline 10 & $25 \%$ & $37.5 \%$ & $75 \%$ & $50 \%$ & $50 \%$ & $50 \%$ & $87.5 \%$ \\
\hline 14 & $0 \%$ & $12.5 \%$ & $75 \%^{a, b}$ & $50 \%^{a}$ & $50 \%^{a}$ & $50 \%^{a}$ & $87.5 \%^{a, b}$ \\
\hline
\end{tabular}

Source: Compiled from Paubert-Braquet et al. $^{50}$.

Experimental setup; Each treatment group consisted of 8 animals. Animals were supplemented for 7 days with non-fermented milk or fermented milks at a rate of $30 \%$ of their normal daily diet. The various probiotic treatments contained the following amounts of bacteria (CFU/ml): LAB- $1,2.5 \times 10^{8}$ of $\mathrm{L}$. casei; LAB-2, $4.9 \times 10^{8}$ of L. casei; L. casei strain Shirota, $1.0 \times 10^{8}$ of L. casei; Yogurt ferment, $8.3 * 10^{8}$ of Streptococcus thermophilus $+1.1 \times 10^{8}$ of Lactobacillus bulgaricus; LAB- $1+$ Yogurt ferment, $1.1 \times 10^{8}$ of St. thermophilus $+8.2 \times 10^{8}$ of L. bulgaricus $+0.8 \times 10^{8}$ of L. casei.

${ }^{a}$ On day 14 all probiotic treatments showed significantly higher survival rates than those observed in the standard milk group

b Survival rates in the LAB-1 group and the yogurt ferment + LAB-1 group were significantly higher than those observed in the LAB-2, yogurt ferment and L. casei strain Shirota treated group.

Most protection was provided by the mixture (Yogurt ferment and LAB-1), causing $87.5 \%$ survival after 14 days. The protective effect induced by the multispecies ferment did not reflect the immunomodulating variables. Only the monostrain fermented milk with LAB-1 and the Shirota strain induced a significant increase in the phagocytosis index when compared to the mice fed standard milk. The group supplemented with the yogurt ferment produced a significantly lower index than that seen in the group given standard milk. Likewise, only the LAB-1 and Shirota-strain fermented milk induced significantly higher levels of serum IgA and of ß-glucuronidase in the supernatant of peritoneal macrophages when compared to the standard-milk 
group. It can be concluded that the effects of the probiotics on immunomodulating variables were not associated with those on survival. Nevertheless, it is clear that the combination of $L$. casei and yogurt ferment offered most protection against S. typhimurium challenge.

\section{Efficacy of different probiotic bacteria in reducing Escherichia coli 0157:H7 shedding by sheep}

Escherichia coli $0157: \mathrm{H} 7$ is an enterohemorrhagic type of $E$. coli commonly implicated in human food-borne illness. This serotype is particularly dangerous because of its low infectious dose, and its unusual acid tolerance. E. coli 0157:H7 is frequently harboured in apparently healthy ruminants. It has been suggested that the fasting of ruminants just before slaughter can induce an increase in ruminal fluid $\mathrm{pH}$ because of a lack of easily fermentable sugars for microbial acid production, resulting in optimal conditions for unrestricted growth of E. coli 0157:H7. This causes a higher risk of contaminating the meat during slaughter. Previous studies ${ }^{24}$ have indicated that $E$. coli 0157:H7 shedding can be reduced by inoculating ruminants with certain probiotic bacteria prior to infection.

Lema et al. $^{25}$ have studied the efficacy of Lactobacillus acidophilus, Enterococcus faecium, Lactobacillus casei, Lactobacillus fermentum and Lactobacillus plantarum as to reduce E. coli 0157:H7 shedding by sheep already infected earlier with the pathogen. Two monostrain preparations containing either $L$. acidophilus or $E$. faecium were tested and also two multispecies preparations containing a mixture of L. acidophilus and E. faecium or a mixture of L. acidophilus, E. faecium, L. casei, L. fermentum and L. plantarum. The microbial supplements were composed of freezedried fermentation products of the bacteria and contained $2 * 10^{9}$ CFU of microorganisms per gram of product. Thirty Suffolk ram lambs were inoculated with a $1 \mathrm{ml}$ suspension of $10^{10} \mathrm{CFU}$ of E. coli $0157: \mathrm{H7}$, starting on the same day as probiotic treatment and the probiotic treatment continued thereafter for seven weeks. The control group received a basal diet without microbial supplements. The four experimental groups received the same basal diet supplemented daily by mixing one of the four microbial treatments with the diet at a rate of 0.3 grams per kilogram diet $\left(6.0 * 10^{6} \mathrm{CFU} / \mathrm{kg}\right.$ diet). The feed was offered to the lambs for ad libitum consumption. Fresh faeces were retrieved from the rectum every week directly followed by selective enumeration of E. coli 0157:H7. Faecal consistency was scored the time of sampling in order to see whether the animals had diarrhoea. Animal performance variables such as feed consumption (FC), gain-to-feed ratio (G:F) and average daily weight gain (ADG) were monitored for the entire experimental period.

All lambs remained clinically healthy throughout the experimental period without evidence of diarrhoea. Lambs that were administered the mixture of L. acidophilus, 
E. faecium, L. casei, L. fermentum and L. plantarum shed significantly lower numbers of E. coli 0157:H7 in the faeces than did the other groups and this held for the entire experimental period (Table 2.5). As to monostrain preparations, no effect of L. acidophilus supplementation was observed when compared to the control. In contrast, E. faecium supplementation produced a significantly lower mean count of E. coli. The combination of L. acidophilus and E. faecium did not reduce E. coli shedding. In conclusion, the multispecies preparation containing five strains was more effective than the two-strain or monostrain preparations. From Table 2.5 it can be suggested that beyond the 7-week duration of the experimental period only the multispecies preparation containing five strains may provide successful clearance. Both multispecies preparations had a significantly positive effect on average daily growth and the feed-to-gain ratio when compared to the control and the monostrain groups.

It is important to note that the probiotic effect of E. faecium as to $E$. coli shedding was counteracted by the addition of L. acidophilus. On the other hand, the same combination did enhance gain-to-feed ratio and average daily gain when compared with the administration of either E. faecium alone or L. acidophilus alone. It could be suggested that not only strain-specific properties exist but also combination-specific properties. In conclusion, supplementing lambs with E. faecium reduced faecal E. coli O157:H7 shedding, but more effective reduction was obtained by treatment with the multispecies preparation containing L. acidophilus, E. faecium, L. casei, L. fermentum and L. plantarum. 


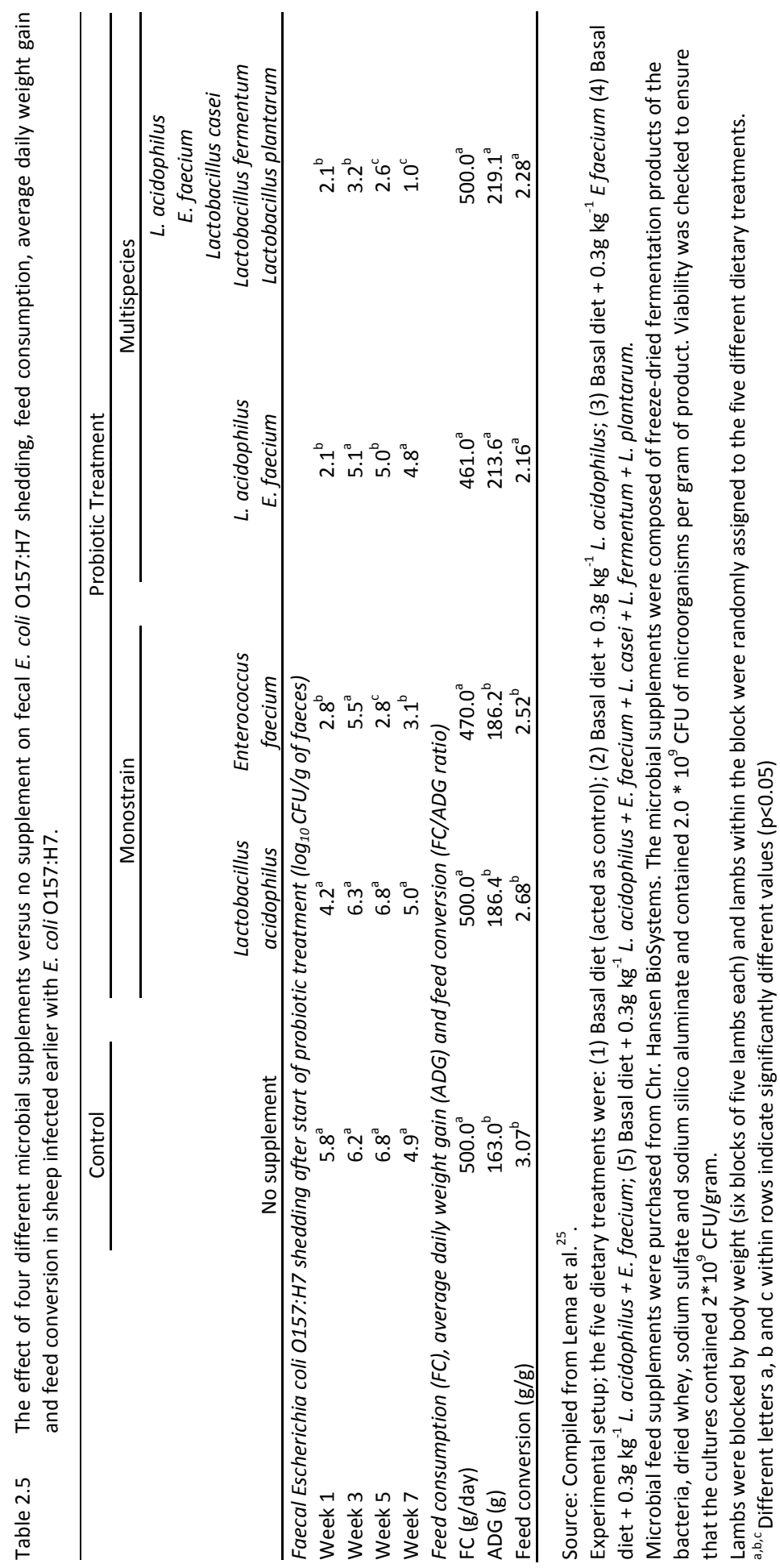

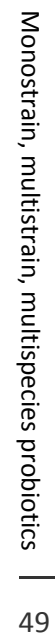




\section{The effect on growth of mono- versus multistrain/multispecies probiotics in rats challenged with Salmonella enteritidis}

We have conducted an experiment in rats challenged with Salmonella enteritidis to compare the protection induced by a monostrain probiotic versus that induced by multistrain and/or multispecies probiotics ${ }^{26}$. In the experiment male Wistar (U-WU) rats were challenged with a single oral dose of $1.0 * 10^{9} \mathrm{~S}$. enteritidis. Before challenge the rats were trained to ingest their restricted amount of daily feed within one hour. The diets were administered as freshly prepared porridges mixed with different probiotic cultivars (Table 2.6). The control animals were fed a diet mixed with fermentation broth containing heat-killed Lactobacillus casei. All the other animals received with their diet a total of $1 * 10^{9} \mathrm{CFU}$ of different probiotic organisms per day. Multistrain probiotics were individually grown and then mixed. All probiotic preparations were microbiologically enumerated to check their viable numbers. The animals were challenged with an anticipated sublethal dose of $S$. enteritidis, none of the rats died and no signs of disease were seen. Salmonella could be cultured from the faeces collected (data not shown) so that it was concluded that the virulence of the strain was not high enough to induce systemic complications. However, we did see treatment differences in weight gain throughout the post-challenge period. A distinction can be made between weight loss as a consequence of the infection with $S$. enteritidis, subsequent recovery and post-challenge weight gain.

This kind of Salmonella infection-associated weight changes have also been described by Gill et al. ${ }^{27}$. They performed a similar experiment in which the protective effect of Lactobacillus rhamnosus strain HNOO1 against translocation of Salmonella typhimurium in mice was tested. After a single oral dose of $10^{7} \mathrm{~S}$. typhimurium the general health score (GHS; a 1-5 score index for the clinical appearance) was recorded daily as well as the food and water intake, and weight change. Changes in the GHS became evident on day 5 post-challenge and the scores had fallen noticeably on days 6 and 7. Mortality was first seen on day 6 in the controls, and among the probiotictreated animals only on day 10 . Weight change during the first 7 days post-challenge was significantly different between the two groups, the probiotic-treated animals gaining weight and the control animals losing weight. Also in our experiment with rats we found that 3 days after challenge animals gained weight again. During the first 3 days post-challenge mean weight reduction was lowest in the animals receiving more than 2 different probiotic strains (Table 2.6). Post-challenge weight gain was highest for the group treated with the mixture of Lactobacillus casei, Lactobacillus acidophilus, Lactobacillus salivarius and Lactococcus lactis. Interestingly, growth recovery and overall growth were lower if Lactobacillus plantarum was added to these four species. This observation led us to conclude in agreement with Lema et al. ${ }^{25}$ that 
certain combinations of probiotic strains are not beneficial and lead to diminished efficacy.

Probiotics are appreciated for their antimicrobial activity, but this property may also be a potential weakness for probiotic mixtures. Secreted antimicrobial compounds such as lactic acid, hydrogen peroxide and bacteriocins not only inhibit potential pathogens but also closely related species ${ }^{28}$. Therefore we conducted a series of in vitro experiments to determine whether inhibitory activity exists between strains and whether this correlates with in vivo efficacy. In short, individual strains were cocultured with all other strains according to the cross-streak method as applied in the CAMP-test $^{29}$. L. acidophilus, L. salivarius and Lc. lactis showed no inhibitory activity towards the other individual strains. L. casei inhibited growth of $L$. acidophilus and L. salivarius but not of Lc. lactis. It was this combination that showed highest efficacy in the in vivo study. L. plantarum inhibited all strains except Lc. lactis. This strong in vitro inhibition tended to mimic the in vivo situation, in which addition of $L$. plantarum clearly inhibited in vivo efficacy of the four-strain mixture (Table 2.6).

\section{Possible mechanisms involved in multispecies probiotics}

Knowing that health effects of probiotics are genera, species and strain specific ${ }^{9}$ it could be suggested that multistrain and/or multispecies probiotics may be more effective than monostrain probiotics. In this review it is investigated whether probiotics consisting of more than one strain of the same species or genus (named multistrain or multispecies probiotics) are superior to monostrain probiotics. The studies described indeed provide evidence for multistrain probiotics being more effective than monostrain probiotics. The use of multispecies preparations, containing multiple strains of more than one genus, could even be more effective than that of multistrain probiotics. The multispecies probiotic VSL\#3 has been shown to be superior to the 'traditional' therapies with antibiotics or 'conventional' monostrain probiotics in the treatment of pouchitis and ulcerative colitis ${ }^{30-32}$. The superiority of multistrain or multispecies probiotics, when compared with monostrain probiotics, is evident for different preparation techniques such as fermented products ${ }^{21,23}$ and freeze-dried cultures ${ }^{14-16,25}$. 


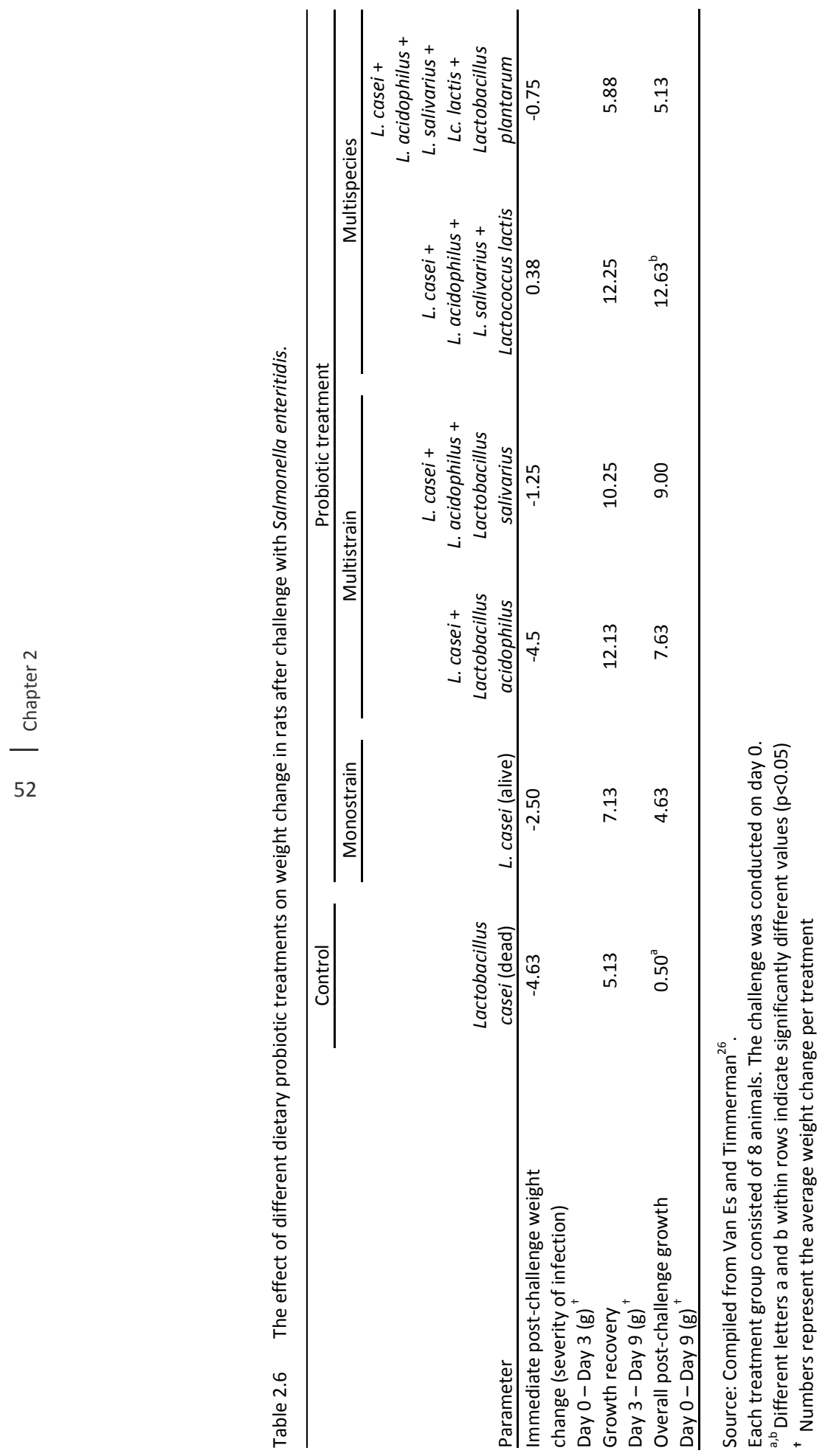


The studies described were not specifically designed to compare the efficacy of multistrain or multispecies probiotics with that of monostrain probiotics. Thus, the mechanisms underlying the enhanced effects of these probiotic mixtures remain obscure. Table 2.7 summarizes factors that may positively influence efficacy of multispecies probiotics when compared to monostrain probiotics. One well-known health effect of probiotics is that they can fortify colonization resistance (CR) in the intestinal ecosystem against potential pathogens. However, the probiotic itself first has to overcome CR exerted by the resident microflora once it is ingested. Furthermore, host properties, such as an acidic environment in the stomach, bile acids and pancreatic enzymes in the duodenum, determine to what extent the probiotic will survive. With probiotic preparations containing different strains there will be an increased chance of at least partial survival since there may be strains that are less affected. Survival rates of $20-40 \%$ have been estimated for selected strains ${ }^{33}$. Multistrain probiotics may be able to create a probiotic niche which enhances colonization of 'damaged' strains. Strains with an optimal $\mathrm{pH}$ range of 6-7 (pH upper intestinal tract) may display rapid growth, causing a local decline in $\mathrm{pH}$ and thereby creating the optimal $\mathrm{pH}$ range of more acidophilic bacteria in the probiotic. Certain probiotic species are dependent on other strains for their carbohydrate supply. For example, Lactobacillus strains produce mainly lactate which is catabolized by propionibacteria into propionic acid ${ }^{34}$. In vitro data indicate two different mechanisms that may be beneficial for multispecies probiotics in creating their own probiotic niche. First, certain strains like Streptococcus thermophilus are oxygen scavengers and create anaerobic conditions that could enhance the growth and survival of strict anaerobes like bifidobacteria ${ }^{35}$. Secondly, the ability to adhere to mucosal surfaces is related to various probiotic health effects, and it is regarded as a prerequisite for stimulation of the immune system and for antagonistic activity against enteropathogens ${ }^{36}$. The ability of different strains and their mixtures to adhere to human intestinal mucus was studied in vitro. Surprisingly, it appeared that certain combinations showed synergistic effects. The presence of Lactobacillus rhamnosus GG or Lactobacillus delbrueckii subsp. bulgaricus more than doubled the adhesion of Bifidobacterium animalis BB-12 while the adhesion of Propionibacterium freudenreuchii P6 was more than tripled by the presence of $L$. rhamnosus $G G$ and almost doubled by the presence of $B$. animalis $B B-12^{36,37}$. The feature of stimulation of adhesion of one strain by another greatly enhances successful colonization of multistrain probiotics. This also holds for promising probiotic species such as representatives of the Propionibacterium genus which by themselves would be considered as non-probiotic because of their low adhesiveness. 
Table 2.7 Overview of differences between monostrain probiotics and multispecies probiotics as to their successful colonisation and subsequent health promoting effects.

Monostrain probiotic Multispecies probiotics

Successful colonisation

Survival is depended on properties of one specific strain;

Different strains with different characteristics have an enhanced chance of colonization;

- $\quad$ This strain has to overcome on its own all barriers exploited by the host and its endogenous microflora

- Greater divergency of strong points; enhanced chance of survival of at least one or several strains

- Creation of a probiotic niche; improving chances of successful colonisation of the other strains, through e.g.

- Reduction of antagonistic activity of the endogenous microflora against other sensitive probiotic strains

- Induction of an optimal $\mathrm{pH}$ range

- Creation of an anaerobic niche

- Enhanced adhesion

Health effects exerted by the probiotic preparation

Probiotic effect is limited to the strain specific

Probiotic effect enhanced due to combination of strain properties specific properties

- Additive effect of specific strain properties such as colonization of different niches

- Synergistic effects of different strains with specific properties; The total probiotic effect may be more than the sum of the separate health promoting properties

Positive interrelationships between strains which enhances their biological activity

- Symbioses between different strains e.g. due to exchange of different metabolites

The advantage of multistrain and multispecies probiotics is that a number of favourable characteristics of individual strains are combined in a single preparation ${ }^{38}$. This may be particularly relevant for users with a variety of gastrointestinal complaints. However, it is also obvious from other consi-derations and experimental results. One consideration relates to the specific niche of probiotic bacteria: whereas Lactobacillus is the most abundant member of the LAB-genera in the proximal small intestine, Bifidobacterium has a strong preference for the large intestine. Experimental evidence for enhanced efficacy of multistrain probiotics against gastrointestinal pathogens comes from Drago et al. ${ }^{39}$ and from Apella et al. ${ }^{40}$. Drago et al. ${ }^{39}$ have tested three promising newly isolated human Lactobacillus strains as to their individual and combined activity against selected enteropathogens (Escherichia 
coli, Salmonella enteritidis and Vibrio cholerae). Measures were taken to rule out inhibition by $\mathrm{pH}$ variation or nutrient consumption. Only the mixture of the three Lactobacillus strains was able to almost completely inhibit growth of $E$. coli and $S$. enteritidis, whereas no significant inhibition of $V$. cholerae growth was observed. Apella et al. $^{40}$ found similar results in regard to the inhibitory effect of lactobacilli on growth of Shigella sonnei. The increased efficacy of multistrain probiotics against pathogens may be caused by the greater variety of antimicrobial capacities associated with mixed preparations, such as production of weak organic acids, bacteriocins, hydrogen peroxide, coaggregation molecules (blocks the spread of the pathogen) and/or biosurfactants (inhibit adhesion), and the stimulation of slgA production and mucus secretion by the host (see also Table 2.7).

A part of the additive and synergistic health-promoting effects of individual strains in multistrain probiotics, may be explained from possible interrelationships between strains in these mixtures. Symbioses may enhance certain probiotic characteristics like growth or metabolic activity of strains (see Table 2.7). Growth of the probiotic organism is necessary to maintain sustainable numbers at a certain site in the gastrointestinal tract. This growth can be stimulated by the presence of other strains as is known for certain starter cultures in the manufacture of fermented dairy products $^{28,41,42}$. For probiotic bacteria such as L. acidophilus and Bifidobacterium spp., it is known that they grow slowly in milk because they lack proteolytic activity. Addition of typical yoghurt bacteria particularly L. delbrueckii subsp. bulgaricus will enhance growth of the probiotic strains ${ }^{43}$. The positive interaction between strains was referred to by Driessen et al. $^{44}$ as protocooperation and is explained by the exchange of certain growth factors, such as amino acids, free peptides, formate and $\mathrm{CO}_{2}$. Gomes and colleagues ${ }^{41}$ reported a progressive increment of $B$. animalis growth through the presence of $L$. acidophilus which hydrolyzes milk caseins using extracellular proteinases and yielding amino acids and peptides that stimulate growth of $B$. animalis. On the other hand, growth of $L$. acidophilus can also be enhanced by the presence of $B$. animalis, possibly due to the production of acetate ${ }^{28}$.

Another probiotic bacterium used in the manufacture of Swiss-type cheeses, Propionibacterium freudenreuchii 7025, produces 2-amino-3carboxy-1,4naphthoquinone that enhances growth of bifidobacteria ${ }^{45}$. Whereas growth of propionibacteria can be stimulated through peptides produced from casein by Lactobacillus helveticus $^{46}$. Lactobacilli are also able to produce bifidogenic growth factors in the form of extracellular polysaccharides (EPS). EPS may protect the microorganism against anti-microbial factors because it surrounds the bacterial cell as a capsule or is secreted into the extracellular environment as slime. Surprisingly, EPS produced by Lactococcus lactis subsp. cremoris cannot be used as an energy source by the bacterium itself ${ }^{47}$. However, EPS produced by Lactobacillus sanfranciscencis serves as a prebiotic or bifidogenic growth factor for bifidobacteria ${ }^{48}$. Together with growth, metabolic activity is also influenced by symbiotic relationships. Sodini et al. ${ }^{49}$ have identified interacting mixed cultures of lactic acid bacteria through the use of a 
mathematical model. Acidifying activity of mixed cultures was predicted on the basis of acidification tests conducted with the pure cultures. In the case of underestimation of acidifying activity by the designed model, a positive interaction between the strains was assumed. Different combinations of Streptococcus thermophilus and Lactobacillus delbrueckii strains were tested. Only two positive interactive mixtures were found, suggesting that symbiotic relationships are generally not on the species level, but rather on the strain level. It can be generally concluded that different strains of the genera Lactobacillus, Lactococcus, Streptococcus, Bifidobacterium and Propionibacterium show symbiotic relationships towards each other which enhances growth and metabolic activity. Furthermore, it can be expected that this enhanced probiotic activity causes an increased nutrient consumption, a well known probiotic mechanism in the control of intestinal pathogens. The use of positively interacting strains of these genera in multistrain or multispecies probiotics should be encouraged.

\section{Conclusive remarks}

With this review we tried to show the relevance of developing multispecies probiotics which may have improved functionality as compared to single strain probiotics. It is clearly shown that multispecies preparations have advantages when compared to monostrain probiotics or, to a lesser extent, multistrain probiotics. Well-designed multispecies probiotics can benefit from a certain amount of synergism when different probiotic effects of different probiotic species are combined. The activity can also be stimulated through symbiosis among strains in the preparation. We recommend further research on multispecies preparations in which combinations of strain-specific properties are chosen to be additive or synergistic. In vitro research should aim at finding combinations which show synergistic and symbiotic activities towards each other to maximize the chance of providing clinically more effective probiotic preparations. Special attention should also be paid to avoid combinations of probiotic strains showing mutual inhibitory properties, e.g. through the production of $\mathrm{H}_{2} \mathrm{O}_{2}$, bacteriocins or bacteriocin-like substances ${ }^{28}$. 


\section{References}

1. Ouwehand AC, Salminen S, Isolauri E. Probiotics: an overview of beneficial effects. Antonie Van Leeuwenhoek. 2002;82:279-89.

2. Fasoli S, Marzotto M, Rizzotti L, Rossi F, Dellaglio F, Torriani S. Bacterial composition of commercial probiotic products as evaluated by PCR-DGGE analysis. Int J Food Microbiol. 2003;82:59-70.

3. Hamilton-Miller JM, Shah S. Deficiencies in microbiological quality and labelling of probiotic supplements. Int J Food Microbiol. 2002;72:175-6.

4. Hamilton-Miller JM, Shah S, Winkler JT. Public health issues arising from microbiological and labelling quality of foods and supplements containing probiotic microorganisms. Public Health Nutr. 1999;2:223-9.

5. Temmerman R, Scheirlinck I, Huys G, Swings J. Culture-independent analysis of probiotic products by denaturing gradient gel electrophoresis. Appl Environ Microbiol. 2003;69:220-6.

6. Weese JS. Microbiologic evaluation of commercial probiotics. J Am Vet Med Assoc. 2002;220:794-7.

7. Klaenhammer TR, Kullen MJ. Selection and design of probiotics. Int J Food Microbiol. 1999;50:45-57.

8. Famularo G, Di Simone C, Matteuzzi D, Pirovano F. Traditional and high potency probiotic preparations for oral bacteriotherapy. Biodrugs. 1999;12:455-70.

9. Sanders $\mathrm{ME}$, Huis in't Veld J. Bringing a probiotic-containing functional food to the market: microbiological, product, regulatory and labeling issues. Antonie Van Leeuwenhoek. 1999;76:293-315.

10. Dunne C, Murphy L, Flynn S, O'Mahony L, O'Halloran S, Feeney M, Morrissey D, Thornton G, Fitzgerald G, Daly C, Kiely B, Quigley EM, O'Sullivan GC, Shanahan F, Collins JK. Probiotics: from myth to reality. Demonstration of functionality in animal models of disease and in human clinical trials. Antonie Van Leeuwenhoek. 1999;76:279-92.

11. Rolfe RD. The role of probiotic cultures in the control of gastrointestinal health. J Nutr. 2000;130:396S-402S.

12. Sanders ME. Summary of conclusions from a consensus panel of experts on health attributes of lactic cultures: significance to fluid milk products containing cultures. J Dairy Sci. 1993;76:1819-28.

13. Jin LZ, Ho YW, Ali MA, Abdullah N, Ong KB, Jalaludin S. Adhesion of Lactobacillus isolates to intestinal epithelial cells of chicken. Lett Appl Microbiol. 1996;22:229-32.

14. Jin LZ, Ho YW, Abdullah N, Ali MA, Jalaludin S. Effects of adherent Lactobacillus cultures on growth, weight of organs and intestinal microflora and volatile fatty acids in broilers. Anim Feed Sci Technol. 1998;70:197-209.

15. Jin LZ, Ho YW, Abdullah N, Jalaludin S. Digestive and bacterial enzyme activities in broilers fed diets supplemented with Lactobacillus cultures. Poult Sci. 2000;79:886-91.

16. Zoppi G, Cinquetti M, Benini A, Bonamini E, Minelli E. modulation of the intestinal ecosystem by probiotics and lactulose in children during treatment with ceftriaxone. Curr Therap Res. 2001;62: 418-35.

17. Welling GW, Meijer-Severs GJ, Helmus G, van Santen E, Tonk RH, de Vries-Hospers HG, van der Waaij $D$. The effect of ceftriaxone on the anaerobic bacterial flora and the bacterial enzymatic activity in the intestinal tract. Infection. 1991;19:313-6.

18. Arvola T, Laiho K, Torkkeli S, Mykkanen H, Salminen S, Maunula L, Isolauri E. Prophylactic Lactobacillus GG reduces antibiotic-associated diarrhea in children with respiratory infections: a randomized study. Pediatrics. 1999;104:e64.

19. Smith EA, Macfarlane GT. Enumeration of amino acid fermenting bacteria in the human large intestine; effects of $\mathrm{pH}$ and starch on peptide metabolism and dissimilation of amino acids. FEMS micribiol ecol. 1998;25:355-68.

20. Wollowski I, Rechkemmer G, Pool-Zobel BL. Protective role of probiotics and prebiotics in colon cancer. Am J Clin Nutr. 2001;73:451S-5S.

21. Perdigon G, Nader de Macias ME, Alvarez S, Oliver G, Pesce de Ruiz Holgado AA. Prevention of gastrointestinal infection usingimmunobiological methods with milk fermented with Lactobacillus casei and Lactobacillus acidophilus. J Dairy Res. 1990;57:255-64.

22. Perdigon G, Nader de Macias ME, Alvarez S, Oliver G, Pesce de Ruiz Holgado AA. Enhancement of immune response in mice fed with Streptococcus thermophilus and Lactobacillus acidophilus. J Dairy Sci. 1987;70:919-26. 
23. Paubert-Braquet M, Gan XH, Gaudichon C, Hedef N, Serikoff A, Bouley C, Bonavida B, Braquet P. Enhancement of host resistance against Salmonella typhimurium in mice fed a diet supplemented with yogurt or milks fermented with various lactobacillus casei strains. Int J Immunother. 1995;11:153-61.

24. Zhao T, Doyle MP, Harmon BG, Brown CA, Mueller PO, Parks AH. Reduction of carriage of enterohemorrhagic Escherichia coli $\mathrm{O} 157: \mathrm{H7}$ in cattle by inoculation with probiotic bacteria. J Clin Microbiol. 1998;36:641-7.

25. Lema M, Williams L, Rao DR. Reduction of faecal shedding of enterohemorrhagic Escherichia coli 0157:H7 in lambs by feeding microbial feed supplement. Small Rumin Res. 2001;39:31-9.

26. van Es M, Timmerman HM. Onderzoek naar multispecies probiotica voor niet-humane toepassingen: BTS-project 98186; 2002.

27. Gill HS, Shu Q, Lin H, Rutherfurd KJ, Cross ML. Protection against translocating Salmonella typhimurium infection in mice by feeding the immuno-enhancing probiotic Lactobacillus rhamnosus strain HN001. Med Microbiol Immunol. 2001;190:97-104.

28. Kailasapathy K, Chin J. Survival and therapeutic potential of probiotic organisms with reference to Lactobacillus acidophilus and Bifidobacterium spp. Immunol Cell Biol. 2000;78:80-8.

29. Smibert RM, Krieg NR. Phenotypic characterization. Methods for General and Molecular Bacteriology. Washington, DC: American Society for Microbiology; 2005.

30. Gionchetti P, Rizzello F, Venturi A, Ugolini F, Rossi M, Brigidi P, Johansson R, Ferrieri A, Poggioli G, Campieri M. Review--antibiotic treatment in inflammatory bowel disease: rifaximin, a new possible approach. Eur Rev Med Pharmacol Sci. 1999;3:27-30.

31. Shibolet O, Karmeli F, Eliakim R, Swennen E, Brigidi P, Gionchetti P, Campieri M, Morgenstern S, Rachmilewitz D. Variable response to probiotics in two models of experimental colitis in rats. Inflamm Bowel Dis. 2002;8:399-406.

32. Ulisse S, Gionchetti P, D'Alo S, Russo FP, Pesce I, Ricci G, Rizzello F, Helwig U, Cifone MG, Campieri M, De Simone C. Expression of cytokines, inducible nitric oxide synthase, and matrix metalloproteinases in pouchitis: effects of probiotic treatment. Am J Gastroenterol. 2001;96:2691-9.

33. Bezkorovainy A. Probiotics: determinants of survival and growth in the gut. Am J Clin Nutr. 2001;73:399S-405S.

34. Frolich-Wyder MT, Bachmann HP, Casey MG. Interactions between propionibacteria and starter/nonstarter lactic acid bacteria in Swiss-type cheese. Lait. 2002;82:1-15.

35. Shankar P, Davies F. Associated bacterial growth in yogurt starters, initial observation on stimulatory factors. J Soc Dairy Technol. 1976;30:31-2.

36. Ouwehand AC, Isolauri E, Kirjavainen PV, Tolkko S, Salminen SJ. The mucus binding of Bifidobacterium lactis $\mathrm{Bb} 12$ is enhanced in the presence of Lactobacillus $\mathrm{GG}$ and Lact. delbrueckii subsp. bulgaricus. Lett Appl Microbiol. 2000;30:10-3.

37. Ouwehand A, Suomalainen T, Tolkko S, Salminen S. In vitro adhesion of propionoc acid bacteria to human intestinal mucus. Lait. 2002;82:123-30.

38. Campieri M, Gionchetti P. Probiotics in inflammatory bowel disease: new insight to pathogenesis or a possible therapeutic alternative? Gastroenterol. 1999;116:1246-9.

39. Drago L, Gismondo MR, Lombardi A, de Haen C, Gozzini L. Inhibition of in vitro growth of enteropathogens by new Lactobacillus isolates of human intestinal origin. FEMS Microbiol Lett. 1997;153:455-63.

40. Apella MC, Gonzalez SN, Nader de Macias ME, Romero N, Oliver G. In vitro studies on the growth of Shigella sonnei by Lactobacillus casei and Lact. acidophilus. J Appl Bacteriol. 1992;73:480-3.

41. Gomes AM, Malcata FX, Klaver FA. Growth enhancement of Bifidobacterium lactis Bo and Lactobacillus acidophilus Ki by milk hydrolyzates. J Dairy Sci. 1998;81:2817-25.

42. Warminsko-Radyko I, Laniewska-Moroz L, A. B. Possibilities for stimualtion of Bifidobacterium growth by propionibacteria. Lait. 2002;82:113-21.

43. Shihata A, Shah NP. Proteolytic profiles of yogurt and probiotic bacteria. Int Dairy J. 2000;10:401-8.

44. Driessen FM, Kingma F, Stadhouder J. Evidence that Lactobacillus bulgaricus in yoghurt is stimulated by carbon dioxide produced by Streptococcus thermophilus. Neth Milk Dairy J. 1982;36:135-44.

45. Mori H, Sato Y, Taketomo N, Kamiyama T, Y. Y, Meguro S, Sato H, Kaneko T. Isolation and structural identification of bifidogenic growth stimulator produced by Propionibacterium freudenreichii. J Dairy Sci. 1997;80:1959-64. 
46. Piveteau $\mathrm{P}$, Condon S, Cogan TM. Inability of dairy propionibacteria to grow in milk from low inocula. J Dairy Res. 2000;67:65-71.

47. Looijesteijn PJ, Trapet L, de Vries E, Abee T, Hugenholtz J. Physiological function of exopolysaccharides produced by Lactococcus lactis. Int J Food Microbiol. 2001;64:71-80.

48. Bello FD, Walter J, Hertel C, Hammes WP. In vitro study of prebiotic properties of levan-type exopolysaccharides from Lactobacilli and non-digestible carbohydrates using denaturing gradient gel electrophoresis. Syst Appl Microbiol. 2001;24:232-7.

49. Sodini I, Latrille E, Corrieu G. Identification of interacting mixed cultures of lactic acid bacteria by their exclusion from a model predicting the acidifying activity of non-interacting mixed cultures. Appl Microbiol Biotechnol. 2000;54:715-8. 


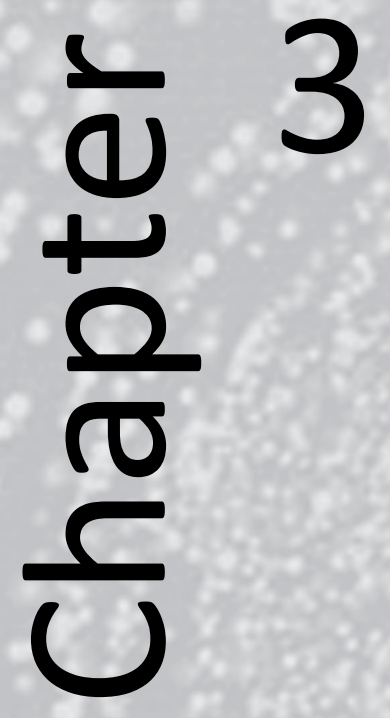




\section{The effect of a multispecies probiotic on the intestinal microbiota and bowel movements in healthy volunteers taking the antibiotic amoxycillin}

Catherina J.M. Koning, Daisy M.A.E. Jonkers, Ellen E. Stobberingh, Linda Mulder, Frans M. Rombouts, Reinhold W. Stockbrügger Am J Gastroenterol. 2007;102:1-12 


\section{Abstract}

One of the side effects of antimicrobial therapy is a disturbance of the intestinal microbiota potentially resulting in antibiotic-associated diarrhoea. In this placebo-controlled double-blind study, the effect of a multispecies probiotic on the composition and metabolic activity of the intestinal microbiota and bowel habits was studied in healthy volunteers taking amoxycillin.

Forty-one healthy volunteers were given $500 \mathrm{mg}$ amoxycillin twice daily for 7 days and were randomized to either 5 grams of a multispecies probiotic, Ecologic ${ }^{\circledR}$ AAD $\left(10^{9} \mathrm{cfu} / \mathrm{gr}\right)$, or placebo, twice daily for 14 days. Faeces and questionnaires were collected on day 0, 7, 14 and 63 . Faeces was analyzed as to the composition of the intestinal microbiota, and $\beta$-glucosidase activity, endotoxin concentration, Clostridium difficile toxin $\mathrm{A}$, short chain fatty acids and $\mathrm{pH}$ were determined. Bowel movements were scored according to the Bristol stool form scale. Mean number of enterococci increased significantly from log 4.1 at day 0 to $\log 5.8$ (day 7) and $\log 6.9$ (day 14) cfu/gram faeces $(\mathrm{p}<0.05)$ during probiotic intake. Although no other significant differences were observed between both intervention groups, within each group significant changes were found over time in both microbial composition and metabolic activity. Moreover, bowel movements with a frequency $\geq 3$ per day for at least 2 days and/or a consistency $\geq 5$ for at least 2 days, were reported less frequently in the probiotic compared to the placebo group $(48 \%$ vs. $79 \%(p<0.05))$. Apart from an increase in enterococci no significant differences in microbial composition and metabolic activity were observed in the probiotic compared with the placebo group. However, changes over time were present in both groups, which differed significantly between the probiotic and the placebo arm, suggesting that the amoxycillin effect was modulated by probiotic intake. Moreover, the intake of a multispecies probiotic significantly reduced diarrhoea-like bowel movements in healthy volunteers receiving amoxycillin. 


\section{Introduction}

One of the collateral effects of antimicrobial therapy is antibiotic-associated diarrhoea (AAD), which can occur shortly after antibiotic intake, up to 8 weeks after cessation ${ }^{1,2}$. The incidence of AAD ranges from 5-39\%, depending on the definition of diarrhoea, the type of antibiotic used and host factors ${ }^{2}$. In general, amoxycillin, amoxycillin/clavulanic acid, clindamycin and cephalosporines are associated with a high risk of $A A D^{3}$. $A A D$ may range from mild disturbances to severe pseudomembranous colitis due to Clostridium difficile ${ }^{4}$. This bacterium is thought to be the causative agent in up to $20 \%$ of AAD patients; however the mechanisms causing the majority of cases of AAD are not clear ${ }^{5,6}$. Most of the cases of AAD are thought to be due to a disturbance of the intestinal microbiota by antibiotics, which is associated with loss of colonization resistance (leading to overgrowth of potential pathogens), changes in carbohydrate digestion and production of short-chain fatty acids, altered metabolism of bile acids, and changes in both the mucosal and systemic immune response ${ }^{7}$. In addition, antibiotics may have direct allergic and toxic effects on the mucosa, direct effects on immune-cell function, and pharmacological effects on intestinal motility ${ }^{7-9}$. Possible consequences of AAD in health care facilities include an increase in the incidence of nosocomial infections and an increase in morbidity and mortality, longer hospitalization and higher costs of care ${ }^{2}$. Although in general practice $A A D$ is often merely considered a nuisance, it may lead to a lack of compliance of antibiotic intake, which is associated with the development of antibiotic resistance $^{10}$. Furthermore, antibiotic use and the subsequent disturbance of the intestinal microbiota is a risk factor for the development of irritable bowel syndrome ${ }^{11,12}$.

Probiotics, which are defined as "mono- or mixed cultures of live micro-organisms that, when applied to animal or human, beneficially affect the host by improving the properties of the indigenous microbiota", may prevent and restore a disbalance caused by antibiotics and are therefore of increasing interest for the prevention and treatment of $A A D^{13}$. Several probiotic strains have been used in controlled studies, aiming at the prevention and treatment of $A A D$, such as Lactobacillus acidophilus, Lactobacillus rhamnosus GG, Bifidobacterium longum, Enterococcus faecium and Saccharomyces boulardii, and resulted in a significant decrease in the incidence of diarrhoea (0-10\% in the probiotic versus $14-27 \%$ in the placebo group $)^{14-22}$. However, other studies failed to show any benefit from probiotics in the prevention of $A A D^{23-25}$. Two meta-analyses on the use of probiotics in the prevention of AAD evaluated nine and seven placebo-controlled, double-blind trials, and reported an odds ratio of 0.37 and a relative risk of 0.40 , respectively, in favour of probiotic administration ${ }^{26,27}$. A recent meta-analysis, which included 25 randomized controlled trials confirmed these findings (relative risk of 0.43 ), and showed that the probiotic efficacy could be attributed to three types of probiotics: S. boulardii, L. rhamnosus GG and probiotic mixtures ${ }^{28}$. Most studies on probiotics and $A A D$ have only investigated the 
development of diarrhea (i.e. clinical outcome); only in a few studies the effect on the composition of the faecal microbiota was also examined, albeit to a very limited degree ${ }^{21,29,30}$.

It has recently been demonstrated that multispecies and, to a lesser extent, multistrain probiotics have certain advantages over monostrain preparations. Mixed preparations may complement each others' effect through synergism and/or symbiosis $^{31}$. Ouwehand et al. reported, for example, that the in vitro adhesion of B. lactis $\mathrm{Bb} 12$ was more than doubled by the presence of L. rhamnosus GG and L. delbrueckii spp. Bulgaricus ${ }^{32}$. A progressive increase in B. lactis growth and acidification in the presence of $L$. acidophilus in vitro was demonstrated by Gomes et al. ${ }^{33}$.

It is well known that the composition of the faecal microbiota and its role in colonization resistance, but also its metabolic activity (producing several bacterial enzymes, short chain fatty acids (SCFAs), amines and bacteriocins) will affect the host. However few studies have assessed the influence of probiotics on the metabolic activity of the intestinal microbiota during and after antibiotic treatment. Commonly, studies on AAD concerned the use of monospecies probiotics. The results of these studies are difficult to generalize, since there is a lot of variation between species; properties that apply to one strain are not necessarily applicable to another.

The objective of this placebo-controlled, randomized, double-blind study was to evaluate the effect of a multispecies probiotic on the composition of the intestinal microbiota in healthy volunteers during and after amoxycillin intake. Moreover, the effect of the probiotic on the metabolic activity of the intestinal microbiota and on bowel habits was studied.

\section{Materials and methods}

\section{Subjects}

Healthy volunteers between 18 and 65 years of age were eligible for the study. Exclusion criteria were: smoking, pregnancy, lactation, hypersensitivity to $\beta$-lactam antibiotics or tetracycline, pre-existing bowel pathology (including irritable bowel syndrome, inflammatory bowel disease, diverticulitis and cancer), treatment with immune-suppressive medication or immune-compromised subjects, diarrhoea or constipation (in the last three days prior to inclusion), allergic and inflammatory reactions as well as infections within two weeks prior to inclusion. Furthermore, the volunteers were not allowed to use; 1 ) gastric acid inhibitors, laxatives, antidiarrhoea medication or antibiotics for at least two months before the start of and during the study; 2) corticosteroids for at least four weeks before the start of and during the study; 3 ) other probiotics and prebiotics for at least two weeks before the start of and during the study. Finally, participants were asked to continue their ordinary dietary 
habits. All volunteers gave written informed consent. The study was approved by the medical ethics committee of the University Hospital Maastricht, the Netherlands.

\section{Study design}

The study was executed according to a parallel, randomized, placebo-controlled, double-blind design. The total duration of the intervention and follow-up period was 63 days. Volunteers received $500 \mathrm{mg}$ amoxycillin twice daily from day 1-7 and were randomized to receive either 5 grams of a multispecies probiotic or 5 grams placebo twice daily from day 1-14. This resulted in three time periods defined as; day 1-7, "the antibiotic/probiotic period" in which all volunteers received amoxycillin in combination with either probiotic or placebo; day 8-14, "the probiotic only period" in which volunteers received either probiotic or placebo; day 15-63, "the post-treatment follow-up period". Amoxycillin was taken with milk before breakfast and dinner, while the placebo or probiotic was taken before lunch and before bed-time. The time between antibiotic and probiotic intake had to be at least two hours. Fresh faecal samples were collected on day 0 (i.e. baseline), 7, 14 and 63 . On the same day, a questionnaire was filled out including questions on bowel movements (stool frequency and consistency (ranging from " 1 ", hard lumps to " 7 ", completely watery) according to the Bristol stool form scale ${ }^{34}$ ), use of pre- and probiotics, other medication taken, (drastic) change of eating habits and compliance. In addition, a short questionnaire on bowel habits and side-effects (nausea, abdominal cramps, bloating, flatulence or other) had to be completed daily during probiotic/placebo intake.

\section{Probiotic}

The multispecies probiotic (Ecologic $A A D$ ) and the placebo were kindly provided by Winclove Bio Industries, Amsterdam, the Netherlands. Ecologic ${ }^{\circ}$ AAD consists of 10 different bacterial species at each $10^{8}$ colony forming units (cfu)/gr the total dose being $10^{9} \mathrm{cfu} / \mathrm{gr}$ (B. bifidum W23, B. lactis W18, B.longum W51, E. faecium W54, L. acidophilus W37 and W55, L. paracasei W20, L. plantarum W62, L. rhamnosus W71 and $L$. salivarius W24), $5 \%$ mineral mix (potassium chloride ( 67,3\%), magnesium sulphate $(\sim 32,6 \%)$ en manganese sulphate $(\sim 0,1 \%))$ and $15 \%$ Raftilose synergy1 (inulin enriched with oligofructose). Each participant consumed sachets containing 5 gram Ecologic ${ }^{\oplus}$ AAD or placebo twice daily for two weeks. Sachets were dissolved in lukewarm water, left for 10 minutes, stirred, and thereafter ingested. The placebo sachets were indistinguishable in colour, smell and taste from the probiotic sachets but contained no bacteria. 


\section{Sample processing}

Faecal samples were brought to the laboratory within 12 hours after defecation and divided into three portions: a) ten grams were centrifuged at $47000 \mathrm{~g}$ for 2 hours at $4^{\circ} \mathrm{C}$ to obtain faecal water, which was frozen immediately in twofold at $-80^{\circ} \mathrm{C}$ for analysis of endotoxin concentrations and determination of $\mathrm{pH}, \mathrm{b}$ ) five grams was diluted (1:4) with peptone water (Oxoid CM9, Basingstoke, Hants, UK) supplemented with cysteine $(2.1 \mathrm{mM})$ and glycerol $(30 \%)$. Bacterial cultures of the faecal dilution were performed immediately and the remainder was frozen at $-20^{\circ} \mathrm{C}$ for the subsequent analyses of enzyme activities, Clostridium difficile toxin $\mathrm{A}$ and short-chain fatty acids, c) the remaining faecal sample (1-15 grams) was frozen directly at $-20^{\circ} \mathrm{C}$ for additional analyses.

\section{Bacteriological culture}

Tenfold serial dilutions of the faecal dilution were made in physiological saline $(0.85 \%)$ with cysteine- $\mathrm{HCl}(0.05 \%)$ and $40 \mu \mathrm{l}$ of these dilutions was inoculated using a spiral plater (Eddy Jet v1.2, IUL-instruments, Barcelona, Spain) onto the following agar plates: blood agar (Oxoid CM271) for total (facultative) aerobic bacteria, eosinmethylene blue (methylthioninium chloride) agar (Oxoid CM69) for enterobacteriaceae, KF-streptococcus agar (Oxoid CM701) for enterococci, fastidious anaerobic agar (Laboratory M LabGo, Lancashire, UK) for total (facultative) anaerobic bacteria, bile-esculine agar (Becton Dickinson 287920, La Pont de Claix, France) for Bacteriodes spp., LAMVAB agar for lactobacilli, Sabouraud agar with gentamicin and chloramphenicol (GM+C) (Becton Dickinson 254041) for yeasts and egg yolk-neomycin agar for spore-forming clostridia. LAMVAB agar was prepared according to the method described by Hartemink et al. ${ }^{35}$. Egg yolk-neomycin agar was prepared by adding a sterile neomycin solution (final concentration, $100 \mu \mathrm{g} / \mathrm{ml}$ ) to egg yolk agar with freshly prepared egg yolk emulsion ${ }^{36}$. Before inoculation of the egg yolkneomycin agar, faecal dilutions were heated at $80 \circ \mathrm{C}$ for $10 \mathrm{~min}$.

Blood agar and eosin-methylene blue agar plates were incubated aerobically at 37으 for 24 hours. Sabouraud $\mathrm{GM}+\mathrm{C}$ and KF-streptococcus agar plates were incubated aerobically at $37^{\circ} \mathrm{C}$ and $42^{\circ} \mathrm{C}$, respectively, for 48 hours. Fastidious anaerobic, bileesculine, egg yolk and LAMVAB agar plates were incubated under anaerobic conditions at $37^{\circ} \mathrm{C}$ for 48 hours.

\section{Viability of E. faecium W54}

From each KF-streptococcus agar plate two dominant colonies were isolated on both day 7 and 14 and purified on blood agar plates. Isolates were frozen at $-80^{\circ} \mathrm{C}$ awaiting further identification. At the end of the study, the enterococci of 10 individuals (i.e. 40 colonies), who had received probiotic treatment, were typed by pulse field gel 
electrophoreses (PFGE), using Smal according to the method described by van den Braak et al. $^{37,38}$.

\section{Bacterial enzyme activity}

Bacterial $\beta$-glucosidase activity was determined as previously described ${ }^{39}$. Briefly, faecal dilutions were mixed (1:1) with $0.1 \mathrm{M}$ PBS ( $\mathrm{pH} 6.8$ ), sonicated for one minute and centrifuged at $1700 \mathrm{~g}$ for 15 minutes. The supernatants were lyophilized for 75 minutes by Speed-Vac (Savant DNA 120, GMI, Inc., Minnesota, USA) and the remaining fractions were used to determine $\beta$-glucosidase (at $420 \mathrm{~nm}$ ) activity by using $p$-nitrophenyl $\beta$-D-glucopyranoside as a substrate.

\section{Endotoxin}

The endotoxin (i.e. lipopolysaccharide) concentration was determined in faecal water using the Limulus amoebocyte lysate endochrome technique (Endosafe, end-point chromogenic analysis endochrome test kit, Charles River, Kent, UK). The analysis was performed according to the manufacturer's specifications under pyrogen-free conditions. Pyrogen-free water was used to dilute the faecal samples, the testsolutions and as negative control. The detection range of the assay was 0.015 to $0.12 \mathrm{EU} / \mathrm{ml}$ (9 EU/ng). Concentration of faecal endotoxin was expressed as nanogram of endotoxin per $\mathrm{ml}$ of faecal water.

\section{Clostridium difficile toxin A}

Clostridium difficile toxin A was determined using an Enzyme-Linked Fluorescent Immunoassay technique (VIDAS ${ }^{\circ} \mathrm{C}$. difficile Toxin A II assay, BioMerieux, Lyon, France). The analysis was performed according to the manufacturer's specifications using the VIDAS system (BioMerieux, Lyon, France).

\section{Short-chain fatty acids}

Short-chain fatty acids (SCFAs) were measured in the faecal dilutions using gas-liquid chromatography. The gas-liquid chromatography system consisted of a CP9002 gas chromatograph equipped with a flame ionization detector in conjunction with Maestro software (Chrompack, Middelburg, the Netherlands) for calculations. The chromatographic column used was WCOT fused silica ( $25 \mathrm{~m} \times 0.32 \mathrm{~mm}$ id), coated with FFAP-CB df 0.3. This column was used in an isothermal mode at $140{ }^{\circ} \mathrm{C}$ and both the injector and detector temperature was $270 \circ \mathrm{C}$. The sample size was $1.0 \mu \mathrm{l}$, which was split 50:1 to give $0.02 \mu \mathrm{l}$ sample on the column. Helium was used as the carrier gas with a head pressure of 0.8 bar. SCFAs were extracted and analyzed as previously described $^{39}$. 
$\mathrm{pH}$

The $\mathrm{pH}$ of faecal water was determined using a PHM standard $\mathrm{pH}$ meter with a PHC3006 electrode (Radiometer Nederland BV, Zoetermeer, The Netherlands).

\section{Protein concentration}

Homogenized faecal samples were diluted (1:99) in $0.1 \mathrm{M}$ PBS $\left(\mathrm{pH} 6.8,5-7{ }^{\circ} \mathrm{C}\right.$ ) and added to BioRad Assay Protein Dye Reagent (1:1). After 30 minutes, the absorbance was read at $595 \mathrm{~nm}$. Concentrations of proteins were calculated from a standard curve for proteins ranging from $0-120 \mu \mathrm{g} / \mathrm{ml}$ and expressed as $\mathrm{mg}$ total protein per gram faeces.

\section{Defecation-score}

In this study a diarrhoea-like defecation has been defined as a defecation frequency $\geq 3$ per day and/or a faecal consistency $\geq 5$ per day, on the Bristol stool form scale, for at least two days.

\section{Statistics}

The treatment allocation was concealed to all investigators and volunteers, until the study had been completed and all analyses had been performed.

The primary outcome of this study was to compare the changes that occurred in the composition of the intestinal microbiota during and after amoxycillin intake between probiotic and placebo treated subjects. Secondary outcomes were the changes that occurred in the metabolic activity of the intestinal microbiota and changes in defecation-score during and after amoxycillin between probiotic and placebo treated subjects.

Only data from volunteers who completed the study, had a probiotic/placebo and antibiotic compliance of $\geq 90 \%$ and delivered all four faecal samples, was included in the data analyses.

Statistical evaluation of differences between groups and changes within groups (at all time-points during the study period) was carried out using linear mixed model analysis. In this analysis the fixed effects were DAY and TREATMENT and the random effect was SUBJECT. For two-group comparisons of independent ordinal and interval values the nonparametric Mann-Whitney U-test was used while the nonparametric Wilcoxon signed-ranked test was used for comparison of related ordinal and interval values. All tests were conducted using SPSS version 11.0 (SPSS Inc, Chicago, IL) and a p-value below 0.05 was considered statistically significant.

Based on data from previous probiotic studies, it was estimated that 19 volunteers per treatment group would provide a $80 \%$ power to detect a one log difference in 
numbers of specific micro-organisms cultured, assuming a variance of 1.1 and a twosided significance level of 0.05 .

\section{Results}

\section{Subjects}

Forty healthy volunteers completed the study, 19 in the probiotic (5 males and 14 females; mean age 25.5 (SD 10.2) years) and 21 in the placebo group (10 males and 11 females; mean age 28.2 (SD 11.5) years). One subject in the probiotic group was found to be allergic to amoxycillin and had to be excluded. Two subjects in the placebo group did not complete the daily questionnaire. On day 14 , subjects delivered faecal samples to the hospital and subsequently handed in the daily questionnaire. As a consequence information from the questionnaire was available for day 1-13. The compliance for antibiotic intake was at least $93 \%$, and for probiotic/placebo intake at least $97 \%$ in both groups. One subject in the placebo group and three in the probiotic group incidentally (i.e. maximally twice a week) consumed yoghurt containing L. rhamnosus GG between day 14 and 7 before starting the study. Moreover, in the probiotic group one other subject incidentally consumed that probiotic during the first two weeks of the study. Apart from one subject in the probiotic group taking omeprazole once daily on day 45 and 46 of the study, no medication potentially affecting the intestinal microbiota was taken during the study.

\section{Bacteriological culture}

During probiotic intake, a significant increase in the mean number of faecal enterococci was found on day 7 (5.8 vs $4.0 \mathrm{log} \mathrm{cfu} / \mathrm{g}$ faeces $(p<0.02))$ and on day 14 (6.9 vs. $4.3(p<0.001))$ in the probiotic group compared to the placebo group (Table 3.1). Moreover, the mean number of faecal enterococci within the probiotic group increased significantly during antibiotic/probiotic intake (day 7) and increased further during probiotic therapy alone (day 14). A significant decrease in the mean number of faecal enterococci was observed 7 weeks after cessation of probiotic intake $(p<0.05)$ having returned to pre-treatment level (Table 3.1). No further differences in either aerobic or anaerobic bacterial species could be seen between the probiotic and the placebo group.

However, group specific differences were observed over time: within the probiotic group a significant decrease was found in total aerobes (day 63 vs. day 7) and significant increases were observed over time in total anaerobes (day 14 vs. day 0) and Bacteroides spp. (day 7 and day 14 vs. day 0 ) ( $p<0.05$ ). Within the placebo group a significant increase was found over time in enterococci (day 14 vs. day 0) and 
significant decreases were found in lactobacilli (day 7 vs. 0) and spore-forming clostridia (day 7 vs. day 0 and 63) $(p<0.05)$ (Table 3.1).

For all bacterial species, studied in both the probiotic and the placebo group, values on day 63 did not differ significantly from day 0.

The PFGE profile of 39 out of the 40 enterococci strains, isolated from the faeces of the healthy volunteers receiving probiotic, was similar to that of the orally administrated probiotic $E$. faecium W54 strain.

Table 3.1 Numbers of bacteria cultured expressed as log cfu/g faeces (Mean values ( \pm SEM)).

\begin{tabular}{|c|c|c|c|c|}
\hline & Day 0 & Day 7 & Day 14 & Day 63 \\
\hline \multicolumn{5}{|c|}{ Total aerobic microbiota } \\
\hline Probiotic $^{1}$ & $7.0(0.2)$ & $7.3(0.1)$ & $6.9(0.2)$ & $6.8(0.2)$ \\
\hline Placebo & $6.8(0.1)$ & $7.1(0.2)$ & $6.8(0.2)$ & $7.1(0.2)$ \\
\hline \multicolumn{5}{|c|}{ Enterobacteriaceae } \\
\hline Probiotic & $6.1(0.3)$ & $6.5(0.3)$ & $5.9(0.3)$ & $6.0(0.3)$ \\
\hline Placebo & $6.6(0.2)$ & $6.6(0.2)$ & $6.3(0.2)$ & $6.4(0.4)$ \\
\hline \multicolumn{5}{|l|}{ Enterococci } \\
\hline Probiotic $^{2}$ & $4.1(0.3)$ & $5.8(0.3)^{*}$ & $6.9(0.3)^{*}$ & $4.4(0.3)$ \\
\hline Placebo $^{3}$ & $3.5(0.3)$ & $4.0(0.3)$ & $4.3(0.3)$ & $4.2(0.4)$ \\
\hline \multicolumn{5}{|c|}{ Total anaerobic microbiota } \\
\hline Probiotic $^{4}$ & $8.2(0.2)$ & $8.3(0.2)$ & $8.7(0.2)$ & $8.7(0.2)$ \\
\hline Placebo & $8.0(0.2)$ & $8.2(0.2)$ & $8.1(0.3)$ & $8.5(0.2)$ \\
\hline \multicolumn{5}{|c|}{ Bacteroides spp. } \\
\hline Probiotic $^{5}$ & $6.1(0.2)$ & $6.8(0.1)$ & $6.6(0.2)$ & $6.5(0.1)$ \\
\hline Placebo & $6.1(0.1)$ & $6.5(0.2)$ & $6.2(0.1)$ & $6.4(0.2)$ \\
\hline \multicolumn{5}{|c|}{ Spore-forming clostridia } \\
\hline Probiotic & $4.6(0.2)$ & $4.2(0.2)$ & $4.2(0.3)$ & $4.3(0.2)$ \\
\hline Placebo $^{6}$ & $4.5(0.2)$ & $3.8(0.2)$ & $4.2(0.3)$ & $4.5(0.2)$ \\
\hline \multicolumn{5}{|l|}{ Lactobacilli } \\
\hline Probiotic & $4.7(0.3)$ & $4.7(0.2)$ & $5.0(0.3)$ & $4.6(0.4)$ \\
\hline Placebo $^{7}$ & $5.1(0.3)$ & $4.3(0.3)$ & $4.6(0.4)$ & $4.7(0.4)$ \\
\hline
\end{tabular}

*Between group difference $p<0.02 ;{ }^{1}$ Within group decrease $t=63$ vs. $t=7, p<0.05 ;{ }^{2}$ Within group increase $t=7 / 14$ vs. $t=0 / 63$ and $t=7$ vs. $t=14, p<0.05 ;{ }^{3}$ Within group increase $t=14$ vs. $t=0, p<0.05 ;{ }^{4}$ Within group increase $t=14$ vs. $t=0, p<0.05 ;{ }^{5}$ Within group increase $t=7 / 14$ vs. $t=0, p<0.05 ;{ }^{6}$ Within group decrease $t=7$ vs. $t=0 / 63, p<0.05 ;{ }^{7}$ Within group decrease $t=7$ vs. $t=0, p<0.05$.

\section{Metabolic activity}

$\beta$-Glucosidase activity did not differ significantly between the probiotic and the placebo group during the total study period (Table 3.2). Within both groups, a decrease in $\beta$-glucosidase was observed at day 7 (significant for the placebo group), which increased again on day 63 (significant for the probiotic group). In both groups, the $\beta$-glucosidase activity returned to baseline values 7 weeks after cessation of amoxycillin intake (day 63). 
Table 3.2 Metabolic activity: $\beta$-glucosidase activity (expressed as $\mathrm{mg} / 60 \mathrm{~min} / \mathrm{g}$ faeces); SCFA concentration (expressed in $\mathrm{mmol} / \mathrm{g}$ faeces) and $\mathrm{pH}$ (Mean values $( \pm \mathrm{SEM})$ ).

\begin{tabular}{llcccc}
\hline & & Day 0 & Day 7 & Day 14 & Day 63 \\
\hline \multirow{3}{*}{-glucosidase } & Probiotic $^{1}$ & $0.87(0.19)$ & $0.57(0.14)$ & $0.58(0.14)$ & $0.88(0.19)$ \\
& Placebo $^{2}$ & $0.75(0.14)$ & $0.40(0.11)$ & $0.60(0.14)$ & $0.67(0.16)$
\end{tabular}

$\begin{array}{llcrrr}\text { SCFA } & & & & \\ \text { Acetic acid } & \text { Probiotic }^{3} & 110.6(12.0) & 83.9(11.2) & 84.1(11.6) & 92.3(11.2) \\ & \text { Placebo }^{4} & 103.6(15.6) & 78.8(14.9) & 105.3(17.1) & 79.3(12.5) \\ \text { Propionic acid } & \text { Probiotic }^{5} & 29.4(3.6) & 35.9(3.9) & 24.6(3.5) & 26.1(3.1) \\ & \text { Placebo }^{*} \text { Butyric acid } & 28.5(5.6) & 26.5(5.8) & 25.6(3.1) & 24.1(4.6) \\ & \text { Probiotic }^{6} & 30.9(5.1) & 19.2(3.7) & 19.3(3.0) & 30.2(5.6) \\ & \text { Placebo }^{7} & 30.1(6.1) & 13.4(2.7) & 22.4(4.0) & 19.1(3.9) \\ \mathrm{pH} & & & & & 6.7(0.2) \\ & \text { Probiotic } & 6.5(0.2) & 6.3(0.2) & 6.5(0.2) & 6.5(0.2)\end{array}$

${ }^{1}$ Within group increase $t=63$ vs. $t=7, p<0.05$ and a tendency to a within group decrease $t=7$ vs. $t=0$ and increase $t=63$ vs. $t=14, p<0.06 ;{ }^{2}$ Within group decrease $t=7$ vs. $t=0, p<0.05 ;{ }^{3}$ Within group decrease $t=7 / 14$ vs. $t=0, p<0.05 ;{ }^{4}$ Within group increase $t=14$ vs. $t=7, p<0.05$ and within group decrease $t=63$ vs. $t=14$, $p<0.05 ;{ }^{5}$ Within group decrease $t=14 / 63$ vs. $t=7 ;{ }^{6}$ Within group decrease $t=7 / 14$ vs. $t=0, p<0.05$ and within group increase $t=63$ vs. $t=7 / 14, p<0.05 ;{ }^{7}$ Within group decrease $t=7 / 63$ vs. $t=0, p<0.05$.

Endotoxin concentrations (mean $\pm \mathrm{SEM}$ ), expressed as log $\mathrm{ng} / \mathrm{ml}$ faecal water, did not differ significantly between the probiotic and the placebo group on day $0(2.15 \pm 0.07$ vs. $2.04 \pm 0.08)$, day $7(2.30 \pm 0.06$ vs. $2.22 \pm 0.07)$ and day $14(1.92 \pm 0.10$ vs. $1.89 \pm 0.11)$. However, in both groups, a small but not significant increase in mean endotoxin concentration was observed on day 7 , whereas one week after cessation of antibiotic intake (day 14) a significant decrease $(p<0.05)$ in endotoxin concentration was observed compared to day 7.

Clostridium toxin A was detected in the faeces of two volunteers in the placebo group one week after cessation of antibiotic intake (day 14) and in one volunteer in the probiotic group at the start of the study (day 0).

No significant differences between the groups were observed for any of the SCFAs tested (Table 3.2). However, within both groups changes were found over time. Butyric acid concentrations significantly decreased in both groups during antibiotic intake, but by day 63 had recovered to baseline in the probiotic group. This effect was also observed for acetic acid. Furthermore, an increase in propionic acid concentrations was observed on day 7 in the probiotic group.

No significant changes were found in the $\mathrm{pH}$ of the faecal water between and within both groups, during the total study period (Table 3.2).

At all time points, a negative correlation $(p<0.05)$ was observed between the amount of protein per gram faeces and the consistency score (except at $t=63$ days). In addition, a positive correlation $(p<0.05)$ was observed between the amount of faecal water per 10 gram faeces and the consistency score at all time points (an example is shown in Figure 3.1). 


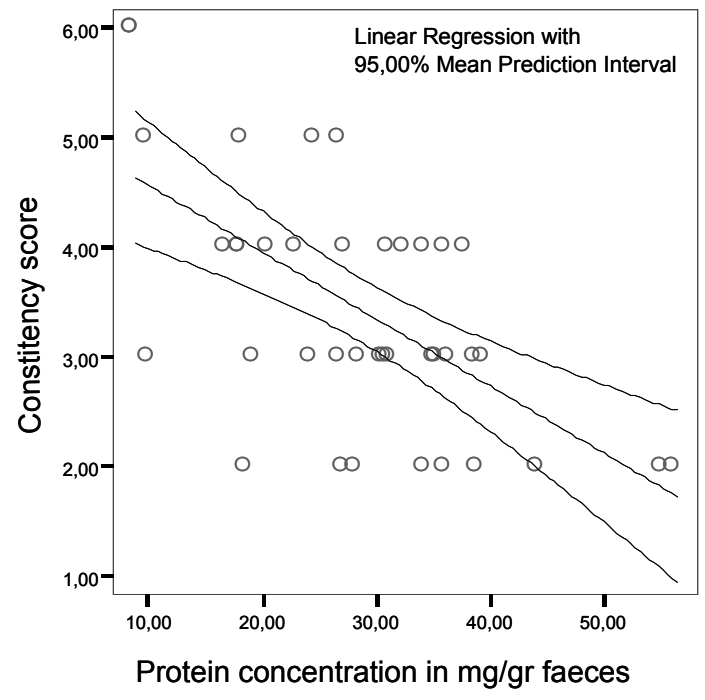

Figure 3.1 Linear regression of faecal consistency (scored with the Bristol stool form scale) in relation to the protein concentration per gram faeces $(R=0.61 ; p<0.01)$. Consistency ranging from 1 (hard lumps) to 7 (watery) according to the Bristol stool form scale. Dots represent faecal samples from each volunteer collected on day 14.

\section{Defecation-score}

The mean defecation frequency and consistency before antibiotic and probiotic intake (day 0 i.e. baseline), during the antibiotic/probiotic period (day 1-7) and during the probiotic only period (day 8-13) are listed in Table 3.3. The defecation frequency during the probiotic only period (day $8-13$ ) was significantly lower $(p<0.05)$ in the probiotic than in the placebo group. During the total probiotic period (day 1-14), diarrhoea-like bowel movements were reported less frequently in the probiotic (48\%) than in the placebo group (79\%) $(p<0.05)($ Table 3.4).

Table 3.3 Mean daily faecal frequency and consistency scores before (day 0), during antibiotic/probiotic intake (day 1-7) and during probiotic intake alone (day 8-13) (Mean values ( \pm SEM)).

\begin{tabular}{lcccccc}
\hline & Day 0 & $\begin{array}{c}\text { Frequency } \\
\text { Day 1-7 }\end{array}$ & Day 8-13 & Day 0 & $\begin{array}{c}\text { Consistency }^{1} \\
\text { Day 1-7 }\end{array}$ & Day 8-13 \\
\hline $\begin{array}{l}\text { Probiotic } \\
(\mathrm{n}=19)\end{array}$ & $1.0(0.2)$ & $1.4(0.1)$ & $1.2(0.1) *$ & $3.5(0.3)$ & $3.9(0.1)$ & $3.5(0.1)$ \\
$\begin{array}{l}\text { Placebo } \\
(\mathrm{n}=19)\end{array}$ & $0.9(0.2)$ & $1.5(0.1)$ & $1.5(0.1)$ & $4.0(0.3)$ & $3.9(0.1)$ & $3.8(0.1)$ \\
\hline
\end{tabular}

*Significant difference between probiotic and placebo group $(\mathrm{p}<0.05) ;{ }^{1}$ Consistency ranging from 1 (hard lumps) to 7 (watery) according to the Bristol stool form scale. 


\begin{tabular}{|c|c|c|}
\hline & $\begin{array}{c}\text { Placebo } \\
n=19\end{array}$ & $\begin{array}{c}\text { Probiotic } \\
n=19\end{array}$ \\
\hline 1. Stool frequency $\geq 3$ per day for at least 2 days & $11 \%$ & $11 \%$ \\
\hline 2. Stool consistency ${ }^{1 *} \geq 5$ for at least 2 days & $42 \%$ & $21 \%$ \\
\hline $\begin{array}{l}\text { 3. Stool frequency } \geq 3 \text { per day and a consistency }{ }^{1} \geq 5 \\
\text { for at least } 2 \text { days }\end{array}$ & $26 \%$ & $16 \%$ \\
\hline $\begin{array}{l}\text { 4. Stool frequency } \geq 3 \text { per day and/or a consistency } \geq 5 \\
\text { for at least } 2 \text { days (being the sum of } 1-3 \text { ) }\end{array}$ & $79 \% *$ & $48 \%$ \\
\hline
\end{tabular}

* $\mathrm{p}<0.05 ;{ }^{1}$ Consistency ranging from 1 (hard lumps) to 7 (watery) according to the Bristol stool form scale.

\section{Side-effects}

The placebo and probiotic group were comparable regarding the percentage (Figure 3.2) and severity of side effects reported: $79 \%$ mild-moderate symptoms in the probiotic group versus $90 \%$ mild-moderate symptoms in the placebo group. Side effects most frequently reported were nausea, abdominal cramps, bloating and flatulence. Finally, side effects were significantly more frequent during the antibiotic/probiotic period (day 1-7) than during the probiotic only period (day 8-13) $(p<0.05)$, for both the probiotic and placebo group (Figure 3.2).

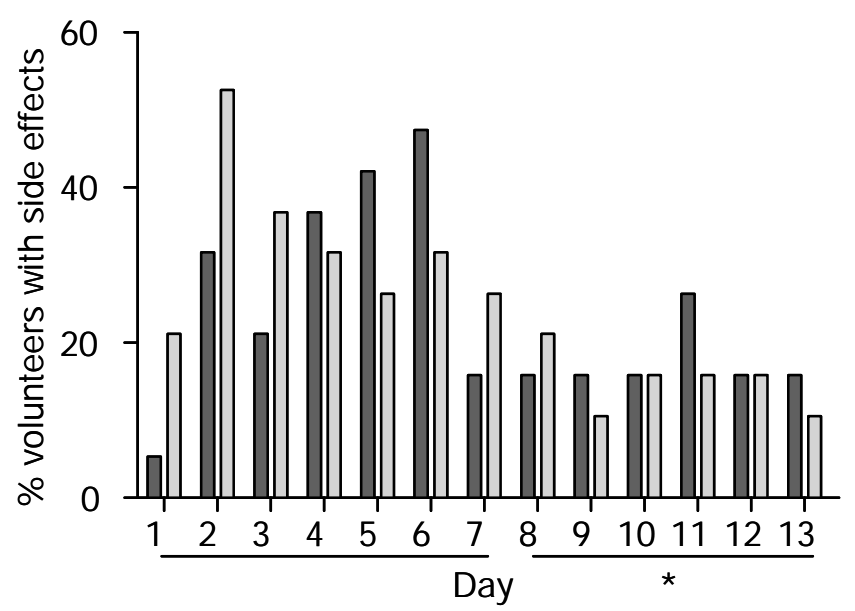

Figure 3.2 Percentage of volunteers with side effects during (day 1-7) and after (day 8-13) antibiotic intake. $\square=$ probiotic $(n=19)$ and $\square=$ placebo $(n=19), * p<0.05$. 


\section{Discussion}

In this placebo-controlled double-blind study, investigating the effect of a multispecies probiotic in healthy volunteers after amoxycillin intake, no differences in the composition of the intestinal microbiota were observed in the probiotic group versus the placebo group, apart from a significant increase in faecal enterococci. Although no other differences were observed between groups, group specific changes were seen over time. Such changes were also observed for metabolic activity. Finally, a significantly better defecation-score (decrease in diarrhoea-like bowel movements) was observed in the probiotic group versus the placebo group.

In $A A D$, differences in efficacy have been reported for different bacterial species, bacterial strains and for probiotic mixtures ${ }^{28}$. The efficacy of multispecies probiotic mixtures is further supported by the successful use of the multispecies probiotic VSL\#3 in several gastrointestinal disorders ${ }^{40-42}$. In the present study, we used a multispecies probiotic containing 10 different probiotic strains selected on the basis of their in vitro ability to inhibit growth of Clostridium spp. and to survive a low pH (2.5) as well as bile and digestive enzymes (pancreatin and pepsin) (data not shown). In addition, their resistance profile against a wide range of antibiotics was taken into account to prevent possible transfer of resistance from the probiotic bacteria to the indigenous microbiota. Finally, the combination of strains chosen was tested to exclude antagonistic effects in growth.

The composition of the faecal microbiota regarding total aerobic bacteria, clostridia and lactobacilli counts before intervention, was comparable with previous findings in healthy volunteers using the same culture methods ${ }^{39,43}$. However, in this study lower mean faecal bacterial concentrations were found for total anaerobic bacteria and Bacteroides spp., which cannot be explained.

One of the possible mechanisms by which probiotics exert their effect is by affecting the composition of the intestinal microbiota and preventing the overgrowth of possible pathogens. Only the faecal microbiota was investigated in this study, even though mucosa associated bacteria may also be very relevant. Due to inter-individual variation and possible sampling error, various biopsies ought to have been taken at all the different time points of the study. Considering the invasiveness and the potential risks this was considered not to be ethically acceptable in healthy volunteers.

The consumption of the multispecies probiotic, containing E. faecium, was associated with a significant increase in the concentration of faecal enterococci in the probiotic group from log $4.1 \mathrm{cfu} / \mathrm{gram}$ to $\log 5.8 \mathrm{cfu} / \mathrm{gram}$ on day 7 and to $\log 6.9 \mathrm{cfu} / \mathrm{gram}$ on day 14. This increase disappeared 7 weeks after cessation of probiotic intake, demonstrating that the consumption of this multispecies probiotic, containing E. faecium, can transiently alter the number of viable enterococci. Considering a consumption of $1 \times 10^{9} \mathrm{cfu}$ E. faecium per day, present in the multispecies product, and 
a faecal volume of $100 \mathrm{~g}$ per day, the recovery of around log 7 enterococci per gram faeces after probiotic intake indicates that E. faecium is able to survive passage through the gastrointestinal tract very well. Moreover, the PFGE patterns of the enterococci isolated from the faecal samples were similar to the orally administered E. faecium. A study, in which a monospecies E. faecium probiotic $\left(4.5-7.5 \times 10^{9} \mathrm{cfu}\right.$ daily) was given to healthy volunteers, also found a high increase (100-fold) in the total number of enterococci ${ }^{44}$. Furthermore, the recovery of viable enterococci in the placebo group was not affected during amoxycillin intake, indicating that in this study amoxycillin had little effect on the indigenous enterococci population.

In contrast to the counts of enterococci, twice daily probiotic consumption containing $3 \times 10^{9}$ cfu lactobacilli (L. salivarius, L. plantarum and $L$. rhamnosus), did not significantly increase the number of faecal lactobacilli. However, a previous study by our group, in which 20 healthy volunteers consumed L. plantarum 299v for 4 weeks did show a 1000 -fold increase in the mean number of faecal lactobacilli ${ }^{39}$. An increase in the mean faecal number of lactobacilli was also observed by others after a six months consumption of L.rhamnosus and a three week consumption of L. acidophilus ${ }^{45,46}$. However, during amoxycillin intake a decrease was observed in the total number of faecal lactobacilli in the placebo group but not in the probiotic group. Comparable results were observed in a study performed by Plummer et al. in which probiotic supplementation was given during $H$. pylori eradication therapy ${ }^{30}$. These findings indicate that the probiotic intake might prevent a decrease of lactobacilli caused by antibiotic intake.

Apart from lactobacilli and the E. faecium, the multispecies probiotic used also contained bifidobacteria. However, no bifidobacteria were cultured, due to insufficient selectivity and sensitivity of media available. In future studies, quantification of bifidobacteria ought to be performed with molecular based techniques.

Looking at both intervention groups, specific changes during and after amoxycillin intake were observed, indicating an effect of amoxycillin intake on the gut microbiota. These results are in line with the literature ${ }^{47-50}$. The various effects over time in the probiotic group compared to the placebo group, suggest that the intake of the multispecies probiotic had an impact on the microbiota during amoxycillin intake, possibly contributing to the better defecation-score. This probiotic effect on the microbiota is partly caused by the bacteria themselves, as is reflected in the increase of enterococci in the probiotic group. In addition, the increase in for example the total anaerobic microbiota and the absence of a decrease in the spore-forming clostridia during amoxycillin intake suggests that the probiotic bacteria were able to induce a change in the intestinal environment favouring the growth of these commensal organisms. The fact that the differences between the groups were not significant is probably due to the high inter-individual variation.

Alteration of the colonic microbiota due to antibiotic treatment can result in overgrowth of $C$. difficile in the colon. However no increase in Clostridium spp. was 
observed in either group during or after antibiotic therapy. Moreover, during antibiotic therapy Clostridium toxin A was not detected in the stool of any of the volunteers. This was to be expected as the prevalence of $C$. difficile colonization among healthy adults is very low, generally less than $2 \%^{51}$. The spores of these bacteria are usually acquired from hospitals and long-term-care facilities where the prevalence ranges from $5-20 \%{ }^{52,53}$ which can further increase with length of stay ${ }^{54}$.

A change in the composition of the intestinal microbiota might affect its metabolic characteristics, such as $\beta$-glucosidase activity. $\beta$-glucosidase has been implicated in carcinogenesis, since it is able to hydrolyse dietary substrates into carcinogenic compounds ${ }^{55,56}$. A decrease of this activity is therefore potentially beneficial. It has been demonstrated that a change in the composition of the intestinal microbiota or the intake of Lactobacillus spp. can influence $\beta$-glucosidase activity, although the results differ between strains and populations studied ${ }^{39,46,57-61}$. In the present study $\beta$-glucosidase activity decreased in both groups during amoxycillin intake and returned to baseline values 7 weeks after cessation of amoxycillin. No effect of probiotic intake was observed.

The endotoxin concentrations in both groups increased during amoxycillin intake, though not significantly, and decreased significantly one week after cessation of amoxycillin intake. This is in accordance with evidence from several studies showing that antibiotics increase the bioavailability of endotoxin originating from Gramnegative bacteria ${ }^{62-65}$. The level of intestinal endotoxin, however, does not only correlate with the number of Gram-negative bacteria, which is in line with the fact that no changes were seen in total counts of enterobacteriaceae, but can also be associated with the metabolic activity associated with proliferation ${ }^{62}$. The clinical significance of antibiotic-induced endotoxin release remains to be clarified. There is evidence that endotoxaemia may be of importance in patients with increased gut permeability and that probiotics show potential in preventing loss of gut barrier integrity ${ }^{66,67}$. Some studies suggest that a reduction in intestinal endotoxin concentration may be associated with decreased endotoxin leakage across the gut wall, and subsequently with the control of endotoxin related conditions ${ }^{68}$. In our study, probiotic intake had no effect on intestinal endotoxin concentrations.

The major SCFAs arising from the bacterial fermentation of non-digestible carbohydrates are acetic acid, propionic acid and butyric acid. They serve as important energy sources (mostly butyric acid) for colonocytes, are associated with the regulation of water and electrolyte transport and decrease colonic $\mathrm{pH}$, thereby inhibiting overgrowth of potential pathogens ${ }^{69}$. In a study with 31 severe AAD patients disturbances in the intestinal microbiota were observed as was a reduction of the amounts of all major faecal SCFAs ${ }^{70}$. SCFA concentrations and anaerobic cultural counts also decreased after systemic ceftriaxone treatment in 10 healthy volunteers ${ }^{71}$. Probiotics, by interacting with the intestinal microbiota and being saccharolytic, can alter SCFA concentrations in the colon. Studies have demonstrated different effects on SCFA concentrations after probiotic intake, with some showing no effect ${ }^{39,43,72-74}$, 
and others showing either an increase ${ }^{75,76}$ or a decrease in specific SCFA concentrations $^{61}$. Possible explanations for these inconsistent findings are the techniques applied, the populations studied and the different probiotic strains used. In the present study, decreased acetic acid and butyric acid concentrations were observed during antibiotic treatment, only returning to baseline 7 weeks after cessation of antibiotic intake in the probiotic group. Moreover, an increased propionic acid concentration was observed in the probiotic group at day 7. In contrast, the main fermentation products of the bacteria present in the multispecies probiotic are lactate, acetate and formate (the latter only formed by bifidobacteria) and do not include propionate. In this respect, metabolic cross-feeding is likely to have occurred as lactate can be converted into butyrate or propionate. Which metabolic pathway is utilized depends on the composition of the microbiota as well as environmental conditions, and shows high inter-individual variation ${ }^{77,78}$. In general, the overall SCFA concentration seemed to be higher in the probiotic group which could be one of the explanations for the less diarrhoea-like defecation-score, in this group, due to a better water and electrolyte absorption ${ }^{79}$. It should be noted that only $1-5 \%$ of the amount of SCFAs produced are excreted in the faeces and that changes in SCFA concentration can be due to both changes in production and/or absorption and altered motility ${ }^{80}$.

This study demonstrated that the intake of a multispecies probiotic resulted in a significantly better defecation-score (decrease in diarrhoea-like bowel movements), which is in accordance with previous studies showing that probiotics significantly reduce the relative risk of developing $A A D^{26-28}$. Faecal consistency was estimated by the validated Bristol stool form scale. The significant correlation of the consistency with both the amount of protein and faecal water per gram faeces supports the validity of this scale.

During antibiotic intake a significant number of side effects were reported in both groups, but their numbers did not differ between the probiotic and the placebo group. These results suggest that the multispecies probiotic that was able to decrease diarrhoea-like defecation, does not reduce other gastro-intestinal side effects, but also does not result in adverse events. The clinical relevance of the improved defecation-score has to be further studied in specific patient populations, who have an increased risk of $A A D$, due to host factors (age, immune-status), hospitalization status and exposure to higher doses of antibiotics ${ }^{2}$.

The compliance for both antibiotic and probiotic/placebo intake were high in this study, although we readily admit that this was self-reported. We also acknowledge that many gastrointestinal bacteria remain uncultured and that molecular based techniques would allow a more complete assessment of microbial diversity. However, culture provides information on quantitative alterations in viable counts of specific groups of bacteria, which is also important for the metabolic activity of the intestinal microbiota. 
In conclusion, comparing the specially developed multispecies probiotic Ecologic AAD with placebo no differences were observed in bacterial counts nor in metabolic activity, apart from an increase in enterococci. However, changes over time were present in both groups indicating an amoxycillin effect, which differed between the probiotic and the placebo group. Moreover, the intake of a multispecies probiotic significantly reduced diarrhoea-like bowel movements in healthy volunteers receiving amoxycillin. Although the changes over time in microbial composition and metabolic activity by themselves were small, the sum of potentially beneficial changes may have contributed to the improved defecation-score observed. The present study therefore supports the hypothesis that multispecies probiotics could be used in the prevention of $A A D$, as they affect the composition and function of the intestinal microbiota. 


\section{References}

1. Bartlett JG. Antibiotic-associated diarrhea. Clin Infect Dis. 1992;15:573-81.

2. McFarland LV. Epidemiology, risk factors and treatments for antibiotic-associated diarrhea. Dig Dis. 1998;16:292-307.

3. McFarland LV. Epidemiology of infectious and iatrogenic nosocomial diarrhea in a cohort of general medicine patients. Am J Infect Control. 1995;23:295-305.

4. Gustafsson A, Berstad A, Lund-Tonnesen S, Midtvedt T, Norin E. The effect of faecal enema on five microflora-associated characteristics in patients with antibiotic-associated diarrhoea. Scand J Gastroenterol. 1999;34:580-6.

5. Kelly CP, Pothoulakis C, LaMont JT. Clostridium difficile colitis. N Engl J Med. 1994;330: 257-62.

6. Aronsson B, Mollby R, Nord CE. Diagnosis and epidemiology of Clostridium difficile enterocolitis in Sweden. J Antimicrob Chemother. 1984;14:85-95.

7. Hogenauer C, Hammer HF, Krejs GJ, Reisinger EC. Mechanisms and management of antibioticassociated diarrhea. Clin Infect Dis. 1998;27:702-10.

8. Beaugerie L, Petit JC. Microbial-gut interactions in health and disease. Antibiotic-associated diarrhoea. Best Pract Res Clin Gastroenterol. 2004;18:337-52.

9. Van Vlem B, Vanholder R, De Paepe P, Vogelaers D, Ringoir S. Immunomodulating effects of antibiotics: literature review. Infection. 1996;24:275-91.

10. Levy SB. The 2000 Garrod lecture. Factors impacting on the problem of antibiotic resistance. J Antimicrob Chemother. 2002;49:25-30.

11. De Giorgio R, Barbara G, Stanghellini V, Cremon C, Salvioli B, De Ponti F, Corinaldesi R. Diagnosis and therapy of irritable bowel syndrome. Aliment Pharmacol Ther. 2004;20 Suppl 2:10-22.

12. Madden JA, Plummer SF, Tang J, Garaiova I, Plummer NT, Herbison M, Hunter JO, Shimada T, Cheng L, Shirakawa T. Effect of probiotics on preventing disruption of the intestinal microflora following antibiotic therapy: a double-blind, placebo-controlled pilot study. Int Immunopharmacol. 2005;5: 1091-7.

13. McAuliffe OE, Klaenhammer TR. Genomic perspectives on probioitcs and the gastrointestinal microflora. In: Tannock GW, editor. Probiotics and Prebiotics, Where are we going? Norfolk: Caister Academic Press; 2002:263-309.

14. Gotz V, Romankiewicz JA, Moss J, Murray HW. Prophylaxis against ampicillin-associated diarrhea with a lactobacillus preparation. Am J Hosp Pharm. 1979;36:754-7.

15. Surawicz CM, Elmer GW, Speelman P, McFarland LV, Chinn J, van Belle G. Prevention of antibioticassociated diarrhea by Saccharomyces boulardii: a prospective study. Gastroenterol. 1989;96:981-8.

16. Wunderlich PF, Braun L, Fumagalli I, D'Apuzzo V, Heim F, Karly M, Lodi R, Politta G, Vonbank F, Zeltner L. Double-blind report on the efficacy of lactic acid-producing Enterococcus SF68 in the prevention of antibiotic-associated diarrhoea and in the treatment of acute diarrhoea. J Int Med Res. 1989;17:333-8.

17. Siitonen S, Vapaatalo H, Salminen S, Gordin A, Saxelin M, Wikberg R, Kirkkola AL. Effect of Lactobacillus GG yoghurt in prevention of antibiotic associated diarrhoea. Ann Med. 1990;22:57-9.

18. McFarland LV, Surawicz CM, Greenberg RN, Elmer GW, Moyer KA, Melcher SA, Bowen KE, Cox JL. Prevention of beta-lactam-associated diarrhea by Saccharomyces boulardii compared with placebo. Am J Gastroenterol. 1995;90:439-48.

19. Vanderhoof JA, Whitney DB, Antonson DL, Hanner TL, Lupo JV, Young RJ. Lactobacillus GG in the prevention of antibiotic-associated diarrhea in children. J Pediatr. 1999;135:564-8.

20. Armuzzi A, Cremonini F, Bartolozzi F, Canducci F, Candelli M, Ojetti V, Cammarota G, Anti M, De Lorenzo A, Pola P, Gasbarrini G, Gasbarrini A. The effect of oral administration of Lactobacillus GG on antibiotic-associated gastrointestinal side-effects during Helicobacter pylori eradication therapy. Aliment Pharmacol Ther. 2001;15:163-9.

21. Arvola T, Laiho K, Torkkeli S, Mykkanen H, Salminen S, Maunula L, Isolauri E. Prophylactic Lactobacillus GG reduces antibiotic-associated diarrhea in children with respiratory infections: a randomized study. Pediatrics. 1999;104:e64.

22. Adam J, Barret A, Barret-Bellet C. Esais cliniques controles en doubles insu de l'ultra-leur lyophyilisee. Etude multi-centrique par 25 medicines de 38 cas. Gaz Med Francaise. 1977;84:2072-8. 
23. Tankanow RM, Ross MB, Ertel IJ, Dickinson DG, McCormick LS, Garfinkel JF. A double-blind, placebocontrolled study of the efficacy of Lactinex in the prophylaxis of amoxicillin-induced diarrhea. Dicp. 1990;24:382-4.

24. Thomas MR, Litin SC, Osmon DR, Corr AP, Weaver AL, Lohse CM. Lack of effect of Lactobacillus GG on antibiotic-associated diarrhea: a randomized, placebo-controlled trial. Mayo Clin Proc. 2001;76:883-9.

25. Lewis SJ, Potts LF, Barry RE. The lack of therapeutic effect of Saccharomyces boulardii in the prevention of antibiotic-related diarrhoea in elderly patients. J Infect. 1998;36:171-4.

26. Cremonini F, Di Caro S, Nista EC, Bartolozzi F, Capelli G, Gasbarrini G, Gasbarrini A. Meta-analysis: the effect of probiotic administration on antibiotic- associated diarrhoea. Aliment Pharmacol Ther. 2002; 16:1461-7.

27. D'Souza AL, Rajkumar C, Cooke J, Bulpitt CJ. Probiotics in prevention of antibiotic associated diarrhoea: meta- analysis. BMJ. 2002;324:1361.

28. McFarland LV. Meta-analysis of probiotics for the prevention of antibiotic associated diarrhea and the treatment of Clostridium difficile disease. Am J Gastroenterol. 2006;101:812-22.

29. Orrhage K, Sjostedt S, Nord CE. Effect of supplements with lactic acid bacteria and oligofructose on the intestinal microflora during administration of cefpodoxime proxetil. J Antimicrob Chemother. 2000;46:603-12.

30. Plummer SF, Garaiova I, Sarvotham T, Cottrell SL, Le Scouiller S, Weaver MA, Tang J, Dee P, Hunter J. Effects of probiotics on the composition of the intestinal microbiota following antibiotic therapy. Int J Antimicrob Agents. 2005;26:69-74.

31. Timmerman HM, Koning CJ, Mulder L, Rombouts FM, Beynen AC. Monostrain, multistrain and multispecies probiotics--A comparison of functionality and efficacy. Int J Food Microbiol. 2004;96: 219-33.

32. Ouwehand AC, Isolauri E, Kirjavainen PV, Tolkko S, Salminen SJ. The mucus binding of Bifidobacterium lactis $\mathrm{Bb} 12$ is enhanced in the presence of Lactobacillus GG and Lact. delbrueckii subsp. bulgaricus. Lett Appl Microbiol. 2000;30:10-3.

33. Gomes AM, Malcata FX, Klaver FA. Growth enhancement of Bifidobacterium lactis Bo and Lactobacillus acidophilus Ki by milk hydrolyzates. J Dairy Sci. 1998;81:2817-25.

34. O'Donnell LJ, Virjee J, Heaton KW. Detection of pseudodiarrhoea by simple clinical assessment of intestinal transit rate. BMJ. 1990;300:439-40.

35. Hartemink R, Domenech VR, Rombouts FM. LAMVAB - a new selective medium for the isolation of lactobacilli from faeces. J Microbiol Methods. 1997;29:77-84.

36. Summanen p, Baron EJ, Citron DM, Strong CA, Wexler HM, Finegold SM. Wadsworth anaerobic bacteriology manual. 5th ed. Belmont, California: Star publishing company; 1993.

37. Tenover FC, Arbeit RD, Goering RV, Mickelsen PA, Murray BE, Persing DH, Swaminathan B. Interpreting chromosomal DNA restriction patterns produced by pulsed-field gel electrophoresis: criteria for bacterial strain typing. J Clin Microbiol. 1995;33:2233-9.

38. van den Braak N, van Belkum A, van Keulen M, Vliegenthart J, Verbrugh HA, Endtz HP. Molecular characterization of vancomycin-resistant enterococci from hospitalized patients and poultry products in The Netherlands. J Clin Microbiol. 1998;36:1927-32.

39. Goossens D, Jonkers D, Russel M, Stobberingh E, Van Den Bogaard A, StockbrUgger R. The effect of Lactobacillus plantarum $299 \mathrm{v}$ on the bacterial composition and metabolic activity in faeces of healthy volunteers: a placebo-controlled study on the onset and duration of effects. Aliment Pharmacol Ther. 2003;18:495-505.

40. Bibiloni R, Fedorak RN, Tannock GW, Madsen KL, Gionchetti P, Campieri M, De Simone C, Sartor RB. VSL\#3 probiotic-mixture induces remission in patients with active ulcerative colitis. Am J Gastroenterol. 2005;100:1539-46.

41. Kim HJ, Camilleri M, McKinzie S, Lempke MB, Burton DD, Thomforde GM, Zinsmeister AR. A randomized controlled trial of a probiotic, VSL\#3, on gut transit and symptoms in diarrhoeapredominant irritable bowel syndrome. Aliment Pharmacol Ther. 2003;17:895-904.

42. Mimura T, Rizzello F, Helwig U, Poggioli G, Schreiber S, Talbot IC, Nicholls RJ, Gionchetti P, Campieri $\mathrm{M}, \mathrm{Kamm}$ MA. Once daily high dose probiotic therapy (VSL\#3) for maintaining remission in recurrent or refractory pouchitis. Gut. 2004;53:108-14. 
43. Goossens D, Jonkers D, Russel M, Thijs A, van den Bogaard A, Stobberingh E, Stockbrugger R. Survival of the probiotic, L. plantarum $299 \mathrm{v}$ and its effects on the faecal bacterial flora, with and without gastric acid inhibition. Dig Liver Dis. 2005;37:44-50.

44. Lund B, Edlund C, Barkholt L, Nord CE, Tvede M, Poulsen RL. Impact on human intestinal microflora of an Enterococcus faecium probiotic and vancomycin. Scand J Infect Dis. 2000;32:627-32.

45. Link-Amster $\mathrm{H}$, Rochat F, Saudan KY, Mignot O, Aeschlimann JM. Modulation of a specific humoral immune response and changes in intestinal flora mediated through fermented milk intake. FEMS Immunol Med Microbiol. 1994;10:55-63.

46. Tannock GW, Munro K, Harmsen HJ, Welling GW, Smart J, Gopal PK. Analysis of the fecal microflora of human subjects consuming a probiotic product containing Lactobacillus rhamnosus DR20. Appl Environ Microbiol. 2000;66:2578-88.

47. Brismar B, Edlund C, Nord CE. Impact of cefpodoxime proxetil and amoxicillin on the normal oral and intestinal microflora. Eur J Clin Microbiol Infect Dis. 1993;12:714-9.

48. Christensson B, Nilsson-Ehle I, Ljungberg B, Nömm I, Oscarsson G, Nordström L. A randomized multicentre trial to compare the influence of cefaclor and amoxycillin on the colonization resistance of the digestive tract in patients with lower respiratory tract infection. Infection. 1991;19:208-15.

49. Gipponi M, Sciutto C, Accornero L, Bonassi S, Raso C, Vignolo C, Cafiero F. Assessing modifications of the intestinal bacterial flora in patients on long-term oral treatment with bacampicillin or amoxicillin: a random study. Chemioterapia. 1985;4:214-7.

50. Leigh DA. Pharmacology and toxicological studies with amoxycillin, talampicillin and ampicillin and a clinical trial of parenteral amoxycillin in serious hospital infections. Drugs Exp Clin Res. 1979;5:129-39.

51. Poutanen SM, Simor AE. Clostridium difficile-associated diarrhea in adults. CMAJ. 2004;171:51-8.

52. McFarland LV, Mulligan ME, Kwok RY, Stamm WE. Nosocomial acquisition of Clostridium difficile infection. N Engl J Med. 1989;320:204-10.

53. Rivera EV, Woods S. Prevalence of asymptomatic Clostridium difficile colonization in a nursing home population: a cross-sectional study. J Gend Specif Med. 2003;6:27-30.

54. Johnson S, Gerding DN, Olson MM, Weiler MD, Hughes RA, Clabots CR, Peterson LR. Prospective, controlled study of vinyl glove use to interrupt Clostridium difficile nosocomial transmission. Am J Med. 1990;88:137-40.

55. Goldin BR. In situ bacterial metabolism and colon mutagens. Annu Rev Microbiol. 1986;40:367-93.

56. Rowland I. Metabolic interaction in the gut. In: Fuller R, editor. Probiotics: The scientific basis. London: Chapman and Hall; 1992.

57. Cole $C B$, Fuller R, Mallet AK, Rowland IR. The influence of the host on expression of intestinal microbial enzyme activities involved in metabolism of foreign compounds. J Appl Bacteriol. 1985;59: 549-53.

58. Gadelle D, Raibaud P, Sacquet E. beta-Glucuronidase activities of intestinal bacteria determined both in vitro and in vivo in gnotobiotic rats. Appl Environ Microbiol. 1985;49:682-5.

59. Goldin BR, Swenson L, Dwyer J, Sexton M, Gorbach SL. Effect of diet and Lactobacillus acidophilus supplements on human fecal bacterial enzymes. J Natl Cancer Inst. 1980;64: 255-61.

60. Marteau P, Pochart P, Flourie B, Pellier P, Santos L, Desjeux JF, Rambaud JC. Effect of chronic ingestion of a fermented dairy product containing Lactobacillus acidophilus and Bifidobacterium bifidum on metabolic activities of the colonic flora in humans. Am J Clin Nutr. 1990;52:685-8.

61. Spanhaak S, Havenaar R, Schaafsma G. The effect of consumption of milk fermented by Lactobacillus casei strain Shirota on the intestinal microflora and immune parameters in humans. Eur J Clin Nutr. 1998;52:899-907.

62. Goris H, de Boer F, van der Waaij D. Kinetics of endotoxin release by gram-negative bacteria in the intestinal tract of mice during oral administration of bacitracin and during in vitro growth. Scand J Infect Dis. 1988;20:213-9.

63. Holzheimer RG. Antibiotic induced endotoxin release and clinical sepsis: a review. J Chemother. 2001;13 Spec No 1:159-72.

64. Hurley JC. Endotoxemia: methods of detection and clinical correlates. Clin Microbiol Rev. 1995; 8:268-92.

65. Hurley JC. Antibiotic-induced release of endotoxin. A therapeutic paradox. Drug Saf. 1995;12:183-95.

66. Llopis M, Antolin M, Guarner F, Salas A, Malagelada JR. Mucosal colonisation with Lactobacillus casei mitigates barrier injury induced by exposure to trinitronbenzene sulphonic acid. Gut. 2005;54:955-9. 
67. Madsen K, Cornish A, Soper P, McKaigney C, Jijon H, Yachimec C, Doyle J, Jewell L, De Simone C. Probiotic bacteria enhance murine and human intestinal epithelial barrier function. Gastroenterol. 2001;121:580-91.

68. Van Saene JJM, Stoutenbeek CC, Van Saene HK, Matera G, Martinez-Pellus AE, Ramsay G. Reduction of the inestinal endotoxin pool by three different SDD regimens in human volunteers. J Endotoxin Res. 1996;3:337-43.

69. Cook SI, Sellin JH. Review article: short chain fatty acids in health and disease. Aliment Pharmacol Ther. 1998;12:499-507.

70. Gustafsson A, Lund-Tonnesen S, Berstad A, Midtvedt T, Norin E. Faecal short-chain fatty acids in patients with antibiotic-associated diarrhoea, before and after faecal enema treatment. Scand J Gastroenterol. 1998;33:721-7.

71. Meijer-Severs GJ, Van Santen E, Meijer BC. Short-chain fatty acid and organic acid concentrations in feces of healthy human volunteers and their correlations with anaerobe cultural counts during systemic ceftriaxone administration. Scand J Gastroenterol. 1990;25:698-704.

72. Fukuda M, Kanauchi O, Araki Y, Andoh A, Mitsuyama K, Takagi K, Toyonaga A, Sata M, Fujiyama Y, Fukuoka M, Matsumoto $Y$, Bamba T. Prebiotic treatment of experimental colitis with germinated barley foodstuff: a comparison with probiotic or antibiotic treatment. Int J Mol Med. 2002;9:65-70.

73. Hove H, Nordgaard-Andersen I, Mortensen PB. Effect of lactic acid bacteria on the intestinal production of lactate and short-chain fatty acids, and the absorption of lactose. Am J Clin Nutr. 1994;59:74-9.

74. Rochet V, Rigottier-Gois L, Sutren M, Krementscki MN, Andrieux C, Furet JP, Tailliez P, Levenez F, Mogenet A, Bresson JL, Meance S, Cayuela C, Leplingard A, Dore J. Effects of orally administered Lactobacillus casei DN-114 001 on the composition or activities of the dominant faecal microbiota in healthy humans. Br J Nutr. 2006;95:421-9.

75. Johansson ML, Nobaek S, Berggren A, Nyman M, Bjorck I, Ahrne S, Jeppsson B, Molin G. Survival of Lactobacillus plantarum DSM $9843(299 \mathrm{v})$, and effect on the short-chain fatty acid content of faeces after ingestion of a rose-hip drink with fermented oats. Int J Food Microbiol. 1998;42:29-38.

76. Schneider SM, Girard-Pipau F, Filippi J, Hebuterne X, Moyse D, Hinojosa GC, Pompei A, Rampal P. Effects of Saccharomyces boulardii on fecal short-chain fatty acids and microflora in patients on longterm total enteral nutrition. World J Gastroenterol. 2005;11:6165-9.

77. Bourriaud C, Robins RJ, Martin L, Kozlowski F, Tenailleau E, Cherbut C, Michel C. Lactate is mainly fermented to butyrate by human intestinal microfloras but inter-individual variation is evident. J Appl Microbiol. 2005;99:201-12.

78. Louis P, Scott KP, Duncan SH, Flint HJ. Understanding the effects of diet on bacterial metabolism in the large intestine. J Appl Microbiol. 2007;102:1197-208.

79. Wong JM, de Souza R, Kendall CW, Emam A, Jenkins DJ. Colonic health: fermentation and short chain fatty acids. J Clin Gastroenterol. 2006;40:235-43.

80. Macfarlane GT, Macfarlane S. Human colonic microbiota: ecology, physiology and metabolic potential of intestinal bacteria. Scand J Gastroenterol. 1997;222:3-9. 



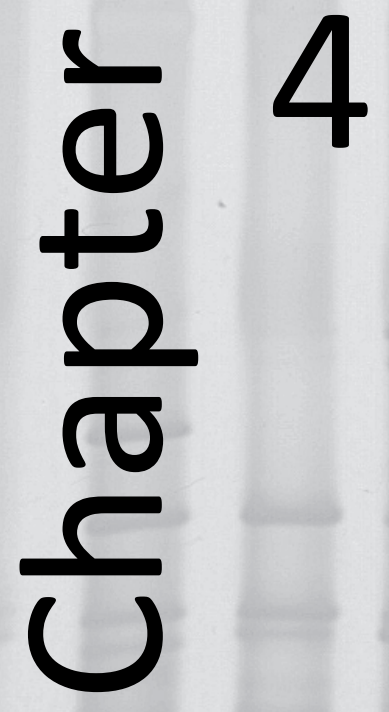




\section{Monitoring the effect of a multispecies probiotic and short-term amoxicillin intake on the fecal microbiota in healthy volunteers}

Catherina J.M. Koning, Daisy M.A.E. Jonkers, Hauke Smidt, Susana Fuentes, Frans M. Rombouts, Bjorn Winkens, Ellen E. Stobberingh, Reinhold W. Stockbrügger Submitted 


\section{Abstract}

Each individual has a unique, relatively stable, intestinal microbiota, which can be disturbed by antibiotics potentially resulting in antibiotic-associated diarrhoea. The goal of this study was to assess the effect of amoxycillin on the diversity and temporal stability of the faecal microbiota and a potential restoration by multispecies probiotics in healthy volunteers. In this randomized controlled double-blind study 40 healthy volunteers received amoxycillin $(1 \mathrm{~g} / \mathrm{day})$ for 7 days and a multispecies probiotic $\left(10^{10} \mathrm{cfu} / \mathrm{day}\right)$ or placebo for 14 days. Faeces was collected on day 0, 3, 7, 14, 35 and 63. Changes in the predominant faecal microbiota, enterococci and bifidobacteria were determined by DGGE of PCR-amplified 16S-rRNA genes. Using quantitative PCR, total bacteria, lactobacilli and bifidobacteria were enumerated. During amoxycillin intake, low temporal stability, based on similarity indices (SI) of DGGE profiles, and microbiota richness were observed in both groups. Thereafter, SIs remained low in the placebo group, but increased significantly in the probiotic group at day 35 ( $65 \%$ vs $48 \%, p<0.05)$, indicating a faster stabilization of microbiota composition towards the situation before antibiotic intake. Regardless of probiotic intake, one month after cessation of amoxycillin intake a significantly decreased SI was observed in volunteers developing diarrhoea-like bowel movements. This study demonstrates that the richness and stability of the faecal microbiota was markedly affected by amoxycillin, which could be restored by a multispecies probiotic. Moreover, an association between the disruption of the faecal microbiota and diarrhoea-like bowel movements was found. 


\section{Introduction}

The human intestinal tract comprises a complex bacterial ecosystem that plays an important role in human physiology, colonization resistance, several metabolic processes and modulation of mucosal and systemic immunology. In healthy subjects the intestinal microbiota is thought to be relatively stable over time ${ }^{1-6}$. Antibiotic intake can markedly disturb this microbiota leading to antibiotic-associated diarrhoea $(A A D)^{7}$. Recently Jernberg et al. showed that short-term antibiotic use can cause longterm disturbances in specific bacterial populations ${ }^{8}$. Knowledge of the effects of antibiotics on the intestinal microbiota and ways of restoring their unique composition are therefore of clinical importance.

Probiotics can affect the composition of the intestinal microbiota and beneficial effects have been observed in the prevention and treatment of $A A D^{9-12}$. There is, however, great variation in efficacy of the different species and strains of bacteria used. Multispecies probiotics, combining a variety of bacterial properties, are expected to be more effective and their advantages have been shown for various applications ${ }^{13}$ including $A A D^{12}$.

The effect of probiotic intake on the composition of the faecal microbiota during and after antibiotic intake has recently been investigated in studies focusing on survival of ingested probiotic strains, emergence of antibiotic resistance or prevention of disturbances in specific bacterial groups ${ }^{14-18}$. In the past, mainly culture-dependent approaches were used investigating predefined bacterial species or groups, as also in a previous study from our group, where we could show that only enterococci significantly increased in abundance due to treatment with a multispecies probiotic mixture containing strains of Enterococcus, Bifidobacterium and Lactobacillus ${ }^{19}$. However, the human gastrointestinal tract harbours a large and diverse microbiota of which many microbial species can not be cultured effectively with currently applied approaches ${ }^{3,20,21}$. Therefore, to comprehensively study the temporal and treatmentrelated dynamics of the intestinal microbiota molecular techniques using small subunit ribosomal RNA (16S rRNA) gene sequences as culture-independent informative biomarkers have to be applied. A combination of polymerase chain reaction (PCR) and denaturing gradient gel electrophoresis (DGGE) can be used to provide a fast and more comprehensive insight into the diversity and stability of the intestinal microbiota ${ }^{5,22-24}$. Furthermore, by using group-specific primers, it is possible to focus the analysis of subpopulations within the microbiota, which otherwise would remain unnoticed in total bacterial profiles due to their low relative abundance ${ }^{4,25}$. Some studies have applied these techniques for examining the effect of either probiotic $^{26,27}$ or antibiotic intake ${ }^{28}$, but only a few subjects were analyzed. Thus far, no studies have investigated the effect of probiotic intake to prevent and restore disturbances of the intestinal microbiota caused by antibiotics or have assessed such disturbances in subjects who develop AAD compared to those who did not. 
We previously described that the intake of a multispecies probiotic significantly reduces diarrhoea-like bowel movements in healthy volunteers receiving amoxycillin $^{19}$.

In this context, the aim of the present study was to apply cultivation-independent microbial profiling to comprehensively assess the effect of amoxycillin on the diversity and temporal stability of the predominant intestinal microbiota and a potential restoration of microbiota composition by multispecies probiotics, comprising strains of enterococci, bifidobacteria and lactobacilli, in healthy volunteers. Moreover, subjects who develop AAD were compared to those who did not. Previously, cultivation-dependent studies could only demonstrate a significant increase in abundance of enterococci due to probiotic treatment, but no effect was observed on either bifidobacteria or lactobacilli ${ }^{19}$. As it is generally acknowledged that cultivationbased approaches can only detect part of the microbiota residing in the gastrointestinal tract, 16S rRNA gene-targeted quantitative PCR was used to confirm the observed lack of effect of probiotic administration on abundance of bifidobacteria and lactobacilli. Furthermore, to test the hypothesis that probiotic treatment might not only affect abundance, but also composition within these microbial groups, we analyzed in addition to total microbiota composition, the population dynamics within the enterococci and bifidobacteria as two examples of microbial groups for which changes could or could not be observed by cultivation-based approaches.

\section{Materials and methods}

\section{Subjects and study design}

The design and the clinical details of the study have been described in detail elsewhere ${ }^{19}$. Briefly, 41 healthy volunteers between $18-65$ years of age were enrolled in the study. All volunteers received amoxycillin $500 \mathrm{mg}$ twice daily for 7 days and were randomized to receive either $5 \mathrm{~g}$ of a multispecies probiotic, Ecologic ${ }^{\circledR} \mathrm{AAD}$ (Winclove Bio Industries, Amsterdam, the Netherlands), consisting of 10 different bacterial species at $10^{8}$ colony forming units (CFU)/g each (Bifidobacterium bifidum W23, B. lactis W18, B. lactis W51 (formerly classified as B. longum), Enterococcus faecium W54, Lactobacillus acidophilus W37 and W55, L. paracasei W20, L. plantarum W62, L. rhamnosus W71 and L. salivarius W24) or placebo twice daily for 14 days starting simultaneously with antibiotic intake. Participants were asked to continue their usual dietary habits and to refrain from dieting and excessive alcohol intake. The total duration of the intervention and follow-up period per volunteer was 63 days. Fresh faecal samples were collected in sterile containers at day 0, 3, 7, 14, 35 and 63 and transported to the laboratory within 12 hours after defecation. The samples were frozen directly at $-20^{\circ} \mathrm{C}$ until further analysis. 
The study was approved by the Medical Ethics Committee of the University Hospital Maastricht, the Netherlands and all volunteers gave written informed consent.

\section{DNA extraction}

DNA was isolated from approximately $0.1 \mathrm{~g}$ of frozen faeces, using the FastDNA SPIN Kit for Soil (Qbiogene, Carlsbad, CA, USA) and a FastPrep Instrument (FP120, Savant Instruments, Farmingdale, USA) following instructions of the manufacturer. Extracted DNA was checked by agarose gel $(1.2 \% \mathrm{wt} / \mathrm{vol})$ electrophoresis in the presence of ethidium bromide. DNA of individual probiotic strains was isolated from lyophilized material as described above for faeces.

\section{PCR amplification and DGGE analysis}

Total bacterial profiles from all samples were analyzed by DGGE of $16 \mathrm{~S}$ rRNA gene fragments amplified by PCR with primers 0968-f-GC and 1401-r as described previously $^{29,30}$. For the group-specific amplification of 16S rRNA gene fragments of bifidobacteria, primers Bif-164-f and Bif-662-GC-r were used ${ }^{31}$. Enterococcus spp. specific amplification was achieved using a nested PCR approach. First, PCR was performed with primers $968-f$ and 1401-r. Products from this reaction were 10-fold diluted and used as template in a second specific PCR with primers Ent-1017-f and Ent-1263-r-GC ${ }^{4}$.

Amplicons generated by PCR were separated by DGGE in $8 \%$ polyacrylamide gels using a Dcode TM system (Bio-Rad Laboratories, Hercules, USA) as described elsewhere ${ }^{24,30}$. For the separation of amplicons, gradients of $40-50 \%$ for total bacterial and enterococci-specific profiles, and of $45-55 \%$ for bifidobacteria-specific profiles were used. A $100 \%$ denaturing solution was defined as $7 \mathrm{M}$ urea and $40 \%$ formamide. Gels were stained with $\mathrm{AgNO}_{3}{ }^{32}$. The DGGE gels were analyzed using Bionumerics 4.0 (Applied Maths BVBA, Sint-Martens-Latem, Belgium).

Following normalization of gel images using markers loaded on either side and in the central lane of each gel, bands were defined for each sample using the bands searching algorithm within the program. Corresponding densitometric curves were used for a manual check of band definition, and bands with less than $1 \%$ of the total area of all bands were omitted from further analysis ${ }^{33}$. The similarity (expressed as similarity index (SI)) between the DGGE profiles of day 0 with following days (e.g. 0-3, 0-7, 0-14, etc.) and between consecutive days (e.g. 0-3, 3-7, 7-14, etc.) was determined by calculating a Dice correlation coefficient (band based) according to the principle of moving window correlation ${ }^{34}$.

\section{Quantitative PCR}

Quantitative detection of lactobacilli and bifidobacteria was performed using an iCycler IQ real-time detection system associated with the iCycler optical system 
interface software version 2.3 (Bio-Rad, Veenendaal, the Netherlands). Reactions were carried out in a volume of $25 \mu \mathrm{l}$, and contained $12.5 \mu \mathrm{l}$ of IQ SYBR Green Supermix (Bio-Rad), $0.2 \mu \mathrm{M}$ of each primer set and $5 \mu \mathrm{l}$ of the template DNA. Total bacterial 16S rRNA gene copies were quantified with primers Bact-1369-f and Prok$1492-r^{35}$ as described previously ${ }^{36}$. Lactobacilli were quantified using primers LactoF and LactoR ${ }^{37}$ and bifidobacteria by primers Bif $164-f$ and $662-r^{31}$. Following an initial denaturation at $95^{\circ} \mathrm{C}$ for $3 \mathrm{~min}, 40$ cycles were applied that consisted of denaturation at $95^{\circ} \mathrm{C}$ for $30 \mathrm{~s}$, annealing at $62^{\circ} \mathrm{C}$ for $40 \mathrm{~s}$, and extension at $72^{\circ} \mathrm{C}$ for $1 \mathrm{~min}$.

\section{Statistical analysis}

The treatment allocation was concealed to all investigators and volunteers, until the study had been completed and all analyses had been performed.

The primary outcome of this study was to assess disturbances of the predominant intestinal microbiota during and after amoxycillin intake in probiotic- and placebotreated subjects using DGGE fingerprinting of PCR-amplified 165 rRNA gene fragments. Secondary outcomes were to assess disturbances by amoxycillin of; 1) the Enterococcus and Bifidobacterium subpopulations in probiotic- and placebo-treated subjects; 2) the predominant intestinal microbiota in subjects who develop AAD compared to those who did not.

Statistical evaluation of changes in quantitative PCR (qPCR) results between groups and within groups during the study period was carried out using linear mixed model analysis. More specifically, a random intercept model with DAY and TREATMENT as fixed factors was applied to qPCR data. Mixed model analysis could not be applied to SIs, as these are the result of a comparison between two time points. For continuous variables, the nonparametric Mann-Whitney U-test was used for comparison between groups (probiotic versus placebo), whereas the nonparametric Wilcoxon signedranked test was used for within-group comparisons. For dichotomous variables, Pearson's $\chi^{2}$ test was applied to test differences between groups, with Fisher Exact Test when necessary.

In previous work diarrhoea-like bowel movements (defined as a defecation frequency $\geq 3$ per day and/or a faecal consistency $\geq 5$ per day, on the Bristol stool form scale, for at least two days) were determined ${ }^{19}$. Here the association between the disruption of the intestinal microbiota (SIS) and the development of diarrhoea-like bowel movements was analyzed.

Data storing and tests were conducted using SPSS version 11.0 (SPSS Inc, Chicago, IL) and a $\mathrm{p}$-value below 0.05 was considered statistically significant. 


\section{Results}

\section{Subjects}

Forty healthy volunteers completed the study, 19 in the probiotic (5 males, 14 females; median age 21 (18-49) years) and 21 in the placebo group (10 males, 11 females; median age 25 (19-56) years). One participant in the probiotic group was found to be allergic to amoxycillin and had to be excluded. The self-reported compliance was $\geq 93 \%$ for antibiotic intake and $\geq 97 \%$ for probiotic/placebo intake. All participants continued their usual diet and no excessive alcohol intake or dieting was reported. One participant in the placebo group and three in the probiotic group incidentally (i.e. maximally twice a week) consumed yoghurt containing L. rhamnosus GG between 14 and 7 days prior to the study. In the probiotic group one other participant incidentally consumed that yoghurt during the first two weeks of the study. Apart from one subject in the probiotic group taking $20 \mathrm{mg}$ omeprazole once daily at day 45 and 46 of the study, no medication potentially affecting the intestinal microbiota was taken during the total study period.

\section{PCR-DGGE analysis of the predominant faecal microbiota}

DGGE analysis of the predominant faecal microbiota showed high inter-individual variation in total bacterial profiles between volunteers and a mean band richness of 19.4 bands at the start of the study (day 0). An example of a DGGE profile is shown in Figure 4.1. No difference in band richness between the probiotic and the placebo group was found throughout the study (Figure 4.2). During amoxycillin intake band richness decreased significantly in both groups and returned back to baseline after cessation of amoxycillin (Figure 4.2).

During amoxycillin intake, low SIs of bacterial fingerprints compared to baseline profiles were observed in both groups (Table 4.1a). No bands corresponding to the probiotic bacteria were observed in the total bacterial profiles. In the probiotic group the SI increased significantly after 35 days, whereas in the placebo group it remained low. Consequently, at day 35 a significantly higher SI was observed in the probiotic group compared to the placebo group. The faecal microbiota in subjects from the probiotic group was also more stable in the entire period after cessation of amoxycillin compared with the placebo group as evidenced by higher SIs between consecutive time intervals (Table 4.1b). 


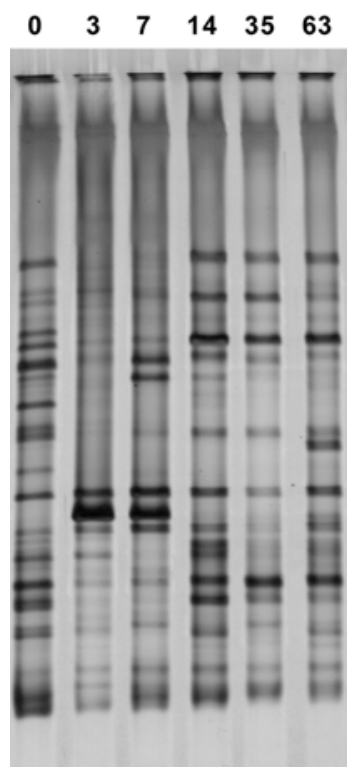

Figure 4.1 PCR-DGGE profile of the total bacterial community (day 0, 3, 14, 35 and 63) of faecal samples obtained from a volunteer in the placebo group suffering from diarrhoea-like bowel movements. Marked disruptions are observed during amoxycillin intake (day 1-7).

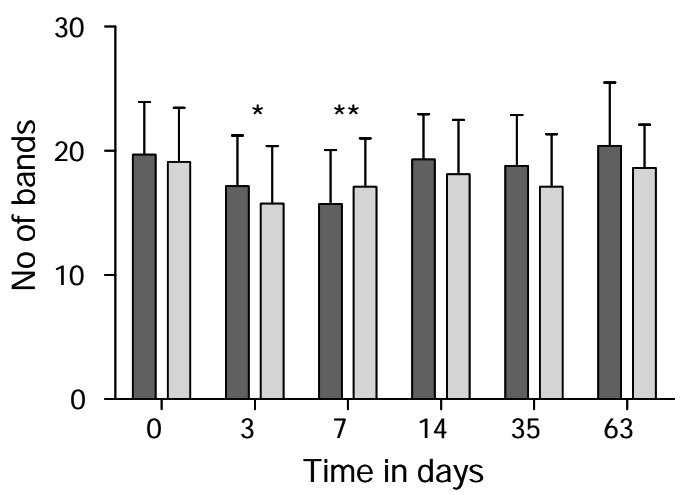

Figure 4.2 Total bacterial band richness (Mean $( \pm S D)$ no of bands) obtained from DGGE profiles of healthy volunteers during (day 1-7) and after amoxycillin intake; $\square=$ probiotic $(n=19)$ and $\square=$ placebo $(n=21)$. *Decrease of richness in placebo group and $* *$ in both groups compared to baseline, $p<0.05$. 
Table 4.1 Median (range) similarity indices of the total bacterial profiles in percentages in the probiotic versus the placebo group compared to baseline (1a) and between consecutive intervals (1b).

\begin{tabular}{lccccc}
\hline a) & \multicolumn{5}{c}{ SI (\%) compared to day 0 (baseline) } \\
\cline { 2 - 5 } & $0-3$ & $0-7$ & $0-14$ & $0-35$ & $0-63$ \\
\hline Probiotic $^{1}(\mathrm{n}=19)$ & $50(20-89)$ & $52(24-78)$ & $56(30-80)$ & $65(38-89)^{*}$ & $61(24-80)$ \\
Placebo $^{2}(\mathrm{n}=21)$ & $59(20-87)$ & $51(16-73)$ & $49(18-75)$ & $48(14-72)$ & $50(14-78)$ \\
\hline b) & \multicolumn{5}{c}{$\mathrm{SI}(\%)$ between consecutive days } \\
\cline { 2 - 5 } & $0-3$ & $3-7$ & $7-14$ & $14-35$ & $35-63$ \\
\hline Probiotic $^{3}(\mathrm{n}=19)$ & $50(20-89)$ & $52(28-86)$ & $52(24-78)$ & $70(44-96)$ & $78(54-93)^{*}$ \\
Placebo $(\mathrm{n}=21)$ & $59(20-87)$ & $65(30-100)$ & $55(24-87)$ & $63(14-88)$ & $66(11-88)$ \\
\hline
\end{tabular}

*between group difference, $p<0.05 ;{ }^{1}$ Within group increase $0-35$ vs. 0-3, 0-7, 0-14, 0-63, $p<0.05 ;{ }^{2}$ Within group decrease $0-7,0-14,0-35,0-63$ vs. $0-3, p<0.05 ;{ }^{3}$ Within group increase $14-35,35-63$ vs. 0-3, 3-7, 7-14, $\mathrm{p}<0.05$.

Subsequently the association between the SIs of the total bacterial profiles during amoxycillin and probiotic intake and the occurrence of diarrhoea-like bowel movements was analyzed. A marked reduction in Sls was observed in the group of volunteers who developed diarrhoea-like bowel movements compared to those who did not, regardless of probiotic intake (Table 4.2).

Table 4.2 Median (range) similarity indices of the total bacterial profiles of volunteers that developed diarrhoea-like bowel movements compared to those who did not.

\begin{tabular}{lccccc}
\hline $\begin{array}{l}\text { Diarrhoea-like bowel } \\
\text { movements }^{a}\end{array}$ & $0-3$ & $0-7$ & $0-14$ & $0-35$ & $0-63$ \\
\hline Yes $(n=24)$ & $49(20-82)^{*}$ & $50(17-67)^{*}$ & $49(18-74)^{*}$ & $50(14-77)^{*}$ & $50(14-78)$ \\
No $(n=14)$ & $69(27-89)$ & $57(32-78)$ & $60(35-80)$ & $65(37-89)$ & $63(24-80)$ \\
\hline
\end{tabular}

${ }^{a}$ Two subjects in the placebo group did not complete the questionnaire. Therefore, no defecation-score could be determined; * between group difference, $p<0.05$

\section{PCR-DGGE analysis of enterococci and bifidobacteria faecal populations}

In addition to the predominant faecal microbiota, two subpopulations were analyzed by DGGE. Profiles of both enterococci (mean number of bands 3.1) and bifidobacteria (mean number of bands 6.9) were less complex than total bacterial profiles. Moreover, $15 \%$ of all samples were Enterococcus negative at the start of the study. The occurrence of specific bands indicative for the probiotic E. faecium W54 was observed in all volunteers during probiotic intake and after cessation decreased to $22 \%$ (one month) and 5\% (two months) (Table 4.3a). Furthermore, the occurrence of one specific band indicative for the probiotic Bifidobacterium strains (all strains migrating at the same position) was observed in $59 \%$ of volunteers during probiotic intake and after cessation decreased to $0 \%$ (one month) and 6\% (two months) of 
volunteers (Table $4.3 \mathrm{~b})$. The bands indicative for the probiotic strains were hardly observed in the placebo group (Table 4.3).

Table 4.3 The occurrence of bands indicative for the probiotic specific strains in the Enterococcus and Bifidobacterium DGGE profiles.

\begin{tabular}{|c|c|c|c|c|c|c|c|}
\hline \multirow[t]{3}{*}{ a) } & Enterococcus & day 0 & day 3 & day 7 & day 14 & day 35 & day 63 \\
\hline & Probiotic $(n=19)$ & $0 \%$ & $90 \%$ & $100 \%$ & $100 \%$ & $22 \%$ & $5 \%$ \\
\hline & Placebo $(n=20)$ & $5 \%$ & $5 \% *$ & $10 \% *$ & $5 \% *$ & $0 \% *$ & $0 \%$ \\
\hline \multirow[t]{3}{*}{ b) } & Bifidobacterium & day 0 & day 3 & day 7 & day 14 & day 35 & day 63 \\
\hline & Probiotic $(n=17)$ & $6 \%$ & $47 \%$ & $59 \%$ & $41 \%$ & $0 \%$ & $6 \%$ \\
\hline & Placebo $(n=19)$ & $5 \%$ & $5 \% *$ & $5 \% *$ & $0 \% *$ & $5 \%$ & $0 \%$ \\
\hline
\end{tabular}

*between group difference, $p<0.05$

During amoxycillin intake, low SIs of the Enterococcus DGGE profiles were observed in both groups, which remained low two months after cessation of intake. Profiles of subjects in the probiotic group revealed little variation during probiotic intake, indicated by a high SI between consecutive time intervals. Moreover SIs remained higher in the probiotic group even after cessation of probiotic intake (Table 4.4a, b).

Table 4.4 Median (range) similarity indices of the Enterococcus population in percentages in the probiotic versus the placebo group compared to baseline (4a) and between consecutive time intervals (4b).

\begin{tabular}{lccccc}
\hline a) & \multicolumn{5}{c}{ SI (\%) compared to day 0 (baseline) } \\
\cline { 2 - 5 } & $0-3$ & $0-7$ & $0-14$ & $0-35$ & $0-63$ \\
\hline Probiotic $^{\text {a }}(\mathrm{n}=18)$ & $32(07-77)$ & $32(07-72)$ & $28(06-66)^{*}$ & $39(02-93)$ & $47(06-91)$ \\
Placebo $^{\text {b }}(\mathrm{n}=19)$ & $45(09-97)$ & $47(10-96)$ & $56(14-94)$ & $44(08-73)$ & $28(06-93)$ \\
\hline b) & \multicolumn{5}{c}{$\mathrm{SI}(\%)$ between consecutive days } \\
\cline { 2 - 5 } & $0-3$ & $3-7$ & $7-14$ & $14-35$ & $35-63$ \\
\hline Probiotic $^{c}(\mathrm{n}=18)$ & $32(07-77)$ & $93(63-99)^{*}$ & $96(74-99)^{*}$ & $58(16-93)$ & $62(08-96)^{*}$ \\
Placebo $^{d}(\mathrm{n}=19)$ & $45(09-97)$ & $43(07-93)$ & $56(11-96)$ & $44(14-84)$ & $34(05-80)$ \\
\hline
\end{tabular}

*between group difference, $\mathrm{p}<0.05$; ${ }^{a}$ Within group increase 0-63 vs. 0-14, $\mathrm{p}<0.05 ;{ }^{\mathrm{b}}$ Within group decrease $0-63$ vs. $0-3,0-7,0-14$ and $0-35$ vs. $0-14, p<0.05 ;{ }^{c}$ Within group increase $3-7,7-14,14-35,35-63$ vs. $0-3$ and decrease $14-35,35-63$ vs. $3-7,7-14, p<0.05 ;{ }^{d}$ Within group decrease $35-63$ vs. $7-14, p<0.05$.

For both groups low SIs of the bifidobacteria DGGE profiles was also found during amoxycillin intake, but no effect of probiotic intake was observed (Table 4.5a, b). 
Table 4.5 Median (range) similarity indices of the Bifidobacterium population in percentages in the probiotic versus the placebo group compared to baseline (5a) and between consecutive time intervals (5b).

\begin{tabular}{lccccc}
\hline a) & \multicolumn{5}{c}{ SI (\%) compared to day 0 (baseline) } \\
\cline { 2 - 5 } & $0-3$ & $0-7$ & $0-14$ & $0-35$ & $0-63$ \\
\hline Probiotic $^{\text {a }}(\mathrm{n}=17)$ & $80(0-100)$ & $53(0-100)$ & $78(0-98)$ & $74(0-96)$ & $57(0-96)$ \\
Placebo $^{\text {( }}(\mathrm{n}=19)$ & $67(0-100)$ & $50(0-100)$ & $72(0-100)$ & $76(0-100)$ & $73(0-100)$ \\
\hline b) & \multicolumn{5}{c}{$\mathrm{SI}(\%)$ between consecutive days } \\
\cline { 2 - 5 } & $0-3$ & $3-7$ & $7-14$ & $14-35$ & $35-63$ \\
\hline Probiotic $^{c}(\mathrm{n}=17)$ & $80(0-100)$ & $67(29-100)$ & $63(22-96)$ & $85(45-100)$ & $91(0-100)$ \\
Placebo $^{d}(\mathrm{n}=19)$ & $67(0-100)$ & $67(17-100)$ & $53(0-100)$ & $77(22-100)$ & $88(43-100)$ \\
\hline
\end{tabular}

No significant between group difference; ${ }^{a}$ Within group decrease 0-7 vs. 0-3, 0-35, 0-63, $p<0.05 ;{ }^{b}$ Within group decrease 0-7 vs. 0-3, 0-14, 0-35, 0-63, $\mathrm{p}<0.05 ;{ }^{c}$ Within group increase 14-35 vs. 3-7, 7-14, $p<0.05 ;{ }^{d}$ Within group increase $35-63$ vs. SI 0-3, 3-7, 7-14 and 14-35 vs. 3-7, 7-14, p<0.05.

\section{Quantitative PCR}

No differences in total bacteria, lactobacilli or bifidobacteria were observed between the probiotic and the placebo group. Within both groups, a significant decrease of bifidobacteria was found during amoxycillin intake, which increased again after cessation of amoxycillin. A similar tendency, though less pronounced (no significant difference compared to baseline), was observed in both groups for total bacteria (Figure 4.3). During amoxycillin intake a small decrease in lactobacilli was observed in the placebo group, which significantly increased again after cessation. In the probiotic group a significant increase in lactobacilli was observed during probiotic intake (Figure 4.3). To adjust for possible differences in faecal consistency, data were also analyzed expressed as copies of DNA per mg faecal protein (data not shown) but no difference was observed compared to the unadjusted data. 

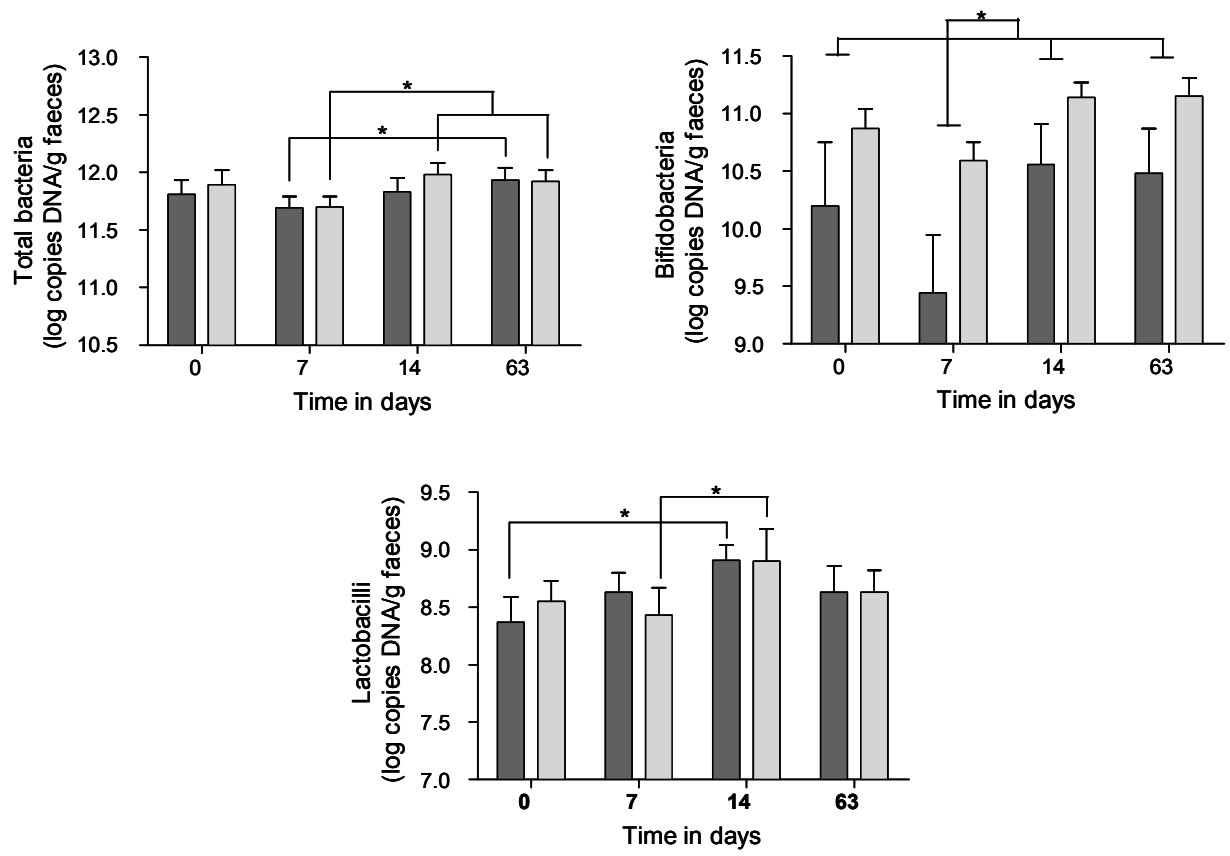

Figure 4.3 Quantitative PCR results expressed as mean ( \pm SEM) log copies $16 \mathrm{~S}$ rRNA gene/gram faeces; $\square=$ probiotic $(n=17)$ and $\square=$ placebo $(n=20), * p<0.05$.

\section{Discussion}

In the present double-blind placebo-controlled randomized study, cultureindependent DGGE profiling of PCR-amplified 16S rRNA gene fragments was used to investigate the effect of amoxycillin intake and the effect of a multispecies probiotic on the richness and temporal stability of the intestinal microbiota. Low similarity indices (SIS) and a low band number indicated that the stability and richness of the predominant faecal microbiota were markedly affected by amoxycillin intake and two months after cessation had not yet returned to its initial profile. However, when a multispecies probiotic was given during and after amoxycillin intake, a significantly better restoration of the microbiota was achieved after one month. Markedly lower SIs were observed in the group of volunteers who developed diarrhoea-like bowel movements compared to those who did not.

Studies have shown that antibiotic treatment has an effect on the composition of the intestinal microbiota ${ }^{38}$. However, it is assumed that the microbiota is only temporarily disturbed, returning to its original composition 1-2 months after cessation. In the 
present study, amoxycillin intake strongly affected the stability of the predominant faecal microbiota when analyzed by PCR-DGGE. A low mean SI was still observed two months after cessation of amoxycillin intake, indicating that short term antibiotic intake can cause medium-term changes in the microbiota composition. A comparable finding in the Bacteroides community was recently observed by Jernberg et al. after clindamycin exposure ${ }^{8}$. In contrast to the present study, however, they observed only short-term disturbances in total bacterial profiles. We readily acknowledge that to support the significance of the observed instability it would have been useful to also have an analysis of SIs within and between the groups 1-2 weeks before the start of amoxycillin intake. However, though intra-individual fluctuations have been reported, we know from literature that in healthy humans, such as the individuals that participated in the current trial, the faecal microbiota is host specific and relatively stable over time $(\mathrm{SIs}>80 \%)^{1-6}$.

After cessation of amoxycillin the SIs increased in the probiotic group and, when analyzing Sls between consecutive time intervals, the faecal microbiota remained more stable in this group. Both results suggest that probiotics have a restoring and stabilizing impact on the microbiota. A similar observation was made by Kajander et al., when a multispecies probiotic was given to IBS patients ${ }^{39}$. The DGGE results in the present study also demonstrated that during amoxycillin treatment a lower band number was observed in both groups. Even though microbial band richness returned to pre-treatment level after cessation of amoxycillin intake, Sls remained low, suggesting a shift in microbiota composition. Higher Sls in the probiotic group compared to the placebo group one and two months after cessation of amoxycillin suggest a less pronounced compositional shift in the probiotic group.

The usefulness of culture-independent profiling by DGGE in the analysis of the gastrointestinal microbiota has already been clearly demonstrated ${ }^{40,41}$. However, this method also has some limitations. It is semi-quantitative and cannot distinguish between viable and non-viable bacteria, unless combined with specific approaches ${ }^{42}$. In addition, DGGE provides a description of predominant bacterial populations, representing at least $1 \%$ of the total microbiota ${ }^{43}$. Insight into the effect of antibiotics on subdominant populations and their ability to restore may also be very relevant, but can only be achieved by combining DGGE with group-specific PCR-amplification ${ }^{4,25}$. The recently developed Human Intestinal Tract (HIT) Chip, a micro-array designed for comprehensive and high throughput analyses of the human intestinal microbiota ${ }^{44}$, could provide such information in future trials.

E. faecium, bifidobacteria and lactobacilli are present in the multispecies probiotic used in the present study, however, cultivation-dependent analyses revealed only significant changes in abundance of enterococci. Therefore, to test the hypothesis that probiotic administration might affect composition rather than abundance, group specific primers were applied for the detection of enterococci and bifidobacteria populations by PCR-DGGE. Using a nested PCR approach, Enterococcus spp still remained undetectable in $15 \%$ op the samples, confirming the low abundance as 
observed by cultivation ${ }^{19}$, as well as previous reports that not all faecal samples yield detectable Enterococcus-specific DGGE profiles ${ }^{4}$. In addition, the band richness was very low, which has to be kept in mind when interpreting the results. During probiotic intake (i.e. $1 \times 10^{9}$ E. faecium W54 daily) four specific bands indicative of E. faecium W54 were observed in faecal samples of all healthy volunteers. The occurrence of multiple bands for single isolates has been observed before, and can be attributed to the presence of multiple, non-identical rRNA genes in bacterial genomes ${ }^{45}$. Previously we already demonstrated the viable recovery of the same E. faecium strain from faeces after probiotic intake ${ }^{19}$. Furthermore, in $78 \%$ of volunteers, these four bands could no longer be detected at day 35 , which is in line with previous studies demonstrating that probiotic bacteria are only transiently present in the Gl tract ${ }^{46}$. Nevertheless, the fact that in a small number (i.e. $22 \%$ ) of volunteers the $E$. faecium strain could still be detected four weeks after cessation of probiotic intake, is also in line with previous reports of more sustainable colonization, though this was observed only in a subgroup of volunteers and in low numbers (<log $4 \mathrm{cfu} / \mathrm{g})^{47-49}$.

Next to Bacteroides and Eubacterium, the genus Bifidobacterium is most commonly found in the intestinal microbiota and normally shows little temporal variation ${ }^{4}$. However, amoxycillin intake caused strong variation in the Bifidobacterium subpopulation, an observation also made by others ${ }^{16,50}$. A specific band representing B. bifidum $\mathrm{W} 23, B$. lactis $\mathrm{W} 18$ and $B$. lactis $\mathrm{W} 51$ in the multispecies product could be observed in only $59 \%$ of the volunteers taking probiotic. It has previously been observed that different species within the bifidobacteria can produce bands with the same migration behaviour in DGGE analysis ${ }^{31}$. The probiotic bifidobacteria might have been present in all volunteers but probably could not be visualized by DGGE, as a daily consumption of $3 \times 10^{9} \mathrm{cfu}$ bifidobacteria may not account for at least $1 \%$ of the population in a subset of volunteers.

In addition to qualitative data on microbiota composition obtained by DGGE, quantitative analysis was performed by qPCR to complement previous cultivationdependent analyses ${ }^{19}$. In line with the DGGE results, the number of bifidobacteria was significantly affected in both groups. High susceptibility of bifidobacteria to broadspectrum antibiotics has been observed before ${ }^{51-54}$. During amoxycillin intake a decrease was observed in the total number of faecal lactobacilli in the placebo but not in the probiotic group, which was also noted by conventional cultivation ${ }^{19}$. Similar results were observed by Plummer et al. during Helicobacter pylori eradication ${ }^{16}$. Apart from the stabilization of the lactobacilli population in the probiotic group, no further effect of probiotic intake could be observed, though the intake of bifidobacteria and lactobacilli usually results in a transient rise in both populations ${ }^{40,46,55}$. In the present study, the daily consumption of $10^{9} \mathrm{cfu}$ bifidobacteria or lactobacilli, considering a mean faecal volume of $100 \mathrm{~g}$ per day, would account for a maximum number of $10^{7} \mathrm{cfu}$ of these bacteria per gram faeces. However, the mean numbers before the intake of the multispecies probiotic was 
already $10^{8} \mathrm{cfu} / \mathrm{g}$ faeces or more, explaining why the additional probiotic bacteria could not be detected.

It is well documented that antibiotic intake can cause diarrhoea, probably due to a disruption of the intestinal microbiota. In previous work, less volunteers suffering from diarrhoea-like bowel movements were observed in the probiotic (48\%) versus the placebo $(79 \%)$ group $(p<0.05)^{19}$. Moreover, in this study, the mean Sls were markedly lower in those volunteers who developed diarrhoea-like bowel movement compared to those who did not. This supports the hypothesis that a lower stability of the predominant intestinal microbiota (i.e. more disruption) is related to a higher chance of developing AAD.

In the present study, probiotics seemed to restore and stabilize the predominant faecal microbiota and earlier also a decrease in diarrhoea-like bowel movements by probiotic intake was observed ${ }^{19}$. However, also in the probiotic group some subjects still developed diarrhoea-like bowel movements, which is in accordance with a metaanalysis showing that probiotics have a pooled relative risk of 0.43 for preventing $A A D^{12}$. In future studies it would be very interesting to identify host-related, microbiota-related or environmental risk factors to characterize subjects at risk of developing $A A D$ and who would benefit from probiotic intake. Alteration of the intestinal microbiota due to a gastrointestinal infection or treatment with antibiotics can induce or exacerbate $\mathrm{IBS}^{56}$, pointing toward a possible role of the intestinal microbiota. It would therefore be interesting to see whether especially those subjects with a markedly and long-term disruption of the intestinal microbiota are prone to develop IBS.

In conclusion, the present study demonstrates that short-term intake of amoxycillin strongly affects the diversity and stability of the faecal microbiota over a prolonged period of time in certain individuals, which can be influenced by the intake of a multispecies probiotic contributing to a restoration of the faecal microbiota more similar to the pre-antibiotic state. Moreover the association between the disruption of the intestinal microbiota and the development of diarrhoea-like bowel movements contributes to understanding the patho-physiology of AAD. 


\section{References}

1. Gibson GR, Roberfroid MB. Dietary modulation of the human colonic microbiota: introducing the concept of prebiotics. J Nutr. 1995;125:1401-12.

2. Maukonen J, Matto J, Satokari R, Soderlund H, Mattila-Sandholm T, Saarela M. PCR DGGE and RT-PCR DGGE show diversity and short-term temporal stability in the Clostridium coccoides-Eubacterium rectale group in the human intestinal microbiota. FEMS Microbiol Ecol. 2006;58:517-28.

3. Rajilic-Stojanovic M, Smidt H, de Vos WM. Diversity of the human gastrointestinal tract microbiota revisited. Environ Microbiol. 2007;9:2125-36.

4. Vanhoutte T, Huys G, De brandt E, Swings J. Temporal stability analysis of the microbiota in human feces by denaturing gradient gel electrophoresis using universal and group-specific 16S rRNA gene primers. FEMS Microbiol Ecol. 2004;48:437-46.

5. Zoetendal EG, Akkermans AD, De Vos WM. Temperature gradient gel electrophoresis analysis of $16 \mathrm{~S}$ rRNA from human fecal samples reveals stable and host-specific communities of active bacteria. Appl Environ Microbiol. 1998;64:3854-9.

6. Zoetendal EG, Rajilic-Stojanovic M, de Vos WM. High-throughput diversity and functionality analysis of the gastrointestinal tract microbiota. Gut. 2008;57:1605-15.

7. Gustafsson A, Berstad A, Lund-Tonnesen S, Midtvedt T, Norin E. The effect of faecal enema on five microflora-associated characteristics in patients with antibiotic-associated diarrhoea. Scand J Gastroenterol. 1999;34:580-6.

8. Jernberg C, Lofmark S, Edlund C, Jansson JK. Long-term ecological impacts of antibiotic administration on the human intestinal microbiota. Isme J. 2007;1:56-66.

9. Cremonini F, Di Caro S, Nista EC, Bartolozzi F, Capelli G, Gasbarrini G, Gasbarrini A. Meta-analysis: the effect of probiotic administration on antibiotic- associated diarrhoea. Aliment Pharmacol Ther. 2002;16:1461-7.

10. D'Souza AL, Rajkumar C, Cooke J, Bulpitt CJ. Probiotics in prevention of antibiotic associated diarrhoea: meta- analysis. BMJ. 2002;324:1361.

11. Hickson M, D'Souza AL, Muthu N, Rogers TR, Want S, Rajkumar C, Bulpitt CJ. Use of probiotic Lactobacillus preparation to prevent diarrhoea associated with antibiotics: randomised double blind placebo controlled trial. BMJ. 2007;335:80.

12. McFarland LV. Meta-analysis of probiotics for the prevention of antibiotic associated diarrhea and the treatment of Clostridium difficile disease. Am J Gastroenterol. 2006;101:812-22.

13. Timmerman HM, Koning CJ, Mulder L, Rombouts FM, Beynen AC. Monostrain, multistrain and multispecies probiotics--A comparison of functionality and efficacy. Int J Food Microbiol. 2004;96: 219-33.

14. Jernberg C, Sullivan A, Edlund C, Jansson JK. Monitoring of antibiotic-induced alterations in the human intestinal microflora and detection of probiotic strains by use of terminal restriction fragment length polymorphism. Appl Environ Microbiol. 2005;71:501-6.

15. Madden JA, Plummer SF, Tang J, Garaiova I, Plummer NT, Herbison M, Hunter JO, Shimada T, Cheng L, Shirakawa T. Effect of probiotics on preventing disruption of the intestinal microflora following antibiotic therapy: a double-blind, placebo-controlled pilot study. Int Immunopharmacol. 2005;5:1091-7.

16. Plummer SF, Garaiova I, Sarvotham T, Cottrell SL, Le Scouiller S, Weaver MA, Tang J, Dee P, Hunter J. Effects of probiotics on the composition of the intestinal microbiota following antibiotic therapy. Int J Antimicrob Agents. 2005;26:69-74.

17. Sullivan A, Barkholt L, Nord CE. Lactobacillus acidophilus, Bifidobacterium lactis and Lactobacillus F19 prevent antibiotic-associated ecological disturbances of Bacteroides fragilis in the intestine. J Antimicrob Chemother. 2003;52:308-11.

18. Sullivan A, Johansson A, Svenungsson B, Nord CE. Effect of Lactobacillus F19 on the emergence of antibiotic-resistant microorganisms in the intestinal microflora. J Antimicrob Chemother. 2004;54:791-7.

19. Koning CJ, Jonkers DM, Stobberingh EE, Mulder L, Rombouts FM, Stockbrugger RW. The Effect of a Multispecies Probiotic on the Intestinal Microbiota and Bowel Movements in Healthy Volunteers Taking the Antibiotic Amoxycillin. Am J Gastroenterol. 2007;102:1-12. 
20. Tannock GW. Analysis of the intestinal microflora using molecular methods. Eur J Clin Nutr. 2002;56:S44-9.

21. Zoetendal EG, Vaughan EE, de Vos WM. A microbial world within us. Mol Microbiol. 2006;59:1639-50.

22. Matsuki T, Watanabe K, Fujimoto J, Miyamoto Y, Takada T, Matsumoto K, Oyaizu H, Tanaka R. Development of 16S rRNA-gene-targeted group-specific primers for the detection and identification of predominant bacteria in human feces. Appl Environ Microbiol. 2002;68: 5445-51.

23. Matsuki T, Watanabe K, Fujimoto J, Takada T, Tanaka R. Use of 16S rRNA gene-targeted group-specific primers for real-time PCR analysis of predominant bacteria in human feces. Appl Environ Microbiol. 2004;70:7220-8.

24. Muyzer G, de Waal EC, Uitterlinden AG. Profiling of complex microbial populations by denaturing gradient gel electrophoresis analysis of polymerase chain reaction-amplified genes coding for $16 \mathrm{~S}$ rRNA. Appl Environ Microbiol. 1993;59:695-700.

25. Vaughan EE, Heilig HG, Ben-Amor K, de Vos WM. Diversity, vitality and activities of intestinal lactic acid bacteria and bifidobacteria assessed by molecular approaches. FEMS Microbiol Rev. 2005;29:477-90.

26. Rochet V, Rigottier-Gois L, Sutren M, Krementscki MN, Andrieux C, Furet JP, Tailliez P, Levenez F, Mogenet A, Bresson JL, Meance S, Cayuela C, Leplingard A, Dore J. Effects of orally administered Lactobacillus casei DN-114 001 on the composition or activities of the dominant faecal microbiota in healthy humans. Br J Nutr. 2006;95:421-9.

27. Vanhoutte T, De Preter V, De Brandt E, Verbeke K, Swings J, Huys G. Molecular monitoring of the fecal microbiota of healthy human subjects during administration of lactulose and Saccharomyces boulardii. Appl Environ Microbiol. 2006;72:5990-7.

28. De La Cochetiere MF, Durand T, Lepage P, Bourreille A, Galmiche JP, Dore J. Resilience of the dominant human fecal microbiota upon short-course antibiotic challenge. J Clin Microbiol. 2005;43:5588-92.

29. Nubel U, Engelen B, Felske A, Snaidr J, Wieshuber A, Amann RI, Ludwig W, Backhaus H. Sequence heterogeneities of genes encoding $16 \mathrm{~S}$ rRNAs in Paenibacillus polymyxa detected by temperature gradient gel electrophoresis. J Bacteriol. 1996;178:5636-43.

30. Sousa DZ, Pereira MA, Stams AJ, Alves MM, Smidt H. Microbial communities involved in anaerobic degradation of unsaturated or saturated long-chain fatty acids. Appl Environ Microbiol. 2007;73:1054-64.

31. Satokari RM, Vaughan EE, Akkermans AD, Saarela M, de Vos WM. Bifidobacterial diversity in human feces detected by genus-specific PCR and denaturing gradient gel electrophoresis. Appl Environ Microbiol. 2001;67:504-13.

32. Sanguinetti CJ, Dias Neto E, Simpson AJ. Rapid silver staining and recovery of PCR products separated on polyacrylamide gels. Biotechniques. 1994;17:914-21.

33. Konstantinov SR, Zhu W-Y, Williams BA, Tamminga S, de Vos WM, Akkermans ADL. Effect of fermentable carbohydrates on faecal bacterial communities as revealed by DGGE analysis of $16 \mathrm{~S}$ rDNA. FEMS Microbiol Ecol. 2003;43:225-35.

34. Possemiers S, Verthe K, Uyttendaele S, Verstraete W. PCR-DGGE-based quantification od stability of the microbial community in a stimulator of the human intestinal microbial ecosystem. FEMS Microbiol Ecol. 2004;49:495-507.

35. Suzuki MT, Taylor LT, DeLong EF. Quantitative analysis of small-subunit rRNA genes in mixed microbial populations via 5'-nuclease assays. Appl Environ Microbiol. 2000;66: 4605-14.

36. Fuentes S, Egert M, Jimenez-Valera M, Monteoliva-Sanchez M, Ruiz-Bravo A, Smidt H. A strain of Lactobacillus plantarum affects segmented filamentous bacteria in the intestine of immunosuppressed mice. FEMS Microbiol Ecol. 2008;63:65-72.

37. Byun R, Nadkarni MA, Chhour KL, Martin FE, Jacques NA, Hunter N. Quantitative analysis of diverse Lactobacillus species present in advanced dental caries. J Clin Microbiol. 2004;42:3128-36.

38. Sullivan A, Edlund C, Nord CE. Effect of antimicrobial agents on the ecological balance of human microflora. Lancet Infect Dis. 2001;1:101-14.

39. Kajander K, Myllyluoma E, Rajilic-Stojanovic M, Kyronpalo SS, Rasmussen M, Jarvenpaa SS, Zoetendal EG, de Vos WM, Vapaatalo H, Korpela R. Clinical trial: multispecies probiotic supplementation alleviates the symptoms of IBS and stabilises intestinal microbiota. Aliment Pharmacol Ther. 2007;27:48-57. 
40. Tannock GW, Munro K, Harmsen HJ, Welling GW, Smart J, Gopal PK. Analysis of the fecal microflora of human subjects consuming a probiotic product containing Lactobacillus rhamnosus DR20. Appl Environ Microbiol. 2000;66:2578-88.

41. Zoetendal EG, von Wright A, Vilpponen-Salmela T, Ben-Amor K, Akkermans AD, de Vos WM. Mucosaassociated bacteria in the human gastrointestinal tract are uniformly distributed along the colon and differ from the community recovered from feces. Appl Environ Microbiol. 2002;68:3401-7.

42. Ben-Amor K, Heilig H, Smidt H, Vaughan EE, Abee T, de Vos WM. Genetic diversity of viable, injured, and dead fecal bacteria assessed by fluorescence-activated cell sorting and 16S rRNA gene analysis. Appl Environ Microbiol. 2005;71:4679-89.

43. Muyzer G, Smalla K. Application of denaturing gradient gel electrophoresis (DGGE) and temperature gradient gel electrophoresis (TGGE) in microbial ecology. Antonie Van Leeuwenhoek. 1998;73:127-41.

44. Rajilic-Stojanovic M, Heilig HG, Molenaar D, Kajander K, Surakka A, Smidt H, de Vos WM. Development and application of the human intestinal tract chip, a phylogenetic microarray: analysis of universally conserved phylotypes in the abundant microbiota of young and elderly adults. Environ Microbiol. 2009.

45. Klappenbach JA, Saxman PR, Cole JR, Schmidt TM. rrndb: the Ribosomal RNA Operon Copy Number Database. Nucleic Acids Res. 2001;29:181-4.

46. Goossens D, Jonkers D, Russel M, Stobberingh E, Van Den Bogaard A, Stockbrügger R. The effect of Lactobacillus plantarum $299 \mathrm{v}$ on the bacterial composition and metabolic activity in faeces of healthy volunteers: a placebo-controlled study on the onset and duration of effects. Aliment Pharmacol Ther. 2003;18:495-505.

47. Collins JK, Dunne C, Murphy L, Morrissey D, O'Mahony L, O'Sullivan E, Fitzgerald G, Kiely B, O'Sullivan GC, Marteau P, Shanahan F. A randomised controlled trial of a probiotic Lactobacillus strain in healthy adults: assessment of its delivery, transit and influence on microbial flora and enteric immunity. Microbial Ecol Health Dis. 2002;14:81-9.

48. Fujiwara S, Seto Y, Kimura A, Hashiba H. Establishment of orally-administered Lactobacillus gasseri SBT2055SR in the gastrointestinal tract of humans and its influence on intestinal microflora and metabolism. J Appl Microbiol. 2001;90:343-52.

49. Fujiwara S, Seto $\mathrm{Y}$, Kimura A, Hashiba H. Intestinal transit of an orally administered streptomycinrifampicin-resistant variant of Bifidobacterium longum SBT2928: its long-term survival and effect on the intestinal microflora and metabolism. J Appl Microbiol. 2001;90: 43-52.

50. Adamsson I, Nord CE, Lundquist P, Sjostedt S, Edlund C. Comparative effects of omeprazole, amoxycillin plus metronidazole versus omeprazole, clarithromycin plus metronidazole on the oral, gastric and intestinal microflora in Helicobacter pylori-infected patients. J Antimicrob Chemother. 1999;44:629-40.

51. Ammor MS, Florez AB, Mayo B. Antibiotic resistance in non-enterococcal lactic acid bacteria and bifidobacteria. Food Microbiol. 2007;24:559-70.

52. Brismar B, Edlund C, Nord CE. Impact of cefpodoxime proxetil and amoxicillin on the normal oral and intestinal microflora. Eur J Clin Microbiol Infect Dis. 1993;12:714-9.

53. Lode H, Von der Hoh N, Ziege S, Borner K, Nord CE. Ecological effects of linezolid versus amoxicillin/clavulanic acid on the normal intestinal microflora. Scand J Infect Dis. 2001;33:899-903.

54. Woodmansey EJ, McMurdo ME, Macfarlane GT, Macfarlane S. Comparison of compositions and metabolic activities of fecal microbiotas in young adults and in antibiotic-treated and non-antibiotictreated elderly subjects. Appl Environ Microbiol. 2004;70:6113-22.

55. Link-Amster H, Rochat F, Saudan KY, Mignot O, Aeschlimann JM. Modulation of a specific humoral immune response and changes in intestinal flora mediated through fermented milk intake. FEMS Immunol Med Microbiol. 1994;10:55-63.

56. Spiller R, Campbell E. Post-infectious irritable bowel syndrome. Curr Opin Gastroenterol. 2006;22: 13-7. 



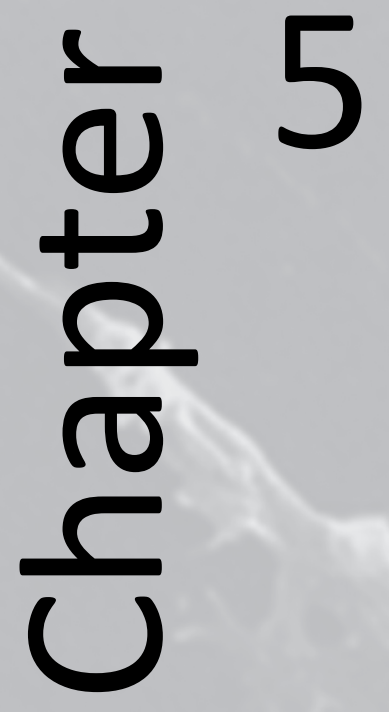




\section{The effect of a multispecies probiotic on biomarkers of the mucosal and systemic immune system in healthy volunteers treated with amoxycillin}

Catherina J.M. Koning, Daisy M.A.E. Jonkers, Harro M. Timmerman, Rene Lutter, Theo A. Out, Ellen E. Stobberingh, Reinhold W Stockbrügger. 


\section{Abstract}

Both probiotics and antibiotics can affect the immune system directly or indirectly, via modulation of the intestinal microbiota. Most evidence comes from in vitro studies and effects in healthy individuals are not clear. Therefore, a double-blind, placebo-controlled study was conducted to assess the influence of amoxycillin and a multispecies probiotic on components of both the systemic and mucosal immune system in healthy volunteers. Forty healthy volunteers were given amoxycillin $(1 \mathrm{~g} /$ day $)$ for 7 days and $10 \mathrm{~g}$ of a multispecies probiotic $\left(10^{10} \mathrm{cfu} /\right.$ day) or placebo for 14 days, starting simultaneously with amoxycillin intake. Blood was collected at day 0, 7, 14 and 63, and sputum at day 0 and 7 for leukocyte counts, immunoglobulins, inflammation markers and ex vivo cytokine production in stimulated whole blood. Probiotic intake did not alter the systemic and mucosal biomarkers apart from a significant increase of serum slgA two months after cessation of amoxycillin intake. In the systemic compartment amoxycillin resulted in lower IL-4, IL-6, IL-13 and IFN- $\gamma$ and enhanced IL-10 production. Although no differences were observed between both groups, probiotic intake resulted in a further decrease of IL- 4 and IL-13 and a less pronounced increase of IL-10. In healthy volunteers a short course of amoxycillin is able to induce in- and ex vivo immunological changes, which are further affected by probiotic intake and may result from a disturbance of the intestinal microbiota. 


\section{Introduction}

Antibiotics are routinely prescribed to treat infections. Apart from their antimicrobial effect, which can result in a disturbance of the intestinal microbiota, antibiotics are also reported to affect the immune system. The effects of antimicrobial agents on the immune system are heterogeneous and very much dependent on the type of antibiotic used, and include alteration of phagocytosis, chemotaxis, endotoxin release, cytokine and antibody production and delayed type hypersensitivity reaction ${ }^{1}$. Several antibiotics directly affect immune function, either by stimulation or suppression. Effects can also be indirect via a disturbance of the intestinal microbiota. It is well recognised that the commensal intestinal microbiota influences the mucosal as well as the systemic immunity and that there is an active "cross-talk" between the intestinal microbiota and the immune system ${ }^{2}$. Commensal bacteria have an important role in the development and normal functioning of the host's immune system which in its turn elicits different responses to commensals and pathogens ${ }^{3-5}$. Disturbance of this intestinal microbiota due to antibiotics can be associated with local inflammation and a disturbed immunological functioning of the host ${ }^{6-8}$. These immunological consequences are not restricted to the gut associated lymphoid tissue (GALT) and may extend to other mucosal sites, such as the bronchus associated lymphoid tissue (BALT) and to the systemic compartment ${ }^{9}$.

Probiotics can affect the composition of the intestinal microbiota and they have been applied to stabilise and restore microbial disturbances caused by antibiotic use. Another important property attributed to probiotics is their ability to stimulate both specific and non-specific components of the immune system ${ }^{10,11}$. Although it is not precisely clear which mechanisms are involved in this immunomodulation, probiotics can influence signal transduction pathways and gene expression in epithelial and immune cells in a strain-dependent way ${ }^{12}$. Many probiotic studies report on in vitro data. The limitation of this lies in the extrapolation of the results to in vivo benefits, which do not always correlate with in vitro effects. It has recently been demonstrated that multispecies probiotics, combining a variety of bacterial properties, are expected to be more effective as they may complement each others' effect through synergism and/or symbiosis ${ }^{13}$. However, it has to be taken into account that certain strains can also have a cross-regulatory effect. Therefore, selecting the right combination of strains for the prevention and treatment of a specific disease is of great importance. The aim of the present study was to assess the influence of a multispecies probiotic on components of both systemic and the mucosal immune system in healthy volunteers taking amoxycillin. For this purpose peripheral blood was studied for the systemic compartment and sputum for the mucosal compartment (not directly in contact with the probiotic applied) in order to assess parameters of the innate and the acquired immunity as well as the Th1/Th2 balance. 


\section{Materials and methods}

\section{Subjects and study design}

The design and the clinical details of the study have been described elsewhere ${ }^{14}$. Briefly, forty-one healthy volunteers between 18-65 years of age were enrolled in the study. All volunteers received $500 \mathrm{mg}$ amoxycillin twice daily for 7 days and were randomized to receive either 5 gram of a multispecies probiotic or placebo twice daily for 14 days starting simultaneously with antibiotic intake. The multispecies probiotic (Ecologic $\left.{ }^{\circ} A A D\right)$ and the placebo were kindly provided by Winclove Bio Industries, Amsterdam, the Netherlands. Ecologic ${ }^{\circ}$ AAD consists of 10 different bacterial species at $10^{8}$ colony forming units (CFU)/g each (Bifidobacterium bifidum W23, B. lactis W18, B. lactis W51 (formerly classified as B. longum), Enterococcus faecium W54, Lactobacillus acidophilus W37 and W55, L. paracasei W20, L. plantarum W62, L. rhamnosus W71 and L. salivarius W24), 5\% mineral mix and 15\% Raftilose Synergy1. All individual probiotic strains carry the European Union Qualified Presumption of Safety (QPS) ${ }^{15}$ and the study products (probiotic and placebo) were prepared under Good Manufacturing Practice (GMP) ${ }^{16}$ conditions. Both probiotic and placebo were packaged in identical, numbered sachets. The placebo product, indistinguishable in colour, smell and taste, also contained 5\% mineral mix and $15 \%$ Raftilose Synergy1 but contained extra cornstarch instead of the probiotic bacteria. The total duration of the intervention and follow-up period per volunteer was 63 days. Blood samples were collected at day 0, 7, 14 and 63. In addition, sputum inductions were performed at day 0 and 7 .

The study was approved by the Medical Ethics Committee of the University Hospital Maastricht, the Netherlands and all volunteers gave written informed consent.

\section{Blood samples}

Peripheral blood samples were collected in heparinised, EDTA or serum Vacutainers (Becton Dickinson, Plymouth, UK). Total and differential leukocyte counts were performed in EDTA-blood using a Coulter Counter and a Coulter VCS differential counter (Beckman Coulter, USA). Serum samples were obtained after $1 \mathrm{~h}$ of clotting at room temperature and centrifugation for $10 \mathrm{~min}$ at $1200 \mathrm{~g}$. Plasma samples were obtained by immediate centrifugation of EDTA-blood for $10 \mathrm{~min}$ at $1200 \mathrm{~g}$ at room temperature. Serum and plasma samples were frozen in aliquots at $-80^{\circ} \mathrm{C}$ until subsequent analysis.

\section{Sputum induction and processing}

Before sputum induction, all subjects were pre-treated with $200 \mu \mathrm{g}$ salbutamol administered via an inhalatory chamber. Subsequently subjects inhaled $4.5 \%$ hypertonic saline nebulized via an ultrasonic nebulizer (Ultra-Neb 2000; De Vilbiss, 
Somerset, PA) during three 7-minute periods. ${ }^{17}$ After each 7-minute period subjects blew their nose and rinsed their mouth with water and then coughed up all produced expectorate into a sterile $50-\mathrm{ml}$ Greiner tube, placed on ice until processing.

Sputum was weighted and liquefied on ice, under constant agitation for 15 to $30 \mathrm{~min}$, with an equal weight (=volume) of $10 \mathrm{mM}$ dithiotreitol (DTT; Sigma, St. Louis, MO) in $0.45 \%(w / v) ~ N a C l, 25 \mathrm{mM}$ HEPES, $25 \mathrm{mM} \mathrm{NaHCO}_{3}$, adjusted to $\mathrm{pH} 8.0$ with $\mathrm{NaOH}$. The liquefied sputum was centrifuged at $450 \mathrm{~g}$ for $10 \mathrm{~min}$ at $4^{\circ} \mathrm{C}$. Supernatants were immediately frozen at $-80^{\circ} \mathrm{C}$ until analysis. The remaining pellet was resuspended in $1 \mathrm{ml}$ PBS with $2 \%$ human serum albumin. Cell count and viability were assessed with a Bürker counting chamber and trypan blue exclusion, respectively. Cytospins were stained with May-Grünwald Giemsa and Quick Diff (Dade Behring, Leusden, The Netherlands). Differential cell counts were performed by one experienced blinded technician counting 500 non-squamous cells, and $10 \%$ of the samples were checked independently by a second blinded technician.

\section{Whole blood stimulation}

To analyse the cytokine producing capacity of peripheral blood leukocytes, whole blood (WB) stimulation was performed as described previously ${ }^{18}$. Briefly, heparinised blood from subjects was collected aseptically and kept at room temperature for $2.5 \mathrm{~h}$. The blood was diluted five-fold in IMDM (Iscove's Modified Dulbecco's Medium, Bio Whittaker, Verviers, Belgium) supplemented with $0.1 \%$ (v/v) FCS, 100 IU penicillin, $100 \mu \mathrm{g} / \mathrm{ml}$ streptomycin and $25 \mathrm{IU} / \mathrm{ml} \mathrm{Na-heparin} \mathrm{and} \mathrm{cultured} \mathrm{in} \mathrm{sterile} \mathrm{en}$ pyrogenfree $5 \mathrm{ml}$ tubes (Kendall) at $37^{\circ} \mathrm{C}$ with $5 \% \mathrm{CO}_{2}$. Stimulations were performed with control medium (non-stimulated control), $10 \mu \mathrm{g} / \mathrm{ml}$ lipopolysaccharide (LPS) (Sigma) or $5 \mu \mathrm{g} / \mathrm{ml} \operatorname{lgE} \alpha \mathrm{CD} 3 / \operatorname{lgG} \alpha \mathrm{CD} 28$ (Sanquin). After $24 \mathrm{~h}$ samples were centrifuged at room temperature for $10 \mathrm{~min}$ at $1000 \mathrm{~g}$ and supernatants were collected and frozen at $-80^{\circ} \mathrm{C}$ until analysis. The production of the cytokines IL-4, IL-6, IL-10, IL-13 and IFN- $\gamma$ in the supernatant were measured as described earlier ${ }^{19}$. The pleiotropic cytokines IL- 6 and IL-10, both produced by a variety of cell types, among which monocytes/macrophages are the main sources, were determined as parameters of innate immunity. IFN- $\gamma$ was determined to measure Th1 activation and IL-4 and IL-13 to measure Th2 activation.

\section{Measurement of inflammation markers IL-8 and TNF- $\alpha$}

Tumor necrosis factor- $\alpha$ (TNF- $\alpha$ and interleukin-8 (IL-8) in plasma were determined using the PeliKine Compact Elisa's from Sanquin (Amsterdam, the Netherlands) according to the manufacturer's instructions. IL-8 in sputum was determined with the antibody pair MAB 208 and BAF 208 (R\&D, Abingdon, UK) ${ }^{20}$. 


\section{Measurement of peripheral blood and sputum albumin and immunoglobulins}

Albumin and IgG in serum and sputum, as well as serum IgA were determined using immunoturbidimetric assays (BN ProSpec, Dade Behring) ${ }^{21}$. Secretory $\lg A$ (slgA) in serum and sputum was determined by an ELISA as reported previously ${ }^{22}$. All assays were validated for the presence of the sulphur-bridge reducing agent dithiotreitol (DTT), by using a standard curve in DTT-solutions and by testing recovery of exogenously added marker protein to DTT-treated sputum samples. For most assays, sputum samples had to be diluted at least 50 -fold to rule out interference of DTT.

\section{Statistical analysis}

The allocation of probiotic or placebo was concealed to all investigators and volunteers until the study had been completed and all analyses had been performed.

Statistical evaluation of peripheral blood and sputum cell counts, inflammation markers, cytokine production in stimulated whole blood, albumin and immunoglobulins was carried out using linear mixed model analysis as described previously ${ }^{14,23}$. Mixed model analysis corrects for baseline differences, within subject correlation and assumes missing at random.

For all other data the nonparametric Mann-Whitney U-test was used for two-group comparisons of independent ordinal and interval values while the nonparametric Wilcoxon signed-ranked test was used for comparison of related ordinal and interval values. If data were normally distributed the Students t-test was used.

In previous work the similarity index ( $\mathrm{SI})$ of denaturing gradient gel electrophoresis (DGGE) profiles compared to baseline (0-7, 0-14 and 0-63) was calculated, indicating the amount of disruption of the intestinal microbiota (low SI meaning more disruption). The correlation between the disruption of the intestinal microbiota (SIs) and the immunological parameters was analyzed during and after amoxycillin intake. As data was not normally distributed, all correlations were determined with the Spearman rank test. Data storing and tests were conducted using SPSS version 15.0 (SPSS Inc., Chicago, IL, USA) and a p-value below 0.05 was considered statistically significant.

\section{Results}

\section{Subjects}

Forty healthy volunteers completed the study. The subject characteristics were comparable for the probiotic and the placebo group (Table 5.1). None of the subjects used $\beta_{2}$-agonists, theophylline or antihistamines during the study. One subject in the probiotic group was found to be allergic to amoxycillin and had to be excluded. One 
subject in the placebo group and three in the probiotic group incidentally (i.e. maximally twice a week) consumed yoghurt containing L. rhamnosus GG between 14 and 7 days prior to the study. In the probiotic group one other subject incidentally consumed that yoghurt during the first two weeks of the study. Apart from one subject in the probiotic group taking $20 \mathrm{mg}$ omeprazole once daily at day 45 and 46 of the study, no medication potentially affecting the intestinal microbiota or the immune system was taken during the total study period.

Table 5.1 Subject characteristics.

\begin{tabular}{lcc}
\hline & Placebo & Probiotic \\
\hline No & 21 & 19 \\
Age (Median (range)) & $25(19-56)$ & $21(18-49)$ \\
Sex (M/F) & $10 / 11$ & $5 / 14$ \\
Compliance $^{\text {a }}$ probiotic/placebo intake (\%) & $\geq 97$ & $\geq 97$ \\
Compliance $^{\text {a }}$ antibiotic intake (\%) & $\geq 93$ & $\geq 93$ \\
\hline
\end{tabular}

${ }^{\text {a }}$ Compliance is self-reported.

\section{Sputum induction}

Sputum induction was well-tolerated by all subjects. Adequate amounts of sputum were produced by 39 of 40 healthy volunteers $(97.5 \%)$ at day 0 and by all volunteers $(100 \%)$ at day 7. All subjects had normal FEV1 values (percentage of predicted value) and no change in FEV1 $>10 \%$ occurred in any of the subjects during the procedure.

\section{Peripheral blood and induced sputum cell counts}

Total and differential cell counts in peripheral blood and induced sputum are shown in Table 5.2. The total cell counts in blood and sputum were not different between the probiotic and the placebo group nor within each group over time.

Differential cell counts in blood did not differ significantly between the probiotic and the placebo group. However, within the probiotic group a significant decrease in eosinophils was observed at day 14 (one week after cessation of antibiotic intake) compared to day 7 (Table 5.2). Within the placebo group a significant decrease at day 14 for basophils and day 63 for both monocytes and basophils was observed compared to day 7. 
Table 5.2 Total and differential cell counts in peripheral blood and induced sputum (Mean values ( \pm SD)).

\begin{tabular}{|c|c|c|c|c|c|c|c|c|c|}
\hline \multirow{3}{*}{ WBC $\left(10^{6} / \mathrm{ml}\right)$} & \multirow[b]{3}{*}{ Placebo } & \multicolumn{8}{|c|}{ Peripheral blood } \\
\hline & & \multicolumn{2}{|c|}{ day 0} & \multicolumn{2}{|c|}{ day 7} & \multicolumn{2}{|c|}{ day 14} & \multicolumn{2}{|c|}{ day 63} \\
\hline & & 5.9 & $(1.4)$ & 5.7 & $(0.84)$ & 6.0 & $(1.4)$ & 6.1 & (1.0) \\
\hline & Probiotic & 6.2 & $(1.4)$ & 6.7 & $(1.8)$ & 6.5 & $(1.4)$ & 6.9 & (1.7) \\
\hline \multirow[t]{2}{*}{ Neutrophils (\%) } & Placebo & 55.9 & $(8.1)$ & 55.2 & $(5.8)$ & 58.2 & (7.9) & 55.6 & (8.6) \\
\hline & Probiotic & 55.9 & $(8.6)$ & 56.5 & $(7.4)$ & 57.6 & (7.9) & 58.2 & (7.7) \\
\hline \multirow[t]{2}{*}{ Lymphocytes (\%) } & Placebo & 32.9 & $(7.3)$ & 32.6 & $(5.6)$ & 30.9 & $(6.5)$ & 33.8 & $(8.1)$ \\
\hline & Probiotic & 32.4 & $(7.5)$ & 32.2 & (6.9) & 31.4 & $(7.1)$ & 30.5 & $(5.6)$ \\
\hline \multirow[t]{2}{*}{ Monocytes (\%) } & Placebo $^{a}$ & 8.2 & $(2.3)$ & 8.6 & $(2.5)$ & 7.8 & $(1.7)$ & 7.6 & $(1.5)$ \\
\hline & Probiotic & 8.5 & (2.9) & 7.8 & $(1.5)$ & 8.2 & $(2.1)$ & 8.0 & $(2.5)$ \\
\hline \multirow[t]{2}{*}{ Eosinophils (\%) } & Placebo & 2.7 & (1.5) & 3 & $(2.1)$ & 2.8 & $(2.0)$ & 2.9 & (2.0) \\
\hline & Probiotic $^{b}$ & 2.8 & $(2.8)$ & 3.4 & (3.3) & 2.5 & $(2.0)$ & 3.1 & (3.4) \\
\hline \multirow[t]{4}{*}{ Basophils (\%) } & Placebo $^{c}$ & 0.71 & $(0.5)$ & 0.90 & $(0.3)$ & 0.52 & $(0.5)$ & 0.55 & $(0.5)$ \\
\hline & Probiotic & 0.58 & $(0.5)$ & 0.63 & $(0.5)$ & 0.68 & $(0.5)$ & 0.63 & $(0.5)$ \\
\hline & & \multicolumn{8}{|c|}{ Induced sputum } \\
\hline & & \multicolumn{2}{|c|}{ day 0} & \multicolumn{2}{|c|}{ day 7} & \multicolumn{2}{|c|}{ day $14^{+}$} & \multicolumn{2}{|c|}{ day $63^{+}$} \\
\hline \multirow[t]{2}{*}{ Total cells $\left(10^{6} / \mathrm{ml}\right)$} & Placebo & 2.1 & $(1.8)$ & 1.9 & $(1.4)$ & 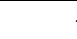 & 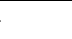 & - & \\
\hline & Probiotic & 1.8 & $(1.3)$ & 1.6 & $(0.9)$ & . & & - & \\
\hline \multirow[t]{2}{*}{ Neutrophils (\%) } & Placebo & 53.3 & $(22.0)$ & 53.4 & $(22.2)$ & 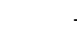 & 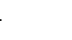 & - & \\
\hline & Probiotic & 51.7 & $(28.0)$ & 42.3 & $(26.1)$ & 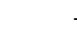 & 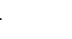 & - & \\
\hline \multirow[t]{2}{*}{ Lymphocytes (\%) } & Placebo & 2.9 & $(2.6)^{*}$ & 2.4 & $(1.7)$ & 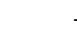 & & - & \\
\hline & Probiotic & 1.8 & $(1.1)$ & 1.5 & $(1.1)$ & 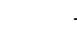 & - & - & \\
\hline \multirow[t]{2}{*}{ Monocytes (\%) } & Placebo & 0.34 & $(0.45)$ & 0.36 & $(0.40)$ & 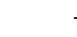 & & - & \\
\hline & Probiotic & 0.29 & $(0.29)$ & 0.37 & $(0.40)$ & . & 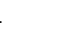 & - & \\
\hline \multirow[t]{2}{*}{ Macrophages (\%) } & Placebo & 43.1 & $(21.5)$ & 43.4 & $(21.6)$ & . & & - & \\
\hline & Probiotic & 45.9 & $(27.7)$ & 55.1 & $(25.7)$ & 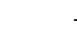 & 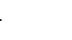 & - & \\
\hline \multirow[t]{2}{*}{ Eosinophils (\%) } & Placebo & 0.31 & $(0.64)$ & 0.46 & $(1.28)^{*}$ & . & . & - & \\
\hline & Probiotic $^{d}$ & 0.29 & $(0.32)$ & 1.27 & (3.26) & 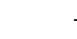 & & - & \\
\hline \multirow[t]{2}{*}{ Epithelial cells (\%) } & Placebo & 44.3 & $(32.4)$ & 51.0 & $(26.7)$ & 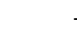 & & - & \\
\hline & Probiotic & 54.0 & $(25.1)$ & 60.4 & $(25.8)$ & - & - & - & \\
\hline
\end{tabular}

${ }^{+}$not measured; * between group difference, $\mathrm{p}<0.01 ;{ }^{a}$ Within group decrease day 63 vs. day $7, \mathrm{p}<0.05$;

${ }^{\mathrm{b}}$ Within group decrease day 14 vs. day $7, \mathrm{p}<0.05$; ${ }^{\mathrm{c}}$ Within group decrease day $14 / 63$ vs. day $7, p<0.01$;

${ }^{d}$ Within group increase day 7 vs. day $0, p<0.05$.

Differential cell counts in sputum did not differ significantly between the probiotic and the placebo group, apart from a significant difference in lymphocytes at day 0 and in eosinophils at day 7 (Table 5.2). Within the probiotic group a significant increase in eosinophils was observed during antibiotic/probiotic intake (day 7). In addition, an increase in total serum eosinophils was significantly associated with an increase in total plasma eosinophils at both day $0\left(R^{2}=0.19, p<0.05\right)$ and day $7\left(R^{2}=0.19, p<0.05\right)$.

\section{Cytokine production in stimulated whole blood}

Cytokine producing capacity did not always reach detectable levels after in vitro induced stimulation. IL-4 production was below the lower detection limit (1 pg/ml) of the assay in 26, 37, 79 and $95 \%$ of volunteers in the probiotic group and in 33, 42, 86 and $84 \%$ of volunteers in the placebo group over time. IL-13 production was below 
the lower detection limit ( $2 \mathrm{pg} / \mathrm{ml}$ ) of the assay in $16,11,42$ and $58 \%$ of volunteers in the probiotic group and in 14, 0,57 and $37 \%$ of volunteers in the placebo group at day $0,7,14$ and 63 respectively.

No difference in IL-4, IL-13, IFN- $\gamma$, IL-6 and IL-10 production upon in vitro induced stimulation between the probiotic and the placebo group was found throughout the study (Figure 5.1).

Within the groups a significantly decreased production of IL-4 was found at day 14 and 63 in the probiotic group and at day 14 in the placebo group (Figure 5.1). A similar tendency for IL-13 was seen. In addition, in the placebo group a significant increase in IL-13 was observed at day 63 compared to day 14.
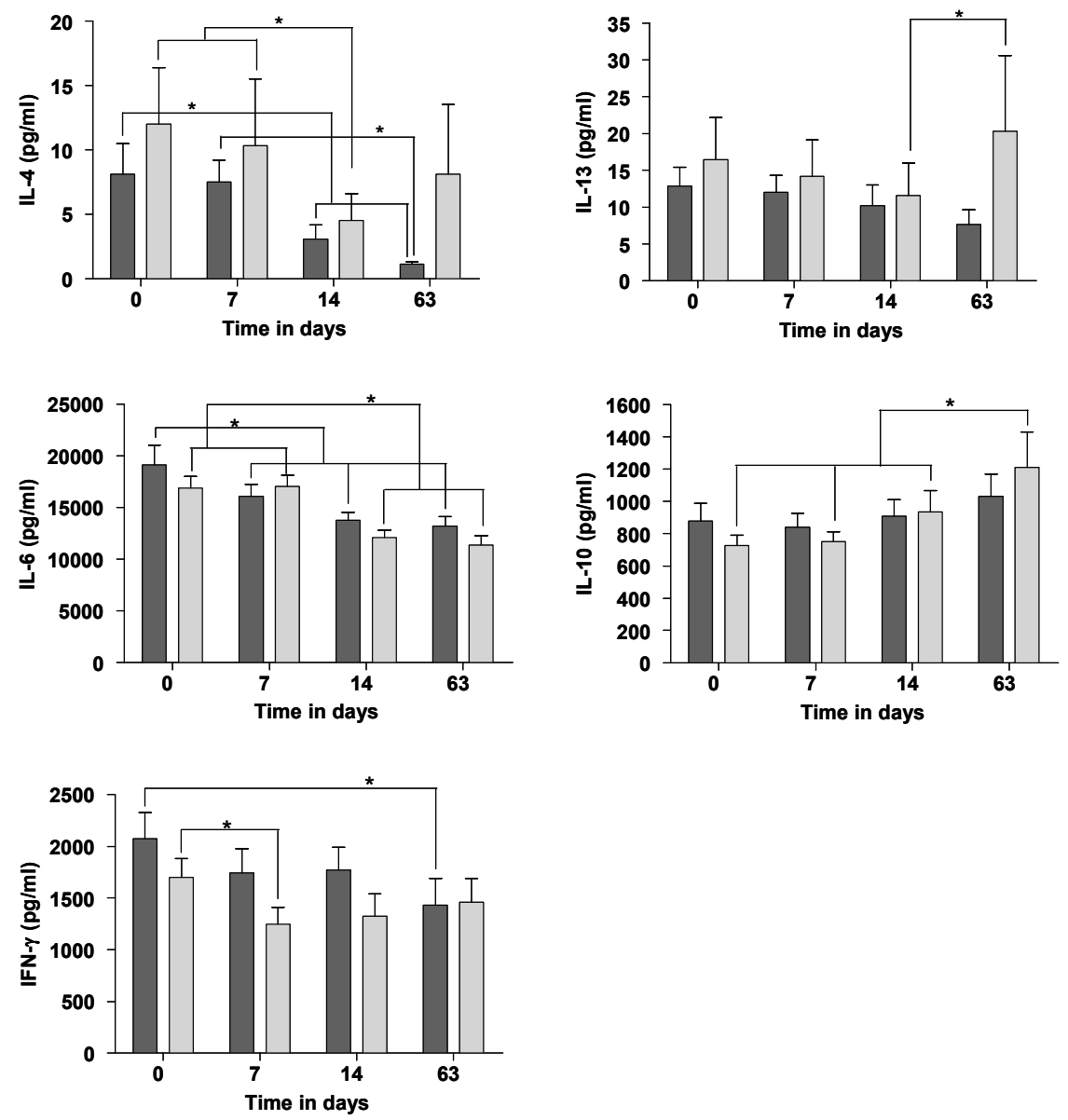

Figure 5.1 Cytokine production of stimulated whole blood cultures (CD3/CD28 for IL-4, IL-13 and IFN- $\gamma$ and LPS for IL-10 and IL-6). Results are expressed as mean ( \pm SEM).

$\square=$ probiotic and $\square=$ placebo, $*$ p $<0.05$. 
A significantly decreased IFN- $\gamma$ production was observed at day 7 in the placebo group and at day 63 in the probiotic group (Figure 5.1). Moreover, IL-6 production decreased in both groups at day 14 and 63 . In contrast, IL-10 production significantly increased at day 63 in the placebo group only (Figure 5.1).

To further investigate the cytokine secreting capacity, we evaluated the in vitro stimulated secretion of the cytokines per blood cell type (monocyte or lymphocyte) and the ratio of IFN- $-/ \mathrm{IL}-4$ and IFN- $/ / \mathrm{IL}-13$ levels (Figure 5.2). Again, no difference between the probiotic and the placebo group was observed. Within both groups a similar tendency as described above was observed when cytokine production upon in vitro induced stimulation was expressed per blood cell type (Figure 5.2). The ratio's IFN- $\gamma /$ IL-4 and IFN- $\gamma /$ IL-13 showed an increase in both groups at day 14 (Figure 5.2).

\section{Inflammation markers, TNF- $\alpha$ and IL-8}

Except for two subjects in the placebo group, plasma TNF- $\alpha$ levels were below the lower detection limit $(5 \mathrm{pg} / \mathrm{ml})$ of the assay and were therefore not further considered. Plasma IL-8 was below the lower detection limit $(0.5 \mathrm{pg} / \mathrm{ml})$ of the assay in $5,32,26$ and $37 \%$ of volunteers in the probiotic group and in 33, 33, 29 and $5 \%$ of volunteers in the placebo group at day $0,7,14$ and 63 respectively. Both plasma and sputum IL-8 levels did not significantly differ between or within each group over time (Figure 5.3). No significant association between sputum IL-8 and plasma IL-8 was observed. A significant association between sputum IL-8 and sputum neutrophils was found at both day $0\left(R^{2}=0.29, p<0.05\right)$ and day $7\left(R^{2}=0.51, p<0.05\right)$.

\section{Peripheral blood and sputum albumin}

Both plasma and sputum albumin levels did not significantly differ between the probiotic and the placebo group (Figure 5.3) and no differences over time were observed in the probiotic group. Within the placebo group a tendency $(p=0.055)$ to a decrease in serum albumin was observed at day 7. At day 63, serum albumin was significantly decreased compared to baseline (Figure 5.3).

Sputum-to-serum ratios of albumin did not significantly differ between the two groups or during the study (Placebo, $0.19 \pm 0.36$ and $0.27 \pm 0.47$; Probiotic, $0.13 \pm 0.15$ and $0.15 \pm 0.11$ at $t=0$ and $t=7$, respectively), indicating that there was no difference in microvascular leakage. Therefore, the values of the analyses in sputum were not corrected for microvascular leakage. 

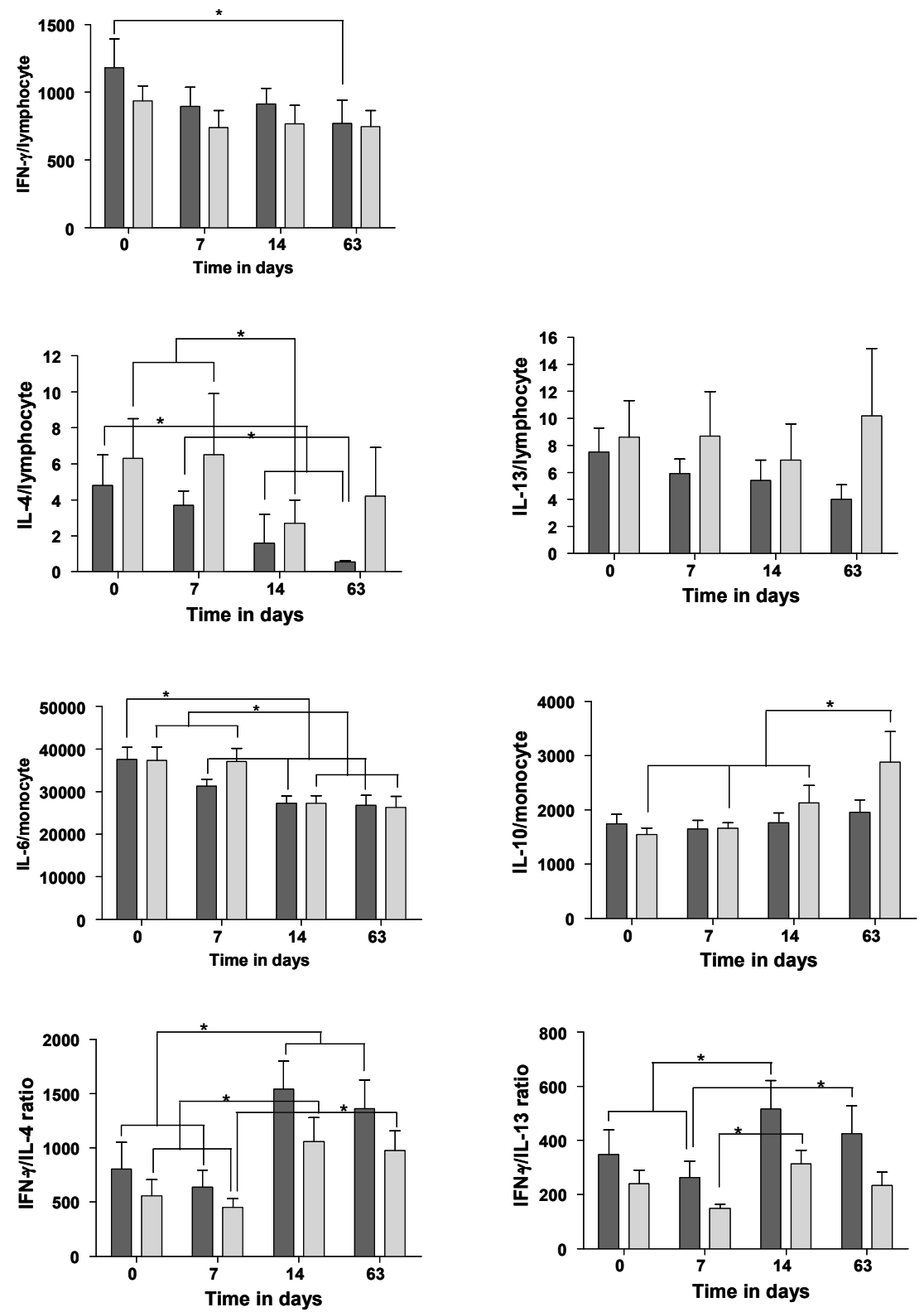

Figure 5.2 Cytokine production in whole blood culture (CD3/CD28 for IL-4, IL-13 and IFN- $\gamma$ and LPS for IL-10 and IL-6) per blood cell type or as a ratio. Results are expressed as mean ( \pm SEM). $\square=$ probiotic and $\square=$ placebo, $* p<0.05$. 

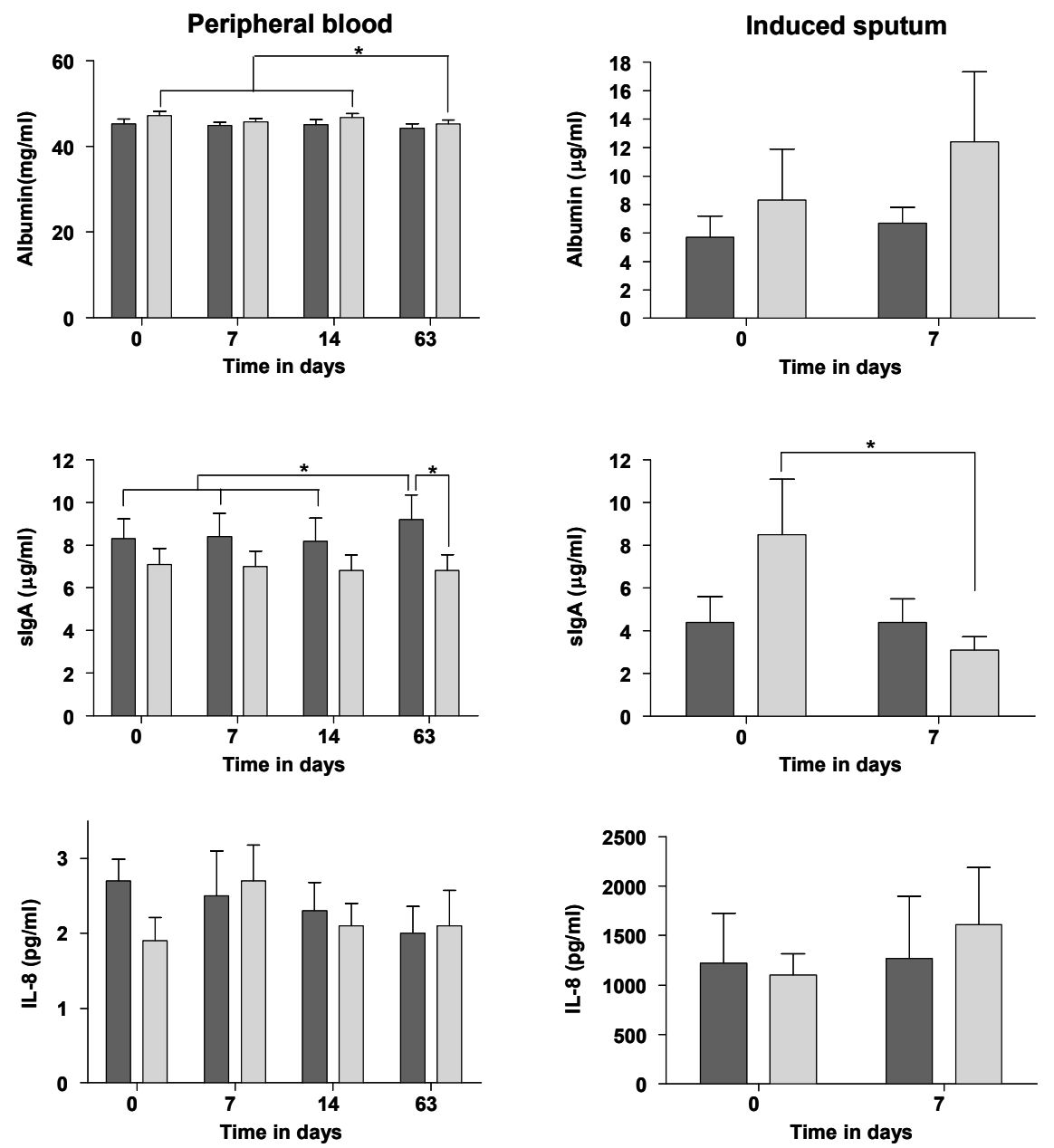

Figure 5.3 Albumin, slgA and IL-8 concentration in peripheral blood and in induced sputum. Results are expressed as mean ( \pm SEM). $\square=$ probiotic and $\square=$ placebo, $* p<0.05$

\section{Immunoglobulins}

Serum IgA, serum IgG and sputum IgA levels did not significantly differ between or within each group over time during the study (data not shown). However, a significant increase in serum slgA was found at day 63 in the probiotic group compared to the placebo group (Figure 5.3). Moreover, though no significant difference could be observed in sputum slgA between both groups, within the placebo group only a significant decrease in sputum slgA was found at day 7 (Figure 5.3). A significant 
decrease in the sputum-to-serum ratio of slgA was also observed in the placebo group at day 7 (mean $( \pm S D$ ), $1.5 \pm 2.2$ and $0.6 \pm 0.5, p<0.05$ at $t=0$ and $t=7$ respectively).

\section{Correlations between the similarity index and immunological parameters}

Plasma IL-8 at day $14\left(R^{2}=0.15\right)$, the IL-8/monocyte at day $7\left(R^{2}=0.14, p<0.05\right)$ and day $14\left(R^{2}=0.20, p<0.05\right)$, the IL-10/monocyte at day $14\left(R^{2}=0.14\right)$ and total plasma eosinophils at day $63\left(R^{2}=0.17, p<0.05\right)$ showed a significant inverse association with the similarity index (low SI indicates more disruption of the intestinal microbiota). No association between the other immunological parameters and the SI was observed.

\section{Discussion}

In the present double-blind placebo-controlled randomised study, to the best of our knowledge, for the first time systemic and mucosal biomarkers were simultaneously assessed to investigate the in vivo effect on immune parameters of the intake of amoxycillin in combination with a multispecies probiotic in healthy volunteers. The intake of a multispecies probiotic did not alter the analyzed systemic and mucosal biomarkers apart from a significant increase of serum secretory IgA two months after cessation of amoxycillin intake. In the systemic compartment amoxycillin intake resulted in lower IL-4, IL-6, IL-13 and IFN- $\gamma$ production and enhanced IL-10 production by stimulated whole blood cells. Although no differences were observed in the probiotic group versus the placebo group, the intake of a multispecies probiotic resulted in an even further decreased production of IL-4 and IL-13 and a less pronounced increase of IL-10 production. In addition, during and/or shortly after amoxycillin intake IL- 8 and IL-10 showed an inverse association with the similarity index.

Antibiotics can modulate the host immune response in several ways. Beta-lactams and penicillin in particular are considered to exhibit modest immunomodulating effects, but this has mainly been studied in vitro ${ }^{1}$. In the present human study, the penicillinderivate amoxycillin was given. During amoxycillin intake (observed in the placebo group) no changes in total peripheral blood or sputum leukocytes were observed. This is in agreement with Dufour et al. showing no effect of amoxycillin/clavulanic acid ${ }^{24}$. In contrast, the slight increase in peripheral blood monocytes and basophils during amoxycillin intake in the placebo group suggest a small immunomodulating effect by amoxycillin. Probiotic intake seems to be able to counteract this effect, as this increase was not observed in the probiotic group. Moreover, the consumption of the multispecies probiotic was associated with a significant increase in sputum eosinophils and a small increase in peripheral blood eosinophils during amoxycillin intake. In 
studies, mainly using allergen-induced models ${ }^{25-30}$, the effect of probiotic intake on eosinophils was heterogeneous, very much depending on the type of model used, the probiotic administered and the compartment studied.

Studies using WB or peripheral blood mononuclear cells (PBMC) stimulated with LPS in the presence or absence of various antibiotics, have demonstrated that antibiotics can inhibit or stimulate cytokine production ${ }^{31-34}$. Similar observations have been made for probiotics ${ }^{35}$. The use of WB reflects the in vivo situation more reliably than the use of PBMC as it leaves the peripheral blood cells in a more natural environment, neither eliminating potentially important regulatory proteins nor synergistic or antagonistic cell to cell interactions.

The overall tendency towards a decreased production of IL-4, IL-13, IFN- $\gamma$ and IL- 6 in the placebo group points to an inhibitory effect of the oral administration of amoxycillin in healthy volunteers. Only few studies have investigated cytokine profiles after oral amoxycillin intake. Gismondo et al. did not find any change in cytokine production of healthy subjects after ampicillin intake ${ }^{36}$. In contrast, using a rat model, Melhus et al. reported that amoxycillin intake caused an up-regulated expression of IL-6, TNF- $\alpha$ and IL-10 but not of TGF- $\beta$ during experimental otitis media ${ }^{37}$.

Although overall cytokine expression in both Th1 (IFN- $\gamma$ ) and Th2 (IL-4,IL-13) subsets appeared suppressed, when looking at the IFN- $\gamma / \mathrm{IL}-4$ and IFN- $\gamma / \mathrm{IL}-13$ ratios, these were skewed towards a Th2-type response during amoxycillin intake. These findings are in line with the common hypothesis that antibiotics can induce a shift to a Th2 response, caused by unbalanced development and homeostasis of the intestinal immune system due to disturbances of the intestinal microbiota.

To our knowledge, no human studies so far reported on the effect of probiotic intake on cytokine production during oral antibiotic intake. Although no effect in cytokine production was observed between both groups, our data demon-strates that the intake of a multispecies probiotic during and after oral amoxycillin treatment can result in a further decrease of IL-4, IL-13 and IFN- $\psi$. However, this decrease was found to coincide with an increase in IL-10. Taken together, these findings suggest that the intake of a multispecies probiotic may have an inhibiting effect on the Th1/Th2 cytokine production during and after amoxycillin intake.

Earlier we have shown that the composition of the dominant faecal microbiota was markedly disrupted by amoxycillin intake $\mathrm{e}^{23}$. As the intestinal microbiota acts as a primary stimulus for the intestinal immune system, these pertur-bations may have led to an alteration of the immunological gut homeostasis. This is supported by our data demonstrating a correlation between the disturbance of the dominant faecal microbiota (low similarity index) and an increase in plasma IL-8, IL-8/monocyte and IL-10/monocyte during and shortly after amoxycillin intake, and eosinophils two months after cessation. Thus, amoxycillin intake strongly affects the faecal microbiota over a prolonged period contributing to immunomodulating effects. Interestingly, 
even though results are controversial, a number of epidemiological studies have demonstrated an association between the use of antibiotics during early childhood and an increased risk for acquiring allergy or asthma ${ }^{38-41}$. It would therefore be very interesting to investigate whether subjects with a markedly and long-term disruption of the intestinal microbiota after antibiotic intake tend to have a disturbed immunological homeostasis causing intestinal inflammatory disorders and allergic hypersensitivity.

In the probiotic group an increase in serum slgA and IL-10 (though not significant for the latter) was observed, which is in line with the fact that IL-10 and TGF- $\beta$ can induce the switch from $\operatorname{IgM}^{+} B$ cells to $\operatorname{lgA}^{+} B$ cells ${ }^{2}$. However, significant increase in IL-10 was observed in the placebo group, not accompanied by an increase in serum slgA, suggesting that factors besides IL-10 could play an important role.

Evidence from several human and animal studies demonstrates that probiotics can increase the levels of slgA, in both the intestine and blood (though mostly pathogenspecific $)^{42-46}$ as well as the number of $\operatorname{lgA}^{+} B$ cells ${ }^{47-50}$. SIgA is an important immunological defence barrier by preventing adhesion and entry of toxins and pathogens into the epithelium. Therefore, a probiotic induced increase in slgA can be considered beneficial. The intake of a multispecies probiotic resulted in a significant increase in serum slgA and seemed to counteract the amoxycillin induced decrease in sputum slgA observed in the placebo group. However, it is not clear if an increase in serum slgA is associated with increase in mucosal slgA as sputum was not collected after day 7. Moreover, whether the observed increase in plasma slgA in the probiotic group is high enough to have a clinical relevant effect remains to be elucidated.

As the various mucosal compartments are functionally and operationally linked with one another, we choose to analyse sputum (i.e. a mucosal compartment) as a reflection of the intestinal compartment. Though some systemic effects have been observed, effects on the mucosal parameters studied were small. In this context it has to be taken into account that the mucosa associated lymphoid tissue is functionally and operationally distinct from the peripheral and systemic immune system. In addition, care has to be taken to extrapolate these results from sputum to the gastrointestinal compartment, since other immunomodulating effects could still be present at this location. Therefore, to study the effect of antibiotics and probiotics on intestinal mucosal histology and immune activation, in future studies intestinal biopsies should be included. Considering the invasiveness and the potential risks, this was considered non-ethical in a study with healthy volunteers.

In conclusion, in healthy volunteers a short course of amoxycillin is able to induce in- and ex vivo immunological changes consisting mainly of a decreased sputum slgA production and a decreased IL-4, IL-6, IL-13 and IFN- $\gamma$ and an enhanced IL-10 production capacity in stimulated WB. This change in the innate and adaptive immune 
system is probably the result of the disturbance of intestinal microbiota by amoxycillin. The addition of a multispecies probiotic further enhances these changes in cytokine production, results in an increase in serum slgA and seems to counterbalance the decrease in sputum slgA. Although an increase in slgA is generally regarded as beneficial, the overall impact of the observed immunological changes still needs to be unravelled.

In a recent overview article Preidis and Versalovic have tried to systematically illustrate several physiological features such as the innate and adaptive immunity that may be modified by perturbations in the composition and functioning of the human microbiome ${ }^{8}$. It is obvious that the same pro- and anti-inflammatory immunological mediators play important roles in several immunomodulating processes and that clinically relevant net changes will depend on a multitude of known (and unknown) factors. It is therefore possible that the promising findings of the present study in healthy volunteers may be different in patient populations, especially those with an already compromised immune system and a strong and long-lasting disturbance of the indigenous intestinal microbiota. 


\section{References}

1. Van Vlem B, Vanholder R, De Paepe P, Vogelaers D, Ringoir S. Immunomodulating effects of antibiotics: literature review. Infection. 1996;24:275-91.

2. Macpherson AJ, Uhr T. Induction of protective IgA by intestinal dendritic cells carrying commensal bacteria. Science. 2004;303:1662-5.

3. Anderson KV. Toll signaling pathways in the innate immune response. Curr Opin Immunol. 2000; 12:13-9.

4. Cebra JJ. Influences of microbiota on intestinal immune system development. Am J Clin Nutr. 1999; 69:1046S-51S.

5. Moreau MC, Gaboriau-Routhiau V. Influence of resident intestinal microbiota on the development and functioning on the intestinal-associated lymphoid tissue. In: Fuller R, Perdigon G, editors. Probiotics 3. Immunomodulation by the gut microflora and probiotics. London, United Kingdom: R. Kluer Academic Publishers; 2000. p. 69-104.

6. Othman M, Aguero R, Lin HC. Alterations in intestinal microbial flora and human disease. Curr Opin Gastroenterol. 2008;24:11-6.

7. Rautava S, Isolauri E. The development of gut immune responses and gut microbiota: effects of probiotics in prevention and treatment of allergic disease. Curr Issues Intest Microbiol. 2002;3:15-22.

8. Preidis GA, Versalovic J. Targeting the human microbiome with antibiotics, probiotics, and prebiotics: gastroenterology enters the metagenomics era. Gastroenterol. 2009;136:2015-31.

9. Czerkinsky C, Anjuere F, McGhee JR, George-Chandy A, Holmgren J, Kieny MP, Fujiyashi K, Mestecky JF, Pierrefite-Carle V, Rask C, Sun JB. Mucosal immunity and tolerance: relevance to vaccine development. Immunol Rev. 1999;170:197-222.

10. Guarner F, Malagelada JR. Gut flora in health and disease. Lancet. 2003;361:512-9.

11. Kalliomaki M, Salminen S, Poussa T, Arvilommi H, Isolauri E. Probiotics and prevention of atopic disease: 4-year follow-up of a randomised placebo-controlled trial. Lancet. 2003;361:1869-71.

12. Madsen K. Probiotics and the immune response. J Clin Gastroenterol. 2006;40:232-4.

13. Timmerman HM, Koning CJ, Mulder L, Rombouts FM, Beynen AC. Monostrain, multistrain and multispecies probiotics-A comparison of functionality and efficacy. Int J Food Microbiol. 2004;96: 219-33.

14. Koning CJ, Jonkers DM, Stobberingh EE, Mulder L, Rombouts FM, Stockbrugger RW. The Effect of a Multispecies Probiotic on the Intestinal Microbiota and Bowel Movements in Healthy Volunteers Taking the Antibiotic Amoxycillin. Am J Gastroenterol. 2007;102:1-12.

15. EFSA. Opinion of the Scientific Committee on a request from EFSA on the introduction of a Qualified Presumption of Safety (QPS) approach for assessment of selected microorganisms referred to EFSA. The EFSA Journal. 2007;587:1-16.

16. WHO. Good manufacturing practices for biological products. Technical Report Series No 822 . 1992;Annes 1.

17. Cataldo D, Foidart JM, Lau L, Bartsch P, Djukanovic R, Louis R. Induced sputum: comparison between isotonic and hypertonic saline solution inhalation in patients with asthma. Chest. 2001;120:1815-21.

18. Swaak AJ, van den Brink HG, Aarden LA. Cytokine production in whole blood cell cultures of patients with rheumatoid arthritis. Ann Rheum Dis. 1997;56:693-5.

19. de Jager W, te Velthuis H, Prakken BJ, Kuis W, Rijkers GT. Simultaneous detection of 15 human cytokines in a single sample of stimulated peripheral blood mononuclear cells. Clin Diagn Lab Immunol. 2003;10:133-9.

20. Boorsma M, Lutter R, van de Pol MA, Out TA, Jansen HM, Jonkers RE. Repeatability of inflammatory markers in induced sputum of COPD patients. COPD. 2007;4:321-9.

21. Schoonbrood DF, Lutter R, Habets FJ, Roos CM, Jansen HM, Out TA. Analysis of plasma-protein leakage and local secretion in sputum from patients with asthma and chronic obstructive pulmonary disease. Am J Respir Crit Care Med. 1994;150:1519-27.

22. van de Graaf EA, Out TA, Kobesen A, Jansen HM. Lactoferrin and secretory IgA in the bronchoalveolar lavage fluid from patients with a stable asthma. Lung. 1991;169:275-83. 
23. Koning CJM, Jonkers DMAE, Smidt $H$, Fuentes $S$, Rombouts $F M$, Winkens $B$, Stobberingh EE, Stockbrugger RW. Monitoring the effect of a multispecies probiotic and short-term amoxycillin intake on the fecal microbiota by PCR-DGGE in healthy volunteers. 2010; submitted.

24. Dufour V, Millon L, Faucher JF, Bard E, Robinet E, Piarroux R, Vuitton DA, Meillet D. Effects of a shortcourse of amoxicillin/clavulanic acid on systemic and mucosal immunity in healthy adult humans. Int Immunopharmacol. 2005;5:917-28.

25. Brouwer ML, Wolt-Plompen SA, Dubois AE, van der Heide S, Jansen DF, Hoijer MA, Kauffman HF, Duiverman EJ. No effects of probiotics on atopic dermatitis in infancy: a randomized placebocontrolled trial. Clin Exp Allergy. 2006;36:899-906.

26. Ezendam J, de Klerk A, Gremmer ER, van Loveren H. Effects of Bifidobacterium animalis administered during lactation on allergic and autoimmune responses in rodents. Clin Exp Immunol. 2008;154: 424-31.

27. Ezendam J, van Loveren H. Lactobacillus casei Shirota administered during lactation increases the duration of autoimmunity in rats and enhances lung inflammation in mice. Br J Nutr. 2008;99:83-90.

28. Shimada T, Cheng L, Shi HB, Hayashi A, Motonaga C, Tang J, Enomoto K, Enomoto T. Effect of lysed Enterococcus faecalis FK-23 on allergen-induced immune responses and intestinal microflora in antibiotic-treated weaning mice. J Investig Allergol Clin Immunol. 2007;17:70-6.

29. Shimada T, Zhu LP, Yin M, Motonaga C, Li HB, Shi HB, Enomoto K, Enomoto T, Cheng L. Effects of lysed Enterococcus faecalis FK-23 on allergen-induced peritoneal accumulation of eosinophils and serum total IgE concentration in inbred mice. Asian Pac J Allergy Immunol. 2008;26:137-41.

30. Xiao JZ, Kondo S, Yanagisawa N, Takahashi N, Odamaki T, Iwabuchi N, Iwatsuki K, Kokubo S, Togashi H, Enomoto K, Enomoto T. Effect of probiotic Bifidobacterium longum BB536 [corrected] in relieving clinical symptoms and modulating plasma cytokine levels of Japanese cedar pollinosis during the pollen season. A randomized double-blind, placebo-controlled trial. J Investig Allergol Clin Immunol. 2006;16:86-93.

31. Garcia-Roca P, Mancilla-Ramirez J, Santos-Segura A, Fernandez-Aviles M, Calderon-Jaimes E. Linezolid diminishes inflammatory cytokine production from human peripheral blood mononuclear cells. Arch Med Res. 2006;37:31-5.

32. Morikawa K, Watabe H, Araake M, Morikawa S. Modulatory effect of antibiotics on cytokine production by human monocytes in vitro. Antimicrob Agents Chemother. 1996;40:1366-70.

33. Reato G, Cuffini AM, Tullio V, Palarchio AI, Bonino A, Foa R, Carlone NA. Co-amoxiclav affects cytokine production by human polymorphonuclear cells. J Antimicrob Chemother. 1999;43:715-8.

34. Ziegeler S, Raddatz A, Hoff G, Buchinger H, Bauer I, Stockhausen A, Sasse H, Sandmann I, Horsch S, Rensing $\mathrm{H}$. Antibiotics modulate the stimulated cytokine response to endotoxin in a human ex vivo, in vitro model. Acta Anaesthesiol Scand. 2006;50:1103-10.

35. Niers LE, Timmerman HM, Rijkers GT, van Bleek GM, van Uden NO, Knol EF, Kapsenberg ML, Kimpen $\mathrm{JL}$, Hoekstra MO. Identification of strong interleukin-10 inducing lactic acid bacteria which downregulate T helper type 2 cytokines. Clin Exp Allergy. 2005;35:1481-9.

36. Gismondo MR, Chisari G, Lo Bue AM. Effect of ampicillin and sulbactam/ampicillin on the immune system. J Int Med Res. 1991;19 Suppl 1:24A-8A.

37. Melhus A. Effects of amoxicillin on the expression of cytokines during experimental acute otitis media caused by non-typeable Haemophilus influenzae. J Antimicrob Chemother. 2001;48:397-402.

38. Droste JH, Wieringa MH, Weyler JJ, Nelen VJ, Vermeire PA, Van Bever HP. Does the use of antibiotics in early childhood increase the risk of asthma and allergic disease? Clin Exp Allergy. 2000;30:1547-53.

39. Farooqi IS, Hopkin JM. Early childhood infection and atopic disorder. Thorax. 1998;53:927-32.

40. Johnson CC, Ownby DR, Alford SH, Havstad SL, Williams LK, Zoratti EM, Peterson EL, Joseph CL. Antibiotic exposure in early infancy and risk for childhood atopy. J Allergy Clin Immunol. 2005; 115:1218-24.

41. Wickens K, Pearce N, Crane J, Beasley R. Antibiotic use in early childhood and the development of asthma. Clin Exp Allergy. 1999;29:766-71.

42. Fukushima $\mathrm{Y}$, Kawata $\mathrm{Y}$, Hara H, Terada A, Mitsuoka T. Effect of a probiotic formula on intestinal immunoglobulin A production in healthy children. Int J Food Microbiol. 1998;42:39-44.

43. Fukushima Y, Kawata Y, Mizumachi K, Kurisaki J, Mitsuoka T. Effect of bifidobacteria feeding on fecal flora and production of immunoglobulins in lactating mouse. Int J Food Microbiol. 1999;46:193-7. 
44. Kaila M, Isolauri E, Soppi E, Virtanen E, Laine S, Arvilommi H. Enhancement of the circulating antibody secreting cell response in human diarrhea by a human Lactobacillus strain. Pediatr Res. 1992;32: 141-4.

45. Link-Amster H, Rochat F, Saudan KY, Mignot O, Aeschlimann JM. Modulation of a specific humoral immune response and changes in intestinal flora mediated through fermented milk intake. FEMS Immunol Med Microbiol. 1994;10:55-63.

46. Yasui H, Kiyoshima J, Ushijima H. Passive protection against rotavirus-induced diarrhea of mouse pups born to and nursed by dams fed Bifidobacterium breve YIT4064. J Infect Dis. 1995;172:403-9.

47. de Moreno de LeBlanc A, Maldonado Galdeano C, Chaves S, Perdigon G. Oral administration of $L$ casei CRL 431 increases immunity in bronchus and mammary glands. Eur J Inflamm. 2005;3:23-8.

48. Perdigon G, de Moreno de LeBlanc A, Valdez J, Rachid M. Role of yoghurt in the prevention of colon cancer. Eur J Clin Nutr. 2002;56:S65-8.

49. Perdigon G, Fuller R, Raya R. Lactic acid bacteria and their effect on the immune system. Curr Issues Intest Microbiol. 2001;2:27-42.

50. Vinderola G, Matar C, Palacios J, Perdigon G. Mucosal immunomodulation by the non-bacterial fraction of milk fermented by Lactobacillus helveticus R389. Int J Food Microbiol. 2007;115:180-6. 


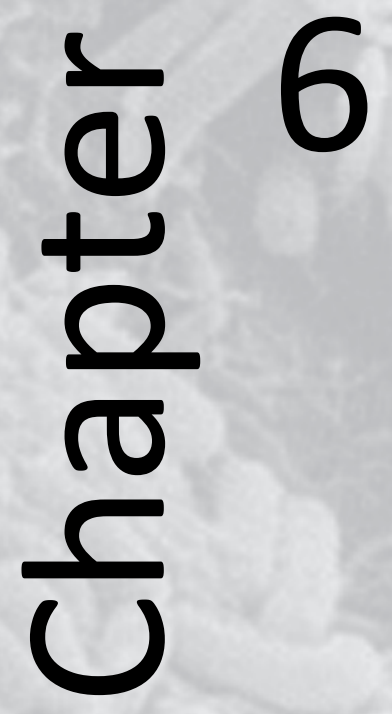




\section{The effect of a multispecies probiotic on the composition of the faecal microbiota and bowel habits in COPD patients treated with antibiotics}

Catherina J.M. Koning, Daisy M.A.E. Jonkers, Hauke Smidt, Frans M. Rombouts, Herman-Jan Pennings, Emiel F. Wouters, Ellen E. Stobberingh, Reinhold W. Stockbrügger

Br J Nutr. 2009;21:1-9 


\section{Abstract}

Short-term antibiotic treatment profoundly affects the intestinal microbiota, which may lead to sustained changes in microbiota composition. Probiotics may restore such a disturbance.

The objective of the present study was to investigate the effect of a multispecies probiotic on the faecal microbiota during and after antibiotic intake in patients with a history of frequent antibiotic use. In this randomized placebo-controlled double-blind study 30 COPD patients treated with antibiotics for a respiratory tract infection received five gram of a multispecies probiotic or placebo twice daily for two weeks. Faecal samples were collected at $0,7,14$ and 63 days. Changes in the composition of the dominant faecal microbiota were determined by PCR-denaturating gradient gel electrophoresis (PCR-DGGE). Changes in bacterial subgroups were determined by quantitative PCR and culture. Bowel movements were scored daily according to the Bristol stool form scale. During and after antibiotic treatment, DGGE-based similarity indices (SIs) were high ( $\geq 84 \%$ ) and band richness was relatively low both remaining stable over time. No difference in SIs was observed between patients with and without diarrhoea-like bowel movements. The multispecies probiotic had a modest effect on the bacterial subgroups. Nevertheless, it did not affect the composition of the dominant faecal microbiota nor the occurrence of diarrhoea-like bowel movements. The dominant faecal microbiota was not affected by antibiotics in this COPD population, suggesting an existing imbalance of the microbiota, which may also have contributed to the lack of effect by probiotic intake. 


\section{Introduction}

In recent years, our knowledge on the composition of the human intestinal microbiota has greatly improved with the introduction of molecular techniques based on 16S rRNA gene sequences, confirming that the microbiota is subject-specific and comprises a complex and very diverse bacterial ecosystem of which most species belong to previously unknown (i.e. uncultivated) lineages ${ }^{1-3}$. In healthy individuals, the dominant intestinal microbiota is found to be relatively stable over time ${ }^{1,4-7}$. However, in various populations it has been demonstrated that antibiotic intake can cause a marked disturbance of the intestinal microbiota as they not only affect pathogens but also the indigenous microbiota, which may result in antibiotic-associated diarrhoea (AAD). It is widely assumed that this disturbance is short-term but recently also medium and long-term disturbances in (specific) bacterial populations have been described $^{8-10}$. However, there are chronically ill patients, such as patients suffering from chronic obstructive pulmonary disease (COPD), who receive frequent antibiotic therapy. COPD is characterized by a progressive airflow obstruction, associated with a chronic inflammatory response in the airways consisting mainly of neutrophils, $\mathrm{CD} 8^{+}$ T-cells and macrophages ${ }^{11,12}$. Acute exacerbations play an important role in the clinical course of the disease and are an important cause of morbidity and mortality ${ }^{13,14}$. Although the underlying pathogenic mechanisms are poorly understood, antibiotic therapy is frequently prescribed. The effects of such frequent antibiotic use on the intestinal microbiota are, to our knowledge, not known.

The intestinal microbiota plays an important role in human physiology, being involved in gut maturation, colonization resistance, several metabolic processes, regulation of intestinal epithelial proliferation and modulation of the mucosal and systemic immune response ${ }^{15-18}$. Based on this, probiotics are often given during and after antibiotic intake and beneficial effects have been observed in the prevention and treatment of $A A D^{19-22}$. Therefore, in the present study a multispecies probiotic was given containing 9 different probiotic strains selected on the basis of their in vitro ability to inhibit growth of Clostridium spp., in vitro survival of $\mathrm{GI}_{\text {passage }}{ }^{23}$ (i.e. low $\mathrm{pH}$ (2.5) as well as bile and digestive enzymes (pancreatin and pepsin)) and the absence of acquired antibiotic resistance. Moreover, a combination of strains was selected in which strainspecific properties were chosen to be additive or synergistic and mutual inhibition was absent. In addition, we previously showed that in healthy volunteers the intake of this multispecies probiotic during and after amoxycillin intake has no adverse effects and affects the faecal microbiota resulting in a faster restoration towards the preantibiotic state ${ }^{10}$.

The aim of the present study was to assess the disturbance of the dominant faecal microbiota and the possible restoration by a multispecies probiotic in patients with COPD treated with antibiotics for an acute exacerbation. Moreover, the effect on specific bacterial subgroups, using both culture-dependent and molecular based 
techniques, bowel habits, the incidence of antibiotic resistance, endotoxins and $\mathrm{pH}$ was also studied.

\section{Materials and methods}

\section{Subjects}

Forty-five patients, $18-80$ years of age, with moderate to severe COPD admitted to the Centre for Integrated Rehabilitation of Organ failure (CIRO Horn, The Netherlands) for a comprehensive interdisciplinary pulmonary rehabilitation program were included in the study. Patients had to have an acute exacerbation of COPD, which according to the Anthonissen-criteria ${ }^{24}$ should be treated by a 7-day antibiotic regimen, as judged by the physician in charge. Exclusion criteria were: immune-compromised subjects or treatment with immune-suppressive medication other than for COPD, pregnancy, lactation, hypersensitivity to the commonly prescribed antibiotics, pre-existing bowel pathology (including irritable bowel syndrome, inflammatory bowel disease, diverticulitis and cancer) and diarrhoea or constipation (in the last three days prior to inclusion). When using doxycyclin maintenance therapy, corticosteroids or gastric acid inhibitors patients had to be on stable medication for more than two weeks. Furthermore, patients were not allowed to use 1) laxatives and anti-diarrhoea medication in the two weeks before the start of and during the study; 2) regular proand prebiotic intake in the two weeks before the start of and during the study. Finally, ex-smokers had to have quitted smoking for at least two weeks before the start of the study.

The present study was conducted according to the guidelines laid down in the Declaration of Helsinki and all procedures involving patients were approved by the Medical Ethics Committee of the University Hospital Maastricht, The Netherlands. Written informed consent was obtained from all patients.

\section{Study design}

The study was executed according to a parallel, randomized, placebo-controlled, double-blind design. The total duration of the intervention and follow-up period was 63 days. All patients were prescribed a 7-day antibiotic treatment and were randomized to receive either 5 gram of a multispecies probiotic, Ecologic ${ }^{\oplus} A A D$, or placebo twice daily for 14 days starting simultaneously with antibiotic treatment. This resulted in three time periods defined as: day 1-7, "the antibiotic/probiotic period" in which all patients received a 7-day antibiotic treatment in combination with either probiotic or placebo; day 8-14, "the probiotic only period" in which patients received either probiotic or placebo; day 15-63, "the post-treatment follow-up period". The antibiotic treatment was given according to the physician's instructions (care as 
usual). The time between antibiotic and probiotic intake had to be at least two hours. Fresh faecal samples were collected on day 1 (the first sample patients were able to produce after inclusion), 7, 14 and 63. On the same day, a questionnaire was filled out including the Clinical COPD Questionnaire (CCQ $)^{25}$, questions on bowel movements (stool frequency and consistency (ranging from "1", hard lumps to "7", completely watery) according to the Bristol stool form scale ${ }^{26}$ ), use of pre- and probiotics, other medication taken, change of eating habits and compliance. In addition, a short questionnaire on bowel habits and side-effects (nausea, abdominal cramps, bloating, flatulence or other) had to be completed daily during probiotic/placebo intake. Moreover, this questionnaire was used to determine diarrhoea-like defecation defined as a defecation frequency $\geq 3$ per day and/or a faecal consistency (on the Bristol stool form scale) $\geq 5$ per day for at least two days.

\section{Probiotic}

The multispecies probiotic (Ecologic $A A D$ ) and the placebo were kindly provided by Winclove Bio Industries, Amsterdam, The Netherlands. Ecologic ${ }^{\oplus}$ AAD consists of 9 different bacterial species at $10^{8}$ colony forming units (CFU)/g each, $5 \%$ mineral mix and $15 \%$ Raftilose Synergy1. All strains are deposited in the Dutch Dairy Institute (NIZO, Ede, The Netherlands) culture collection and are characterised with (GTG)5-PCR fingerprinting as well as further fingerprinting using BOX-A1R and OPY11 primers, followed by SSU (16S)-rRNA sequence analysis (Bifidobacterium bifidum W23, B. lactis W51, Enterococcus faecium W54, Lactobacillus acidophilus W37 and W55, L. paracasei W20, L. plantarum W62, L. rhamnosus W71 and L. salivarius W24). Individual probiotic strains carry the European Union qualified presumption of safety (QPS) and all study products (both probiotic and placebo) were prepared under good manufacturing process (GMP) conditions. Each patient consumed sachets containing $5 \mathrm{~g}$ Ecologic ${ }^{\oplus} \mathrm{AAD}$ or placebo twice daily for two weeks. Sachets had to be dissolved in lukewarm water, left for $10 \mathrm{~min}$, stirred, and thereafter ingested. Both probiotic and placebo were packaged in identical, numbered sachets. The placebo sachets, indistinguish-able in colour, smell and taste, also contained $5 \%$ mineral mix and $15 \%$ Raftilose Synergy1 but contained cornstarch instead of the probiotic bacteria. In a pilot with 5 healthy volunteers, the two week consumption of 1.5 gram Raftilose Synergy1 per day did not affect the bifidobacterial communities (using PCR-DGGE and MPN-PCR) nor faecal lactic acid bacteria and lactobacilli counts (data not published).

\section{Sample processing}

Faecal samples were brought to the laboratory within 12 hours after defecation and divided into three portions: a) ten grams were centrifuged at $47000 \mathrm{~g}$ for 2 hours at $4^{\circ} \mathrm{C}$ to obtain faecal water, which was frozen immediately in twofold at $-80^{\circ} \mathrm{C}$ for analysis of endotoxin concentrations and determination of $\mathrm{pH}, \mathrm{b}$ ) five grams was diluted (1:4) with peptone water (Oxoid CM9, Basingstoke, Hants, UK) supplemented 
with cysteine (2.1 $\mathrm{mM}$ ) and glycerol (30\%) and used immediately for bacterial culture, c) the remaining faecal sample (1-15 g) was frozen directly at $-20^{\circ} \mathrm{C}$ for molecular analysis.

\section{DNA extraction}

DNA was isolated from approximately $0.1 \mathrm{~g}$ of frozen faeces, using the FastDNA SPIN Kit for Soil (Qbiogene, Carlsbad, CA, USA) and a FastPrep Instrument (FP120, Savant Instruments, Farmingdale, USA) following instruc-tions of the manufacturer. Extracted DNA was checked by agarose gel $(1.2 \% \mathrm{wt} / \mathrm{vol})$ electrophoresis in the presence of ethidium bromide.

\section{PCR amplification, DGGE analysis and quantitative PCR}

Total bacterial profiles from all samples were analyzed by DGGE of 16S rRNA gene fragments amplified by PCR with primers 0968-f-GC and 1401-r as described previously $^{27,28}$. Amplicons generated by PCR were separated by DGGE in $8 \%$ polyacrylamide gels using a Dcode TM system (Bio-Rad Laboratories, Hercules, USA) as described elsewhere ${ }^{28,29}$. For the separation of amplicons, gradients of $40-50 \%$ were used ( $100 \%$ denaturing solution was defined as $7 \mathrm{M}$ urea and $40 \%$ formamide). Gels were stained with $\mathrm{AgNO}_{3}{ }^{30}$. The DGGE gels were analyzed using Bionumerics 4.0 (Applied Maths BVBA, Sint-Martens-Latem, Belgium). Following normalization of gel images using markers loaded on either side and in the central lane of each gel, bands were defined for each sample using the bands searching algorithm within the program. Corresponding densitometric curves were used for a manual check of band definition, and bands with less than $1 \%$ of the total area of all bands were omitted from further analysis ${ }^{31}$. The similarity of the DGGE profiles (expressed as similarity index (SI)) with baseline (day 0) (e.g. 0-7, 0-14, etc.), and between consecutive days (e.g. 0-7, 7-14, etc.) was determined by calculating a Dice correlation coefficient (band based) according to the principle of moving window correlation ${ }^{32}$.

Quantitative detection of total bacteria, lactobacilli and bifidobacteria was performed using an iCycler IQ real-time detection system associated with the iCycler optical system interface software version 2.3 (Bio-Rad, Veenendaal, the Netherlands). Total bacterial 16S rRNA gene copies were quantified with primers Bact-1369-f and Prok$1492-r^{33}$, lactobacilli were quantified using primers LactoF and Lacto $R^{34}$ and bifidobacteria by primers Bif 164-f and $662-r^{35}$ as described previously ${ }^{36}$.

\section{Bacteriological culture}

Microbiological analysis of the faecal samples was determined as previously described $^{37}$. Briefly, tenfold serial dilutions of the faecal dilution were made in physiological saline $(0.85 \%)$ with cysteine- $\mathrm{HCl}(0.05 \%)$ and $40 \mu \mathrm{l}$ of these dilutions was inoculated on agar plates to culture and count total (facultative) aerobic bacteria 
(blood agar, Oxoid CM 271), enterobacteria (methylthionium chloride agar, Oxiod CM69), enterococci (KF-streptococcus agar, Oxoid CM701), total (facultative) anaerobic bacteria (fastidious anaerobic agar, Laboratory M LabGo), Bacteroides spp. (bile-esculine agar, Becton Dickinson 287920), lactobacilli (LAMVAB agar ${ }^{38}$ ) and yeasts (Sabouraud GM+C agar, Becton Dickinson 254041). Escherichia coli and enterococci isolates were identified using standard biochemical tests ${ }^{39}$ and stored at $-80 \circ \mathrm{C}$ for susceptibility testing.

\section{Susceptibility testing}

Antimicrobial susceptibilities (as minimal inhibitory concentrations (MIC values)) for the $E$. coli and enterococci isolates were determined using the microbroth dilution method with cation-adjusted Mueller-Hinton broth II (Becton, Dickinson and Company, Sparks, USA) according to the Clinical and Laboratory Standards Institute (CLSI, formerly the National Committee for Clinical Laboratory Standards) guidelines, as described previously ${ }^{40}$. Microtitre plates containing freeze-dried antibiotics were obtained from MCS Diagnostics BV (Swalmen, The Netherlands) after quality testing by the manufacturer and a guaranteed shelf-life of approximately one year. The MIC was defined as the lowest concentration showing no growth in the microtitre plates after $18 \mathrm{~h}$ of incubation at $37^{\circ} \mathrm{C}$. E. coli ATCC 35218 and ATCC 25922 and E. faecalis ATCC 29212 were used as quality control reference strains.

\section{Endotoxin and $\mathrm{pH}$}

The endotoxin (i.e. lipopolysaccharide) concentration was determined in faecal water using the Limulus amoebocyte lysate endochrome technique (Endosafe, end-point chromogenic analysis endochrome test kit, Charles River, Kent, UK), according to the manufacturer's specifications under pyrogen-free conditions. Pyrogen-free water was used to dilute the faecal samples, the test-solutions and was used as a negative control. The detection range of the assay was 0.015 to $0.12 \mathrm{EU} / \mathrm{ml}$ (9 EU/ng). Concentration of faecal endotoxin was expressed as nanogram of endotoxin per $\mathrm{ml}$ of faecal water. The $\mathrm{pH}$ of faecal water was determined using a PHM standard $\mathrm{pH}$ meter with a PHC3006 electrode (Radiometer Nederland BV, Zoetermeer, The Netherlands).

\section{Statistics}

The treatment allocation was concealed to all investigators and volunteers, until the study had been completed and all analyses had been performed.

The primary outcome of this study was to assess the restoration of the dominant intestinal microbiota after antibiotic treatment in probiotic- and placebo-treated patients by PCR-DGGE. Based on data from our previous study in healthy volunteers ${ }^{10}$, it was estimated that 14 volunteers per treatment group would provide a $80 \%$ power 
to detect a $20 \%$ increase in $\mathrm{SI}$ after disturbance of antibiotic intake, assuming a variance of $18 \%$ and a two-sided significance level of 0.05 .

Secondary outcomes were to assess changes in probiotic- and placebo-treated patients during and after antibiotic intake in: 1) specific bacterial subgroups, using both culture-dependent and molecular based techniques; 2) bowel habits; 3) the incidence of antibiotic resistance; 4) endotoxin concentration and $\mathrm{pH}$. In addition, the disturbance of the dominant intestinal microbiota in subjects who developed AAD compared to those who did not was assessed.

Statistical evaluation of DGGE band richness, quantitative PCR, culture, endotoxin concentration and $\mathrm{pH}$ was carried out using linear mixed model analysis as described previously $^{10,37}$.

For all other data the nonparametric Mann-Whitney U-test was used for two-group comparisons of independent ordinal and interval values while the nonparametric Wilcoxon signed-ranked test was used for comparison of related ordinal and interval values. If data was normally distributed the Students t-test was used. For dichotomous variables, Pearson's $\chi^{2}$ test was applied to test for differences between groups. All tests were conducted using SPSS version 11.0 (SPSS Inc, Chicago, IL) and a p-value below 0.05 was considered statistically significant.

\section{Results}

\section{Subjects}

From September 2005 to December 2006, 45 patients were enrolled of which 30 patients completed the study, 17 in the probiotic and 13 in the placebo group. Eleven patients $(73 \%)$ discontinued the study in the first week, three patients $(20 \%)$ in the second week and one patient (7\%) thereafter. The most common reasons for discontinuation included; 'not being able or willing to collect faeces', 'perception of the study load as being too demanding considering the current medical condition' and 'not liking the taste of the study product'. Baseline demographics and clinical characteristics were comparable for both groups (Table 6.1). The antibiotic treatments prescribed for the exacerbation were mostly doxycyclin and amoxicillin/clavulanic acid and were also comparable for both groups. The mean $( \pm S D)$ frequency of antibiotic use was 3.1 \pm 2.4 treatments in the year prior to inclusion.

Eight patients in the probiotic group and five patients in the placebo group $(p=0.72)$ changed their dietary habits during the study period, mostly based on medical indication (energy restriction $(n=10)$, supplementation with nutrient drinks $(n=2)$, loss of appetite $(n=1)$. Apart from the exclusion criteria patients in both groups used diverse and extensive medication mostly belonging to the groups of analgesia, antidepressants, antihypertensives, diuretics, sympa-thicomimetics, xanthines and parasympathicolytics. 
There were no reported adverse events related to the study product. Compliance was assessed by the self reported number of study product (sachets) that was consumed.

Table 6.1 Subject characteristics (Mean values ( \pm SD) are given, unless stated otherwise).

\begin{tabular}{lcccc}
\hline & Probiotic $(\mathrm{n}=17)$ & \multicolumn{2}{c}{ Placebo $(\mathrm{n}=13)$} \\
\hline Gender m/f $(\mathrm{n})$ & $12 / 5$ & & $7 / 6$ & 7.4 \\
Age $($ years) & 59.9 & 13.3 & 63.4 & \\
Current smokers $(\mathrm{n})$ & 3 & & 1 & 4.9 \\
$\mathrm{BMI}\left(\mathrm{Kg} / \mathrm{m}^{2}\right)$ & 27.1 & 6.6 & 27.4 & 5.7 \\
FFMI $\left(\mathrm{Kg} / \mathrm{m}^{2}\right)$ & 17.7 & 2.6 & 18.4 & 28.0 \\
FEV $(\%$ pred) & 43.0 & 20.3 & 40.8 & 19.5 \\
FVC $(\%$ pred) & 84.7 & 17.1 & 75.6 & 0.9 \\
CCQ total score & 3.0 & 0.7 & 3.25 & 2.1 \\
Antibiotic treatments in previous year & 2.9 & 2.6 & 3.3 & \\
Use of pre- and probiotics before the study $(\mathrm{n})$ & 0 & & $1^{\dagger}$ & \\
Compliance ${ }^{\ddagger}$ probiotic/placebo intake $(\%)$ & 98.1 & 4.6 & 99.7 & 1.0 \\
\hline
\end{tabular}

BMI, body mass index; FFMI, fat free mass index; $F E V_{1}$, forced expiratory volume in 1s; FVC, forced vital capacity; $C C Q$, clinical COPD questionnaire. *There was no significant difference $(p>0.05)$ between the probiotic and the placebo group. ${ }^{\dagger}$ Yakult $1 \mathrm{dd} .{ }^{\ddagger}$ Compliance is self-reported.

\section{Bowel habits}

The mean $( \pm$ SEM) defecation frequency (Probiotic, 1.4 $\pm 0.4,2.0 \pm 0.4,1.6 \pm 0.3$; Placebo, $1.1 \pm 0.1,1.4 \pm 0.2,1.6 \pm 0.3$ ) and consistency (Probiotic, 3.9 $\pm 0.4,4.5 \pm 0.3,4.6 \pm 0.2$; Placebo $3.5 \pm 0.4,4.2 \pm 0.4,4.0 \pm 0.4$ ) before antibiotic and probiotic intake (day 0 i.e. baseline), during the antibiotic/probiotic period (day 1-7) and during the probiotic only period (day 8-14) respectively, did not differ significantly between the probiotic and the placebo group. In the probiotic group, the defecation frequency during antibiotic intake was significantly higher $(2.0 \pm 0.4)$ compared to baseline $(1.4 \pm 0.4)$ $(p<0.05)$. During and one week after antibiotic intake (day 1-14), diarrhoea-like bowel movements were reported frequently in both the probiotic (77\%) and the placebo (70\%) group ( $p>0.05)$.

\section{PCR-DGGE analysis of the dominant faecal microbiota}

DGGE analysis of the dominant faecal microbiota showed high inter-individual variation in total bacterial profiles between patients and a mean number of 15.4 bands per profile (i.e. band richness) at the start of the study (day 0 ). No difference in band richness between the probiotic and the placebo group or over time within both groups was found (Figure 6.1).

Similarity indices (SIs) were high and remained stable during and after antibiotic treatment (Table 6.2). No effect of probiotic intake was observed. At day 63 lower SIs (compared to baseline) were found in both groups, which was only significant in the probiotic group. Moreover, no association between the Sls of the total bacterial 
profiles during amoxycillin and probiotic intake and the occurrence of diarrhoea-like bowel movements was observed (data not shown).

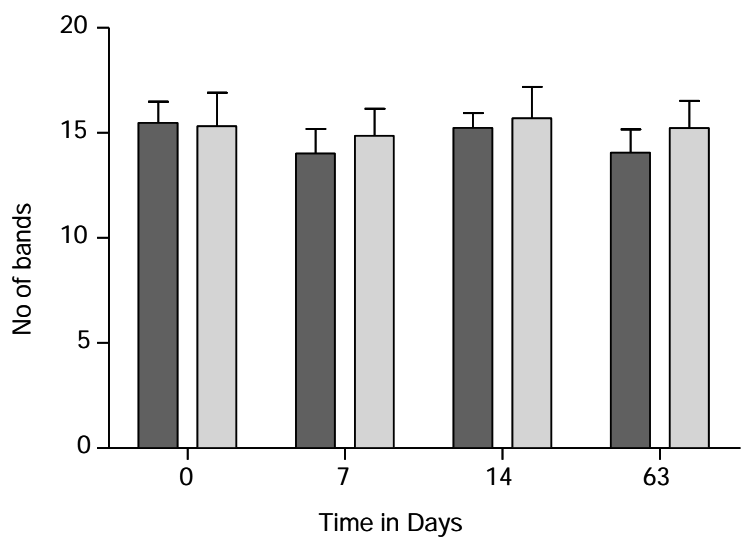

Figure 6.1 Total bacterial band richness (Mean ( \pm SEM) no of bands) obtained from DGGE profiles of probiotic and placebo treated patients before, during (day 1-7) and after antibiotic intake.

$\square=$ probiotic and $\square=$ placebo.

Table 6.2 Median (range) similarity indices (SIs) of the total bacterial profiles in percentages in the probiotic versus the placebo group compared to baseline $(t=0)$ and between consecutive intervals.

\begin{tabular}{lccccc}
\hline & \multicolumn{5}{c}{ SI (\%) } \\
\cline { 2 - 6 } & $0-7$ & $0-14$ & $0-63$ & $7-14$ & $14-63$ \\
\hline Probiotic* $(n=17)$ & $90(69-98)$ & $87(46-96)$ & $88(65-95)$ & $90(56-98)$ & $90(63-98)$ \\
Placebo(n=13) & $94(44-98)$ & $93(45-98)$ & $84(39-97)$ & $91(69-98)$ & $89(55-98)$ \\
\hline
\end{tabular}

$*=$ Within group decrease $0-63$ vs. $0-7, p<0.05$

\section{Quantitative PCR}

No differences in the 16S rRNA gene copy numbers of total bacteria, lactobacilli or bifidobacteria were observed between the probiotic and the placebo group. Within both groups, a significant decrease of bifidobacteria was found during antibiotic intake, which increased again after cessation (Figure 6.2). During probiotic intake (day 14), a small increase in total bacteria was observed in the probiotic group, which significantly decreased again after cessation. Moreover, a significant increase in lactobacilli was observed in the probiotic group (Figure 6.2). For all bacterial species studied values on day 63 did not differ significantly from day 0 apart from a decrease in bifidobacteria in the probiotic group and a decrease in total bacteria in the placebo group (Figure 6.2). To adjust for possible differences in faecal consistency, data were also analyzed as $16 \mathrm{~S}$ rRNA gene copies per $\mathrm{mg}$ faecal protein with similar results compared to the unadjusted data (data not shown). 


\section{Bacteriological culture}

No differences in either aerobic or anaerobic cultured bacterial species were observed between the probiotic and the placebo group (Table 6.3). However, group specific differences were observed over time. During "the probiotic only period (14 days)", the mean number of faecal enterococci increased significantly within the probiotic group, returning to pre-treatment level 7 weeks after cessation $(p<0.05)$ (Table 6.3). Moreover, within the probiotic group a significant decrease was found in enterobacteria (day 7 vs. day 0 ) and significant increases were observed over time in total aerobes (day 7 and day 14 vs. day 0 and day 63), Bacteroides spp. (day 14 vs. day 0 and day 63) and lactobacilli (day 14 and 63 vs. day 7$)(p<0.05)$. Within both groups a significant increase in yeast was found during antibiotic intake (day 7) (Table 6.3).

For all bacterial species, in both groups, bacterial counts on day 63 did not differ significantly from day 0 .
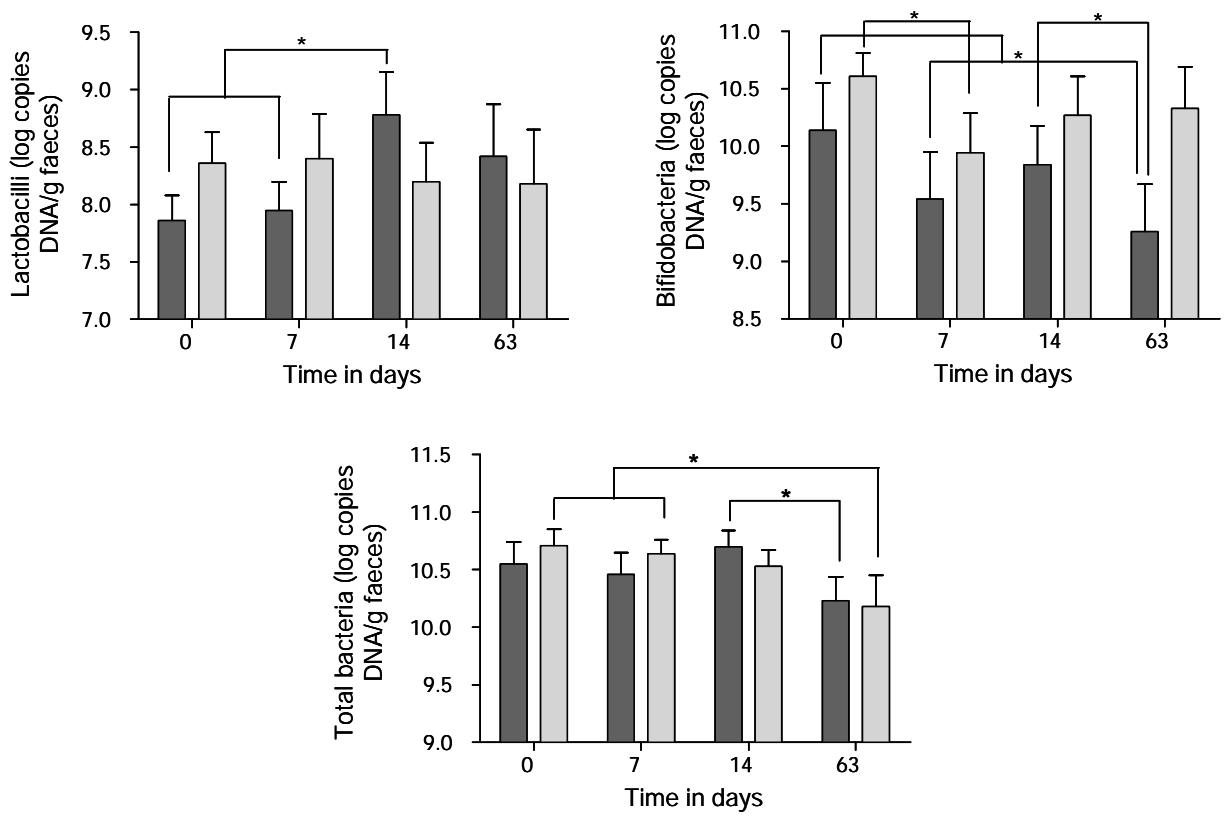

Figure 6.2 Quantitative PCR results expressed as mean ( \pm SEM) log copies DNA/g faeces obtained from faeces of probiotic and placebo treated patients before, during (day 1-7) and after antibiotic intake. $\square=$ probiotic and $\square=$ placebo, ${ }^{*} p<0.05$.

\section{Antimicrobial susceptibility}

E.coli were isolated in $47-82 \%$ (probiotic) and $54-69 \%$ (placebo) of the faecal samples and enterococci were isolated in $77-100 \%$ (probiotic) and 92\% (placebo) of the faecal samples from the patients at the different points of time. No significant differences in antibiotic susceptibility of $E$. coli and enterococci were observed. 


\section{Endotoxin and $\mathrm{pH}$}

Endotoxin concentrations (mean \pm SEM), expressed as log $\mathrm{ng} / \mathrm{ml}$ faecal water, did not differ significantly between groups and within both groups during the study period (Probiotic, 2.5 $\pm 0.1,2.6 \pm 0.08,2.5 \pm 0.07$ and 2.4 \pm 0.09 ; Placebo, 2.5 $\pm 0.06,2.5 \pm 0.09$, $2.5 \pm 0.09,2.5 \pm 0.01$ at $\mathrm{t}=0,7,14$ and 63 , respectively). Also, no significant correlation between the number of enterobacteria cultured and endotoxin concentration was found.

The $\mathrm{pH}$ of faecal water ranged from 6.3-6.7, and did not differ between and within both groups during the study period.

Table 6.3 Numbers of bacteria cultured expressed as log cfu/g faeces (Mean values ( \pm SEM)).

\begin{tabular}{|c|c|c|c|c|}
\hline & Day 0 & Day 7 & Day 14 & Day 63 \\
\hline \multicolumn{5}{|c|}{ Total aerobic microbiota } \\
\hline Probiotic $^{1}$ & $7.4(0.2)$ & $8.2(0.3)$ & $8.4(0.2)$ & $7.4(0.3)$ \\
\hline Placebo & $7.5(0.4)$ & $7.3(0.3)$ & $7.5(0.3)$ & $7.4(0.3)$ \\
\hline \multicolumn{5}{|c|}{ Enterobacteriaceae } \\
\hline Probiotic $^{2}$ & $6.5(0.4)$ & $4.6(0.8)$ & $5.3(0.7)$ & $5.3(0.6)$ \\
\hline Placebo & $5.5(0.7)$ & $4.1(0.8)$ & $4.5(0.8)$ & $5.9(0.6)$ \\
\hline \multicolumn{5}{|l|}{ Enterococci } \\
\hline Probiotic $^{3}$ & $5.5(0.4)$ & $5.8(0.5)$ & $7.1(0.4)$ & $4.9(0.5)$ \\
\hline Placebo & $5.3(0.5)$ & $6.4(0.4)$ & $5.7(0.6)$ & $5.4(0.4)$ \\
\hline \multicolumn{5}{|c|}{ Total anaerobic microbiota } \\
\hline Probiotic & $9.5(0.2)$ & $9.1(0.5)$ & $9.1(0.5)$ & $9.2(0.2)$ \\
\hline Placebo & $9.5(0.1)$ & $9.5(0.2)$ & $9.1(0.7)$ & $9.8(0.1)$ \\
\hline \multicolumn{5}{|c|}{ Bacteroides spp. } \\
\hline Probiotic $^{4}$ & $7.2(0.3)$ & $7.6(0.4)$ & $8.1(0.2)$ & $7.2(0.3)$ \\
\hline Placebo & $7.0(0.5)$ & $7.9(0.2)$ & $7.8(0.3)$ & $7.8(0.2)$ \\
\hline \multicolumn{5}{|l|}{ Lactobacilli } \\
\hline Probiotic $^{5}$ & $5.3(0.4)$ & $5.1(0.5)$ & $6.0(0.5)$ & $5.9(0.5)$ \\
\hline Placebo & $5.3(0.6)$ & $5.1(0.4)$ & $5.7(0.5)$ & $5.6(0.5)$ \\
\hline \multicolumn{5}{|l|}{ Yeast } \\
\hline Probiotic $^{6}$ & $2.8(0.4)$ & $3.9(0.4)$ & $3.2(0.3)$ & $3.2(0.4)$ \\
\hline Placebo $^{7}$ & $2.2(0.4)$ & $3.2(0.4)$ & $2.9(0.4)$ & $2.2(0.3)$ \\
\hline
\end{tabular}

\footnotetext{
${ }^{1}$ Within group increase $t=7 / 14$ vs. $t=0 / 63, p<0.05 ;{ }^{2}$ Within group decrease $t=7$ vs. $t=0, p<0.05$;

${ }^{3}$ Within group increase $t=14$ vs. $t=0 / 7 / 63, p<0.05 ;{ }^{4}$ Within group increase $t=14 v s . t=0 / 63, p<0.05$;

${ }^{5}$ Within group increase $t=14 / 63$ vs. $t=7, p<0.05 ;{ }^{6}$ Within group increase $t=7$ vs. $t=0, p<0.05$;

${ }^{7}$ Within group increase $t=7$ vs. $t=0 / 63, p<0.05$.
}

\section{Discussion}

The present double-blind placebo-controlled randomized study demonstrated that the intake of a multispecies probiotic in this COPD population with a history of frequent antibiotic use had no effect on the composition of the dominant faecal microbiota. Moreover, in contrast to previous findings in healthy volunteers, no effect 
of antibiotic intake on the composition of the dominant faecal microbiota could be found and no difference in SIs was observed between the group of patients who developed diarrhoea-like bowel movements and those who did not. Looking at specific bacterial subgroups, using both molecular and culture-dependent techniques, a significant but small antibiotic effect was observed in both groups, i.e. an increase in yeasts and a decrease in bifidobacteria. No differences were observed when comparing the probiotic with the placebo group. However, changes in specific bacterial groups over time were seen in the probiotic group only, suggesting a modest probiotic effect.

In healthy humans the faecal microbiota is host specific and relatively stable over time (SIs $>80 \%)^{5,6}$. It is well documented that despite methodological differences, antibiotic treatment, especially amoxycillin, cephalosporins, clindamycin or broad-spectrum antibiotics, has a marked effect on the composition of the intestinal microbiota ${ }^{8,41,42}$, which may result in diarrhoea. In line with these findings, we have previously shown that amoxycillin intake strongly affected the composition of the dominant faecal microbiota in healthy volunteers, indicated by a low mean SI $(<52 \%)$ and a decrease in bacterial richness (i.e. number of bands). We also showed that a lower stability of the dominant intestinal microbiota (i.e. more disruption) is related to a higher risk of developing $A A D^{10}$. Remarkably, using the same methods, in the COPD population mean SIs were high (>90\%) and both SIs and band richness remained stable during and after antibiotic intake. Moreover, no difference in SIs (i.e. disruption) was observed in the group of patients who developed diarrhoea-like bowel movements compared to those who did not. This unexpected lack of effect on the microbiota could be attributed to the frequent antibiotic use in the past by this population. Recently, it has been shown that antibiotic intake can cause medium and long-term disturbances in (specific) bacterial populations ${ }^{9,10}$. Moreover, as antibiotics only affect sensitive strains, extensive antibiotic use could have caused a prolonged narrowing of the diversity into a dominant faecal microbiota consisting of microbial populations insensitive to the given antibiotics. This assumption is further supported by the fact that bacterial band richness in COPD patients at the start of the study was relatively low, i.e. being at the same level as in healthy volunteers during amoxycillin intake, in whom band richness was significantly reduced ${ }^{10}$. It is known that the bacterial diversity decreases with age ${ }^{43}$, and we readily acknowledge that the mean age of the patients in the present was significantly higher than of the healthy volunteers in the previous study. However, this can not account for the fact that no antibiotic effect on bacterial diversity was observed in the COPD patients. In fact, this finding was corroborated by a similar trend in endotoxin concentrations. Previously, antibiotics have been shown to increase the bioavailability of endotoxin originating from Gramnegative bacteria ${ }^{44-47}$. However, in our study we found that endotoxin concentrations remained stable during and after antibiotic intake and were even slightly higher than 
the levels found in healthy volunteers during amoxycillin intake where an increase was found ${ }^{37}$.

In addition to qualitative data on microbiota composition obtained by DGGE analysis of $16 \mathrm{~S}$ rRNA gene fragments, quantitative analysis of specific bacterial subgroups was performed by culture and quantitative PCR.

With culture, apart from a small but clinically insignificant rise in yeasts, no changes were observed, that could be attributed to antibiotic intake. Moreover, with quantitative PCR no effect of antibiotic intake was found on total bacteria, which is in line with the DGGE results. This further supports the lack of observed antibiotic effect. However, the number of bifidobacteria was significantly affected in both groups during antibiotic intake corresponding with the reported high susceptibility of bifidobacteria to broad-spectrum antibiotics ${ }^{48-51}$.

Various effects over time were observed in the probiotic group only, which can be attributed to probiotic intake. The increase in faecal enterococci and lactobacilli during probiotic intake is in line with literature showing that the intake of a probiotic is able to transiently increase the faecal number of the ingested strains ${ }^{52-54}$. We previously showed that the consumption of this multispecies probiotic, containing E. faecium, was associated with a significant increase in the concentration of faecal enterococci in the probiotic group and that the pulse field gel electrophoreses patterns of the enterococci cultured were similar to the orally administered E. faecium ${ }^{37}$. Apart from lactobacilli and the E. faecium, the multispecies probiotic also contained bifidobacteria. However, no increase in bifidobacteria could be observed, probably due to the fact that the administered daily amount $\left(2 \times 10^{9} \mathrm{cfu}\right)$ was too low in relation to the baseline value.

The multispecies product was well tolerated and no adverse events related to the product were reported. The majority of literature shows that probiotics can significantly reduce the relative risk of developing $A A D^{19,20,22}$. In contrast, in the present study, the intake of the multispecies probiotic did not result in a decrease in diarrhoea-like bowel movements. However, earlier we showed, in healthy volunteers, that the intake of the same multispecies probiotic had a restoring and stabilizing impact on the dominant faecal microbiota after amoxycillin intake ${ }^{10}$. A comparable observation was made by Kajander et al., when a multispecies probiotic was given to IBS patients ${ }^{55}$. In this study antibiotic intake did not affect the composition of the dominant microbiota, probably contributing to the lack of effect of probiotic intake on the occurrence of diarrhoea-like bowel movements in this COPD population. Furthermore, as the microbiota seems to be profoundly altered by the frequent prior antibiotic use, a much longer probiotic treatment might be required to restore such an effect. 
We acknowledge that this study has some limitations. Inherent to the nature and severity of the disease, diverse and extensive medication was used in this COPD population and we cannot exclude that some medication had an impact on the composition of the microbiota. Nevertheless, patients had to be on stable medication for corticosteroids, gastric acid inhibitors and doxycyclin maintenance therapy before and during the study to limit this effect. Although we clearly showed no effect of antibiotic treatment on the intestinal microbiota due to the heterogeneity of the population and the limited sample size, subtle changes in subgroups analyses may have failed to be detected.

Currently, it is widely accepted that antibiotic treatment profoundly affects the intestinal microbiota. However, our findings show that the dominant faecal microbiota was not affected upon antibiotic treatment in COPD patients with a history of frequent antibiotic use. This prolonged antibiotic pressure seems to have caused a long-term imbalance of the microbiota with a shift toward populations resistant to antibiotics. Furthermore, the present study demonstrates that the short-term intake of a multispecies probiotic had a modest effect on the intestinal microbiota, albeit much smaller than was previously observed for healthy adults. Nevertheless, this did not result in a restoration of the microbiota imbalance and as a result no reduction in diarrhoea-like bowel movements was found.

These results warrant further confirmation in studies with a higher number of patients, with higher doses of probiotics and a longer administration period.

In future studies it would be very interesting to determine to what extent these disturbances are permanent, what the effect of these disturbances is and if probiotic supplementation is able to either prevent or with prolonged use reverse such an imbalance. 


\section{References}

1. Rajilic-Stojanovic M, Smidt H, de Vos WM. Diversity of the human gastrointestinal tract microbiota revisited. Environ Microbiol. 2007;9:2125-36.

2. Turnbaugh PJ, Hamady M, Yatsunenko T, Cantarel BL, Duncan A, Ley RE, Sogin ML, Jones WJ, Roe BA, Affourtit JP, Egholm M, Henrissat B, Heath AC, Knight R, Gordon JI. A core gut microbiome in obese and lean twins. Nature. 2008;457:480-4.

3. Zoetendal EG, Vaughan EE, de Vos WM. A microbial world within us. Mol Microbiol. 2006;59:1639-50.

4. Maukonen J, Matto J, Satokari R, Soderlund H, Mattila-Sandholm T, Saarela M. PCR DGGE and RT-PCR DGGE show diversity and short-term temporal stability in the Clostridium coccoides-Eubacterium rectale group in the human intestinal microbiota. FEMS Microbiol Ecol. 2006;58:517-28.

5. Vanhoutte T, Huys G, De Brandt E, Swings J. Temporal stability analysis of the microbiota in human feces by denaturing gradient gel electrophoresis using universal and group-specific 16S rRNA gene primers. FEMS Microbiol Ecol. 2004;48:437-46.

6. Zoetendal EG, Akkermans AD, De Vos WM. Temperature gradient gel electrophoresis analysis of $16 \mathrm{~S}$ rRNA from human fecal samples reveals stable and host-specific communities of active bacteria. Appl Environ Microbiol. 1998;64:3854-9.

7. Zoetendal EG, Rajilic-Stojanovic M, de Vos WM. High-throughput diversity and functionality analysis of the gastrointestinal tract microbiota. Gut. 2008;57:1605-15.

8. Dethlefsen L, Huse S, Sogin ML, Relman DA. The pervasive effects of an antibiotic on the human gut microbiota, as revealed by deep 16S rRNA sequencing. PLoS Biol. 2008;6:e280.

9. Jernberg C, Lofmark S, Edlund C, Jansson JK. Long-term ecological impacts of antibiotic administration on the human intestinal microbiota. Isme J. 2007;1:56-66.

10. Koning CJM, Jonkers DMAE, Stobberingh EE, Smidt H, Stockbrugger RW. Effect of a multispecies probiotic on the composition of the dominant faecal flora in healthy volunteers. Gut. 2005;54:A243.

11. Barnes PJ. Mechanisms in COPD: differences from asthma. Chest. 2000;117:10S-4S.

12. Turato G, Zuin R, Saetta M. Pathogenesis and pathology of COPD. Respiration. 2001;68:117-28.

13. Burge S, Wedzicha JA. COPD exacerbations: definitions and classifications. Eur Respir J Suppl. 2003; 41:46s-53s.

14. Donaldson GC, Seemungal TA, Patel IS, Lloyd-Owen SJ, Wilkinson TM, Wedzicha JA. Longitudinal changes in the nature, severity and frequency of COPD exacerbations. Eur Respir J. 2003;22:931-6.

15. Cebra JJ. Influences of microbiota on intestinal immune system development. Am J Clin Nutr. 1999;69:1046S-51S.

16. Hogenauer C, Hammer HF, Krejs GJ, Reisinger EC. Mechanisms and management of antibioticassociated diarrhea. Clin Infect Dis. 1998;27:702-10.

17. Macpherson AJ, Uhr T. Induction of protective IgA by intestinal dendritic cells carrying commensal bacteria. Science. 2004;303:1662-5.

18. Noverr MC, Huffnagle GB. Does the microbiota regulate immune responses outside the gut? Trends Microbiol. 2004;12:562-8.

19. Cremonini F, Di Caro S, Nista EC, Bartolozzi F, Capelli G, Gasbarrini G, Gasbarrini A. Meta-analysis: the effect of probiotic administration on antibiotic-associated diarrhoea. Aliment Pharmacol Ther. 2002;16:1461-7.

20. D'Souza AL, Rajkumar C, Cooke J, Bulpitt CJ. Probiotics in prevention of antibiotic associated diarrhoea: meta- analysis. BMJ. 2002;324:1361.

21. Hickson M, D'Souza AL, Muthu N, Rogers TR, Want S, Rajkumar C, Bulpitt CJ. Use of probiotic Lactobacillus preparation to prevent diarrhoea associated with antibiotics: randomised double blind placebo controlled trial. BMJ. 2007;335:80.

22. McFarland LV. Meta-analysis of probiotics for the prevention of antibiotic-associated diarrhea and the treatment of Clostridium difficile disease. Am J Gastroenterol. 2006;101:812-22.

23. Timmerman HM, Niers LE, Ridwan BU, Koning CJ, Mulder L, Akkermans LM, Rombouts FM, Rijkers GT. Design of a multispecies probiotic mixture to prevent infectious complications in critically ill patients. Clin Nutr. 2007;26:450-9.

24. Anthonisen NR, Manfreda J, Warren CP, Hershfield ES, Harding GK, Nelson NA. Antibiotic therapy in exacerbations of chronic obstructive pulmonary disease. Ann Intern Med. 1987;106:196-204. 
25. van der Molen T, Willemse BW, Schokker S, ten Hacken NH, Postma DS, Juniper EF. Development, validity and responsiveness of the Clinical COPD Questionnaire. Health Qual Life Outcomes. 2003;1:13.

26. O'Donnell LJ, Virjee J, Heaton KW. Detection of pseudodiarrhoea by simple clinical assessment of intestinal transit rate. BMJ. 1990;300:439-40.

27. Nubel U, Engelen B, Felske A, Snaidr J, Wieshuber A, Amann RI, Ludwig W, Backhaus H. Sequence heterogeneities of genes encoding 16S rRNAs in Paenibacillus polymyxa detected by temperature gradient gel electrophoresis. J Bacteriol. 1996;178:5636-43.

28. Sousa DZ, Pereira MA, Stams AJ, Alves MM, Smidt H. Microbial communities involved in anaerobic degradation of unsaturated or saturated long-chain fatty acids. Appl Environ Microbiol. 2007;73:1054-64.

29. Muyzer G, de Waal EC, Uitterlinden AG. Profiling of complex microbial populations by denaturing gradient gel electrophoresis analysis of polymerase chain reaction-amplified genes coding for $16 \mathrm{~S}$ rRNA. Appl Environ Microbiol. 1993;59:695-700.

30. Sanguinetti CJ, Dias Neto E, Simpson AJ. Rapid silver staining and recovery of PCR products separated on polyacrylamide gels. Biotechniques. 1994;17:914-21.

31. Konstantinov SR, Zhu W-Y, Williams BA, Tamminga S, de Vos WM, Akkermans ADL. Effect of fermentable carbohydrates on faecal bacterial communities as revealed by DGGE analysis of $16 \mathrm{~S}$ rDNA. FEMS Microbiol Ecol 2003;43:225-35.

32. Possemiers S, Verthe K, Uyttendaele S, Verstraete W. PCR-DGGE-based quantification of stability of the microbial community in a stimulator of the human intestinal microbial ecosystem. FEMS Microbiol Ecol. 2004;49:495-507.

33. Suzuki MT, Taylor LT, DeLong EF. Quantitative analysis of small-subunit rRNA genes in mixed microbial populations via 5'-nuclease assays. Appl Environ Microbiol. 2000;66: 4605-14.

34. Byun R, Nadkarni MA, Chhour KL, Martin FE, Jacques NA, Hunter N. Quantitative analysis of diverse Lactobacillus species present in advanced dental caries. J Clin Microbiol. 2004;42:3128-36.

35. Satokari RM, Vaughan EE, Akkermans AD, Saarela M, de Vos WM. Bifidobacterial diversity in human feces detected by genus-specific PCR and denaturing gradient gel electrophoresis. Appl Environ Microbiol. 2001;67:504-13.

36. Fuentes S, Egert M, Jimenez-Valera M, Monteoliva-Sanchez M, Ruiz-Bravo A, Smidt H. A strain of Lactobacillus plantarum affects segmented filamentous bacteria in the intestine of immunosuppressed mice. FEMS Microbiol Ecol. 2008;63:65-72.

37. Koning CJ, Jonkers DM, Stobberingh EE, Mulder L, Rombouts FM, Stockbrugger RW. The effect of a multispecies probiotic on the intestinal microbiota and bowel movements in healthy volunteers taking the antibiotic Amoxycillin. Am J Gastroenterol. 2007;102:1-12.

38. Hartemink R, Domenech VR, Rombouts FM. LAMVAB - a new selective medium for the isolation of lactobacilli from faeces. J Microbiol Methods. 1997;29:77-84.

39. Bruinsma N, Hutchinson JM, van den Bogaard AE, Giamarellou H, Degener J, Stobberingh EE. Influence of population density on antibiotic resistance. J Antimicrob Chemother. 2003;51:385-90.

40. Nys S, Okeke IN, Kariuki S, Dinant GJ, Driessen C, Stobberingh EE. Antibiotic resistance of faecal Escherichia coli from healthy volunteers from eight developing countries. J Antimicrob Chemother. 2004;54:952-5.

41. De La Cochetiere MF, Durand T, Lepage P, Bourreille A, Galmiche JP, Dore J. Resilience of the dominant human fecal microbiota upon short-course antibiotic challenge. J Clin Microbiol. 2005;43:5588-92.

42. Sullivan A, Edlund C, Nord CE. Effect of antimicrobial agents on the ecological balance of human microflora. Lancet Infect Dis. 2001;1:101-14.

43. Woodmansey EJ. Intestinal bacteria and ageing. J Appl Microbiol. 2007;102:1178-86.

44. Goris H, de Boer F, van der Waaij D. Kinetics of endotoxin release by gram-negative bacteria in the intestinal tract of mice during oral administration of bacitracin and during in vitro growth. Scand J Infect Dis. 1988;20:213-9.

45. Holzheimer RG. Antibiotic induced endotoxin release and clinical sepsis: a review. J Chemother. 2001;13:159-72.

46. Hurley JC. Endotoxemia: methods of detection and clinical correlates. Clin Microbiol Rev. 1995;8: 268-92. 
47. Hurley JC. Antibiotic-induced release of endotoxin. A therapeutic paradox. Drug Saf. 1995;12:183-95.

48. Ammor MS, Florez AB, Mayo B. Antibiotic resistance in non-enterococcal lactic acid bacteria and bifidobacteria. Food Microbiol. 2007;24:559-70.

49. Brismar B, Edlund C, Nord CE. Impact of cefpodoxime proxetil and amoxicillin on the normal oral and intestinal microflora. Eur J Clin Microbiol Infect Dis. 1993;12:714-9.

50. Lode H, Von der Hoh N, Ziege S, Borner K, Nord CE. Ecological effects of linezolid versus amoxicillin/clavulanic acid on the normal intestinal microflora. Scand J Infect Dis. 2001;33:899-903.

51. Woodmansey EJ, McMurdo ME, Macfarlane GT, Macfarlane S. Comparison of compositions and metabolic activities of fecal microbiotas in young adults and in antibiotic-treated and non-antibiotictreated elderly subjects. Appl Environ Microbiol. 2004;70:6113-22.

52. Goossens D, Jonkers D, Russel M, Stobberingh E, Van Den Bogaard A, Stockbrügger R. The effect of Lactobacillus plantarum $299 \mathrm{v}$ on the bacterial composition and metabolic activity in faeces of healthy volunteers: a placebo-controlled study on the onset and duration of effects. Aliment Pharmacol Ther. 2003;18:495-505.

53. Lund B, Edlund C, Barkholt L, Nord CE, Tvede M, Poulsen RL. Impact on human intestinal microflora of an Enterococcus faecium probiotic and vancomycin. Scand J Infect Dis. 2000;32:627-32.

54. Tannock GW, Munro K, Harmsen HJ, Welling GW, Smart J, Gopal PK. Analysis of the fecal microflora of human subjects consuming a probiotic product containing Lactobacillus rhamnosus DR20. Appl Environ Microbiol. 2000;66:2578-88.

55. Kajander K, Myllyluoma E, Rajilic-Stojanovic M, Kyronpalo SS, Rasmussen M, Jarvenpaa SS, Zoetendal EG, de Vos WM, Vapaatalo $H$, Korpela R. Clinical trial: multispecies probiotic supplementation alleviates the symptoms of IBS and stabilises intestinal microbiota. Aliment Pharmacol Ther. 2007;27:48-57. 



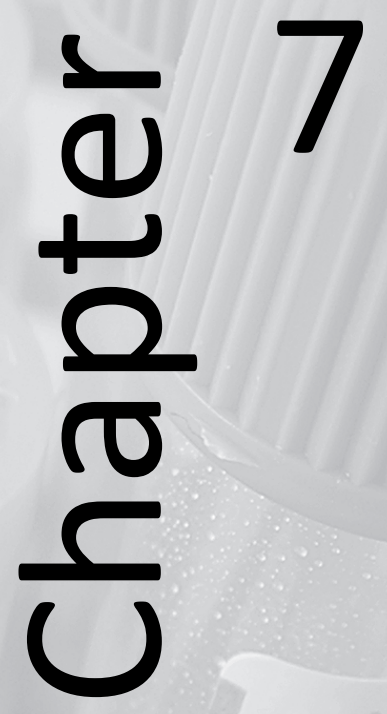




\section{Immunomodulatory effect of a multispecies probiotic during and after antibiotic therapy in COPD patients}




\section{Abstract}

Antibiotic treatment profoundly affects the intestinal microbiota and can lead to long-term changes in microbiota composition. Perturbations in the microbiota can influence immune responses. Probiotics may restore such a disturbance and can also modulate the host immune system. The objective of the present study was to investigate the effect of a multispecies probiotic on immune biomarkers during and after antibiotic intake in patients with a history of frequent antibiotic use. In this randomized placebo-controlled double-blind study, 30 COPD patients treated with antibiotics for an acute exacerbation received five gram of a multispecies probiotic $\left(10^{10} \mathrm{cfu} /\right.$ day $)$ or placebo twice daily for two weeks, starting simultaneously with antibiotic intake. Blood and saliva samples were collected at day 0, 7, 14 and 63 to determine total and differential leukocyte counts, CRP, albumin, immunoglobulins and inflammatory mediators.

Compared to placebo, probiotic intake did not alter the analyzed biomarkers apart from a significant decrease of WBC at day 7. Although no other differences were observed between both groups, within the probiotic group a decrease in SCD14 and an increase in MCP-1 and IL- 8 were observed and within the placebo group a decrease in IL-6 was found.

In conclusion our study shows that the intake of a multispecies probiotic had limited effect on biomarkers of the immune system in COPD patients treated with antibiotics for an acute exacerbation. The observed effects were probably attributed to the resolution of the exacerbation and not linked to perturbations in the dominant microbiota. 


\section{Introduction}

It is generally accepted that antibiotic treatment causes disturbances of the intestinal microbiota. It is widely assumed that this disturbance is of short duration, but recently also medium and long-term disturbances in (specific) bacterial populations have been described $^{1-3}$. Since the intestinal microbiota is known to influence the maturation and functioning of the immune system, perturbations of the microbiota due to antibiotics may also influence immune responses. Although the exact mechanisms are not clear, a disturbance of the intestinal microbiota due to antibiotics has been associated with local inflammation and altered immunological functioning ${ }^{4,5}$ and studies in mice have linked the microbiota composition with specific immune responses ${ }^{6}$. In addition, perturbations of the intestinal microbiota seem to play a pivotal role in numerous immune related conditions, like allergy and inflammatory bowel disease $(I B D)^{5,7}$. However, several gaps in the knowledge of mechanisms linking the intestinal microbiota to immunological responses still exist.

Recognition of the beneficial effect of probiotics has increased the interest in probiotics in preventing antibiotic-associated disturbances. While these effects initially were thought to be due to the improvement of the intestinal microbial environment, there is now considerable evidence that probiotics can also prevent and ameliorate certain diseases at least in part by modulating the host immune system ${ }^{8,9}$. Moreover, it has been shown that both antibiotics and probiotics can influence the immune system ${ }^{8,10}$. However, there are limited human in vivo data on the immunomodulating effect of combined probiotic and antibiotic intake.

We previously showed in healthy volunteers that the intake of a multispecies probiotic during and after amoxycillin intake affects not only the faecal microbiota resulting in a faster restoration towards the pre-antibiotic state ${ }^{3}$, but is also able to induce an in/ex vivo immunological effect ${ }^{11,12}$. Moreover, an inverse association between the disruption of the intestinal microbiota and specific cytokines was found.

The relationship between antibiotic treatment, disturbances of the intestinal microbiota and the immune system and the subsequent effect of probiotic intake may be different in patients compared to healthy volunteers. This is especially anticipated in those patients with an already disturbed immune system or a profound and longlasting disturbance of the intestinal microbiota, due to frequent antibiotic use. A clinical condition for which antibiotics are frequently prescribed is an acute exacerbation of chronic obstructive pulmonary disease (COPD). COPD is characterised by a progressive chronic airway inflammation and airflow obstruction but also by the presence of systemic inflammation ${ }^{13}$. Previously we studied the effect of a multispecies probiotic on the microbiota in COPD-patients treated with antibiotics for an acute exacerbation ${ }^{14}$. The influence on immune biomarkers in blood and saliva in these patients is assessed in the present study. Also, the association between the disruption of the intestinal microbiota and the immune biomarkers will be assessed. 


\section{Methods}

\section{Subjects and study design}

The design and the clinical details of the study have been described elsewhere ${ }^{14}$. Briefly, forty-five patients, between 18-80 years of age, with moderate to severe COPD were enrolled in the study. Patients had to have an acute exacerbation of COPD and were treated with antibiotics, according to the Anthonissen-criteria ${ }^{15}$, as judged by the physician in charge. Next to a 7-day antibiotic treatment, patients were randomized to receive either 5 gram of a multispecies probiotic (Ecologic ${ }^{\oplus}$ AAD) or placebo twice daily for 14 days, starting simultaneously with the antibiotic treatment. Ecologic $A A D$ consists of 9 different bacterial species at $10^{8}$ colony forming units (CFU)/g each (Bifidobacterium bifidum W23, B. lactis W51, Enterococcus faecium W54, Lactobacillus acidophilus W37 and W55, L. paracasei W20, L. plantarum W62, L. rhamnosus W71 and L. salivarius W24), 5\% mineral mix and 15\% Raftilose Synergy1. All individual probiotic strains carry the European Union Qualified Presumption of Safety (QPS) ${ }^{16}$ and both study products (probiotic and placebo) were prepared according to Good Manufacturing Practice $(\mathrm{GMP})^{17}$ conditions. The total duration of the intervention and follow-up period was 63 days. Blood and saliva samples were collected at day 0, 7, 14 and 63.

The study was approved by the Medical Ethics Committee of the Maastricht University Medical Centre, the Netherlands, and all patients gave written informed consent.

\section{Blood samples}

Peripheral blood samples were collected in EDTA and serum vacutainers (Becton Dickinson, Plymouth, UK). Total and differential leukocyte counts were performed in EDTA-blood using the Cobas Micros 18p (Horiba ABX, France). Eosinophil counts were performed by one experienced blinded technician using a Bürker counting chamber, counting at least 500 cells. Serum samples were obtained after $1 \mathrm{~h}$ of clotting at room temperature and centrifugation for $10 \mathrm{~min}$ at $1200 \mathrm{~g}$. Plasma samples were obtained by centrifugation of EDTA-blood for $10 \mathrm{~min}$ at $1200 \mathrm{~g}$ at room temperature.

Serum and plasma samples were frozen in aliquots at $-80^{\circ} \mathrm{C}$ until subsequent analyses.

\section{Saliva samples}

Saliva was collected with a Salivette sampling device (Sarstedt, Germany). Patients were instructed to blow their nose and to rinse their mouth with water. The cotton roll was then placed under their tongue for two minutes and patients were asked not to chew. After being soaked with saliva the cotton roll was placed back into the Salivette tube and stored at $-80^{\circ} \mathrm{C}$ until subsequent analyses. 


\section{Measurement of CRP, albumin and immunoglobulins}

C-reactive protein (CRP) was measured by standard procedure at the department of Clinical Chemistry of the Maastricht University Medical Centre. Albumin, IgA and IgG in serum were determined using immunoturbidimetric assays (BN ProSpec, Dade Behring, IL, USA) according to the manufacturer's instructions. ${ }^{18}$ Secretory IgA (sIgA) in serum and saliva was determined by an ELISA as reported previously. ${ }^{19}$

\section{Cytokine measurements}

Cytokine levels in serum (IFN- - , TNF- $\alpha$, monocyte chemotactic protein-1 (MCP-1), IL-6 and IL-8,) and in saliva (IFN- - , TNF- $\alpha$, MCP-1, IL- 6 and IL-8) were determined on a Luminex platform using single-plexes (BioSource, Camarillo, CA, USA). SCD14 was determined in an ELISA using duo-set reagents (R\&D Systems, MN, USA). The lower detection limit was set at twice the reading for the blank. For measurements in serum these values were $2.0 \mathrm{pg} / \mathrm{ml}$ for IFN- $\gamma, 2.30 \mathrm{pg} / \mathrm{ml}$ for TNF- $\alpha$ and $1.50 \mathrm{pg} / \mathrm{ml}$ for IL-6, and in saliva these values were $1.5 \mathrm{pg} / \mathrm{ml}$ for IFN- $\gamma, 1.0 \mathrm{pg} / \mathrm{ml}$ for TNF- $\alpha$ and $1.0 \mathrm{pg} / \mathrm{ml}$ for IL-6, $1.0 \mathrm{pg} / \mathrm{ml}$ for IL-8 and $5.0 \mathrm{pg} / \mathrm{ml}$ for MCP-1. For statistical analyses, the lower detection limit divided by two was given as a value for those samples under the detection limit.

\section{Statistical analysis}

The allocation of probiotic or placebo was concealed to all investigators and patients until the study had been completed and all analyses had been performed. A perprotocol analysis was performed to investigate the influence on immune biomarkers.

Statistical evaluation of peripheral leukocyte count, albumin, immunoglobulins and circulating and salivary inflammatory mediators was carried out using linear mixed model analysis as described previously ${ }^{20,21}$. Mixed model analysis corrects for baseline differences, within subject correlation and assumes missing at random. For the salivary inflammatory mediators a logarithmic transformation was applied to normalize the highly skewed distributions.

For all other data, the nonparametric Mann-Whitney U-test was used for two-group comparisons of independent ordinal and interval values while the nonparametric Wilcoxon signed-ranked test was used for comparison of related ordinal and interval values. If data were normally distributed the Students t-test was used.

In previous work, the similarity index (SI) of denaturing gradient gel electrophoresis (DGGE) profiles compared to baseline (0-7, 0-14 and 0-63) was calculated, indicating the disruption of the intestinal microbiota (Low SI meaning more disruption) ${ }^{14}$. The correlation between the disruption of the intestinal microbiota (SIs) and the immunological parameters was analysed during and after amoxycillin intake with the Spearman rank test for non-parametric data. Data storing and tests were conducted 
using SPSS version 15.0 (SPSS Inc., Chicago, IL, USA) and a p-value below 0.05 was considered statistically significant.

\section{Results}

\section{Subjects}

Thirty patients out of the 45 enrolled, completed the study: 17 in the probiotic and 13 in the placebo group. The mean $( \pm S D)$ frequency of antibiotic use was $3.1 \pm 2.4$ treatments in the year prior to inclusion. The antibiotic treatments prescribed for the COPD exacerbation were mostly (>75\%) doxycyclin and amoxycillin/clavulanic acid and were comparable for both groups. Of the 15 patients who dropped out of the study, eleven patients (73\%) discontinued the study in the first week, another three $(20 \%)$ in the second week and one patient $(7 \%)$ thereafter. No difference in droppedout rate was observed between the probiotic and the placebo group. The most common reasons for discontinuation included; 'not being able or not willing to collect faeces', 'perception of the study load as being too demanding considering the current medical condition' and 'disliking the taste of the study product'. Baseline demographics and clinical characteristics were comparable for both groups (Table 7.1). There were no adverse events reported with regard to Gl-symptoms, related to the study product. Compliance was assessed by the self-reported number of study product (sachets) consumed. Eight patients in the probiotic group and five patients in the placebo group changed their dietary habits during the study period, based on medical indication (energy restriction $(n=10)$, supplementation with nutrient drinks $(n=2)$, loss of appetite $(n=1))$. Apart from the exclusion criteria, diverse and extensive medication was used in both groups mostly belonging to the groups of analgesia, antidepressants, antihypertensives, inhalation corticosteroids, diuretics, sympathicomimetics, xanthines and para-sympathicolytics.

Table 7.1 Subject characteristics (Mean values ( \pm SD) are given, unless stated otherwise).

\begin{tabular}{lcc}
\hline & Probiotic $(\mathrm{n}=17)$ & Placebo $(\mathrm{n}=13)$ \\
\hline Gender $\mathrm{m} / \mathrm{f}(\mathrm{n})$ & $12 / 5$ & $7 / 6$ \\
Age $($ years) & $59.9(13.3)$ & $63.4(7.4)$ \\
Current smokers $(\mathrm{n})$ & 3 & 1 \\
$\mathrm{BMI}\left(\mathrm{Kg} / \mathrm{m}^{2}\right)$ & $27.1(6.6)$ & $27.4(4.9)$ \\
FFMI $\left(\mathrm{Kg} / \mathrm{m}^{2}\right)$ & $17.7(2.6)$ & $18.4(5.7)$ \\
FEV $(\% \mathrm{pred})$ & $43.0(20.3)$ & $40.8(28.0)$ \\
FVC $(\%$ pred) & $84.7(17.1)$ & $75.6(19.5)$ \\
CCQ total score & $3.0(0.7)$ & $3.3(0.9)$ \\
Antibiotic treatments in previous year & $2.9(2.6)$ & $3.3(2.1)$ \\
Use of pre- and probiotics before the study $(\mathrm{n})$ & 0 & $1^{\dagger}$ \\
Compliance ${ }^{\ddagger}$ probiotic/placebo intake $(\%)$ & $98.1(4.6)$ & $99.7(1.0)$ \\
\hline
\end{tabular}

$\mathrm{BMI}$, body mass index; CRP, C-reactive protein; FFMI, fat free mass index; $\mathrm{FEV}_{1}$, forced expiratory volume in 1s; FVC, forced vital capacity; $C C Q$, clinical COPD questionnaire. *There was no significant difference between the probiotic and the placebo group. ${ }^{\dagger}$ Yakult $1 \mathrm{dd} .{ }^{\ddagger}$ Compliance is self-reported. 


\section{Peripheral leukocyte count}

Peripheral total and differential leukocyte counts are shown in Table 7.2. A significant lower total leukocyte count was found in the probiotic group compared to the placebo group at day 7. Moreover, within the placebo group at day 63 a significant decrease in total leukocyte count was found compared to day 7 and 14 .

Differential cell counts did not differ significantly between the probiotic and the placebo group. Granulocytes decreased significantly within the probiotic group at day 7, 14 and 63. Within the placebo group a significant decrease was only observed at day 63. However, the percentage of granulocytes (Probiotic, 81.8 $\pm 7.2,76.8 \pm 5.6$, 74.5 $\pm 8.7,76.8 \pm 6.4$; Placebo, 79.4 $\pm 10.9,74.1 \pm 9.5,74.5 \pm 9.9,72.9 \pm 7.0$ ) were relatively high at day 0 and decreased significantly in both groups at day 7, 14 and 63 . Lymphocyte numbers increased significantly in both groups at day 14, whereas monocyte numbers increased significantly only in the placebo group at day 7 and 14 . Furthermore, within both the probiotic and the placebo group a significant increase in eosinophils was observed at day 14.

Table 7.2 Peripheral total and differential leukocyte count (Mean values $( \pm S D)$ ).

\begin{tabular}{llcccc}
\hline & & Day 0 & Day 7 & Day 14 & Day 63 \\
\hline WBC (106/ml) & Probiotic & $10.0(2.3)$ & $8.9(2.1)$ & $8.9(2.2)$ & $8.9(2.7)$ \\
& Placeboo $^{1}$ & $9.4(3.1)$ & $9.7(3.0)^{*}$ & $9.9(3.2)$ & $8.5(2.7)$ \\
Granulocytes (106/ml) & Probiotic $^{2}$ & $8.2(2.2)$ & $6.9(1.8)$ & $6.6(2.3)$ & $6.9(2.3)$ \\
& Placebo $^{3}$ & $7.6(3.4)$ & $7.1(2.9)$ & $7.6(3.3)$ & $6.3(2.4)$ \\
Lymphocytes $(106 / \mathrm{ml})$ & Probiotic $^{4}$ & $1.4(0.6)$ & $1.7(0.6)$ & $2.0(0.7)$ & $1.6(0.6)$ \\
& Placebo $^{5}$ & $1.5(0.6)$ & $2.1(0.6)$ & $1.9(0.8)$ & $1.8(0.7)$ \\
Monocytes (106/ml) & Probiotic $^{6}$ & $0.36(0.16)$ & $0.40(0.13)$ & $0.39(0.12)$ & $0.38(0.14)$ \\
& Placebo $^{6}$ & $0.34(0.07)$ & $0.44(0.15)$ & $0.44(0.17)$ & $0.38(0.16)$ \\
Eosinophils $(103 / \mathrm{ml})$ & Probiotic $^{7}$ & $82(94)$ & $157(113)$ & $183(147)$ & $152(105)$ \\
& Placebo $^{8}$ & $132(184)$ & $148(163)$ & $230(211)$ & $161(157)$ \\
\hline
\end{tabular}

*between group difference. ${ }^{1}$ Within group difference $t=7 / 14$ vs. $t=63, p<0.05 ;{ }^{2}$ Within group difference $t=0$ vs. $t=7 / 14 / 63, p<0.05 ;{ }^{3}$ Within group difference $t=63$ vs. $t=0 / 7 / 14, p<0.05 ;{ }^{4}$ Within group difference $t=0$ vs. $t=14, p<0.05 ;{ }^{5}$ Within group difference $t=0$ vs. $t=7 / 14, p<0.05 ;{ }^{6}$ Within group difference $t=0$ vs. $t=7 / 14$, $p<0.05 ;{ }^{7 / 8}$ Within group difference $t=0$ vs. $t=14, p<0.05$.

\section{CRP, albumin and immunoglobulins}

CRP and albumin levels did not differ significantly between the probiotic and the placebo group (Figure 7.1). CRP levels decreased significantly within both groups at day 7, 14 and 63. In both groups no difference in albumin levels was observed over time. Serum IgG, IgA and slgA and salivary slgA did not differ significantly between the probiotic and the placebo group or within each group over time (Figure 7.2). 

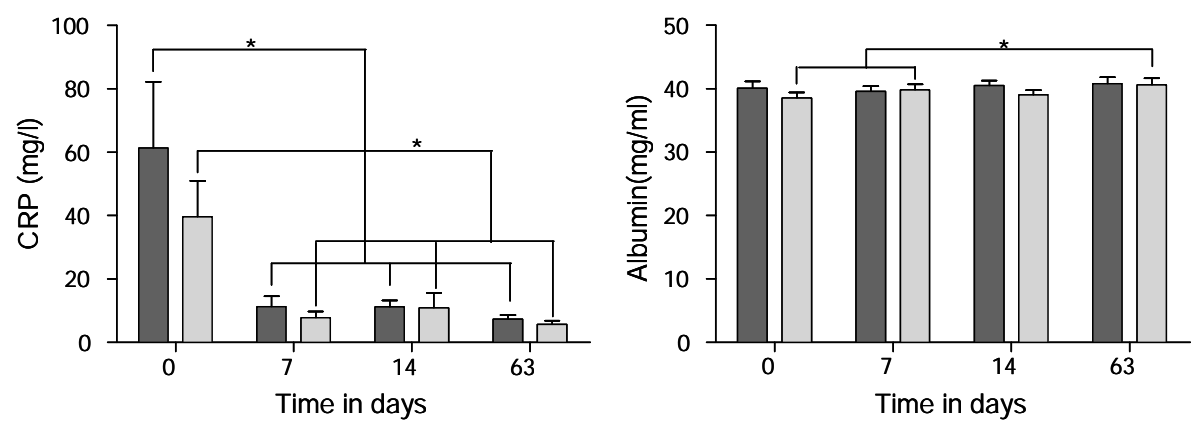

Figure 7.1 Peripheral albumin and C-reactive protein (CRP) concentration expressed as mean ( \pm SEM) $\square=$ probiotic and $\square=$ placebo, $* p<0.05$.
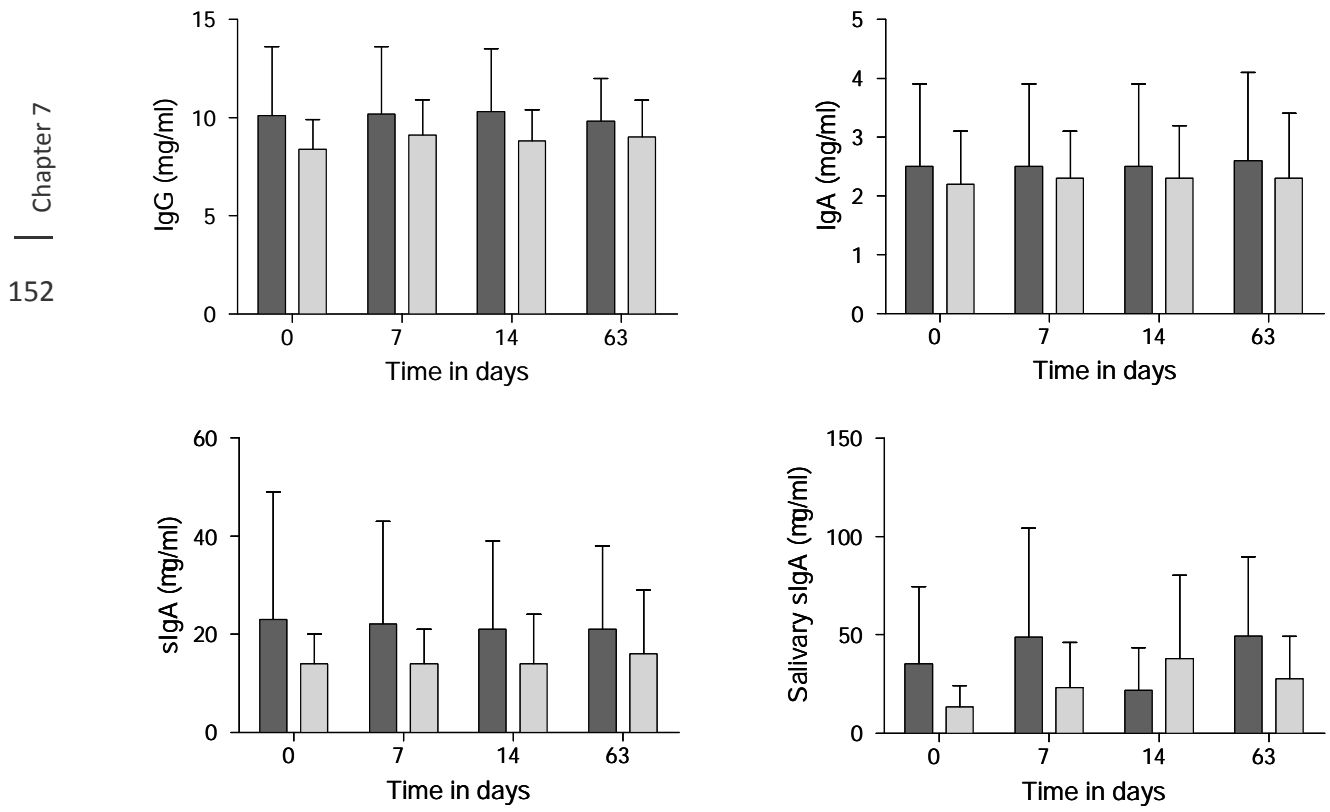

Figure 7.2 Immunoglobulin concentrations expressed as mean ( \pm SD) in serum and saliva. $\square=$ probiotic and $\square=$ placebo. 


\section{Circulating inflammatory mediators}

Except for one patient in the probiotic group, all plasma TNF- $\alpha$ levels were below the detection limit $(2.3 \mathrm{pg} / \mathrm{ml})$ of the assay. Plasma IFN- $\gamma$ levels were below the detection limit $(2.0 \mathrm{pg} / \mathrm{ml})$ in $77,71,65$ and $71 \%$ of patients in the probiotic group and in 62,54 , 62 and $69 \%$ of patients in the placebo group at day $0,7,14$ and 63, respectively. Therefore, both plasma TNF- $\alpha$ and IFN- $\gamma$ were not further considered.

No difference in MCP-1, SCD14, IL-6 and IL-8 levels between the probiotic and the placebo group was found throughout the study (Figure 7.3). Within the probiotic group, a significant increase in MCP-1 levels and a significant decrease in SCD14 levels were found after antibiotic treatment. Moreover, IL-8 increased significantly at day 14. Within the placebo group, IL-6 levels decreased significantly after antibiotic treatment.

In addition, we evaluated the levels of the cytokines per monocyte (Figure 7.3). Again, no difference between the probiotic and the placebo group was observed. Moreover, within both groups a similar tendency as described for the levels of cytokines was observed.

No significant association between serum IL-8 and peripheral granulocytes was observed over time.

\section{Salivary inflammatory mediators}

Salivary IFN- $\gamma$, TNF- $\alpha$ and IL- 6 levels were below the detection limit in $35-59 \%$ of patients in the probiotic group and in $46-62 \%$ of patients in the placebo group and were therefore not further considered.

Salivary MCP-1 (Probiotic, 2.7 $\pm 0.89,2.4 \pm 1.3,2.4 \pm 0.96$ and 2.8 \pm 0.92 ; Placebo, $1.9 \pm 0.80,2.5 \pm 0.77,2.4 \pm 0.83$ and $2.0 \pm 0.68$ at day $0,7,14$ and 63 , respectively) and IL-8 levels (Probiotic, 1.7 $\pm 0.63,1.9 \pm 1.2,1.5 \pm 0.93$ and 1.9 \pm 0.72 ; Placebo, $1.0 \pm 0.58$, $1.9 \pm 0.96,1.7 \pm 0.63$ and $1.6 \pm 1.1$ at day $0,7,14$ and 63 , respectively) expressed as log $\mathrm{pg} / \mathrm{ml}$, did not differ significantly between the probiotic and the placebo group. Apart from a significant increase $(p<0.05)$ in salivary IL-8 in the placebo group at day 7 no significant differences were observed within each group throughout the study.

\section{Correlations between the similarity index and immunological parameters}

No association between serum $\lg \mathrm{A}$, slgA, salivary slgA and the circulating and salivary inflammatory mediators analysed with the similarity index (low SI indicates more disruption of the intestinal microbiota) was observed (data not shown). 

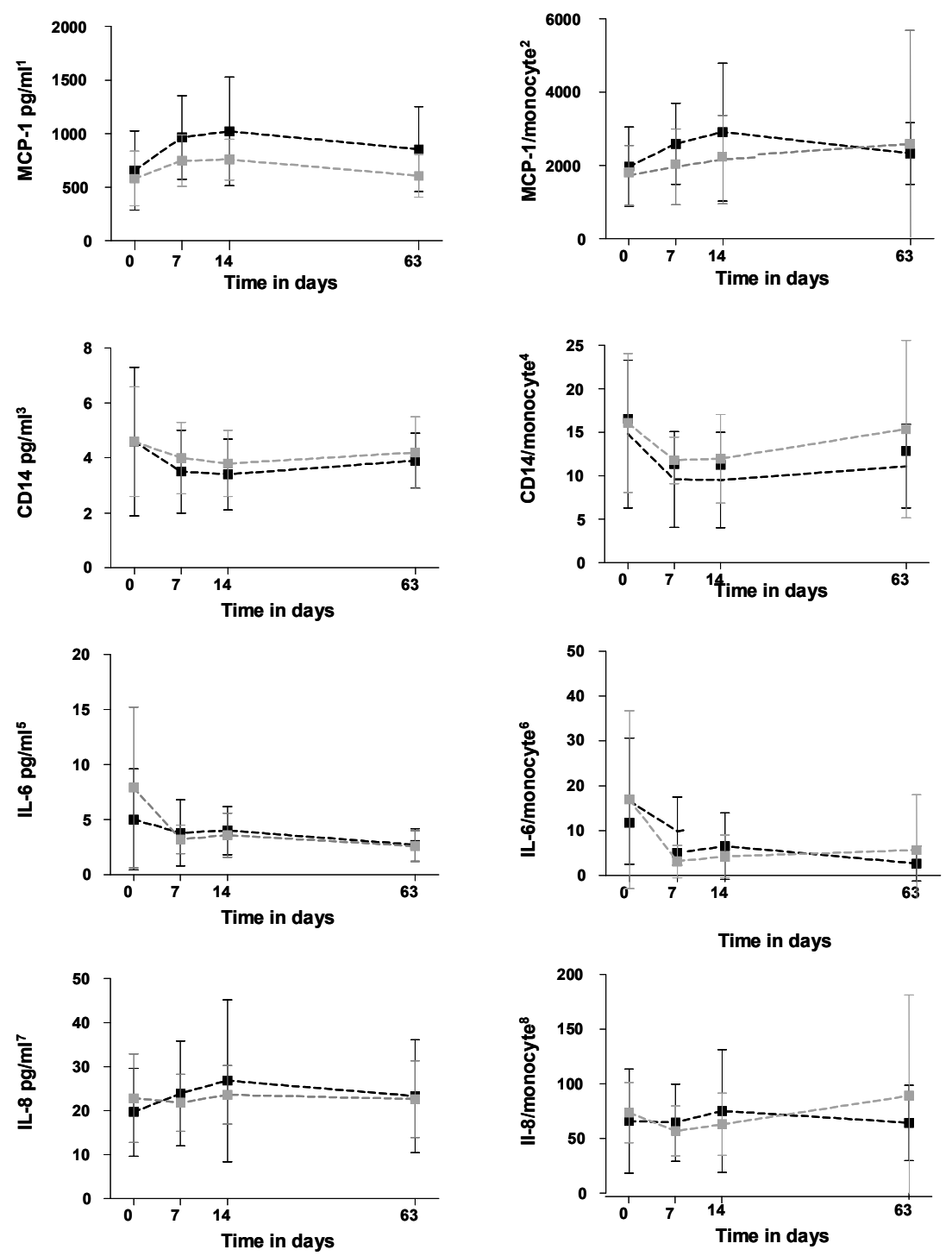

Figure 7.3 Peripheral cytokine levels per/ml serum or per monocyte expressed as mean $( \pm$ SD).

$\mathbf{\square}=$ probiotic and $=$ placebo. ${ }^{1}$ Within group difference probiotic $\mathrm{t}=0$ vs. $\mathrm{t}=7 / 14 / 63, \mathrm{p}<0.05$;

${ }^{2}$ Within group difference probiotic $t=0$ vs. $t=14, p<0.05 ;{ }^{3 / 4}$ Within group difference probiotic $t=0$ vs. $t=7 / 14, p<0.05 ;{ }^{5}$ Within group difference placebo $t=0$ vs. $t=7 / 14 / 63$ and $t=7$ vs. $t=63$, $p<0.05 ;{ }^{6}$ Within group difference probiotic $t=0$ vs. $t=63$ and placebo $t=0$ vs. $t=7 / 14 / 63$, $p<0.05 ;{ }^{7}$ Within group difference probiotic $t=0$ vs. $t=14, p<0.05 ;{ }^{8}$ Within group difference placebo $t=0$ vs. $t=7 / 14 / 63, p<0.05$. 


\section{Discussion}

In the present double-blind placebo-controlled randomised study, the effect of a multispecies probiotic on biomarkers of the immune system in COPD-patients treated with antibiotics for an acute exacerbation was assessed. Compared to placebo, intake of a multispecies probiotic did not alter the analyzed biomarkers apart from a significant decrease of WBC at day 7. Although no other differences were observed between groups, small but significant group specific changes were found over time: versus baseline a significant decrease in SCD14 and an increase in MCP-1 and IL-8 were found in the probiotic group and a decrease in IL-6 was found in the placebo group. None of the analysed biomarkers showed an association with the similarity index of the faecal microbiota.

Apart from a progressive airflow obstruction, CODP is characterized by chronic airway inflammation and the presence of systemic inflammation ${ }^{13,22}$. Moreover, acute exacerbations often occur, which have been associated with an increase in inflammatory response ${ }^{23}$. Antibiotic therapy routinely prescribed to treat exacerbations, could also affect the immune system both directly or indirectly by a disturbance of the intestinal microbiota. Probiotics can contribute to the recovery of the intestinal microbiota and were shown to modulate the host immune response $\mathrm{e}^{24,25}$. Circulating granulocyte numbers were high at the start of the study, which contributed to the relatively high peripheral blood leukocyte count. This is in line with the literature as it has been shown that COPD patients have increased circulating neutrophil numbers during exacerbations ${ }^{26}$. Within both groups a decrease in granulocytes was observed over time most probably due to the resolution of the exacerbation, but we can not exclude an effect of the antibiotic treatment itself.

After antibiotic therapy (day 7), a significantly lower leukocyte count was observed in the probiotic compared to the placebo group. High leukocyte levels can indicate the presence of systemic inflammation and therefore this finding could be considered as a possible beneficial effect of probiotic intake. The clinical relevance however, is not clear and remains to be elucidated. In addition, we expected the decrease in leukocytes to coincide with a decrease in other inflammation markers in the probiotic group compared to the placebo group. However, this was not supported by any of the markers assessed in this study.

Evidence from several human and animal studies demonstrates that probiotics can increase the levels of slgA in both the intestine and blood ${ }^{27-31}$. This was also observed in a previous study in healthy volunteers using the same multispecies probiotic ${ }^{12}$. No increase in slgA due to probiotic intake was observed in the current study. However, compared to healthy volunteers, baseline slgA levels in the COPD patients were already higher, possibly due to the exacerbation, which may have masked a probiotic effect. 
An increased systemic inflammatory reaction in patients with COPD has been observed in several studies as evidenced by increased levels of CRP and circulating cytokines, such as IL-1 $\beta$, IL-6, IL- 8 and TNF- $\alpha^{13,32}$. It was therefore surprising that TNF- $\alpha$ was undetectable in all COPD patients but one, especially as various studies have reported that these increases in peripheral cytokine levels are generally even more pronounced during exacerbations ${ }^{23}$. However, a recent study assessing the ability of 36 biomarkers to confirm the presence of an exacerbation found that of the cytokines also measured in this study, only CRP and IL-6 differed between baseline and exacerbation $^{33}$. Our observations that only CRP and IL-6, but not IL-8 decreased during resolution of the exacerbation (i.e. after antibiotic treatment) are in line with those results. After the exacerbation, CRP levels remained higher than in healthy controls, as seen in several other studies ${ }^{34,35}$. This indeed indicates the presence of a systemic inflammation in the COPD patients.

Approximately $30-50 \%$ of acute exacerbations in COPD are caused by a bacterial infection $^{36}$. Moreover, an acute bacterial infection causes a marked decrease in circulating eosinophils ${ }^{37}$, which was also observed in the present study. Currently it is not possible to differentiate between bacterial and nonbacterial causes of exacerbations, though increased CRP levels $(>50 \mu \mathrm{g} / \mathrm{l})$ may be an indication ${ }^{36}$. Although not significant at baseline, higher CRP levels and lower eosinophil numbers were observed in the probiotic group. Therefore we speculate that more patients in the probiotic group suffered from a bacterial exacerbation. Moreover, increased levels of MCP-1 and IL-8 and lower levels of SCD14 were found in the probiotic group after antibiotic treatment. Antibiotic-induced lyses of bacterial pathogens can cause endotoxin release, which may have resulted in increased translocation of LPS. Increased levels of pro-inflammatory cytokines like IL-8 and MCP-1, have been observed in response to LPS. In addition, SCD14 can inhibit pro-inflammatory responses by diverting LPS from membrane-bound CD14 (mCD14) and by promoting LPS efflux from cell-surface mCD14 and transferring it to plasma lipoproteins.

In general, the present study demonstrates that the intake of the multispecies probiotic had a limited effect on the analysed immunological biomarkers in COPDpatients treated with antibiotics for an acute exacerbation. Compared to placebo, only an increase in WBC was observed after one week.

It is well recognised that the intestinal microbiota has an important role in the development and normal functioning of the host's immune system ${ }^{38-40}$. Although in vivo studies directly linking perturbations of the microbiota with immune modulation are lacking, there are many epidemiological data corroborating this assumption ${ }^{41-44}$. Previously we showed that the diversity and temporal stability of the dominant faecal microbiota of the same COPD patients were not affected upon both antibiotic and probiotic intake ${ }^{14}$, which may explain that no association between similarity index and the immune biomarkers was found. This observation might also clarify the limited 
effect of probiotics on the biomarkers analysed. Moreover, it suggests that the resolution of the exacerbation accounts for the observed antibiotic effect. As described previously denaturing gradient gel electrophoresis (DGGE) was used, which provides a description of the dominant bacterial populations, representing at least $1 \%$ of the total microbiota ${ }^{45}$. As studies have shown that both antibiotic and probiotic intake can influence subdominant populations, at least some immunomodulating effect was expected ${ }^{1,2,46,47}$.

As there is now substantial evidence that probiotics can modulate immune functions, it seems unlikely that this multispecies probiotic, including 10 bacterial strains, will have had no immunomodulating effect at all. However, the ability of probiotics to modulate the immune system are strain dependent and the probiotic strains might affect other biomarkers than the ones analysed in this study. Another possible explanation for the lack of observed probiotic effect is the presence of chronic inflammation in COPD patients. The immuno-modulating effect of the multispecies probiotic might not have been sufficient enough to be detected in the mitts of the immunological perturbations already present.

It has to be taken into account that, inherent to the nature and severity of the disease, diverse and extensive medication was used in this COPD population, which could have affected the measured parameters. Nevertheless, when using corticosteroids, gastric acid inhibitors or doxycyclin maintenance therapy, patients had to be on stable medication before and during the study to limit this effect. Moreover, it should be taken into account that the mucosa associated lymphoid tissue is functionally and operationally distinct from the systemic immune system and that results from saliva can not be extrapolated to sputum. Therefore, in this complex population several factors could have been present causing the immunomodulating effect of probiotic intake to remain undetected.

In summary, our study shows that the intake of a multispecies probiotic had limited effect on biomarkers of the immune system in COPD patients treated with antibiotics for an acute exacerbation. In addition, the observed antibiotic effect was possibly attributed to the resolution of the exacerbation and not linked to perturbations in the dominant microbiota.

Recently Hill et al. showed that antibiotic-induced temporal and spatial changes in intestinal microbiota were associated with alterations in immune cell homeostasis using metagenomic analyses ${ }^{48}$. Earlier we showed that antibiotic treatment did not induce temporal and spatial changes in the dominant faecal microbiota of these COPD patients. This was probably due to the profound alteration of the microbiota by the frequent prior antibiotic use, which seemed to have caused a long-term imbalance of the microbiota. In future studies it would be very interesting to determine not only the impact of antibiotic induced alteration of the microbiota on the immune system, 
but also the durations of the effect, the clinical implications and the possible effect of continuous probiotic supplementation. 


\section{References}

1. Dethlefsen L, Huse S, Sogin ML, Relman DA. The pervasive effects of an antibiotic on the human gut microbiota, as revealed by deep 16S rRNA Sequencing. PLoS Biol. 2008;6:e280.

2. Jernberg C, Lofmark S, Edlund C, Jansson JK. Long-term ecological impacts of antibiotic administration on the human intestinal microbiota. Isme J. 2007;1:56-66.

3. Koning CJM, Jonkers DMAE, Stobberingh EE, Smidt H, Stockbrugger RW. Effect of a multispecies probiotic on the composition of the dominant faecal flora in healthy volunteers. Gut. 2005;54:A243.

4. Abt MC, Artis D. The intestinal microbiota in health and disease: the influence of microbial products on immune cell homeostasis. Curr Opin Gastroenterol. 2009;25:496-502.

5. Othman M, Aguero R, Lin HC. Alterations in intestinal microbial flora and human disease. Curr Opin Gastroenterol. 2008;24:11-6.

6. Ivanov, II, Frutos Rde L, Manel N, Yoshinaga K, Rifkin DB, Sartor RB, Finlay BB, Littman DR. Specific microbiota direct the differentiation of IL-17-producing T-helper cells in the mucosa of the small intestine. Cell Host Microbe. 2008;4:337-49.

7. Penders J, Stobberingh EE, van den Brandt PA, Thijs C. The role of the intestinal microbiota in the development of atopic disorders. Allergy. 2007;62:1223-36.

8. Borchers AT, Selmi C, Meyers FJ, Keen CL, Gershwin ME. Probiotics and immunity. J Gastroenterol. 2009;44:26-46.

9. Ruemmele FM, Bier D, Marteau P, Rechkemmer G, Bourdet-Sicard R, Walker WA, Goulet O. Clinical evidence for immunomodulatory effects of probiotic bacteria. J Pediatr Gastroenterol Nutr. 2009;48:126-41.

10. Van Vlem B, Vanholder R, De Paepe P, Vogelaers D, Ringoir S. Immunomodulating effects of antibiotics: literature review. Infection. 1996;24:275-91.

11. Koning CJ, Jonkers D, Stobberingh E, Out TA, Stockbrügger R. Amoxycillin and multispecies probiotic intake affect cytokine production in healthy volunteers. Gastroenterol. 2007;132:s1266.

12. Koning CJM, Jonkers D, Stobberingh E, Out TA, Stockbrugger R. Effect of a multispecies probiotic on components of the mucosal and systemic immune system in healthy volunteers treated with amoxycillin. Gut. 2005;54:A260.

13. Gan WQ, Man SF, Senthilselvan A, Sin DD. Association between chronic obstructive pulmonary disease and systemic inflammation: a systematic review and a meta-analysis. Thorax. 2004;59:574-80.

14. Koning CJ, Jonkers D, Smidt H, Rombouts F, Pennings HJ, Wouters E, Stobberingh E, Stockbrugger R. The effect of a multispecies probiotic on the composition of the faecal microbiota and bowel habits in chronic obstructive pulmonary disease patients treated with antibiotics. Br J Nutr. 2009:1-9.

15. Anthonisen NR, Manfreda J, Warren CP, Hershfield ES, Harding GK, Nelson NA. Antibiotic therapy in exacerbations of chronic obstructive pulmonary disease. Ann Intern Med. 1987;106:196-204.

16. EFSA. Opinion of the Scientific Committee on a request from EFSA on the introduction of a Qualified Presumption of Safety (QPS) approach for assessment of selected microorganisms referred to EFSA. The EFSA Journal. 2007;587:1-16.

17. WHO. Good manufacturing practices for biological products. Technical Report Series No 822 . 1992;Annes 1.

18. Schoonbrood DF, Lutter R, Habets FJ, Roos CM, Jansen HM, Out TA. Analysis of plasma-protein leakage and local secretion in sputum from patients with asthma and chronic obstructive pulmonary disease. Am J Respir Crit Care Med. 1994;150:1519-27.

19. van de Graaf EA, Out TA, Kobesen A, Jansen HM. Lactoferrin and secretory IgA in the bronchoalveolar lavage fluid from patients with a stable asthma. Lung. 1991;169:275-83.

20. Koning CJ, Jonkers DM, Stobberingh EE, Mulder L, Rombouts FM, Stockbrugger RW. The Effect of a Multispecies Probiotic on the Intestinal Microbiota and Bowel Movements in Healthy Volunteers Taking the Antibiotic Amoxycillin. Am J Gastroenterol. 2007;102:1-12.

21. Koning CJM, Jonkers DMAE, Smidt $H$, Fuentes $S$, Rombouts FM, Winkens $B$, Stobberingh EE, Stockbrugger RW. Monitoring the effect of a multispecies probiotic and short-term amoxycillin intake on the fecal microbiota by PCR-DGGE in healthy volunteers. 2010: submitted.

22. Agusti AG, Noguera A, Sauleda J, Sala E, Pons J, Busquets X. Systemic effects of chronic obstructive pulmonary disease. Eur Respir J. 2003;21:347-60. 
23. Wouters EF, Groenewegen KH, Dentener MA, Vernooy JH. Systemic inflammation in chronic obstructive pulmonary disease: the role of exacerbations. Proc Am Thorac Soc. 2007;4: 626-34.

24. Guarner F, Malagelada JR. Gut flora in health and disease. Lancet. 2003;361:512-9.

25. Kalliomaki M, Salminen S, Poussa T, Arvilommi H, Isolauri E. Probiotics and prevention of atopic disease: 4-year follow-up of a randomised placebo-controlled trial. Lancet. 2003;361:1869-71.

26. Bathoorn E, Liesker JJ, Postma DS, Koeter GH, van der Toorn M, van der Heide S, Ross HA, van Oosterhout AJ, Kerstjens HA. Change in inflammation in out-patient COPD patients from stable phase to a subsequent exacerbation. Int J Chron Obstruct Pulmon Dis. 2009;4:101-9.

27. Fukushima $\mathrm{Y}$, Kawata $\mathrm{Y}$, Hara H, Terada A, Mitsuoka T. Effect of a probiotic formula on intestinal immunoglobulin A production in healthy children. Int J Food Microbiol. 1998;42: 39-44.

28. Fukushima Y, Kawata Y, Mizumachi K, Kurisaki J, Mitsuoka T. Effect of bifidobacteria feeding on fecal flora and production of immunoglobulins in lactating mouse. Int J Food Microbiol. 1999;46:193-7.

29. Kaila M, Isolauri E, Soppi E, Virtanen E, Laine S, Arvilommi H. Enhancement of the circulating antibody secreting cell response in human diarrhea by a human Lactobacillus strain. Pediatr Res. 1992;32: 141-4.

30. Link-Amster H, Rochat F, Saudan KY, Mignot O, Aeschlimann JM. Modulation of a specific humoral immune response and changes in intestinal flora mediated through fermented milk intake. FEMS Immunol Med Microbiol. 1994;10:55-63.

31. Yasui H, Kiyoshima J, Ushijima H. Passive protection against rotavirus-induced diarrhea of mouse pups born to and nursed by dams fed Bifidobacterium breve YIT4064. J Infect Dis. 1995;172:403-9.

32. van Eeden SF, Sin DD. Chronic obstructive pulmonary disease: a chronic systemic inflammatory disease. Respiration. 2008;75:224-38.

33. Hurst JR, Donaldson GC, Perera WR, Wilkinson TM, Bilello JA, Hagan GW, Vessey RS, Wedzicha JA. Use of plasma biomarkers at exacerbation of chronic obstructive pulmonary disease. Am J Respir Crit Care Med. 2006;174:867-74.

34. de Torres JP, Cordoba-Lanus E, Lopez-Aguilar C, Muros de Fuentes M, Montejo de Garcini A, AguirreJaime A, Celli BR, Casanova C. C-reactive protein levels and clinically important predictive outcomes in stable COPD patients. Eur Respir J. 2006;27:902-7.

35. Pinto-Plata VM, Mullerova H, Toso JF, Feudjo-Tepie M, Soriano JB, Vessey RS, Celli BR. C-reactive protein in patients with COPD, control smokers and non-smokers. Thorax. 2006;61:23-8.

36. Bircan A, Gokirmak M, Kilic O, Ozturk O, Akkaya A. C-reactive protein levels in patients with chronic obstructive pulmonary disease: role of infection. Med Princ Pract. 2008;17:202-8.

37. Bass DA. Behavior of eosinophil leukocytes in acute inflammation. II. Eosinophil dynamics during acute inflammation. J Clin Invest. 1975;56:870-9.

38. Anderson KV. Toll signaling pathways in the innate immune response. Curr Opin Immunol. 2000;12:13-9.

39. Cebra JJ. Influences of microbiota on intestinal immune system development. Am J Clin Nutr. 1999;69:1046S-51S.

40. Moreau MC, Gaboriau-Routhiau V. Influence of resident intestinal microbiota on the development and functioning on the intestinal-associted lymfoid tissue. In: Fuller R, Perdigon G, editors. Probiotics 3 Immunomodulation by the gut microflora and probiotics. London, United Kingdom: R. Kluer Academic Publishers; 2000:69-104.

41. Droste JH, Wieringa MH, Weyler JJ, Nelen VJ, Vermeire PA, Van Bever HP. Does the use of antibiotics in early childhood increase the risk of asthma and allergic disease? Clin Exp Allergy. 2000;30:1547-53.

42. Farooqi IS, Hopkin JM. Early childhood infection and atopic disorder. Thorax. 1998;53: 927-32.

43. Johnson CC, Ownby DR, Alford SH, Havstad SL, Williams LK, Zoratti EM, Peterson EL, Joseph CL. Antibiotic exposure in early infancy and risk for childhood atopy. J Allergy Clin Immunol. 2005;115:1218-24.

44. Wickens K, Pearce N, Crane J, Beasley R. Antibiotic use in early childhood and the development of asthma. Clin Exp Allergy. 1999;29:766-71.

45. Muyzer G, Smalla K. Application of denaturing gradient gel electrophoresis (DGGE) and temperature gradient gel electrophoresis (TGGE) in microbial ecology. Antonie Van Leeuwenhoek. 1998;73:127-41. 
46. Goossens D, Jonkers D, Russel M, Stobberingh E, Van Den Bogaard A, Stockbrügger R. The effect of Lactobacillus plantarum $299 \mathrm{v}$ on the bacterial composition and metabolic activity in faeces of healthy volunteers: a placebo-controlled study on the onset and duration of effects. Aliment Pharmacol Ther. 2003;18:495-505.

47. Madden JA, Plummer SF, Tang J, Garaiova I, Plummer NT, Herbison M, Hunter JO, Shimada T, Cheng L, Shirakawa T. Effect of probiotics on preventing disruption of the intestinal microflora following antibiotic therapy: a double-blind, placebo-controlled pilot study. Int Immunopharmacol. 2005;5:1091-7.

48. Hill DA, Hoffmann C, Abt MC, Du Y, Kobuley D, Kirn TJ, Bushman FD, Artis D. Metagenomic analyses reveal antibiotic-induced temporal and spatial changes in intestinal microbiota with associated alterations in immune cell homeostasis. Mucosal Immunol. 2009. 


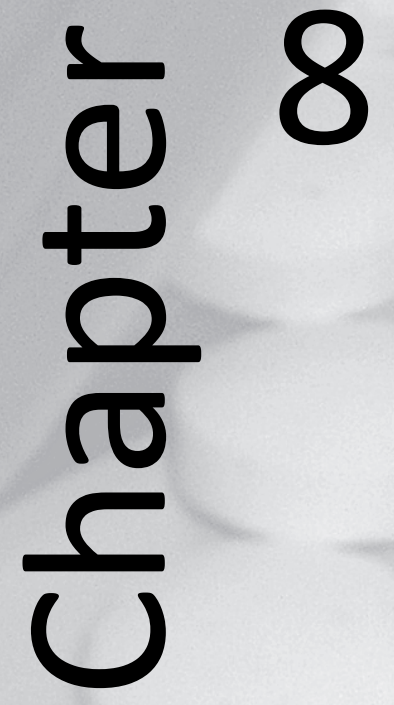




\section{General discussion}





\section{Main findings}

Clinical studies and basic science have significantly contributed to our understanding of the importance of the indigenous microbiota of the gastrointestinal tract. However, given the complexity of the intestinal microbiota and the interaction with the host, much remains to be elucidated. Intestinal microbiota homeostasis can be markedly affected by external factors, such as antibiotic treatment. Though beneficial effects of probiotic intake have been observed in the prevention and treatment of $A A D^{1-4}$, the precise mechanisms of action underlying these effects are not completely clear.

As outlined in Chapter 4, intake of amoxycillin by healthy volunteers resulted in a marked disturbance of the dominant faecal microbiota over a prolonged period. In addition, an association between the disruption of the intestinal microbiota and the development of diarrhoea-like bowel movements was found, supporting the hypothesis that a lower stability of the dominant microbiota is related to a higher risk of developing AAD. Intake of a multispecies probiotic significantly reduced the occurrence of these diarrhoea-like bowel movements (Chapter 3) probably due to the observed restoration of the dominant faecal microbiota towards the pre-antibiotic state (Chapter 4). Remarkably, in COPD patients the dominant faecal microbiota was not affected upon antibiotic intake (Chapter 6 ). We speculated that this was due to a decrease in diversity of the intestinal microbiota as these patients are characterised by a history of frequent antibiotic use and chronic disease, which may explain the lack of probiotic effect in this population.

As outlined in Chapter 1, perturbations of the microbiota due to antibiotics might contribute to variations in immunological behaviour. We showed in Chapter $\mathbf{5}$ that intake of amoxycillin by healthy volunteers influenced cytokine production in stimulated whole blood and resulted in a decrease of sputum slgA. Moreover, a weak but significant association between the disruption of the intestinal microbiota and changes in some immune parameters was observed. Intake of a multispecies probiotic further affected ex vivo cytokine production and resulted in an increase in serum slgA. Again, these effects were not observed in the study with COPD patients (Chapter 7).

\section{Methodological considerations}

Most studies investigating the intestinal microbiota, including the present one, use faecal samples. However, studies have shown clear differences between the microbiota composition in the faeces versus the luminal and mucosa-associated microbiota in the colon, ileum and caecum ${ }^{5-8}$. In addition, the activity of the microbiota will change with passage through the Gl-tract, due to for example the availability of substrates. Moreover, produced metabolites are often quickly absorbed or utilized. The use of faeces can therefore be considered as a limitation of studies on intestinal microbiota composition. Yet, currently no technique is available that allows 
to obtain samples from different intestinal sites in a non-invasive manner, whereas faecal samples are relatively easy to collect and are of value for studying the microbiota of the distal colon.

Moreover, the microbiota can be viewed as a metabolic entity providing many metabolic functions, which are unique and cannot be performed by the host. Metabolites generated by the microbiota during fermentation may have beneficial or deleterious effects on intestinal health and immunity ${ }^{9}$. As changes in the composition of the intestinal microbiota will affect its functionality, also the effect of antibiotic and multispecies probiotic intake on some parameters of the metabolic activity was investigated. In the present study a small subset of metabolites were investigated out of the many metabolites produced. Future studies should use a "trans-genomic" approach. Combining genomics and metabolomics would allow a correlation of changes in metabolite profiles with microbiota metagenomic data, providing novel insight into the composition and functionality of the intestinal microbiota.

Both intervention studies in the present thesis investigated the effect of a multispecies probiotic on preventing diarrhoea-like bowel movements during and after antibiotic intake. Compared to the incidence of AAD (i.e. 5-39\%) reported in literature $^{10}$ a relatively high incidence of diarrhoea-like bowel movements was observed in the placebo group of both studies (79 and 70\%). We choose to define diarrhoea-like bowel movements (i.e. a defecation frequency $\geq 3$ per day and/or a faecal consistency $\geq 5$ per day, using the Bristol stool form scale, for at least two days) instead of diarrhoea. However, the definition for diarrhoea most often used is more strict (i.e. the passage of 3 or more loose or liquid stools per day for at least two consecutive days), contributing to the relatively high incidence of diarrhoea-like bowel movements registered in this study.

The human gastrointestinal tract harbours a large and diverse microbiota, of which many microbial species can not be cultured. Over the past decade, our knowledge of the intestinal microbiota has greatly expanded with the application of cultivationindependent 16S rRNA gene-based molecular techniques, which allow a more complete assessment of the microbial diversity ${ }^{11}$. Yet, in the present thesis microbiological culture of predefined subgroups was used to provide information on quantitative alterations in viable counts of specific bacteria. Viable bacteria are important for the metabolic activity and functionality of the intestinal microbiota. Using traditional culture it was shown that the intake of a multispecies probiotic resulted in a transient increase of the ingested strains in the faeces Chapter $\mathbf{3}$ and Chapter 6). To comprehensively study the temporal and treatment-related dynamics of the intestinal microbiota, denaturing gradient gel electrophoresis (DGGE) was applied. This method only characterizes the dominant intestinal microbiota, making it difficult to obtain indications pointing to the consequences of specific perturbations. As a result, in the present study no such alterations were identified. Therefore, to determine whether specific microbial patterns can predict the development of specific disease states large-scale and in-depth characterisation of the microbiota by high- 
throughput 16S rRNA gene-based technologies are needed, such as barcoded pyrosequencing and phylogenetic microarray analyses.

To our knowledge, this is one of the first studies that showed an association between the disruption of the intestinal microbiota and the development of diarrhoea-like bowel movements. As the intake of a multispecies probiotic had an impact on both the restoration of the dominant faecal microbiota and the occurrence of diarrhoealike bowel movements it seems plausible to assume a causal relation. However, we can not exclude that the decrease in diarrhoea-like bowel movements is caused by a direct effect of the probiotic strains or the induction of a specific microbial species. Such an induction has been reported in an animal model of acute pancreatitis. In that study probiotic treatment was found to increase an unidentified commensal rat ileal bacterium (CRIB), which correlated with reduced severity of pancreatitis and associated sepsis ${ }^{12}$.

In the present thesis, no attention has been paid to the intestinal barrier, the interface between the microbial environment, and the gut associated immune system. Antibiotic treatment causes perturbations in the intestinal microbiota (Chapter 4) which may lead to intestinal barrier dysfunction through alterations in expression of intestinal epithelial cell tight junction proteins, mucin, antimicrobial peptides, and cytokines $^{13}$. Yet, to our knowledge there are no studies directly examining the effect of antibiotic exposure on intestinal barrier function. Probiotics prevent pathogen adherence and invasion of the epithelium, partly by blocking adherence sites and the production of antimicrobial peptides but also by up regulating gene expression of MUC2. Moreover, probiotics can alter expression and redistribution of tight junction proteins and inhibit epithelial apoptosis, thereby reducing intestinal permeability and limiting permeation of noxious molecules from the gut lumen ${ }^{14}$. In future studies it would be interesting to examine whether antibiotic intake can lead to intestinal barrier dysfunction and whether probiotics are able to prevent or restore this.

\section{Probiotics}

There is a vast body of literature on the benefits of probiotics in the prevention and treatment of a wide variety of disorders. However, the precise interaction of probiotics with the microbiota and the host and the mechanisms of action by which these organisms exert their benefits are still largely unknown. Nevertheless, recent findings from in vitro, ex vivo, in vivo and animal studies, including the results from the present thesis, are helping to unravel this black box.

\section{Selecting a probiotic}

There is great variation in the efficacy of the different species and strains of microorganisms used as probiotics and therefore it is a challenge to determine which micro- 
organism or combination of micro-organisms is most efficacious. It is clear that probiotics can have several modes of action. Moreover, it is well known that properties that apply for one probiotic strain do not necessarily apply for another. Even closely related bacterial strains of the same species may have different physiological effects. Furthermore, as the pathophysiology of every specific disorder differs, it seems logical that not all probiotics will be efficacious in all disorders. Probiotics are currently administered as monostrain, multistrain or multispecies preparations. Multispecies probiotics combine genus-, species- and strain-specific properties, which may complement each others' effect through synergism and/or symbiosis. As shown in Chapter 2, this can enhance functionality and efficacy. However, it has to be taken into account that certain strains can also have a crossregulatory effect. This underlines the importance of selecting the right combination of strains for the prevention and treatment of a specific disease. To this end a specific multispecies probiotic, Ecologic ${ }^{\circledR} A A D$, was designed for our study. Ten strains were selected based on in vitro survival of gastrointestinal passage ${ }^{15}$ (i.e. low $\mathrm{pH}$ (2.5) as well as bile and the digestive enzymes pancreatin and pepsin), their in vitro ability to inhibit growth of Clostridium spp. and the absence of acquired antibiotic resistance. In addition, mutual inhibition of the strains and general characteristics such as reproducible growth and shelf life were taken into account.

Was the right combination of strains chosen to prevent and/or treat the studied antibiotic-associated side effects in the present thesis? It is important to realise that data from in vivo, in vitro, or ex vivo studies do not necessarily correlate with one another. Flinterman et al. demonstrated that probiotics have a different potential to modulate the immune response in vitro versus ex vivo ${ }^{16}$. However, in Chapter 3 and Chapter 4 we showed that intake of Ecologic $A A D$ was able to significantly reduce the occurrence of diarrhoea-like bowel movements and had a restoring and stabilizing impact on the dominant faecal microbiota. This implies that with respect to the clinical and bacteriological parameters studied, an efficacious combination of strains was selected. Apart from a significant increase of serum slgA, intake of Ecologic ${ }^{\circ} A D$ seemed to have little effect on the analysed immunological biomarkers. It should be mentioned that although the immune system is clearly one of the targets of probiotic action, none of the strains in Ecologic ${ }^{\circledR}$ AAD had originally been selected based on this target.

\section{Probiotics for maintaining health?}

It is often suggested that consuming probiotics would have a positive effect on general health. Likely mechanisms responsible for this health maintaining effects include the provision of colonization resistance and enhancement of immune function. As outlined in the general introduction, numerous studies have provided evidence for the immunomodulating and pathogen inhibiting effects of probiotics, but the overall clinical relevance of the specific effects still needs to be clarified. 
Furthermore, these observations do not explain the mechanism behind these effects. Which cellular receptors or bacterial molecules for example are responsible for them? The use of for example transgenic or knockout mice could provide more insight in the mechanisms involved.

The question remains whether probiotics can maintain health. 'Health' is difficult to define and therefore the question should perhaps focus on: can probiotics prevent or treat disease? Focussing on the prevention of disease, there is compelling evidence based on methodologically well-designed studies that probiotic are efficacious in preventing $A A D$, infectious diarrhoea, pouchitis and atopic dermatitis ${ }^{17-19}$. In addition, evidence is accumulating that they can be helpful in the prevention of conditions such as necrotizing enterocolitis, CDAD, traveller's diarrhoea, vaginitis/vaginosis, recurrences in Ulcerative Colitis and urinary tract infection ${ }^{17-19}$. With regard to the treatment of disease, some promising results have been demonstrated in Irritable Bowel Syndrome ${ }^{20}$. Moreover, probiotics have been found to alleviate symptoms of lactose intolerance, reduce the side effects induced by Helicobacter pylori eradication therapy and are helpful in the treatment of childhood allergy and eczema ${ }^{17-19}$.

Thus, probiotic intake may be efficacious in preventing and treating a multitude of disorders both inside and outside the Gl tract. However, currently they seem most promising in preventing disease. This is further supported by a study of Sugawara et al., who demonstrated that preoperative plus postoperative symbiotic treatment (L. casei Shirota and Oligomate 55) significantly reduced the incidence of postoperative infectious complications compared to postoperative treatment alone ${ }^{21}$. Moreover, Rychter et al. showed that in mice, pre-treatment with a multispecies probiotics for 2 days preserves the integrity of the intestinal barrier in the late phase of acute pancreatitis, while concurrent treatment does not ${ }^{22}$.

In this context it seems more logical that the decrease in microbiota diversity observed in the COPD population (Chapter 6) can be prevented with probiotics rather than treated. Therefore, probiotic supplementation should be given immediately with antibiotic treatment especially in patients groups with a high risk of future frequent antibiotic use.

\section{Safety}

As outlined in Chapter 1, in general probiotics have a long history of safe use. In the present thesis intake of Ecologic AAD did not result in adverse events. Moreover, no cases of translocation or serious adverse events have been reported in clinical trials regarding probiotics for the prevention of $A A D$ and $C D A D^{23}$. However, the unexpected increased mortality in patients with acute pancreatitis after probiotic intake in comparison with placebo intake has intensified the debate about the safety of probiotics $^{24}$.

Studies specifically designed to assess probiotic safety are currently lacking. In Europe, the European Food Safety Authority proposed a safety approach known as "Qualified 
Presumption of Safety" (QPS), which is similar to the Generally Regarded As Safe (GRAS) system used in the United States. This also takes into account new emerging safety risks such as acquisition of antibiotic resistance and virulence determinants ${ }^{25}$. However, also various other initiatives addressing the safety of probiotics for humans have been undertaken, but a consensus on European level does not yet exist. In future, safety assessments should include:

- evidence of safe historical use of the species

- unambiguous identification at both the genotypic and phenotypic level

- exclusion of pathogenicity (i.e. virulence properties and adverse metabolic activity)

- absence of transferable antibiotic resistance genes

- preferred method of administration (oral or otherwise)

- information on the presence of allergenic material (for example, dairy proteins)

Finally, the physiological status of the consuming population, especially vulnerable subjects such as newborn infants and the critically ill, should be taken into account.

\section{Tailored probiotics}

As stated above, not all probiotic strains are equally beneficial; specific strains have specific effects and the pathophysiology of disorders differs. Furthermore, the optimum dose, duration and timing of treatment (pre- versus post-treatment) have yet to be established for most probiotics. Altogether this provides an important contribution to the inconsistent findings of several probiotic benefits in clinical trails. In this context, it should also be realised that not everyone benefits from probiotic intake. In the present thesis intake of a multispecies probiotic was able to reduce diarrhoea-like bowel movements and to induce a restoration of the faecal microbiota, but only in a subset of healthy subjects. In addition, host factors will also be important. Two clinical trials using a nearly identical study design showed that LGG supplementation prevented atopic dermatitis in a Finnish population but not in a German population ${ }^{26,27}$. Every subject (or population) has a unique genetic background and in every disease numerous environmental factors are involved, which may also differ geographically. Genetic studies provide increasing evidence that for instance polymorphisms in innate-immunity genes like CD14, TLRs and NOD proteins play a prominent role in gene-environment interactions contributing to asthma and IBD. NOD2 polymorphisms are associated with ileal and stricturing phenotypic variants of Crohn's disease in Western countries. The NOD2 mutations affect the leucine-rich region, which acts as the receptor for the bacterial cell wall peptidoglycan component muramyl dipeptide (MDP) and thus influences bacterial handling. NOD2 mutant mice have decreased $\beta$-defensin secretion and increased nuclear factor-kappa $B$ pro-inflammatory signalling in response to MDP. Thus, inconsistent findings of probiotic effect can also be the result of gene-environment interaction. 
In conclusion, probiotics may have different effects in different genetic backgrounds and in diseases that vary in their pathogenesis, and their effects can therefore be highly individual. Developments in a number of molecular profiling technologies, including proteomic profiling, metabolomic analysis, and genomic/genetic testing will allow the development of personalised probiotics, consisting of strains with properties that are not only effective for a particular disorder but are also tailored to that specific individual. 


\section{References}

1. Cremonini F, Di Caro S, Nista EC, Bartolozzi F, Capelli G, Gasbarrini G, Gasbarrini A. Meta-analysis: the effect of probiotic administration on antibiotic- associated diarrhoea. Aliment Pharmacol Ther. 2002; 16:1461-7.

2. D'Souza AL, Rajkumar C, Cooke J, Bulpitt CJ. Probiotics in prevention of antibiotic associated diarrhoea: meta- analysis. BMJ. 2002;324:1361.

3. Hickson M, D'Souza AL, Muthu N, Rogers TR, Want S, Rajkumar C, Bulpitt CJ. Use of probiotic Lactobacillus preparation to prevent diarrhoea associated with antibiotics: randomised double blind placebo controlled trial. BMJ. 2007;335:80.

4. McFarland LV. Meta-analysis of probiotics for the prevention of antibiotic associated diarrhea and the treatment of Clostridium difficile disease. Am J Gastroenterol. 2006;101:812-22.

5. Eckburg PB, Bik EM, Bernstein CN, Purdom E, Dethlefsen L, Sargent M, Gill SR, Nelson KE, Relman DA. Diversity of the human intestinal microbial flora. Science. 2005;308:1635-8.

6. Marteau P, Pochart P, Dore J, Bera-Maillet C, Bernalier A, Corthier G. Comparative study of bacterial groups within the human cecal and fecal microbiota. Appl Environ Microbiol. 2001;67:4939-42.

7. Wang M, Ahrne S, Jeppsson B, Molin G. Comparison of bacterial diversity along the human intestinal tract by direct cloning and sequencing of $16 S$ rRNA genes. FEMS Microbiol Ecol. 2005;54:219-31.

8. Zoetendal EG, von Wright A, Vilpponen-Salmela T, Ben-Amor K, Akkermans AD, de Vos WM. Mucosaassociated bacteria in the human gastrointestinal tract are uniformly distributed along the colon and differ from the community recovered from feces. Appl Environ Microbiol. 2002;68:3401-7.

9. Jacobs DM, Gaudier E, van Duynhoven J, Vaughan EE. Non-digestible food ingredients, colonic microbiota and the impact on gut health and immunity: a role for metabolomics. Curr Drug Metab. 2009;10:41-54.

10. McFarland LV. Epidemiology, risk factors and treatments for antibiotic-associated diarrhea. Dig Dis. 1998;16:292-307.

11. Zoetendal EG, Collier CT, Koike S, Mackie RI, Gaskins HR. Molecular ecological analysis of the gastrointestinal microbiota: a review. J Nutr. 2004;134:465-72.

12. Timmerman HM, Minnen LP, Panneman H, Rombouts FM, Gooszen HG, Akkermans LM, Rijkers GT. Probiotics stimulate a commensal gut bacterium which protects the host from severe pancreatitis and sepsis. In: Multispecies Probiotics -comparison of functionality, PhD thesis. Utrecht University, Utrecht, The Netherlands.

13. Wlodarska M, Finlay BB. Host immune response to antibiotic perturbation of the microbiota. Mucosal Immunol. 2009:(Epub ahead of print).

14. Mennigen R, Bruewer M. Effect of probiotics on intestinal barrier function. Ann $N$ Y Acad Sci. 2009;1165:183-9.

15. Timmerman HM, Niers LE, Ridwan BU, Koning CJ, Mulder L, Akkermans LM, Rombouts FM, Rijkers GT. Design of a multispecies probiotic mixture to prevent infectious complications in critically ill patients. Clin Nutr. 2007;26:450-9.

16. Flinterman AE, Knol EF, van leperen-van Dijk AG, Timmerman HM, Knulst AC, Bruijnzeel-Koomen CA, Pasmans SG, van Hoffen E. Probiotics have a different immunomodulatory potential in vitro versus ex vivo upon oral administration in children with food allergy. Int Arch Allergy Immunol. 2007;143: 237-44.

17. Kaur IP, Kuhad A, Garg A, Chopra K. Probiotics: delineation of prophylactic and therapeutic benefits. J Med Food. 2009;12:219-35.

18. Minocha A. Probiotics for preventive health. Nutr Clin Pract. 2009;24:227-41.

19. Parvez S, Malik KA, Ah Kang S, Kim HY. Probiotics and their fermented food products are beneficial for health. J Appl Microbiol. 2006;100:1171-85.

20. Hoveyda N, Heneghan C, Mahtani KR, Perera R, Roberts N, Glasziou P. A systematic review and metaanalysis: probiotics in the treatment of irritable bowel syndrome. BMC Gastroenterol. 2009;9:15.

21. Sugawara G, Nagino M, Nishio H, Ebata T, Takagi K, Asahara T, Nomoto K, Nimura Y. Perioperative synbiotic treatment to prevent postoperative infectious complications in biliary cancer surgery: a randomized controlled trial. Ann Surg. 2006;244:706-14. 
22. Rychter JW, van Minnen LP, Verheem A, Timmerman HM, Rijkers GT, Schipper ME, Gooszen HG, Akkermans LM, Kroese AB. Pretreatment but not treatment with probiotics abolishes mouse intestinal barrier dysfunction in acute pancreatitis. Surgery. 2009;145: 157-67.

23. McFarland LV. Evidence-based review of probiotics for antibiotic-associated diarrhea and Clostridium difficile infections. Anaerobe. 2009;15:274-80.

24. Besselink MG, van Santvoort HC, Buskens $E$, Boermeester MA, van Goor $H$, Timmerman HM, Nieuwenhuijs VB, Bollen TL, van Ramshorst B, Witteman BJ, Rosman C, Ploeg RJ, Brink MA, Schaapherder AF, Dejong CH, Wahab PJ, van Laarhoven CJ, van der Harst E, van Eijck CH, Cuesta MA, Akkermans LM, Gooszen HG. Probiotic prophylaxis in predicted severe acute pancreatitis: a randomised, double-blind, placebo-controlled trial. Lancet. 2008;371:651-9.

25. Wassenaar TM, Klein G. Safety aspects and implications of regulation of probiotic bacteria in food and food supplements. J Food Prot. 2008;71:1734-41.

26. Kalliomaki M, Salminen S, Arvilommi H, Kero P, Koskinen P, Isolauri E. Probiotics in primary prevention of atopic disease: a randomised placebo-controlled trial. Lancet. 2001;357:1076-9.

27. Kopp MV, Hennemuth I, Heinzmann A, Urbanek R. Randomized, double-blind, placebo-controlled trial of probiotics for primary prevention: no clinical effects of Lactobacillus GG supplementation. Pediatrics. 2008;121:e850-6. 



\section{Summary}





\section{Summary}

The human intestinal microbiota is composed of more than 1000 different species and contains approximately hundred times as many genes as the human genome. Adaptive co-evolution has led to a symbiotic interrelationship between this complex microbiota and the host, which plays an important role in maintaining human health. The intestinal microbiota provides colonization resistance, is involved in several metabolic processes, influences the intestinal barrier function and modulates the immune system (Chapter 1), all working in concert to maintain homeostasis.

Though marked variations are present between individuals, under normal conditions the intestinal microbiota is relatively stable over time. However, this intestinal microbiota homeostasis can be markedly affected by external factors, such as antibiotic treatment, which can clinically result in antibiotic-associated diarrhea (AAD). Probiotics can affect the composition of the intestinal microbiota and there is a vast body of evidence on their beneficial effects in the prevention of AAD. However, most studies focus mainly on clinical outcome and the potential mechanisms of action underlying these effects remain largely unexplored.

The present thesis describes the effect of a multispecies probiotic on bacteriological, immunological and clinical parameters during as well as after antibiotic treatment in healthy volunteers and patients with chronic obstructive pulmonary disease (COPD).

There is much variation in the efficacy of the different species and strains of microorganisms used as probiotics. It is clear that probiotics can have several modes of action and that properties that apply for one probiotic strain do not necessarily apply for another. In Chapter $\mathbf{2}$ the literature was reviewed to compare functionality and efficacy between different types (monostrain, multistrain and multispecies) of probiotics. A monostrain probiotic is defined as containing one strain of a certain species. Multistrain probiotics contain more than one strain of the same species or the same genus, such as Bifidobacterium bifidum and Bifidobacterium lactis. The term multispecies probiotics is used for preparations containing strains that belong to more genera, for instance a Bifidobacterium bifidum, Lactobacillus acidophilus and Enterococcus faecium. From this review it can be concluded that multispecies preparations have advantages compared to monostrain probiotics and, to a lesser extent, multistrain probiotics. In addition, possible mechanisms underlying the enhanced effects of probiotic mixtures are discussed. In a multispecies probiotic the bacterial strains may complement each others' effect through synergism and/or symbiosis, thereby maximizing the chance of providing clinically more effective probiotics. Furthermore, it is noted that special attention should be paid to avoid combinations of probiotic strains showing mutual inhibitory properties.

Chapter 3 describes the effect of a specially designed multispecies probiotic on the composition of the intestinal microbiota in healthy volunteers during and after 
amoxycillin intake. In addition, the effect on the metabolic activity of the intestinal microbiota and on bowel habits was studied. The study showed that the intake of a multispecies probiotic significantly reduced diarrhoea-like bowel movements in healthy volunteers receiving amoxycillin. In addition, intake of the multispecies probiotic was able to affect the composition of the faecal microbiota using conventional bacterial culture. Changes over time were present in both groups and differed between the probiotic and the placebo group. Such changes were also observed for the studied parameters of metabolic activity. Although, the observed changes separately were small, altogether the sum of the changes may have contributed to the clinical improvement observed in the probiotic group.

The human gastrointestinal tract harbours a large and diverse microbiota of which many microbial species can not be cultured optimally with the currently available methods.

Therefore, in Chapter 4 the effect of amoxycillin on the diversity and temporal stability of the dominant faecal microbiota and a potential restoration by the multispecies probiotics in healthy volunteers was assessed using DGGE profiling of PCR-amplified 16S rRNA gene fragments. The low similarity indices (SIs) and the low band number indicated that the stability and richness of the predominant faecal microbiota were markedly affected by amoxycillin intake and two months after cessation had not yet returned to its initial profile. In addition, an association between the disruption of the intestinal microbiota and the development of diarrhoea-like bowel movements was found, supporting the hypothesis that a lower stability of the dominant microbiota is related to a higher chance of developing AAD. Interestingly, when a multispecies probiotic was given during and after amoxycillin intake, a significantly better restoration of the microbiota was achieved after one month. Thereby, this could be one of the mechanisms in which probiotics contribute to the prevention and/or treatment of antibiotic associated diarrhoea.

Both probiotics and antibiotics can influence the immune system directly or indirectly by affecting the intestinal microbiota. Therefore, not only the effect of antibiotic and probiotic intake on bacteriological and clinical parameters but also on immune parameters was determined. Chapter $\mathbf{5}$ addresses the influence of the multispecies probiotic on components of both the systemic and the mucosal immune system in healthy volunteers taking amoxycillin. The study showed that intake of the multispecies probiotic did not alter the analyzed systemic and mucosal biomarkers apart from a significant increase of serum secretory IgA two months after cessation of amoxycillin intake. In addition, amoxycillin intake was able to induce in/ex vivo immunological changes consisting mainly of a decreased sputum slgA production and a decreased IL-4, IL-6, IL-13 and IFN- $\gamma$ and an enhanced IL-10 production capacity in stimulated whole blood. Although no differences were observed in the probiotic group versus the placebo group, the intake of a multispecies probiotic resulted in an 
even further decreased production of IL-4 and IL-13 and a less pronounced increase in IL-10 production. This implies that intake of amoxycillin has immunomodulating effects, which was further affected by probiotic intake. In addition, during and/or shortly after amoxycillin intake an association between the disruption of the intestinal microbiota and IL-8 and IL-10 was observed. However, the overall clinical relevance of the observed immunological changes still needs to be unravelled.

The study in healthy volunteers has demonstrated that short-term antibiotic use can cause long-term disturbances of the intestinal microbiota. However, the effect of frequent antibiotic use on the intestinal microbiota is not known. Chronic obstructive pulmonary disease (COPD) patients often suffer from acute exacerbations for which antibiotic therapy is frequently prescribed.

In Chapter 6 the disturbance of the dominant faecal microbiota and the possible restoration by a multispecies probiotic in COPD patients treated with antibiotics for an acute exacerbation is assessed. Moreover, the effect on specific bacterial groups using both culture and molecular based techniques and on bowel habits was studied. In contrast to the results in healthy volunteers, the dominant faecal microbiota was not affected upon antibiotic intake in this COPD population as both similarity indices and band richness remained stable during and after antibiotic treatment. The PCR-DGGE results indicated that the prolonged antibiotic pressure seemed to have caused a long-term imbalance of the dominant faecal microbiota. As antibiotics only affect sensitive strains, extensive antibiotic use could have caused a prolonged narrowing of the diversity into a dominant faecal microbiota consisting of microbial populations insensitive to the given antibiotics. Furthermore, the study demonstrated that the short-term intake of the multispecies probiotic had a modest effect on the intestinal microbiota, albeit much smaller than was previously observed for healthy adults. Nevertheless, this did not result in a restoration of the microbiota imbalance and no reduction in diarrhoea-like bowel movements was found. However, as the dominant microbiota seemed to be profoundly and long lastingly altered by the frequent prior antibiotic use, it is speculated that a longer probiotic treatment is needed to restore such an effect.

Chapter 7 describes the effect of the multispecies probiotic on immune biomarkers during and after antibiotic intake in these COPD patients with a history of frequent antibiotic use. Furthermore, the association between the disruption of the intestinal microbiota and the immune biomarkers was assessed. Intake of the multispecies probiotic had a limited effect on biomarkers of the immune system in COPD patients treated with antibiotics for an acute exacerbation. In addition, the observed antibiotic effect on the immune biomarkers was possibly attributed to the resolution of the exacerbation and could not be linked to perturbations in the dominant faecal microbiota. 
In conclusion, the studies described in this thesis support the rationale for the use of a multispecies probiotic in the prevention and treatment of antibiotic associated side effects. Intake of the specially designed multispecies probiotic significantly reduced diarrhoea-like bowel movements in healthy volunteers probably due to the observed restoration of the dominant faecal microbiota towards to the pre-antibiotic state. In addition, multispecies probiotic intake was able to affect antibiotic induced changes in ex vivo cytokine production and resulted in a significant increase in serum slgA. However, no such effects were observed in COPD patients with a history of frequent antibiotic use. It is speculated that this was probably due to a profound and long-term imbalance of the intestinal microbiota caused by the frequent prior antibiotic use. Large prospective human intervention trial are needed to determine to what extent antibiotic induced disturbances of the intestinal microbiota are permanent, what their clinical implications are and if probiotic supplementation is able to either prevent or with prolonged use reverse such an imbalance. In addition, it would be interesting to identify host-related, microbiota-related or environmental risk factors to characterize subjects at risk and who would benefit from probiotic intake. 
Samenvatting 



\section{Samenvatting}

In het maag-darmkanaal bevindt zich een complex bacterieel ecosysteem (de intestinale microbiota), dat ongeveer honderd keer meer genen bevat dan het humane genoom. Deze intestinale microbiota bevat maar liefst $10^{14}$ microorganismen en meer dan 1000 verschillende soorten waarvan het grootste deel anaëroob is (99\%). Deze complexe microbiota en de gastheer leven in symbiose met elkaar, hetgeen belangrijk is voor het behoud van een goede gezondheid. De intestinale microbiota kan de gezondheid van de gastheer op drie niveaus beïnvloeden. Allereerst zorgt de microbiota zowel voor de digestie van onverteerbare koolhydraten en de aanmaak van vitamines ( $B$ en $K$ ), als voor de bescherming tegen potentieel pathogene micro-organismen door de productie van antimicrobiële stoffen en de competitie voor bindingsplaatsen en nutriënten. Dit laatste wordt ook wel kolonisatieresistentie genoemd. Ten tweede beïnvloedt de microbiota het darmepitheel en diens barrièrefunctie, waardoor bacteriën en andere schadelijke stoffen het lichaam niet kunnen binnendringen. Ten derde kan de microbiota het immuunsysteem beïnvloeden (Hoofdstuk 1).

De samenstelling van de microbiota verschilt van persoon tot persoon en is onder normale omstandigheden bij een gezonde volwassen persoon relatief stabiel. De microbiota kan door externe factoren zoals het gebruik van antibiotica echter worden verstoord, wat kan resulteren in antibioticum geassocieerde diarree (AAD). Probiotica (meestal melkzuurbacteriën) worden door de World Health Organisation (WHO) gedefinieerd als "levende micro-organismen die, wanneer toegediend in voldoende hoeveelheid, een gezondheidsbevorderend effect hebben voor de gastheer". Probiotica kunnen de microbiota samenstelling (en metabole activiteit) moduleren en er is toenemend bewijs dat ze een gunstige effect hebben in de preventie van AAD. De meeste studies richten zich echter vooral op het klinisch effect (preventie van diarree), terwijl de mogelijke werkingsmechanismen waarop dit effect berust nog grotendeels onbekend zijn.

In dit proefschrift wordt het effect van een multispecies probioticum op bacteriologische, immunologische en klinische parameters tijdens en na antibioticumgebruik beschreven, in zowel gezonde vrijwilligers als patiënten met 'chronic obstructive pulmonary disease' (COPD), een chronische obstructieve longziekte.

$\mathrm{Er}$ is veel variatie in de effectiviteit van de verschillende soorten en stammen van micro-organismen. Het is bekend dat probiotica verschillende werkingsmechanismen hebben en dat eigenschappen die gelden voor één bepaalde stam niet noodzakelijkerwijs ook gelden voor andere stammen. Hoofdstuk $\mathbf{2}$ beschrijft de resultaten een literatuurstudie over de functionaliteit en effectiviteit van verschillende soorten (monostrain, multistrain en multispecies) probiotica. Een 
monostrain probioticum bestaat uit één enkele stam afkomstig van een bepaalde bacteriesoort. Multistrain probiotica bestaan uit meer dan één stam van dezelfde soort, zoals bijvoorbeeld een Bifidobacterium bifidum en een Bifidobacterium lactis. De term multispecies probiotica wordt gebruikt voor producten die bacteriën bevatten van meer dan één bacteriegeslacht, zoals Bifidobacterium bifidum, Lactobacillus acidophilus en Enterococcus faecium. Uit de literatuurstudie bleek dat multispecies probiotica voordelen hebben ten opzichte van monostrain probiotica en in mindere mate, multistrain probiotica. Dit is ook te verwachten: verschillende soorten (micro-organsimen) kunnen, door verschillende eigenschappen, elkaars effect versterken waardoor er synergie optreedt. Ook kunnen ze een symbiose aangaan en elkaars groei versterken. Dit vergroot de kans op een klinisch succesvol probioticum. Hierbij is het wel van belang om te controleren of de bacteriën in een multispecies probioticum elkaar niet negatief beïnvloeden.

In Hoofdstuk 3 wordt het effect beschreven van een speciaal samengesteld multispecies probioticum op de samenstelling van de fecale microbiota in gezonde vrijwilligers tijdens en na amoxycilline gebruik. Tevens is het effect op de metabole activiteit van de microbiota en op het ontlastingspatroon bestudeerd. De studie liet zien dat een diarreeachtig ontlastingspatroon minder vaak voorkwam in de groep die behandeld was met het multispecies probioticum. Daarnaast werd aangetoond dat gebruikmakend van conventionele kweekmethodes, inname van het multispecies probioticum een effect heeft op de samenstelling van de microbiota. Veranderingen in de microbiotasamenstelling over de tijd werden waargenomen in beide groepen, maar deze verschilden tussen de probioticum en de placebo groep. Dergelijke fluctuaties werden ook gezien in de bestudeerde parameters van de metabole activiteit. Hoewel de waargenomen veranderingen op zichzelf klein waren, kan de optelsom van al deze veranderingen toch hebben bijgedragen aan de klinische verbetering (minder diarreeachtige ontlasting) in de groep die behandeld werd met het multispecies probioticum.

Van de complexe en zeer diverse microbiota die aanwezig is in het maag-darmkanaal kunnen veel micro-organismen niet optimaal gekweekt worden met behulp van de huidige kweekmethodes. Daarom is in Hoofdstuk $\mathbf{4}$ het effect van amoxycilline op de diversiteit en stabiliteit van de dominante fecale microbiota en een mogelijk herstel door inname van het multispecies probioticum in gezonde vrijwilligers bestudeerd met behulp van PCR-DGGE. PCR-DGGE is een op 16S rRNA gebaseerde kweekonafhankelijke moleculaire techniek. Middels deze PCR-DGGE werd aangetoond dat amoxycilline inname leidt tot een duidelijke verstoring van de dominante fecale microbiota en dat deze verstoring 2 maanden na stoppen van amoxycilline nog niet hersteld is. Tevens werd aangetoond dat er een associatie is tussen de verstoring van de microbiota door amoxycilline gebruik en het voorkomen van een diarreeachtig ontlastingspatroon. Dit ondersteunt de hypothese dat de mate van verstoring van de microbiota gerelateerd is aan de kans op het ontwikkelen van AAD. Als laatste werd 
aangetoond dat bij gezonde vrijwilligers die behandeld waren met het multispecies probioticum, vier weken na amoxycilline inname een significant beter herstel van de dominante fecale microbiota werd waargenomen. Dit duidt erop dat een herstel van de microbiota daadwerkelijk één van de mechanismen is achter het effect van probioticumgebruik ter preventie van AAD.

Zowel probiotica als antibiotica kunnen het immuunsysteem direct beïnvloeden of indirect via modulatie van de intestinale microbiota. Daarom is er in dit proefschrift niet alleen gekeken naar het effect van antibiotica en probiotica inname op bacteriologische en klinische parameters, maar ook op het immuunsysteem. Het effect van het multispecies probioticum op componenten van zowel het mucosale als het systemische immuunsysteem tijdens en na amoxycilline inname in gezonde vrijwilligers wordt beschreven in Hoofdstuk 5. De resultaten van deze studie laten zien dat inname van het multispecies probioticum geen invloed had op de geanalyseerde immunologische biomarkers, behalve een toename in serum secretoir IgA twee maanden na amoxycilline inname. Daarnaast werd aangetoond dat amoxycilline inname in en ex vivo immunologische veranderingen kon induceren. Deze veranderingen bestonden voornamelijk uit een afname van sputum secretoir IgA en een afname van IL-4, IL-6, IL-13 and IFN- $\nu$ productie en een toename van IL-10 productie in ex vivo gestimuleerd volbloed. Hoewel er geen verschil werd waargenomen tussen de probioticum en placebo groep, resulteerde inname van het multispecies probioticum in een verdere afname van IL-4 en IL-13 productie en een verminderde toename van IL-10 productie. Dit suggereert dat amoxycilline inname immuunmodulerende effecten heeft, welke beïnvloed kunnen worden door probiotica inname. Ook werd er een associatie gevonden tussen de verstoring van de microbiota en IL-8 en IL-10. De exacte klinische relevantie van deze immunologische veranderingen is echter nog niet duidelijk.

De studie in gezonde vrijwilligers liet zien dat kortdurend antibioticagebruik kan leiden tot lange termijn verstoringen van de intestinale microbiota. Echter, het effect van frequent antibioticumgebruik op de intestinale microbiota is niet bekend. COPD patiënten hebben vaak last van een acute verergering (exacerbaties) van hun klachten waarvoor ze worden behandeld met antibiotica.

De verstoring van de dominante fecale microbiota en een mogelijk herstel hiervan door inname van het multispecies probioticum in COPD patiënten die behandeld worden met een antibioticum voor een acute exacerbatie wordt beschreven in Hoofdstuk 6. Tevens werd het effect op specifieke bacteriële subgroepen, met behulp van zowel kweekafhankelijke als kweekonafhankelijke technieken, en op het ontlastingspatroon geanalyseerd. In tegenstelling tot de bevindingen in gezonde vrijwilligers, bleek dat antibiotica inname niet leidt tot een verstoring van de dominante fecale microbiota in deze COPD patiënten. Deze bevinding suggereert dat het langdurig antibioticumgebruik heeft geleid tot een lange termijn verstoring van de 
dominante fecale microbiota. Aangezien antibiotica alleen effect hebben op gevoelige bacteriële stammen, zou het goed mogelijk kunnen zijn dat het frequente antibioticumgebruik tot een versmalling van de microbiota heeft geleid, bestaande uit bacteriële populaties die ongevoelig zijn voor de voorgeschreven antibiotica. Tevens liet de studie zien dat kortdurende inname van het multispecies probioticum een bescheiden effect had op bepaalde bacteriële groepen, welke veel kleiner was dan het effect waargenomen bij de gezonde vrijwilligers. Desondanks resulteerde dit niet in een verandering van de microbiota samenstelling of in een afname van diarreeachtige ontlasting. Echter, aangezien de microbiota zo ernstig en langdurig verstoord lijkt door eerder antibioticumgebruik, denken wij dat het noodzakelijk is om probiotica veel langer in te nemen om herstel te bewerkstelligen.

Hoofdstuk 7 beschrijft het effect van het multispecies probioticum op immunologische biomarkers tijdens en na antibioticumbehandeling in deze COPD patiënten met een voorgeschiedenis van frequent antibioticumgebruik. Tevens is de associatie tussen de immunologische biomarkers en de verstoring van de microbiota bestudeerd. De studie liet zien dat inname van het multispecies probioticum slechts een gering effect had op de gemeten biomarkers. Het waargenomen antibioticum effect op de immunologische biomarkers leek toegeschreven te kunnen worden aan het herstel van de exacerbatie en kon niet gekoppeld worden aan veranderingen in de microbiota samenstelling.

Concluderend kan worden vastgesteld dat de in dit proefschrift beschreven studies de rationale voor het gebruik van probiotica voor de preventie en behandeling van antibioticum geassocieerde bijwerkingen ondersteunen. Inname van een speciaal ontwikkeld multispecies probioticum vermindert het voorkomen van een diarreeachtige ontlasting in gezonde vrijwilligers, wat waarschijnlijk toe te schrijven is aan het waargenomen herstel van de samenstelling van de intestinale microbiota. Daarnaast was het multispecies probioticum in staat de veranderingen in ex vivo cytokine productie die geïnduceerd werden door antibioticumgebruik te beïnvloeden en resulteerde het in een toename van serum secretoir IgA. Dergelijke effecten werden echter niet waargenomen in de studie met COPD patiënten. Het frequent en langdurig antibioticumgebruik van deze patiënten, wat leidde tot een lange termijn verstoring van de dominante fecale microbiota, ligt hier mogelijk aan ten grondslag. In de toekomst zijn prospectieve interventie studies nodig om te onderzoeken in welke mate de antibioticum geïnduceerde veranderingen van de microbiota permanent zijn, wat de klinische implicatie hiervan is en of probioticuminname deze verstoring kan voorkomen dan wel kan herstellen. Door in toekomstig onderzoek ook aandacht te besteden aan het in kaart brengen van gastheer-, microbiota- en omgevingsfactoren, kunnen we tevens meer inzicht verkrijgen in welke personen gebaat zouden zijn bij probioticumgebruik. 


\section{Dankwoord}





\section{Dankwoord}

Na velen jaren zwoegen en zweten, kan ook ik beginnen aan het schrijven van het dankwoord! Het deel van mijn proefschrift dat in elk geval het meest gelezen zal worden. Door de bijzondere constructie van mijn aanstelling, het aantal partners dat bij het project betrokken was, de verschillende afdelingen waartoe ik heb behoord en de iets langer dan gemiddelde tijd die ik voor mijn promotie heb uitgetrokken, zijn er niet alleen een hoop mensen die ik 'moet' bedanken, maar vooral die ik 'wil' bedanken. De lezer is dan ook gewaarschuwd en wordt geadviseerd er eens rustig bij te gaan zitten, aangezien de meeste mensen niet zo snel kunnen lezen als dat ik kan praten. Het is helaas niet mogelijk om iedereen die een bijdrage heeft geleverd aan deze waardevolle en rijke periode persoonlijk te noemen, maar weet allemaal dat mijn dank is groot.

Allereerst mijn promotor Reinhold Stockbrügger: beste Reinhold, jouw enthousiasme, niet alleen voor het uitvoeren van wetenschappelijk onderzoek maar ook voor de resultaten ervan (ook al leken ze soms in eerste instantie niet op wat we verwachten) heeft mij enorm geïnspireerd. Daarnaast zijn ook jouw kennis en het vertrouwen dat je in me gaf belangrijke ingrediënten geweest voor de totstandkoming van dit proefschrift.

Daarnaast mijn co-promotores Ellen Stobberingh en Daisy Jonkers. Beste Ellen, mijn eerste dag als onderzoeker zei je tegen me; "ik heet Ellen hoor" en deze openheid en laagdrempeligheid is sindsdien gebleven. Dankzij jouw inzet, onuitputtelijke werklust, kritische maar ook zeer pragmatische blik op het onderzoek en de ruimte die je me hebt gegeven om mijn mening te uiten en zaken gewoon eens te proberen, heb ik heel veel kunnen leren. Daarnaast zijn ook jouw betrokkenheid en interesse in mij als persoon niet onopgemerkt gebleven.

Daisy, ik denk dat ik met zekerheid kan stellen dat dit proefschrift zonder jou niet tot stand was gekomen. Jouw opendeur beleid maken je tot de ideale praktische begeleider, iets waar menig onderzoeker jaloers op is. Ik heb daardoor ontzettend veel van je kunnen leren, niet alleen op wetenschappelijk vlak maar ook op het gebied van mijn persoonlijke ontwikkeling. Ook wist je me altijd weer te kalmeren en te motiveren als ik het niet meer zag zitten of het weer eens helemaal had gehad en met de stoom uit mijn oren bij je kwam binnenstormen. We hebben in de afgelopen jaren een hoop ups \& downs meegemaakt en ik zal onze reisjes, etentjes, koffiegeleut en onze favoriete dinsdagavondbesteding 'steppen met sportleraar Frank' dan ook enorm gaan missen. Bedankt voor alles en jij en Karel moeten ook maar gewoon in de Randstad komen wonen!

De leden van de beoordelingscommissie bedank ik voor de tijd en energie die ze gestoken hebben in het doorlezen en beoordelen van mijn proefschrift. Het hoofd van de afdeling Medische Microbiologie, Prof. dr. Cathrien Bruggeman en het hoofd van de afdeling Maag-Darm- en Leverziekten, Prof. dr. Ad Masclee wil ik graag bedanken 
voor de mogelijkheid die ze geboden hebben om mijn onderzoek binnen hun afdelingen uit te voeren.

De studies beschreven in dit proefschrift zijn deels uitgevoerd met de hulp van vele mensen uit verschillende ziekenhuizen, universiteiten en behandelingscentra die ik erg dankbaar ben voor hun enthousiasme, kennis en doorzettingsvermogen. Een aantal van hen wil ik graag even specifiek noemen. Hauke Smidt, bedankt voor de prettige samenwerking en dat je ondanks je super drukke schema toch altijd weer de tijd vond om mijn manuscripten van nuttige input te voorzien. Susana, many thanks for introducing me into the wonderful world of qPCRs. Wilma Akkermans-van Vliet and Ineke Heikamp-de Jong bedankt voor alle analyses die jullie voor mij hebben uitgevoerd. Theo Out, jij hebt me als eerste geïntroduceerd in de interessante maar complexe wereld van de immunologie. Ik wil jou en Rene Lutter graag bedanken voor jullie ondersteuning en aanwijzingen bij het uitvoeren van de verschillende analyses maar vooral bij de interpretatie van de ingewikkelde immuundata. Prof. Emiel Wouters en dr. Herman-Jan Pennings wil ik bedanken omdat zij de samenwerking met CIRO Horn hebben mogelijk gemaakt. Herman-Jan, mijn dank voor het zo goed en efficiënt in banen leiden van het onderzoek. Annelies Derks, bedankt voor het verwerken van alle samples. Annie van de Kruijs, wat is een klinische studie zonder een goede researchverpleegkundige........ Alleen dankzij jouw doorzettingsvermogen en enthousiasme is het gelukt om toch nog 30 COPD-patiënten te includeren.

De helft van je werkplezier wordt gevormd door de inhoud, de andere helft door je collega's en ik heb wat dat betreft altijd enorm gelukt gehad. Omdat ik binnen zoveel groepen heb gewerkt weet in nauwelijks waar ik moet beginnen. Laat ik dus maar bij het begin beginnen.

Mijn collega's van de Medische Microbiologie: na wat omzwervingen binnen de afdeling kwam ik op de AlO-Kamer terecht. De AlO-Kamer, die lange tijd het kloppende hart is geweest van de $\mathrm{MMB}$ en onlosmakelijk verbonden was met een goed gevulde snoeppot, herrie, niet-representatieve versiersels, talloze grappen \& grollen, geklets en altijd veel plezier (en ja, er werd ook nog wel eens gewerkt). Allereerst de harde kern; Suzanne 'dwerg' Kapiteins, Koen 'fatboy not so slim' van Cleef en mijn 'home-boy' Erik Beuken. Erik, hoe jij het al die tijd met ons hebt uitgehouden is mij nog steeds een raadsel. Hoewel, was jij niet degene die bedacht had dat we m.b.v. onze truien 500 oranje ballonnen best even aan het plafond konden plakken? Lieve Koen en Suzzie, tot op de dag van vandaag snap ik niet waarom wij 'de Duivel' worden genoemd. Suzzie, weet jij hier iets van ;-)? Wat hebben wij het druk gehad met het opblazen van ballonen, bumperstickers plakken, pinguïn slaan om het lotnummer te bepalen, snoepjes verstoppen, representatief zijn, Sinterklaasgedichten (jullie dan) en het bedenken van de Sound of Music II. De AIO-kamer is helaas niet meer, de Duivel gelukkig nog wel (eenieder is dus gewaarschuwd)! Jullie 
waren top collega's maar zijn nu hele dierbare vriendjes en ik kijk nu alweer uit naar alle mooie momenten die gaan komen. In elk geval (eindelijk), Château Neercanne here we come!!!!!!!

Selma, ook jij bent een ware vriendin gebleken. Altijd een mooie avond met en bij jou, jammer alleen dat je niet kunt koken! Lieve, bedankt voor je luisterend oor en je betrokkenheid, je hebt een hart van goud. Ellen en Hilde, amai jullie hebben je vaak geambeteerd aan ons, ik snap nochtans niet waarom :-)

Daarnaast de losse aanhang, de mensen die in meer (Tijn!) of minder mate in, op en rondom de AIO-kamer aanwezig waren; John, Hans (aka Hanne), Bart, Tijn, Geoffrey, Gert, Jeroen, Laura, Patrick, Guy, Yvonne, Claudia, Frank, Peter en Wil, de mensen van de 'allochtonen-kamer'; Rajaa, Sita, Xavier, en Inge, de mensen van de moleculaire diagnostiek; Petra, Bart, Judith en Katrien, en de talloze stagiaires, enorm bedankt voor jullie luisterend oor, steun, en begrip, maar vooral voor jullie gezelligheid, voor alle John Mullens acties, etentjes, feestjes en voor al het vertier!

Het lab van de Bac-Research mag natuurlijk niet ontbreken in dit dankwoord. Christel, jouw ervaring en hulp op het lab waren voor mij onmisbaar. Altijd kon ik bij je terecht met vragen en voor hulp en was je een fijne rots in de branding. Op het lab was de sfeer altijd top: radio aan en dan maar beginnen met poepjes afwegen, spiralplaten, MICen, platen gieten buizen vullen en duizenden epjes stickeren. Monique, Elke, Lucy, Kim, Dominique, Sita, Tim, Guy, Maartje, Siebe, Ruud, Silvie, Miranda, Clemie en Rachida, bedankt voor al jullie hulp hiermee en de ontzettende leuke tijd die jullie me bezorgt hebben. Hierbij horen natuurlijk ook de mensen van "beneden" van de CPV. Als je iets nodig had uit een grijs verleden of iets wilde weten over anaerobe beestjes dan moest je langs bij Math en Jacqueline. Math, dat je er niet meer bent om het uiteindelijke resultaat hiervan te zien, is een groot gemis voor ons allen.

Een extra woord van dank aan Lucy voor het prikken van alle vrijwilligers en aan Beth voor alle ondersteuning bij het verwerken van de vele monsters. Dit geldt eveneens voor mijn stagiaires (Roger, Sandra, Hanne en Tim), dank voor jullie bijdrage aan dit proefschrift. Tim, het waren twee fantastische dagen!

Natuurlijk mogen de mensen van de spoelkeuken (Ans, John, en Verius) en het secretariaat (Patricia, Angèle, Fia, José, Frank en Anne) niet ontbreken. Bedankt voor alle klusjes die jullie voor mij gedaan hebben. En dan als laatste 'case closed'!

Vervolgens mijn collega's van de MDL: na op de super gezellige AIO-Kamer te hebben gezeten had ik prompt weer geluk met mijn kamergenoten. Willem, met jou als kamergenoot was het altijd feest. Ik kon ook heerlijk met je lachen, bekvechten en biertjes drinken. Daarnaast, heb je me het belang geleerd van een goed thema lied en ben ik er achter gekomen dat je vele kwaliteiten hebt, maar dat zingen er daar niet 
één van is. Snel weer eens afspreken samen met al je mooie meiden (dus toch een meisjes-papa).

Daniel, aka Mr. Grumpy, jouw sprankelende persoonlijkheid doet onze kamer altijd weer stralen! Ha ha ha, wat ben je toch een heerlijke oude mopperkont. En laat me raden; je heb echt geen zin vandaag! Door mijn promotie word jij nu senior-AIO, ik hoop dat je beseft wat voor een enorme verantwoordelijkheid er nu op je schouders gaat rusten! Als VOBertje heb je je draai hier in Maastricht inmiddels helemaal gevonden, mede dankzij partner in crime Samefko. Met jullie beide is er zowel binnen als buiten het werk een hoop te beleven en ik kijk nu al uit naar mijn promotiefeest. Samef, ik ga onze gesprekjes op de kamer echt missen, succes met de IBSers en bij deze super bedankt voor al je hulp bij mijn feest!

De overige MDL-researchers: Steven, er zijn er maar weinig die me zo kunnen uitlachen als jij, bedankt voor de vele gezellige avondjes en idd in Amsterdam hebben ze ook kroegen!; Henrike, bedankt voor jouw onuitputtelijke enthousiasme; Maljaar, wanneer is je housewarming nu ook weer?; Jeoffrey, gauw nog eens een dansje doen; Martine, bedankt dat je er altijd was met goede adviezen, wijze raad of een luisterend oor; Carolina, over jou kan ik alleen maar zeggen bedankt dat je bent zoals je bent, en ik hoop dat we samen nog eens een roadtrip zullen maken; Annemieke, lieve An, wat ben ik blij dat je naar sjoen Mestreech bent verhuisd, hierdoor heb ik er een ontzettend lief, leuk en gaaf vriendinnetje bij gekregen. Eentje die ook nog eens een top MDL-arts gaat worden, want nu je in opleiding bent, merk ik dat je je als in vis in het water voelt; Tim super leuk dat je nu ook weer mijn MDL-collega bent; Marielle en Eveline, wanneer gaan we nog eens naar NY?; Kirsten, geweldig hoe jij soms in je eigen wereldje kunt zitten; Fred, bedankt voor je altijd kritische blik; Pegah, good luck with your study; Andrea; bedankt voor al je hulp en ik hoop dat je je draai gaat vinden in Amersfoort; Maartje; heel veel succes in de VS; Esther, super stagiaire en nu gelukkig onze MDL-analist; Elhaseen, ongelofelijk hoe jij je de Nederlandse cultuur zo snel eigen hebt weten te maken; jullie zijn niet alleen collega's met wie ik heel fijn kan werken, maar ook met wie ik kan genieten van koffietjes, lunchmomenten, congressen, etentje en feestjes. Wat was het saai geweest zonder jullie!

Ook wil ik Ria, Pière, Nicole, Helène en Andrea graag bedanken voor al hun hulp. Hoewel het uitvoeren van een barostat en vooral het schoonmaken van de barastatballon, nu niet het meeste prettige werk is, kwam is dankzij jullie toch graag op de functiekamer!

Verder mogen de dames van het secretariaat (Elly en Mietsie) en Mia natuurlijk niet vergeten worden en wil ik alle clinici en overige onderzoekers die de afgelopen jaren binnen de MDL werkzaam zijn geweest bedanken voor het meedenken, voor hun hulp en voor hun collegialiteit. 
Tiny, bedankt voor je inzet bij de laatste loodjes. Zonder jou had dit boekje er ongetwijfeld een stuk minder professioneel en mooi uitgezien. Rogier, wat ben ik blij met de omslag. Alle elementen die ik in mijn hoofd had zitten erin, ontzettend bedankt hiervoor.

Als laatste mijn collega's van Winclove: Pieter, hoewel jij altijd zegt 'it's all about biology' denk ik toch dat je ongelijk hebt. Binnen Winclove is het toch meer 'it's all about chemistry'. Chemie tussen de werknemers, want als ik ooit een groep ben tegengekomen waarbij het niet uitmaakt of je heel jong bent of erg oud, professor bent of secretaresse, een carnavalsminnende Limbo bent of een Jan Smit-minnende Amsterdammer, dan is het wel bij Winclove en ik denk dat dat iets heel bijzonders is. Allemaal zo verschillend maar samen wel een goed bedrijf en dat kan niet zonder onderlinge 'chemistry'. Beste Pieter en Bram als jullie WBI niet gestart waren was dit boekje er niet gekomen. Bedankt dat jullie mij niet alleen de mogelijkheid hebben geboden om te promoveren maar ook om me op andere vlakken te kunnen ontwikkelen. De R\&D groep: Linda, ik begin natuurlijk met jou want je hebt een grote bijdrage geleverd aan dit proefschrift. Vanaf het begin ben je betrokken geweest bij de vele aspecten ervan en ook jij bent een van de mensen die er was op de momenten dat ik het echt moeilijk had. Ik ben niet alleen blij dat je mijn 'baas' bent, maar ook dat je een ware vriendin bent geworden. Harro, jij bent nóg iemand die erg nauw bij de totstandkoming van dit proefschrift betrokken is geweest. Zoals je zelf al zei: 'gedeelde AIO-smart is halve AIO-smart'. Ik vind het jammer dat je niet meer hier bent, want met jou kon ik heerlijk discussiëren over mijn resultaten, de literatuur, het nut van klinische studies en iedereen in het academische wereldje. Frans, de rustige rots in de branding. Vanaf het begin heb ik genoten van onze samenwerking en al jouw kennis. Ik ben dan ook zeer vereerd dat jij 4 juni deel zult uitmaken van de corona. Marco, jouw doorzettingsvermogen voor dit onderzoek heb ik ontzettend gewaardeerd. Luuk, bedankt voor je adviezen. De overige oude en huidige R\&D medewerkers; Linda T, Monique, Nathalie, Isolde, Saskia, Sarah, Coline, Ronald en al hoor je er niet echt bij Paolo, bedankt voor jullie betrokkenheid en al jullie hulp! Charlotte en Ans, de ziel van het bedrijf, jullie zijn toppers! PK, wanneer mogen Daisy en ik nu eens bij een MVV wedstrijd langskomen? Michiel, wanneer gaan we nu weer eens een drankje doen? Marjolein, lekkere klets; je bent een lieverd en ik ben heel blij dat ik jouw tijdelijke huisgenootje mag zijn! Mijn huidige collega's met wie ik 'op stand' in de stad zit. Paula, Ivor, Kristel, Astrid, Ronald, Meredith, Marco en Martijn, ik ben er nog maar kort maar voel me nu al helemaal op mijn plek in dat gekke gezellige pand. Verder nog veel dank aan alle huidige en oude Winclove en Spencer collega's voor jullie collegialiteit maar vooral voor al het vertier tijdens de skitripjes (die in de trein al begonnen), de boottochtjes, het uitstapje naar Brugge en de vele borrels, feestjes en etentjes. 
Dan twee mannen zonder wie dit proefschrift er absoluut niet gekomen was, mijn paranimfen Martijn en Thijs. Lieve Tijn, Moppie, hoewel we elkaar al kenden van onze studie, is het pas tot een vriendschap gekomen toen wij beiden bij de MMB gingen werken. Onze vriendschap is sindsdien alleen nog maar gegroeid omdat we er niet alleen waren om elkaars hoogtepunten te delen, maar juist ook om elkaar door de dieptepunten heen te slepen. Toen ik op de bodem van de put zat en dacht dat er nooit meer licht aan het eind van de tunnel zou komen, was jij er met je engelengeduld om me hier door heen te slepen en me te vertellen dat het heus wel goed ging komen met me (en je had zo gelijk!). Ik kan niet op papier uitdrukken wat dat voor mij betekend heeft. Wel een beetje schraal dat je zo ver weg bent gaan wonen, maar daardoor ben ik extra blij dat je 4 juni letterlijk en figuurlijk achter me zult staan. Tsja, verder ben je natuurlijk een schatje en kan ik alleen nog maar zeggen, prima niks meer aan doen!

Lieve Thijs, wij leerde elkaar kennen tijdens onze allereerste dag als student ruim 13 jaar geleden, so we go way back! En met jou leerde ik ook Roos kennen. Met z'n drieën hebben we het nodige meegemaakt in al die jaren, hele mooie en hele vervelende momenten. Maar juist als je er ook op mindere momenten bent dan weet je dat je echte vrienden hebt. Hoewel we in de loop van de tijd volwassenen zijn geworden, en jullie 3 prachtige kinderen hebben gekregen, zijn we gelukkig ook lekker gek gebleven en houden we van het goede leven. De manier waarop ik deel uitmaak van jullie gezin (en familie) is voor mij heel bijzonder en het voelt ook echt als thuis. Lieve schatten, bedankt voor deze vriendschap, love you all!

Verder wil ik hier ook Dominique en Marlies nog even noemen. Dominique, wij zijn samen als probiotica-meisjes begonnen en we hebben in de beginfase van mijn promotie veel samengewerkt. Ondanks dat je nu in Utrecht woont, is het contact gebleven en wie weet worden we ooit nog wel weer eens collega's! Marlies, jij bent degene die me het onderzoek in heeft geloodst en indirect dus gezorgd heeft voor de eerste stap richting dit resultaat. Dank hiervoor en ook voor onze waardevolle vriendschap.

Lieve vriendjes en vriendinnetje, uit Brabant (coolste provincie van Nederland), van de studie, uit sjoen Mestreech, van het werk, uit het buitenland of iets anders; 'Happiness is only real when shared' en gelukkig kan ik dit moment met jullie delen. Bedankt voor jullie enthousiasme, interesse, luisterend oor, steun, begrip, en alle mooie momenten. Jullie zorgden voor de broodnodige ontspanning en vermaak en zonder dit alles was het vast niet gelukt.

Het laatste deel van mijn dankwoord is voor mijn familie. Lieve mama, bedankt voor de goede basis die je me gegeven hebt. Mede hierdoor ben ik gekomen waar ik nu ben. We hebben het in het verleden niet altijd gemakkelijk gehad maar ik ben blij dat we onze weg weer gevonden hebben en dat je er voor me bent! Lieve Tante, ook jij mag in dit rijtje niet ontbreken. Onze band is altijd heel hecht geweest en voor mij 
uiterst waardevol. Je bent dan ook niet voor niets mijn surrogaat moeder, bedankt voor alles! Dan mijn broers: lieve Bas, Dirk en Mark hoewel er momenten zijn dat ik jullie achter het behang kan plakken, ben ik heel erg blij en trots met jullie als broers. Mooi om ook telkens weer te ervaren dat onze band, hoe verschillend we ook zijn, toch sterk blijft. Ik hoop dat jullie weten hoe belangrijk jullie voor me zijn. Lieve papa, de laatste woorden zijn voor jou. Maar woorden schieten eigenlijk te kort om je te bedanken voor je onvoorwaardelijke steun en liefde en het vertrouwen dat je altijd in me hebt gehad.

Liefs Ka 

List of publications 



\section{List of publications}

Schruers K, Koning K, Luermans J, Haack MJ, Griez E. Obsessive-compulsive disorder: a critical review of therapeutic perspectives. Acta Psychiatr Scand. 2005;111:261-71.

Timmerman HM, Koning CJ, Mulder L, Rombouts FM, Beynen AC. Monostrain, multistrain and multispecies probiotics - a comparison of functionality and efficacy. Int J Food Microbiol. 2004;96:219-33.

Timmerman HM, Niers LE, Ridwan BU, Koning CJ, Mulder L, Akkermans LM, Rombouts FM, Rijkers GT. Design of a multispecies probiotic mixture to prevent infectious complications in critically ill patients. Clin Nutr. 2007;26:450-9.

Koning $\mathrm{CJ}$, Jonkers DM, Stobberingh EE, Mulder L, Rombouts FM, Stockbrügger RW. The effect of a multispecies probiotic on the intestinal microbiota and bowel movements in healthy volunteers taking the antibiotic amoxycillin. Am J Gastroenterol. 2008;103:178-89.

Ridwan BU, Koning CJ, Besselink MG, Timmerman HM, Brouwer EC, Verhoef J, Gooszen HG, Akkermans LM. Antimicrobial activity of a multispecies probiotic (Ecologic 641) against pathogens isolated from infected pancreatic necrosis. Lett Appl Microbiol. 2008;46:61-7.

Koning CJ, Jonkers D, Smidt H, Rombouts F, Pennings HJ, Wouters E, Stobberingh E, Stockbrügger $\mathrm{R}$. The effect of a multispecies probiotic on the composition of the faecal microbiota and bowel habits in COPD patients treated with antibiotics. Br J Nutr. 2009;21:1-9.

Koning CJ, Jonkers D, Smidt H, Fuentes S, Rombouts FM, Stobberingh EE, Winkens B, Stockbrügger RW. Monitoring the effect of a multispecies probiotic and short-term amoxycillin intake on the fecal microbiota in healthy volunteers. Submitted

Koning CJ, Jonkers D, Timmerman HM, Lutter R, Out TA, Stobberingh E, Stockbrügger $R$. The effect of a multispecies probiotic on biomarkers of the mucosal and systemic immune system in healthy volunteers treated with amoxycillin. Submitted 

Curriculum Vitae 



\section{Curriculum Vitae}

Catherina Johanna Maria Koning was born on May $4^{\text {th }} 1977$ in Bunschoten, the Netherlands. After completing secondary school in 1995 at 'Gymnasium Beekvliet' in St Michielsgestel, she worked as 'au pair' in London for one year. In 1996, she started the study Health Sciences, specializing in Biological Health Sciences, at Maastricht University. During her study, she fulfilled two internships. The first internship was carried out at the department of Neuropsychology and Psychobiology, Maastricht University, where she developed an object memory task for rats. The second internship was performed at the department of Medical Microbiology, Maastricht University Medical Centre, where she examined the mechanisms involved in the development of fluoroquinolon resistance in E. coli. After her graduation in 2001, she worked as a research assistant at the Academic Anxiety Centre, PMS Vijverdal, where she studied deep brain stimulation in patients with therapy resistant obsessivecompulsive disorder. In 2002 she started working at the R\&D department of Winclove Bio Industries on 'The effect of probiotics on the intestinal microbiota and immune parameters after treatment with antibiotics' a joint project by Winclove Bio Industries, Wageningen University, Academic Medical Centre and University Maastricht subsidized by SenterNovem. For this project she was detached as a PhD student at the research school for Nutrition, Toxicology and Metabolism (NUTRIM) of the Maastricht University Medical Centre, where she worked at the department of Internal Medicine, division Gastroenterology-Hepatology and the department of Medical Microbiology. This project resulted in the present thesis. From 2008 until 2010 she studied the effect of a multispecies probiotic on hypersensitivity in IBS patients at the department of Internal Medicine, division Gastroenterology-Hepatology. Currently, she is working as a scientist at the R\&D department of Winclove Bio Industries. 

List of abbreviations 


\section{List of abbreviations}

\begin{tabular}{|c|c|}
\hline AAD & Antibiotic-associated diarrhoea \\
\hline ADG & Average daily weight gain \\
\hline BALT & Bronchus associated lymphoid tissue \\
\hline BMI & Body mass index \\
\hline $\mathrm{CCQ}$ & Clinical COPD questionnaire \\
\hline CDAD & Clostridium difficile-associated diarrhoea \\
\hline CFU & Colony forming unit \\
\hline COPD & Chronic obstructive pulmonary disease \\
\hline $\mathrm{CR}$ & Colonization resistance \\
\hline CRIB & Commensal rat ileal bacterium \\
\hline CRP & C-reactive protein \\
\hline DC & Dendritic cells \\
\hline DGGE & Denaturing gradient gel electrophoresis \\
\hline DSS & Dextran sodium sulphate \\
\hline DTT & Dithiotreitol \\
\hline EDTA & Ethylenediamine tetraacetic acid \\
\hline EPEC & Enteropathogenic $E$. coli \\
\hline EPS & Extracellular polysaccharide \\
\hline FAO & Food and agricultural organization of the United Nations \\
\hline FC & Feed consumption \\
\hline FCS & Foetal calf serum \\
\hline FEV1 & Forced expiatory volume in $1 \mathrm{~s}$ \\
\hline FFMI & Fat free mass index \\
\hline FVC & Forced vital capacity \\
\hline $\mathrm{G}: \mathrm{F}$ & Gain-to-feed ratio \\
\hline GALT & Gut associated lymphoid tissue \\
\hline GHS & General health score \\
\hline GI & Gastrointestinal tract \\
\hline GMP & Good manufacturing practice \\
\hline HIT chip & Human intestinal tract chip \\
\hline IBD & Inflammatory bowel disease \\
\hline IBS & Irritable bowel syndrome \\
\hline IEC & Intestinal epithelial cell \\
\hline IFN & Interferon \\
\hline $\lg$ & Immunoglobulin \\
\hline IL & Interleukin \\
\hline IMDM & Iscove's modified Dulbecco's medium \\
\hline LAB & Lactic acid bacteria \\
\hline LPS & Lipopolysaccharide \\
\hline MAMP & Microbe-associated molecular patterns \\
\hline
\end{tabular}




\begin{tabular}{ll} 
MAPK & Mitogen-activated protein kinase \\
MCP-1 & Monocyte chemotactic protein-1 \\
MDP & Muramyl dipeptide \\
MIC & Minimal inhibitory concentration \\
MLN & Mesenteric lymph node \\
NFKB & Nuclear factor kappa B \\
NOD & Nucleotide-oligomerization domain \\
NTT & Number to treat \\
PBMC & Peripheral blood mononuclear cell \\
PBS & Phosphate-buffered saline \\
PP & Peyer's patch \\
PPAR & Peroxisome proliferator-activated receptor \\
PRR & pattern recognition receptor \\
qPCR & quantitative polymerase chain reaction \\
QPS & Qualified presumption of safety \\
rRNA & ribosomal RNA \\
SCFA & Short chain fatty acid \\
SD & Standard deviation \\
SEM & Standard error of the mean \\
SI & Similarity index \\
TGF & Transforming growth factor \\
Th1 & Thelper cell type 1 \\
Th2 & Thelper cell type 2 \\
TJ & Tight junction \\
TLR & Toll-like receptor \\
T-RFLP & Terminal restriction fragment length polymorphism \\
VFA & Volatile fatty acid \\
WB & Whole blood \\
WBC & White blood cell \\
WHO & \\
& World Health Organization \\
\hline
\end{tabular}

